\title{
Materials Reliability Program: Environmental Fatigue Testing of Type 304L Stainless Steel U-Bends in Simulated PWR Primary Water (MRP-137)
}

\author{
1008207
}

This report describes research sponsored by EPRI and U.S. Department of Energy

(Award No. DE-FC07-031D14536). 



\section{Materials Reliability Program Environmental Fatigue Testing of Type 304L Stainless Steel U-Bends in Simulated PWR Primary Water (MRP-137)}

Phase A:

Completion of Initial Baseline Testing including

Qualification of Bonded HT Strain Gauges

Phase B:

Environmental Tests at High Strain Amplitude

and Moderate Strain Rate

Phase C:

Environmental Tests at Moderate Strain

Amplitude and Moderate Strain Rate

1008207

Technical Update, December 2004

EPRI Project Managers

J. Hickling

J. Carey

Cosponsor

U.S. Department of Energy 


\section{DISCLAIMER OF WARRANTIES AND LIMITATION OF LIABILITIES}

THIS DOCUMENT WAS PREPARED BY THE ORGANIZATION(S) NAMED BELOW AS AN ACCOUNT OF WORK SPONSORED OR COSPONSORED BY THE ELECTRIC POWER RESEARCH INSTITUTE, INC. (EPRI). NEITHER EPRI, ANY MEMBER OF EPRI, ANY COSPONSOR, THE ORGANIZATION(S) BELOW, NOR ANY PERSON ACTING ON BEHALF OF ANY OF THEM:

(A) MAKES ANY WARRANTY OR REPRESENTATION WHATSOEVER, EXPRESS OR IMPLIED, (I) WITH RESPECT TO THE USE OF ANY INFORMATION, APPARATUS, METHOD, PROCESS, OR SIMILAR ITEM DISCLOSED IN THIS DOCUMENT, INCLUDING MERCHANTABILITY AND FITNESS FOR A PARTICULAR PURPOSE, OR (II) THAT SUCH USE DOES NOT INFRINGE ON OR INTERFERE WITH PRIVATELY OWNED RIGHTS, INCLUDING ANY PARTY'S INTELLECTUAL PROPERTY, OR (III) THAT THIS DOCUMENT IS SUITABLE TO ANY PARTICULAR USER'S CIRCUMSTANCE; OR

(B) ASSUMES RESPONSIBILITY FOR ANY DAMAGES OR OTHER LIABILITY WHATSOEVER (INCLUDING ANY CONSEQUENTIAL DAMAGES, EVEN IF EPRI OR ANY EPRI REPRESENTATIVE HAS BEEN ADVISED OF THE POSSIBILITY OF SUCH DAMAGES) RESULTING FROM YOUR SELECTION OR USE OF THIS DOCUMENT OR ANY INFORMATION, APPARATUS, METHOD, PROCESS, OR SIMILAR ITEM DISCLOSED IN THIS DOCUMENT.

ORGANIZATION(S) THAT PREPARED THIS DOCUMENT

\section{Framatome ANP GmbH}

This is an EPRI Technical Update report. A Technical Update report is intended as an informal report of continuing research, a meeting, or a topical study. It is not a final EPRI technical report.

\section{ORDERING INFORMATION}

Requests for copies of this report should be directed to EPRI Orders and Conferences, 1355 Willow Way, Suite 278, Concord, CA 94520. Toll-free number: 800.313 .3774 , press 2, or internally x5379; voice: 925.609.9169; fax: 925.609.1310.

Electric Power Research Institute and EPRI are registered service marks of the Electric Power Research Institute, Inc. EPRI. ELECTRIFY THE WORLD is a service mark of the Electric Power Research Institute, Inc.

Copyright @ 2004 Electric Power Research Institute, Inc. All rights reserved. 


\section{CITATIONS}

This report was prepared by

Framatome ANP GmbH

Freyeslebenstrasse 1

Erlangen, 91052

Germany

Principal Investigator

Dr. R. Kilian

This report describes research sponsored by EPRI and U.S. Department of Energy under the Nuclear Energy Plant Optimization (NEPO) Program (Award No. DE-FC07-031D14536. Task FY03-3-24.3).

Any opinions, findings, and conclusions or recommendations expressed in this material are those of the authors(s) and do not necessarily reflect the views of the Department of Energy.

The report is a corporate document that should be cited in the literature in the following manner:

Materials Reliability Program: Environmental Fatigue Testing of Type 304L Stainless Steel U-bends in Simulated PWR Primary Water (MRP-137): Technical Update, December 2004 , EPRI, Palo Alto, CA, and U.S. Department of Energy, Washington, DC: 2004. 1008207. 



\section{REPORT SUMMARY}

Laboratory data generated in the past decade indicate a significant reduction in component fatigue life when reactor water environmental effects are experimentally simulated. However, these laboratory data have not been supported by nuclear power plant component operating experience. In a recent comprehensive review of laboratory, component and structural test data performed through the EPRI Materials Reliability Program, flow rate was identified as a critical variable that was generally not considered in laboratory studies but applicable in plant operating environments. Available data for carbon/low-alloy steel piping components suggest that high flow is beneficial regarding the effects of a reactor water environment. Similar information is lacking for stainless steel piping materials. This report documents progress made to date in an extensive testing program underway to evaluate the effects of flow rate on the corrosion fatigue of 304L stainless steel under simulated PWR primary water environmental conditions.

\section{Background}

In 2001, the EPRI MRP Fatigue Issue Task Group performed an extensive review of available fatigue data from laboratory and component testing that simulated reactor water environmental effects. Results of this review were published in EPRI report 1003079 (MRP-49). The entire simulated reactor water environmental effects data set was also evaluated relative to its applicability to actual operating conditions and was found to be deficient in several ways. The most important deficiency was that the simulated coolant flow rates were about three orders of magnitude lower than nominal coolant flow rates in plant. Laboratory and full-scale testing of carbon/low-alloy steel specimens and components have demonstrated the importance of coolant flow rate, in that nominal flow rates were found to essentially eliminate all but the most severe reactor water environmental effects. A conclusion of MRP-49 was to extend these findings to austenitic stainless steel components and perform full-scale testing of stainless steel pipe bends with one surface exposed to a simulated, PWR primary water environment.

\section{Objectives}

- To investigate the effect of coolant flow rate on the fatigue of stainless steel piping components under simulated reactor water environments

- To determine the range of applicability of available data to nuclear power plant stainless steel piping components operating under actual plant conditions

\section{Approach}

An extensive test program was established at Framatome ANP (F-ANP GmbH) in Erlangen, Germany utilizing a unique test facility that provides a simulated reactor water environment at moderate flow rates and temperatures. Stainless steel U-bend specimens were fabricated from 304L stainless steel and forwarded to F-ANP for testing. The overall test program involves 
several critical stages, including: complete pre-test characterization of the U-bend samples (including residual stress measurements); optimization of the flow conditions to simulate plant flow profiles; pre-conditioning of the U-bend specimens and the environment test loop; performing a series of baseline tests to fully characterize the test apparatus, understand the sample response, and finalize environmental testing parameters/conditions; and performing a matrix of environmental tests with respect to flow rate

\section{Results}

Pre-test characterization of the U-bend samples, flow optimization analysis and test loop preconditioning, as well as initial baseline testing, were completed in 2003 and are described in EPRI report 1007853 (MRP-100). The environmental fatigue testing of mini-components (cold drawn, 304L stainless steel U-bends) carried out to date in the present EPRI-MRP program allows the following conclusions to be drawn:

- In accordance with literature data, PWR primary water can have a significant effect on the high-temperature fatigue behavior of austenitic stainless steel components, as demonstrated by the observed change in failure mode and location between specimens tested with nitrogen and simulated reactor coolant in contact with the internal surface of the bend.

- Metallography and fractography suggest that the environment is acting by affecting both crack initiation and crack growth.

- No obvious, life-time increasing effect of higher flow rate has been observed in tests to date (cycles to failure differ only by about $6 \%$ ), but this may appear if the environmental influence is increased, e.g., by moving to cyclic loading at slower strain rates.

- The typical, as-received component condition (pickled surface with shallow intergranular attack plus some minor damage from bending) does not appear to be detrimental with regard to the initiation of environmental fatigue.

\section{EPRI Perspective}

The apparent reduction in component fatigue life due to laboratory-simulated reactor water environments, and the management of this phenomenon, has become a significant issue for those utilities seeking license renewal. Results of the testing program described will provide critical information to support development of an aging management plan for stainless steel piping components regarding reactor water environmental effects and will be an integral step toward the resolution of this issue. Additionally, this effort will support reconciliation of laboratory data with actual plant operating conditions.

\section{Keywords}

Environmental Fatigue

Piping flow rate

Nuclear power plant piping

Stainless steel piping 


\title{
EXECUTIVE SUMMARY
}

\author{
Motivation \& Benefits \\ Strategic modernization of I\&C utilizes technology to reduce plant-wide operating costs while \\ maintaining or improving safety and reliability. It generally involves introduction of new \\ infrastructure that facilitates movement of data and information throughout the plant and its \\ parent company. Strategic modernization can enable or enhance high-value capabilities such as \\ on-line condition-based maintenance. It can also lead to streamlining of the I\&C architecture, \\ maintenance processes and organization, and to elimination or consolidation of low-level tasks, \\ components, wiring and local control rooms. By seeking qualitative plant-wide improvements, \\ strategic modernization goes beyond the current practice of tactical I\&C upgrades, which are \\ generally limited to one-for-one replacements of components or systems, with minimal \\ disturbance to existing rack layouts, staff practices and organization.
}

\section{Approach}

This approach for developing modernization strategies outlines a multidimensional process that considers new functional concepts, specific technology, plant processes and the individual tasks within them, and organizational structure and staffing. Infrastructure decisions having potential for positive plant-wide impact are distinguished from narrower implementations involving particular products or focusing on specific plant tasks.

An evaluation process is described that combines task, technology and integrated analysis to maximize the benefits of modernized infrastructure and I\&C architecture. The evaluation considers a long-term time horizon spanning multiple outages, but execution is partitioned into more familiar tactical steps that build upon current established practices.

\section{Program Goals}

The overall program will identify and develop new cost-effective strategies that reduce plant operating costs. During 2005, goals revolve around solidifying the approach to strategic modernization, validating its benefits, evaluating selected infrastructure technologies for their applicability to nuclear power applications, and identifying key technological and organizational gaps. During 2006, goals include initiating a pilot program with a member utility, issuing a guideline for strategic modernization, and documenting selected technology issues deemed priorities by a utility advisory group 



\section{CONTENTS}

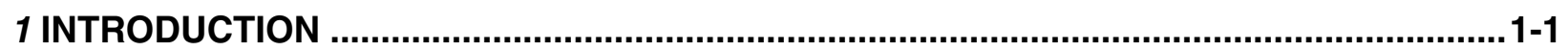

2 QUALIFICATION OF BONDED STRAIN GAUGES ..........................................................

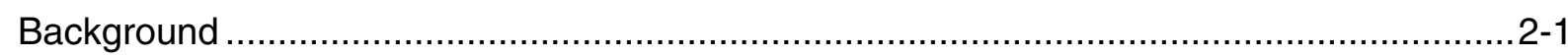

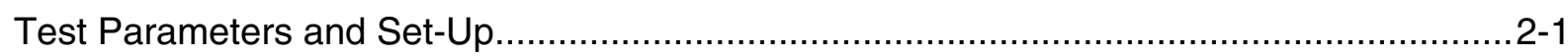

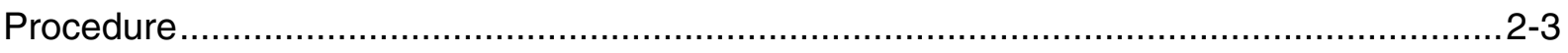

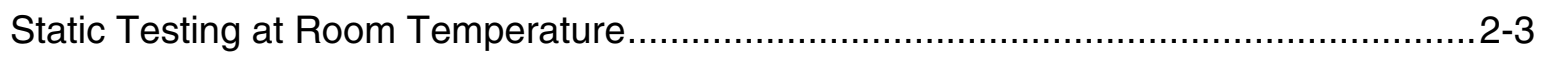

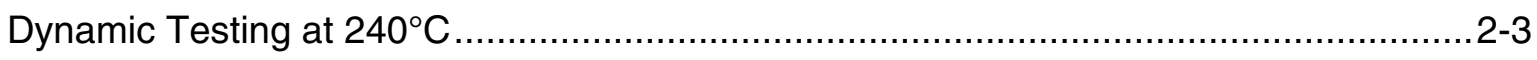

Findings

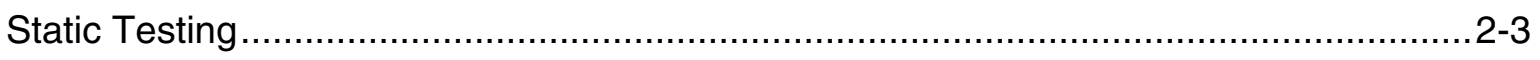

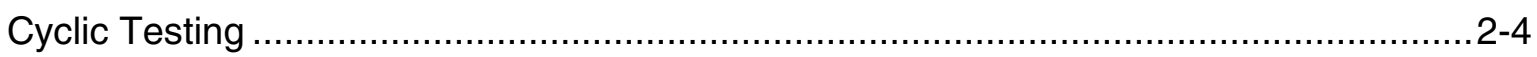

Conclusions from Strain Gauge Qualification............................................................ 2-5

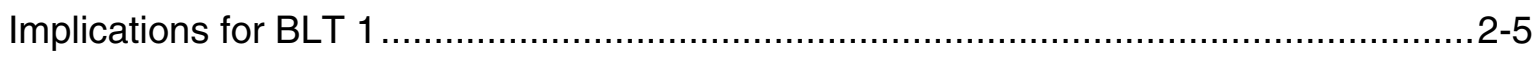

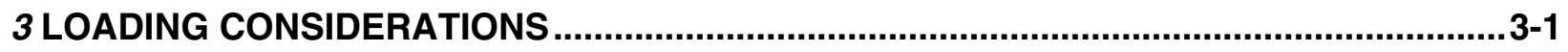

4 BASE LINE TEST 2

Test Set-Up and Approach..................................................................................

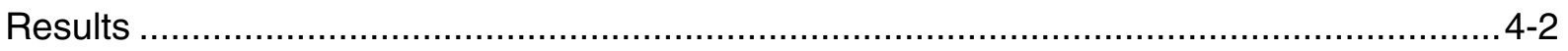

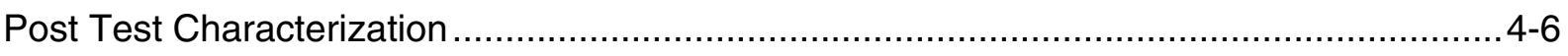

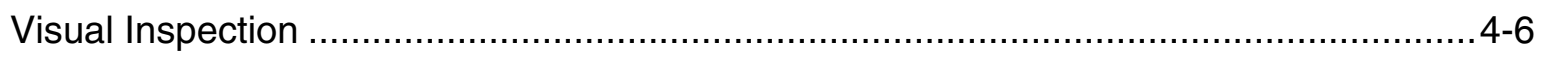

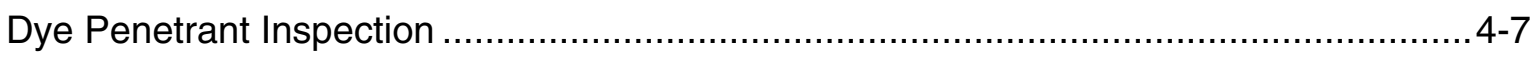

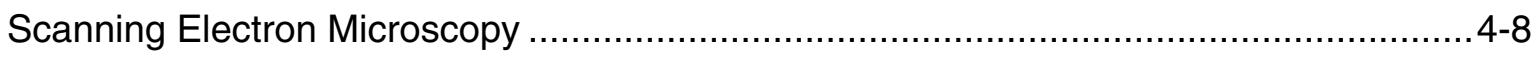

Metallography and Micro Hardness ............................................................... 4-10

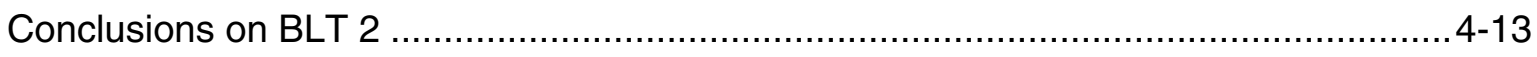

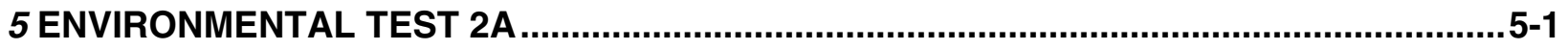

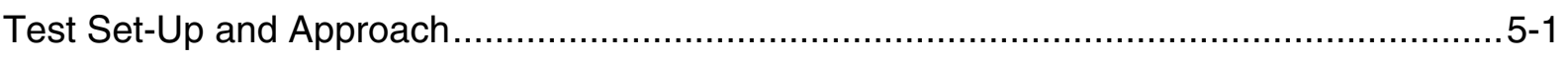




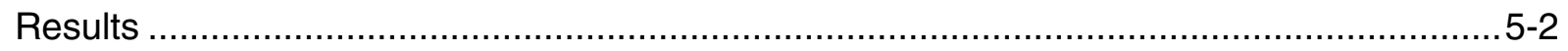

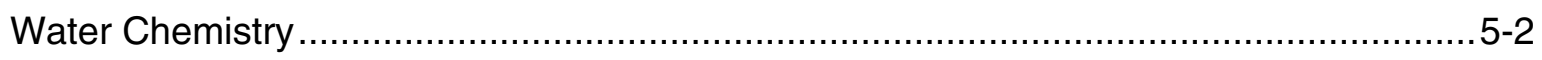

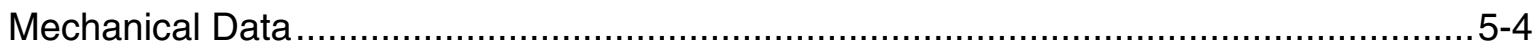

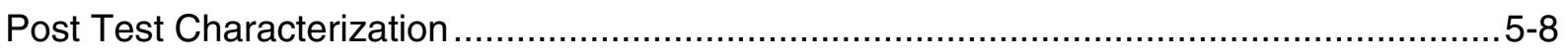

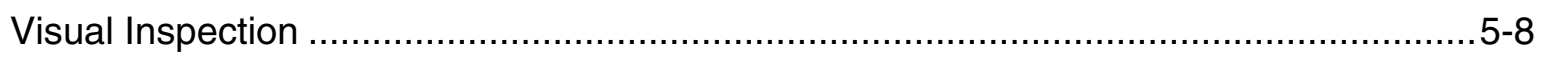

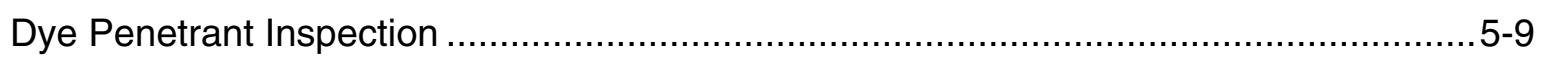

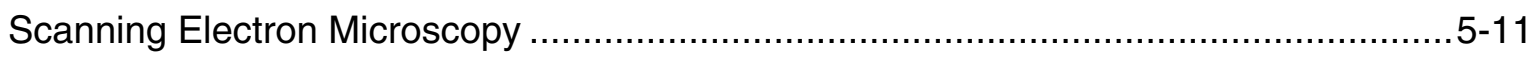

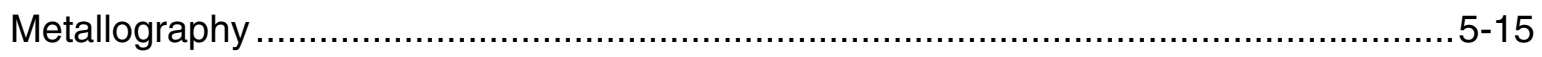

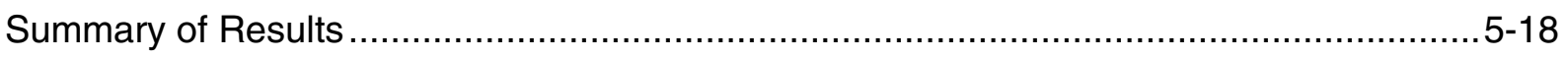

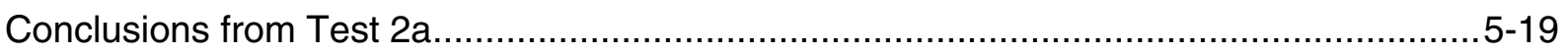

6 ENVIRONMENTAL TEST 2B ......................................................................................6-1

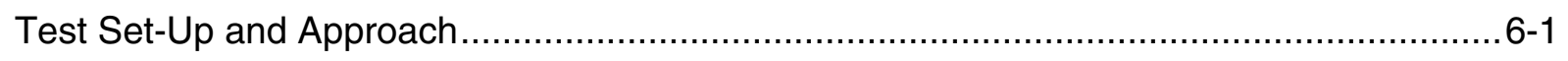

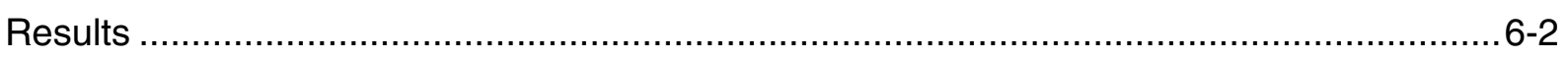

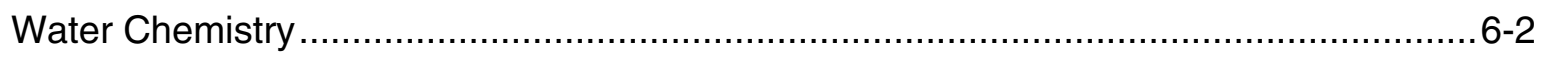

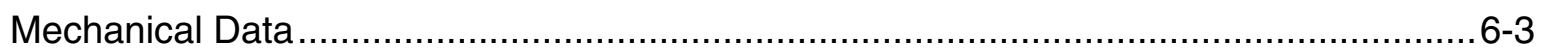

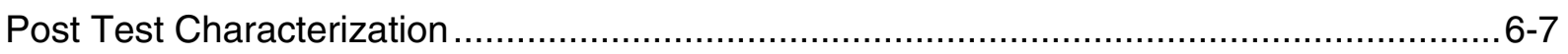

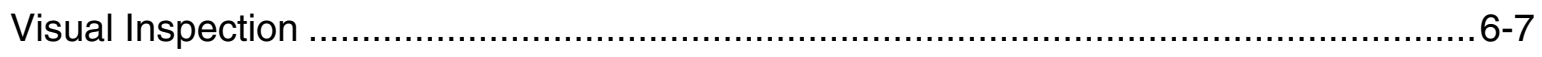

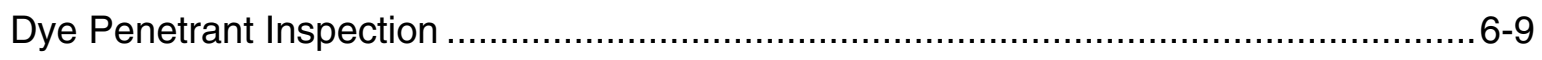

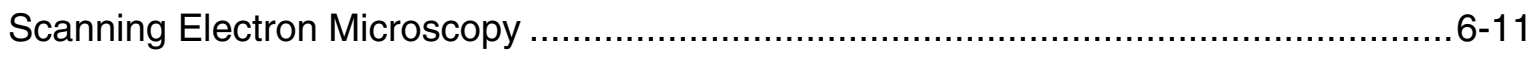

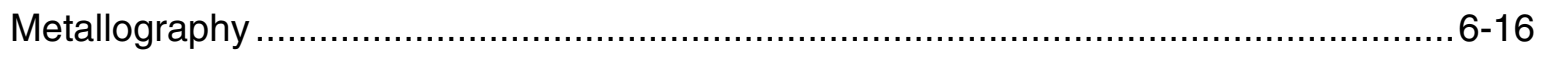

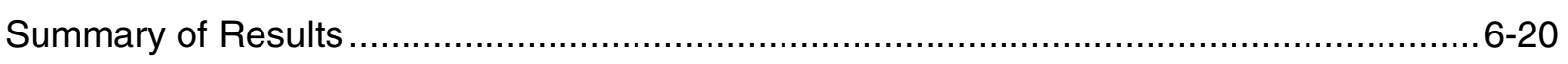

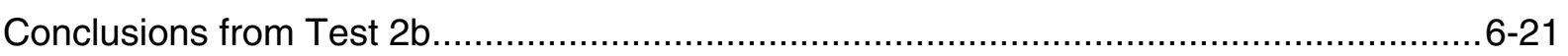

7 SUMMARY OF TEST RESULTS WITH \pm 0.6 \% STRAIN AMPLITUDE...............................

8 ENVIRONMENTAL TEST 4A ....................................................................................... 8-1

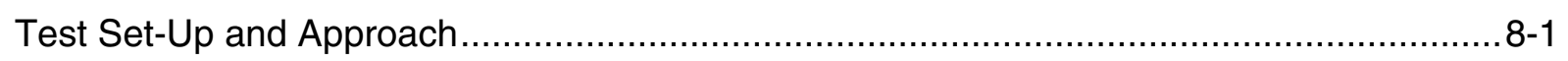

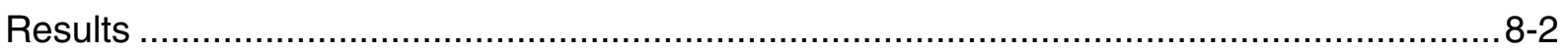

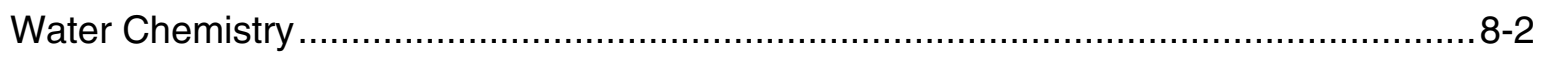

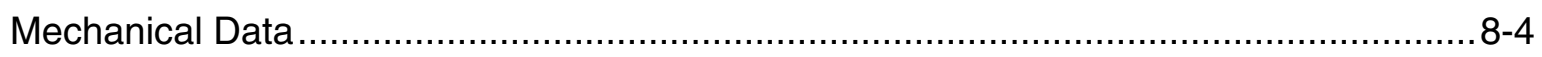

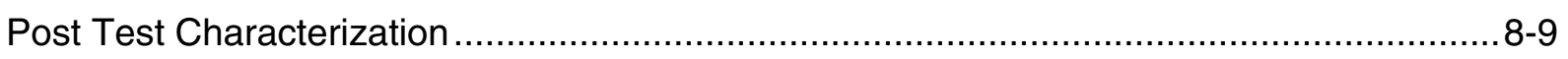

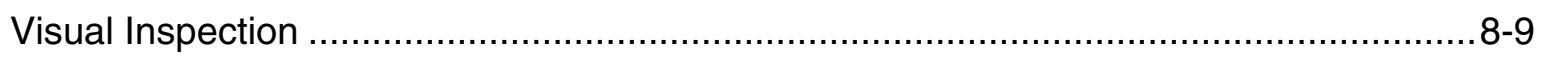

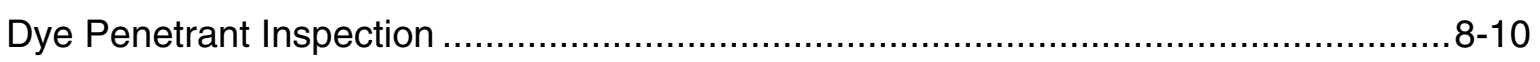

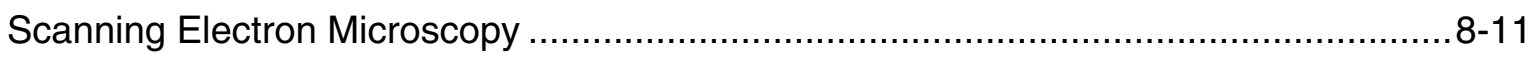




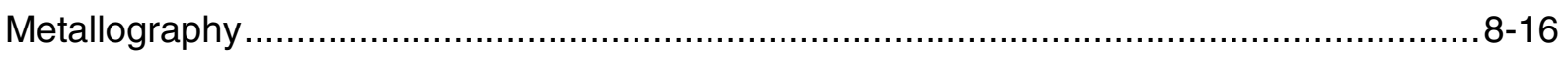

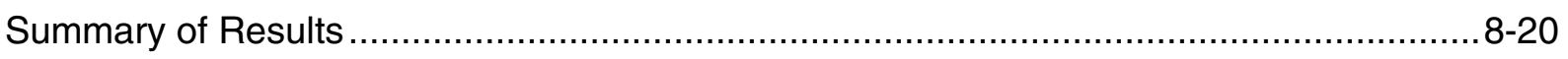

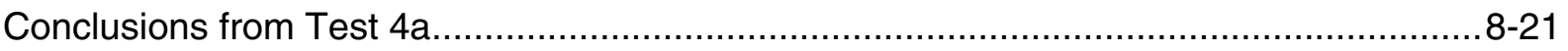

9 ENVIRONMENTAL TEST 4B

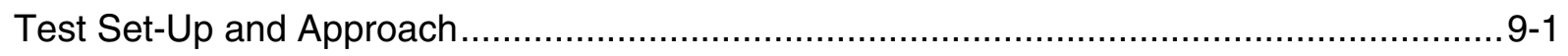

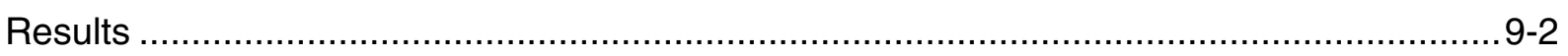

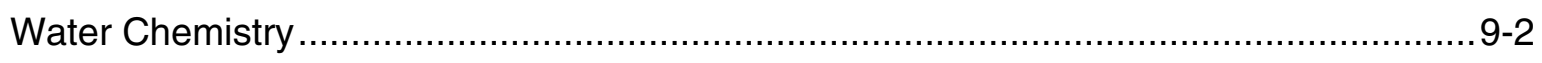

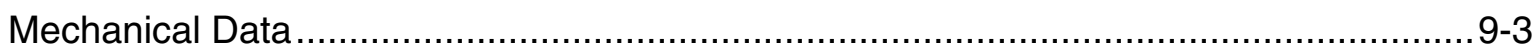

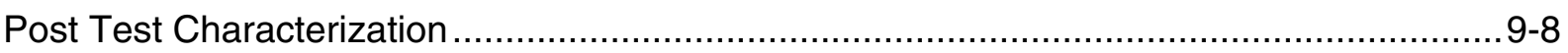

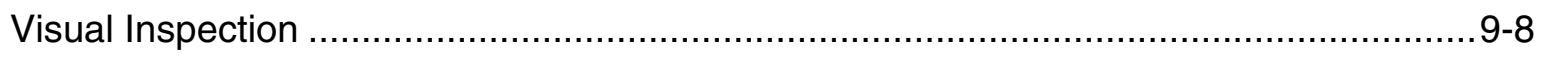

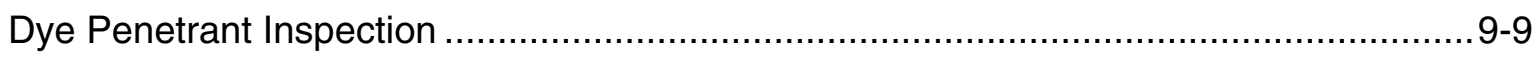

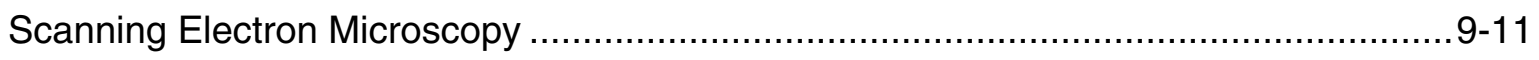

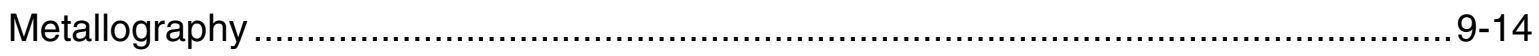

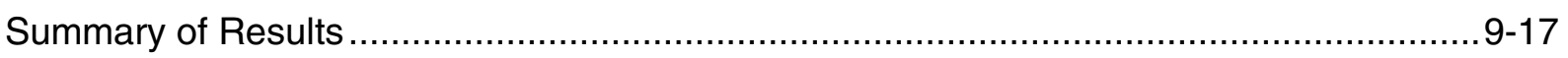

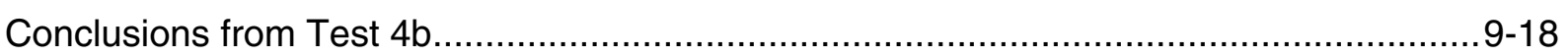

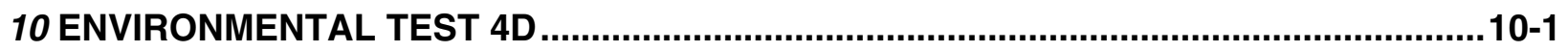

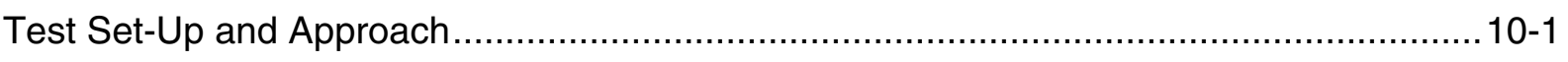

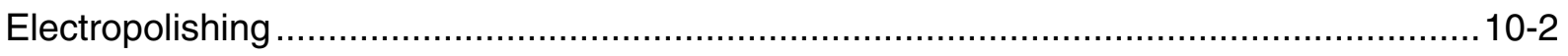

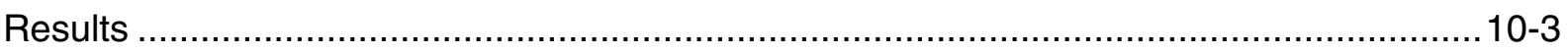

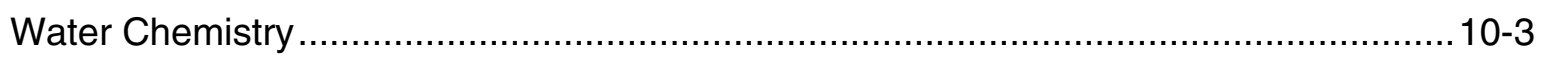

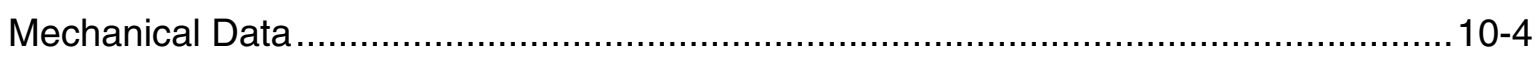

Post-Test Characterization .................................................................................. 10-10

Visual Inspection ..................................................................................... 10-10

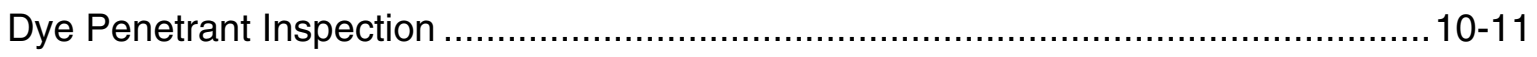

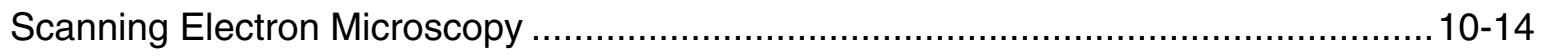

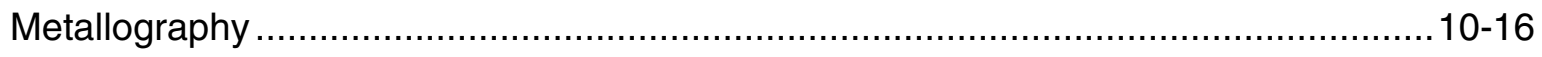

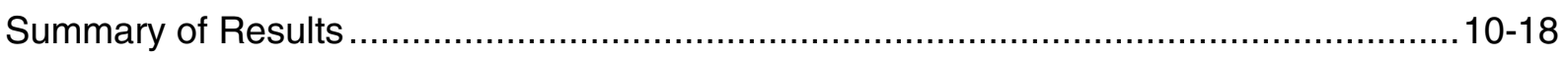

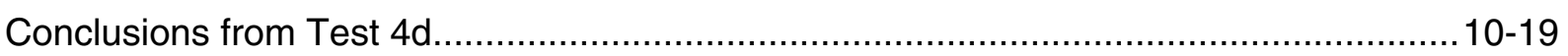

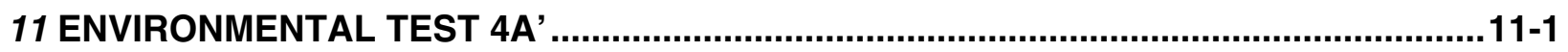

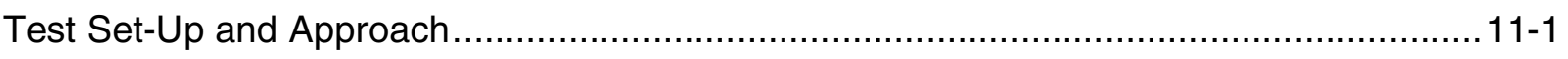

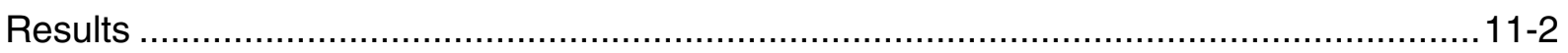

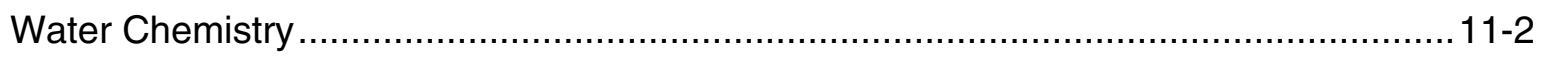




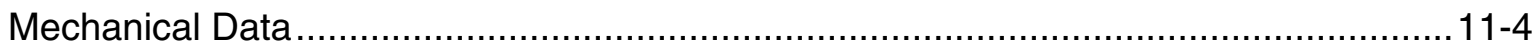

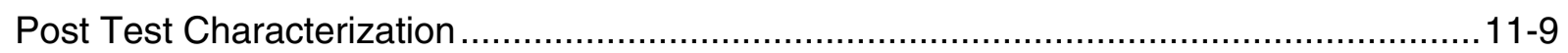

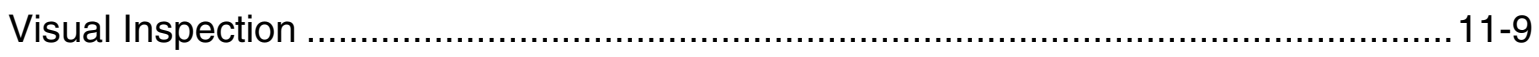

Dye Penetrant Inspection ..........................................................................11-10

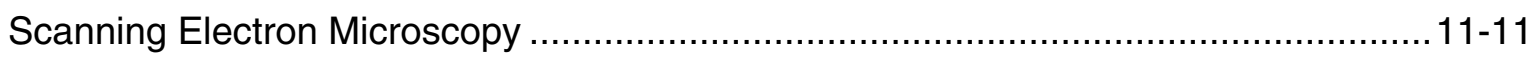

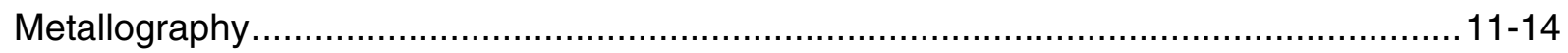

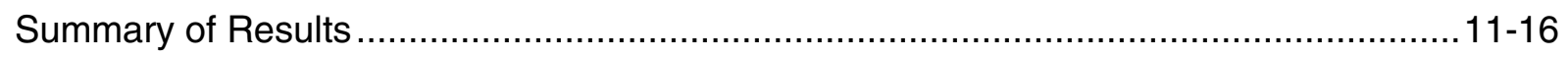

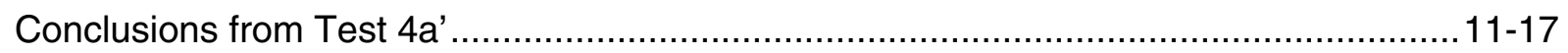

12 SUMMARY OF TEST RESULTS WITH \pm 0.4 \% STRAIN AMPLITUDE..........................12-1

13 SUMMARY, DISCUSSION AND CONCLUSIONS FROM TEST PROGRAM TO

DATE

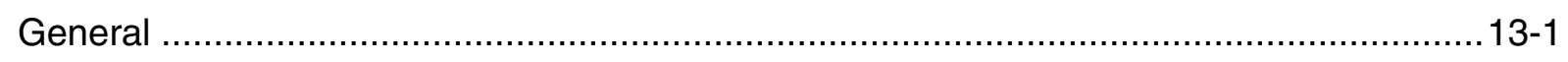

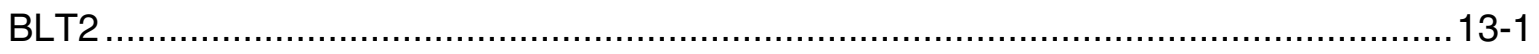

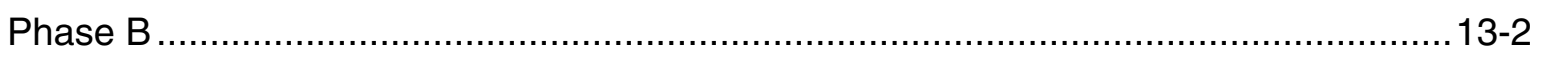

Phase C

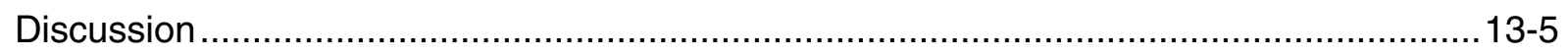

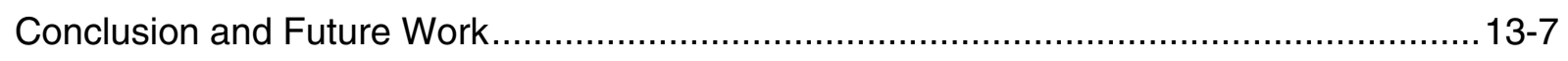

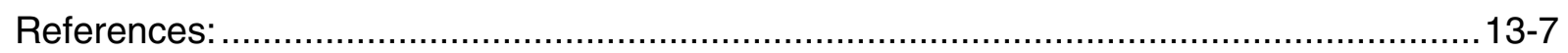




\section{LIST OF FIGURES}

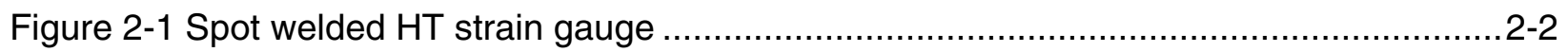

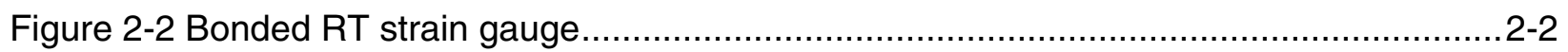

Figure 2-3 Bonded HT strain gauge......................................................................

Figure 2-4 Results of dynamic load testing during strain gauge qualification ..........................2-4

Figure 4-1 First 5 cycles of BLT 2 showing uniform behavior .......................................... 4-3

Figure 4-2 Cycle 6 to 13; Cycle 10 was used for determination of displacements for

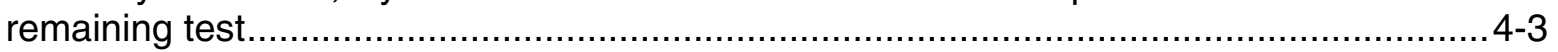

Figure 4-3 Entire test sequence of BLT 2 with the maximum of 1705 cycles ......................... 4-4

Figure 4-4 Strain response of all instrumented strain gauges to cycle 126 ...........................4-4

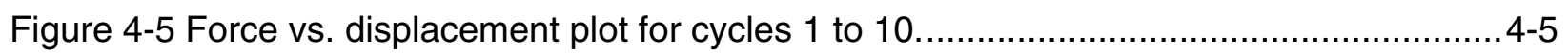

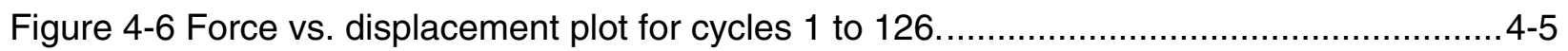

Figure 4-7 Visual inspection of BLT 2; primary failure in the form of circumferential crack ....... 4-6

Figure 4-8 DPI of external surface at intrados revealing an array of circumferential cracks in the intrados area ................................................................................... 4-7

Figure 4-9 DPI of internal surface at intrados showing that the primary circumferential crack had developed into a through wall defect.

Figure 4-10 DPI of external surface of extrados free of indications .................................... 4-8

Figure 4-11 DPI of internal surface of extrados free of indications .................................... 4-8

Figure 4-12 Views obtained during SEM examination; a) typical crack initiation site found along the external surface with average striation spacing of $1 \mu \mathrm{m} ; \mathrm{b}$ ) typical fracture appearance found in mid-section of fracture with average striation spacing of $2 \mu \mathrm{m}$;

c) typical fracture appearance adjacent to internal surface with average striation spacing of $20 \mu \mathrm{m}$

Figure 4-13 Location of specimen extraction for metallurgical examination. .......................... 4-10

Figure 4-14 Overall view of prepared specimen; the white arrows indicate some of the multiple crack initiations on the external surface.

Figure 4-15 Typical view of microstructure with transgranular crack originating from external surface.

Figure 4-16 Transgranular cracking in area where strain gauge was positioned.

Figure 4-17 Micrograph showing cracked strain gauge; the separation of the strain gauge most likely occurred during sample preparation and is not associated with testing.

Figure 4-18 Hardness readings obtained. 
Figure 4-19 Schematic graphically summarizing the cracking locations of BLT 2 . 4-14

Figure 5-1 Water chemistry during environmental Test 2a.

Figure 5-2 Electrochemical potentials during environmental Test 2a. ...................................5-3

Figure 5-3 Cycles 1 to 5 of environmental Test $2 a$ with triangular wave shape........................5-5

Figure 5-4 Cycles 6 to 12 of environmental Test 2a with wave shape according to Case 4 modified.

Figure 5-5 View of entire Test 2a........................................................................ 5

Figure 5-6 Strain response of all instrumented stain gauges............................................. 5-6

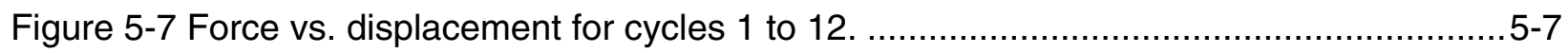

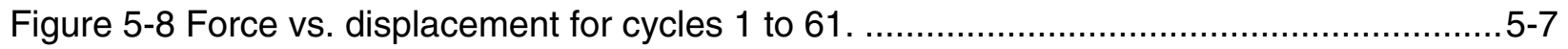

Figure 5-9 Visual inspection of U-bend revealing one primary circumferential crack at the intrados.

Figure 5-10 DPI of external surface of intrados exhibiting array of circumferential indications.

Figure 5-11 DPI of internal surface of intrados.

Figure 5-12 Axial crack indications found at the $90^{\circ}$ position; some of which are indicated by white arrows.

Figure 5-13 Axial crack indications found at the $270^{\circ}$ location; some of which are indicated by white arrows.

Figure 5-14 No indications found on external surface of the extrados.

Figure 5-15 Axial crack found on internal surface of extrados as indicated by the white arrow.

Figure 5-16 SEM examination of internal surface of intrados revealing circumferential and axial cracking.

Figure 5-17 Broken open circumferential crack used for fractography.

Figure 5-18 Broken open primary fracture used for SEM examination.

Figure 5-19 Axial cracking found on the internal surface of intrados.

Figure 5-20 Broken open axial crack showing evidence of corrosion fatigue with a crack front progressing from the internal towards the external surface.

Figure 5-21 Specimen removal plan used for metallurgical analysis.

Figure 5-22 Typical views of cross-section in the $270^{\circ}$ position (Specimen S1) showing transgranular axial cracking progressing from the internal towards the external surface.

Figure 5-23 Typical views of cross-section in the approximate $200^{\circ}$ position (Specimen S2) showing transgranular circumferential cracking progressing from the External towards the internal surface.

Figure 5-24 Typical views of cross-section in the approximate $110^{\circ}$ position (Specimen S3) showing transgranular circumferential cracking progressing from the internal towards the external surface.

Figure 5-25 Typical view of cross-section at the extrados (Specimen S4) showing transgranular axial cracking progressing from the internal towards the external surface. 
Figure 5-26 Cross-sectional sketch of apex schematically showing all crack indications and their depths (if available); please note that sketch is not to scale.

Figure 6-1 Conductivity and temperature vs. testing time.

Figure 6-2 Electrochemical corrosion potential, redox potential and temperature vs. testing time.

Figure 6-3 Mechanical data of Cycle 1 to 5.

Figure 6-4 Mechanical data of Cycle 1 to 10.

Figure 6-5 Response of all strains from Cycles 1 to 10.

Figure 6-6 Load vs. displacement for Cycles 1 to 10.

Figure 6-7 All mechanical data of Test $2 b$ for entire test duration.

Figure 6-8 Force vs. displacement for entire test.

Figure 6-9 Circumferential intrados defect as observed after test termination; the white remnants originated from crystallized boric acid.

Figure 6-10 Close-up of leakage causing defect located in the intrados area.

Figure 6-11 External surface of intrados showing array of circumferential cracks.

Figure 6-12 Internal surface of intrados showing multiple axial cracking and the defect causing leakage in the form of a spot-like indentation in the middle of the halfshell.

Figure 6-13 Internal surface of extrados showing very fine axial cracking...........................6-10

Figure $6-14 \mathrm{p}$ Internal surface of $90^{\circ}$ position showing axial cracking. .................................. 6-10

Figure 6-15 Internal surface of $270^{\circ}$ position showing axial cracking. 6-10

Figure 6-16 External intrados surface showing primary circumferential crack originating within circumferential dent/scratch.

Figure 6-17 Close-up of Figure 6-16.

Figure 6-18 Internal surface of intrados showing axial cracking along the texture provided by the pickling attack.

Figure 6-19 SEM of internal intrados surface also showing circumferential cracking to a certain degree.

Figure 6-20 Broken open circumferential crack used for fractography.

Figure 6-21 Typical view of circumferential mid fracture area; the striations clearly indicate step-wise crack progression typical for mechanical fatigue.

Figure 6-22 Typical fracture appearance found on the internal surface of the intrados; a) axial cracking initiating from the internal surface; b) circumferential cracking initiating from the internal surface.

Figure 6-23 Typical crack morphology found on axial cracks that had initiated on internal surface.

Figure 6-24 Typical crack morphology found on circumferential cracks that had initiated on internal surface.

Figure 6-25 Specimen removal for metallographic examination; the red squares numbered from S1 to S4 indicate the locations of specimen extraction.

Figure 6-26 Typical views of cross section of the external $180^{\circ}$ intrados position (Specimen S3); transgranular, circumferential cracks propagating from the external towards the internal surface. 
Figure 6-27 Typical views of cross section of the internal $180^{\circ}$ intrados position (Specimen S3); transgranular, circumferential cracks propagating from the internal towards the external surface.

Figure 6-28 Typical views of cross section of the internal $270^{\circ}$ position (Specimen S1); environmental, axial cracks propagating from the internal towards the external surface in a transgranular manner; crack initiation appeared to have occurred at attacked grain boundaries from pickling treatment.

Figure 6-29 Typical views of external $110^{\circ}$ position (Specimen S2) showing transgranular crack propagation from the external towards the internal surface; crack initiation appeared to have occurred at attacked grain boundaries from pickling treatment.

Figure 6-30 Typical views of cross section of the internal $110^{\circ}$ position (Specimen S2); environmental, circumferential cracks propagating from the internal towards the external surface in a transgranular manner; crack initiation appeared to have occurred at attacked grain boundaries from pickling treatment.

Figure 6-31 Typical views of the internal $0^{\circ}$ extrados position (Specimen S4); environmental, axial cracks propagating from the internal towards the external surface in a transgranular manner; crack initiation appeared to have occurred at attacked grain boundaries from pickling treatment.

Figure 6-32 Schematic summary of crack locations, orientation and approximate crack depths (if available); schematic provides a cross-sectional view of the apex looking down-stream; please note that schematic is not to scale.

Figure 7-1 Summary of DPI results.

Figure 7-2 Summary of metallographic examination. 7-2

Figure $7-3$ Summary of crack locations, depths and achieved cycles. .................................. $7-3$

Figure 8-1 Temperature, electrochemical and redox potential vs. testing time...................... 8-3

Figure 8-2 Conductivity and temperature vs. testing time............................................... 8-3

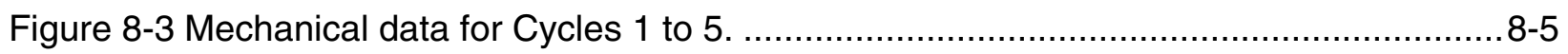

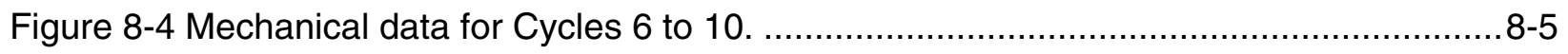

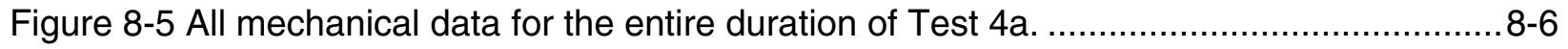

Figure 8-6 Strain data for Cycles 1 to 10 ..................................................................... $8-6$

Figure 8-7 All available strain data..................................................................... $8-7$

Figure 8-8 Force vs. displacment hysteresis for Cycles 1 to 5 (Strain Rate: $1 \times 10^{-5} \mathrm{xs}^{-1}$ )........... 8-7

Figure 8-9 Force vs. displacement hysteresis for cycles 1 to 10 (Strain Rate Cycle 6 to

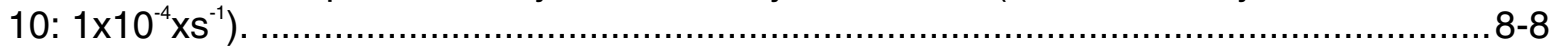

Figure 8-10 Force vs. displacement hysteresis for entire test........................................... 8-8

Figure 8-11 Primary leakage causing failure in the $270^{\circ}$ position....................................... 8-9

Figure 8-12 DPI surface inspection of $270^{\circ}$ position showing multiple axial cracking at both locations.

Figure 8-13 Internal surface of $90^{\circ}$ position showing multiple axial cracking .........................8-11

Figure 8-14 $180^{\circ}$ intrados position showing array of fine circumferential cracking on external surface and fine multiple axial cracking on the internal surface.

Figure 8-15 External surface of intrados showing fine circumferential cracking. 
Figure 8-16 Internal surface of $180^{\circ}$ intrados position showing axial cracking following attacked grain boundaries from the pickling treatment.

Figure 8-17 Internal surface of $90^{\circ}$ position showing axial cracking following attacked grain boundaries from pickling attack

Figure 8-18 Internal surface of $270^{\circ}$ position showing defect causing leakage in the form of axial cracking.

Figure 8-19 Broken open external circumferential crack at $180^{\circ}$ intrados position.

Figure 8-20 Typical views of circumferential crack at $180^{\circ}$ intrados position.

Figure 8-21 Broken open axial crack at $270^{\circ}$ position.

Figure 8-22 Typical views of fracture surface found at the $270^{\circ}$ position; the morphology indicates step-wise crack progression under the combined influence of mechanical loading and environment. ....

Figure 8-23 Specimen removal plan for Test 4a.

Figure 8-24 Typical view of $270^{\circ}$ position showing axial through-wall crack progressing from the internal towards the external surface (Specimen S1).

Figure 8-25 Typical view of $90^{\circ}$ position showing multiple axial cracking progressing from the internal towards the external surface (Specimen S3); the numbers represent approximate crack depths.

Figure 8-26 Typical views from the $180^{\circ}$ position showing circumferential cracking progressing from the external towards the internal surface.

Figure 8-27 Axial cracking found on the internal surface of the $180^{\circ}$ intrados position; apparent multidirectional character resulted from forked progression in combination with the plane the specimen was viewed in.

Figure 8-28 Schematic summary of crack locations, orientation and approximate crack depths (if available) of Test $4 a$; schematic provides a cross-sectional view of the apex looking down-stream; please note that schematic is not to scale.

Figure 9-1 Temperature and conductivity over entire testing time.

Figure 9-2 Temperature, electrochemical corrosion and redox potential vs. testing time.........9-3

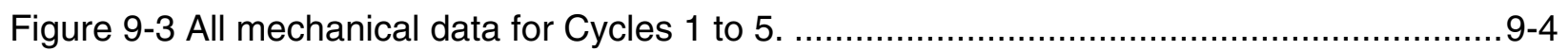

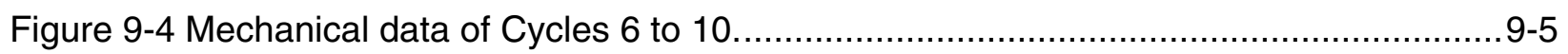

Figure 9-5 All mechanical data vs. testing time. ....................................................... 9-5

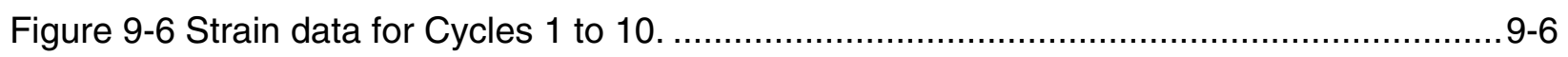

Figure 9-7 All available strain data.......................................................................... 9

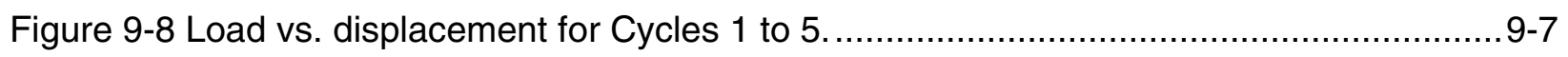

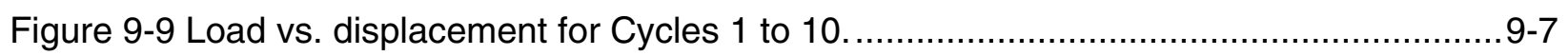

Figure 9-10 Load vs .displacement for the entire test.................................................. 9-8

Figure 9-11 Visual inspection revealed leakage in the $270^{\circ}$ position....................................9-9

Figure 9-12 External surface at $270^{\circ}$ position revealing axial through-wall defect.................9-10

Figure 9-13 Internal surface at $270^{\circ}$ position revealing multiple axial cracking. ....................9-10

Figure 9-14 Internal surface at $90^{\circ}$ position revealing multiple axial cracking. ...................... 9-10

Figure 9-15 Internal surface at $180^{\circ}$ intrados position revealing multiple axial cracking.........9-11 
Figure 9-16 Internal surface examination of $270^{\circ}$ position showing axial cracking that followed attacked grain boundaries from pickling treatment.

Figure 9-17 Internal surface examination of $90^{\circ}$ position showing axial cracking that followed attacked grain boundaries from pickling treatment.

Figure 9-18 Internal surface examination of $180^{\circ}$ position showing axial cracking................ 9-13

Figure 9-19 Opened axial fracture of $270^{\circ}$ position.

Figure 9-20 Typical views of fracture surface found at the $270^{\circ}$ position; the morphology indicates step-wise crack progression under the combined influence of mechanical loading and environment.

Figure 9-21 Specimen removal plan for metallographic examination.

Figure 9-22 Cross sectional view of $270^{\circ}$ position showing multiple transgranular cracks propagating from the internal towards the external surface (Specimen $\mathrm{S1}$ ).

Figure 9-23 Cross-sectional view of $180^{\circ}$ position showing multiple transgranular cracks propagating from the internal towards the external surface (Specimen S1); the numbers represent approximate crack depths.

Figure 9-24 Cross-sectional view of $90^{\circ}$ position showing multiple transgranular cracks propagating from the internal towards the external surface (Specimen S2); the numbers represent approximate crack depths.

Figure 9-25 Schematic summary of crack locations, orientation and approximate crack depths (if available) of Test $4 \mathrm{~b}$; schematic provides a cross-sectional view of the apex looking down-stream; please note that schematic is not to scale.

Figure 10-1 Typical view of electropolished surface obtained by SEM of trial bend............... 10-2

Figure 10-2 Comparison of electropolished surface with typical as-received surface. ........... 10-3

Figure 10-3 Conductivity and temperature vs. testing time......................................... 10-4

Figure 10-4 Temperature, electrochemical corrosion and redox potential vs. testing time......10-4

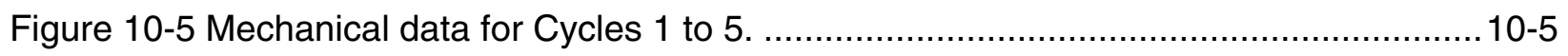

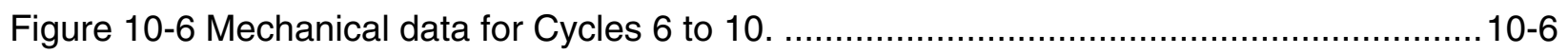

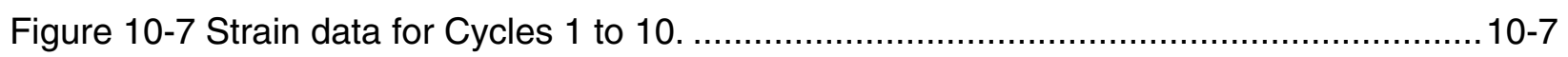

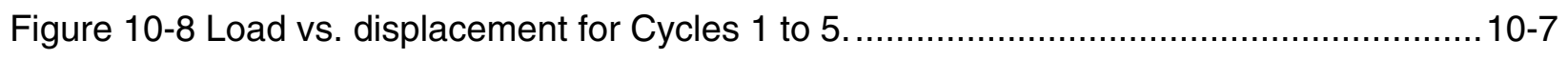

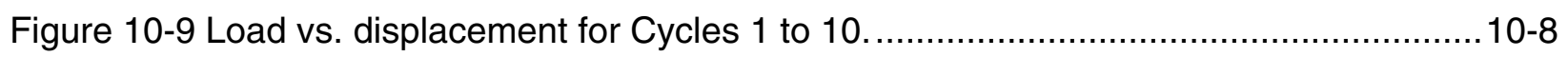

Figure 10-10 All available strain data........................................................................ 10

Figure 10-11 All mechanical data. ....................................................................... 10-9

Figure 10-12 Load vs. displacement for entire test.................................................. 10-10

Figure 10-13 Axial through-wall defect in the $270^{\circ}$ position............................................10-11

Figure 10-14 External $270^{\circ}$ position confirming an axial fissure (approximate length $40 \mathrm{~mm})$.

Figure $10-15$ Internal $270^{\circ}$ position confirming multiple axial cracking (approximate length $60 \mathrm{~mm}$ ).

Figure 10-16 Internal $90^{\circ}$ position confirming multiple axial cracking (approximate length $60 \mathrm{~mm})$.

Figure 10-17 External surface of intrados showing fine circumferential cracking as indicated by white arrows. 
Figure $10-18$ Internal $180^{\circ}$ intrados position showing axial indications as indicated by white arrows.

Figure 10-19 Internal surface of $270^{\circ}$ position showing axial cracking...............................10-14

Figure 10-20 Broken open fracture at $270^{\circ}$ position used for SEM. ................................. 10-15

Figure 10-21 Areas examined at the $270^{\circ}$ position.....................................................10-15

Figure 10-22 Stages of crack progression found at the $270^{\circ}$ position; the morphology indicates step-wise crack progression under the combined influence of mechanical loading and environment. ........................................................................... 10-16

Figure 10-23 Removal plan of extracted specimens..................................................10-16

Figure $10-24$ Cross-sections of the $270^{\circ}$ and $90^{\circ}$ position over the entire wall thickness; the numbers represent approximate crack depths.

Figure $10-25$ Metallography of the $180^{\circ}$ position confirmed both axial and circumferential cracking on the internal and external surface, respectively. The numbers represent approximate crack depths.

Figure 10-26 Schematic summary of crack locations, orientation and approximate crack depths (if available) of Test $4 \mathrm{~d}$; schematic provides a cross-sectional view of the apex looking down-stream; please note that schematic is not to scale.

Figure 11-1 Conductivity and temperature vs. testing time for Test $4 \mathrm{a}$

Figure 11-2 Temperature, corrosion and redox potential vs. testing time for Test $4 a^{\prime}$........... $11-3$

Figure 11-3 Mechanical data for Cycles 1 to 5. 11-5

Figure 11-4 Mechanical data for Cycles 6 to 10 $11-5$

Figure 11-5 Strain response for Cycles 1 to 10 . $11-6$

Figure 11-6 Load vs. displacement hysteresis for Cycles 1 to 5. $11-6$

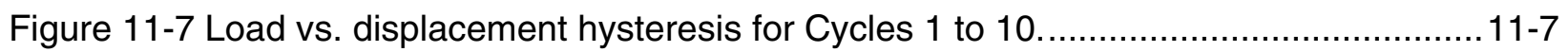

Figure 11-8 All available strain data ......................................................................... 11-7

Figure 11-9 All mechanical data for Test 4 a. .............................................................. 11-8

Figure 11-10 Load vs. displacement hysteresis for entire Test 4a'...................................11-8

Figure $11-11270^{\circ}$ position (in-situ and rotated ca. 90 degrees) showing leakage indicated by white arrow.

Figure 11-12 $\mathrm{DPI}$ at $270^{\circ}$ position showing axial cracking on both the internal and external surfaces.

Figure 11-13 $\mathrm{DPI}$ at $90^{\circ}$ position showing multiple axial cracking. $11-10$

Figure 11-14 DPI at $180^{\circ}$ intrados position confirming circumferential cracking on the external and axial cracking on the internal surfaces.

Figure 11-15 SEM surface examination confirming axial cracking that predominantly followed attacked grain boundaries.

Figure 11-16 Broken open crack at $270^{\circ}$ position that was used for fractography. $11-12$

Figure 11-17 Different stages of crack progression confirming corrosion fatigue at $270^{\circ}$ position.

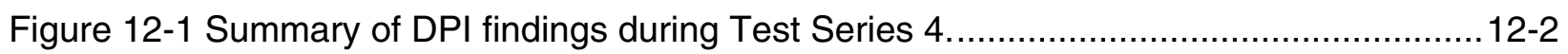

Figure 12-2 Summary of SEM surface examination during Test Series 4 . ...........................12-3

Figure 12-3 Summary of crack locations and depths observed during Test Series 4............12-4 
Figure 13-1 Summary of results obtained during Test Series 2 and BLT 2 (Strain amplitude: $\pm 0.6 \%$; strain rate: $1 \times 10^{-4} \mathrm{~s}^{-1}$ ).

Figure 13-2 Summary of results obtained during Test Series 4 (strain amplitude: $\pm 0.4 \%$; strain rate: $\left.1 \times 10^{-4} \mathrm{~s}^{-1}\right)$. 


\section{LIST OF TABLES}

Table 1-1 Original matrix for environmental fatigue testing of stainless steel U-bend specimens

Table 2-1 Results from static testing during strain gauge qualification .................................. 2-4

Table 4-1 Basic test parameters during BLT 2 .............................................................. 4-2

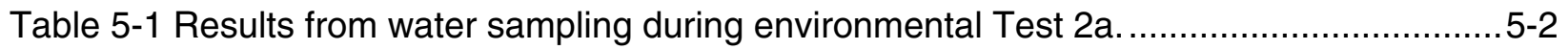

Table 5-2 Basic test parameters of mechanical loading during environmental Test $2 \mathrm{a} . \ldots \ldots \ldots \ldots . . . .5-4$

Table 6-1 Results from water sampling during environmental Test $2 b$.................................6-2

Table 6-2 Basic test parameters of mechanical loading during environmental Test 2b...........6-4

Table 8-1 Results from water sampling during environmental Test 4 a................................. 8-2

Table 8-2 Basic test parameters of mechanical loading during environmental Test $4 a . \ldots \ldots \ldots . . . .8-4$

Table 9-1 Results from water sampling during environmental Test 4b................................9-2

Table 9-2 Basic test parameters of mechanical loading during environmental Test 4b...........9-4

Table 10-1 Results from water sampling during environmental Test $4 \mathrm{~d}$. ..............................10-3

Table 10-2 Basic test parameters of mechanical loading during Test $4 \mathrm{~d}$. ............................ 10-5

Table 11-1 Water chemistry data of Test $4 a^{\prime}$...............................................................11-2

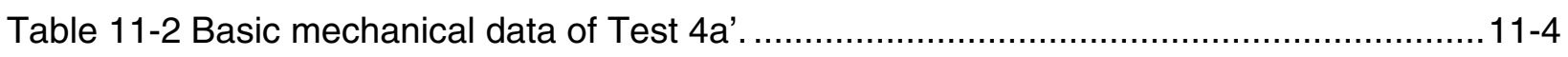

Table 13-1 Condensed summary of important results for all tested bends..........................13-2 



\section{1 \\ INTRODUCTION}

Environmental fatigue testing of austenitic stainless steel components under simulated pressurized water reactor (PWR) operating conditions (temperature, reactor water flow rate, strain range and strain rate) is being sponsored by the EPRI Materials Reliability Program (MRP) Fatigue Issue Task Group (ITG) to fill in some important gaps in the knowledge base.

An analysis and assessment of existing fatigue data for stainless steel exposed to the PWR primary environment has identified a lack of data with respect to flow rate effects. The majority of existing data has been gained under static or quasi-static flow conditions, where the tendency to environmental enhancement of cyclic crack growth is expected to increase. However plant experience - where high-flow conditions prevail - shows significantly lower susceptibility to crack initiation due to corrosion fatigue. Obtaining such environmental fatigue data on stainless steel specimens with direct relevance to plant components under test conditions that more realistically simulate plant operations is a high priority within the EPRI MRP program.

The main objective of the present test program is therefore the identification of flow-rate effects on the initiation and growth of low-cycle corrosion fatigue (LCF) cracks in stainless steel tubebend specimens undergoing cyclic loading and simultaneous exposure to simulated PWR primary water at the inner tube surface. The original, intended test matrix is shown in Table 1-1. EPRI report 1007853 (MRP-100) from December 2004 describes modifications to the preexisting test facility at F-ANP in Germany, characterization of the stainless steel U-bend test specimens, results of initial baseline testing in an inert environment and optimization of test procedures. The present Technical Update report covers additional baseline testing within Phase A (including qualification of bonded, HT strain gauges), the environmental test pair $2 \mathrm{a} / 2 \mathrm{~b}$ at high cyclic strain amplitude and moderate strain rate, as well as the environmental test pair 4a/4b (plus 2 additional, related experiments) at moderate cyclic strain amplitude and moderate strain rate.

The program will continue in 2005 with an additional baseline test comparable to tests 4a/4b, but in an inert environment, and a further environmental test pair 3a/3b at moderate cyclic strain and low strain rate. 
Table 1-1

Original matrix for environmental fatigue testing of stainless steel U-bend specimens

\begin{tabular}{|c|c|c|c|c|c|c|c|c|c|c|c|}
\hline \multirow[b]{2}{*}{ 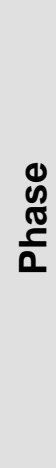 } & \multirow[b]{2}{*}{$\begin{array}{l}0_{0}^{0} \\
\stackrel{1}{0} \\
\stackrel{1}{0}\end{array}$} & \multicolumn{5}{|c|}{ Loading conditions } & \multicolumn{5}{|c|}{ Environmental Conditions } \\
\hline & & 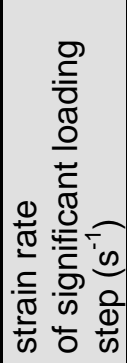 & 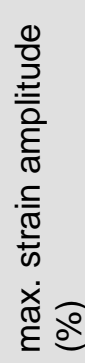 & 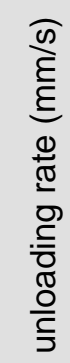 & $\frac{0}{\frac{\pi}{\alpha}}$ & 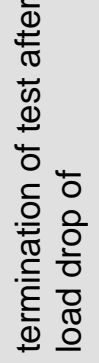 & 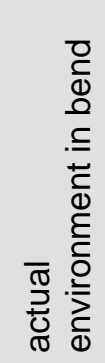 & $\begin{array}{l}0 \\
\frac{0}{\pi} \\
3 \\
0 \\
\end{array}$ & $\begin{array}{l}0 \\
0 \\
\vdash\end{array}$ & $\begin{array}{l}\text { 응 } \\
\text { 응 } \\
\text { 응 }\end{array}$ & 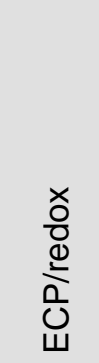 \\
\hline A & $\begin{array}{l}\text { BLT1 } \\
\text { BLT2A } \\
\text { BLT2 }\end{array}$ & $10^{-4}$ & \pm 0.6 & $\begin{array}{r}0.5 \\
0.5 \\
0.2 \\
0.2\end{array}$ & -1 & $5 \%$ & $\mathrm{~N}_{2}$ & --- & $\begin{array}{l}240 \\
R T \\
240\end{array}$ & --- & --- \\
\hline \multirow{2}{*}{ C } & $1 a$ & $10^{-6}$ & \pm 0.6 & 0.5 & -1 & $5 \%$ & PWR & High & 240 & $<10$ & $\begin{array}{l}\text { mea- } \\
\text { sured }\end{array}$ \\
\hline & $1 \mathrm{~b}$ & $10^{-6}$ & \pm 0.6 & 0.5 & -1 & $5 \%$ & PWR & Low & 240 & $<10$ & $\begin{array}{l}\text { mea- } \\
\text { sured }\end{array}$ \\
\hline \multirow{2}{*}{ B } & $2 a$ & $10^{-4}$ & \pm 0.6 & 0.5 & -1 & $5 \%$ & PWR & High & 240 & $<10$ & $\begin{array}{l}\text { mea- } \\
\text { sured }\end{array}$ \\
\hline & $2 b$ & $10^{-4}$ & \pm 0.6 & 0.5 & -1 & $5 \%$ & PWR & Low & 240 & $<10$ & $\begin{array}{l}\text { mea- } \\
\text { sured }\end{array}$ \\
\hline \multirow{4}{*}{ C } & $3 a$ & $10^{-6}$ & \pm 0.4 & 0.5 & -1 & $5 \%$ & PWR & High & 240 & $<10$ & $\begin{array}{l}\text { mea- } \\
\text { sured }\end{array}$ \\
\hline & $3 b$ & $10^{-6}$ & \pm 0.4 & 0.5 & -1 & $5 \%$ & PWR & Low & 240 & $<10$ & $\begin{array}{l}\text { mea- } \\
\text { sured }\end{array}$ \\
\hline & $4 a$ & $10^{-4}$ & \pm 0.4 & 0.5 & -1 & $5 \%$ & PWR & High & 240 & $<10$ & $\begin{array}{l}\text { mea- } \\
\text { sured }\end{array}$ \\
\hline & $4 b$ & $10^{-4}$ & \pm 0.4 & 0.5 & -1 & $5 \%$ & PWR. & Low & 240 & $<10$ & $\begin{array}{l}\text { mea- } \\
\text { sured }\end{array}$ \\
\hline
\end{tabular}




\section{QUALIFICATION OF BONDED STRAIN GAUGES}

\section{Background}

Due to challenges encountered during earlier testing (BLT 1 and BLT2 RT) in the form of premature crack initiation at spot welds and differences in readings between the two tests, the necessity arose to change the type of strain gauges. After discussing the issue with Framatome strain gauge experts it was decided to switch from spot welded types to bonded high temperature (HT) strain gauges. Before actual testing was performed with instrumented bends, the bonded HT strain gauges were qualified by comparison to a calibrated high precision extensometer of a tensile testing machine.

\section{Test Parameters and Set-Up}

To qualify the accuracy of bonded HT strain gauges, a round tensile specimen was prepared and instrumented with three different types of strain gauges as displayed in Figure 2-1 to Figure 2-3:

- One bonded HT strain gauge (to be qualified): TML ZFLA-1-11 Batch S609211

- One spot welded HT strain gauge: Micro Epsilon MG128-01-10-9S Batch 0116 Gauge No 4.

- One bonded RT strain gauge: (no further data available)

The bonded HT strain gauge to be qualified was applied in strict accordance with the manufacturer's recommendations. The application included a specific curing procedure under constant contact pressure at elevated temperatures (curing temperatures were to be $20 \mathrm{~K}$ higher than the actual operating temperature: $240^{\circ} \mathrm{C}+20 \mathrm{~K}=260{ }^{\circ} \mathrm{C}$ ). Finally, after curing, the bonded HT strain gauge was subject to a heating cycle from room temperature up to operating temperature in a non-loaded condition to evaluate the strain hysteresis.

The round tensile specimen was equipped with threaded heads for load distribution and had a reduced section with a diameter of $9 \mathrm{~mm}$. The active length of the reduced section was $50 \mathrm{~mm}$. The spot welded HT gauge was declared the leading gauge, according to which the qualification test was controlled. 


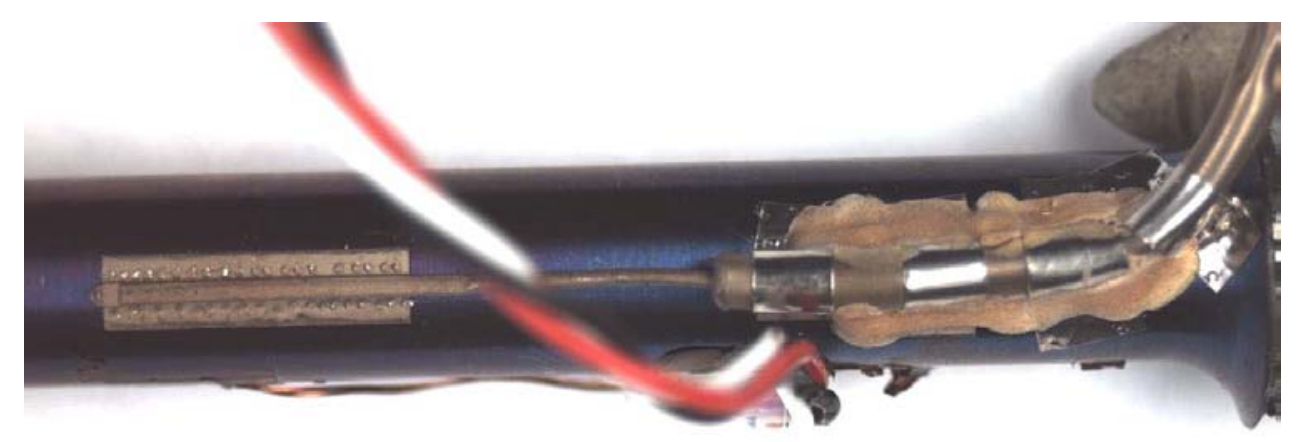

Figure 2-1

Spot welded HT strain gauge

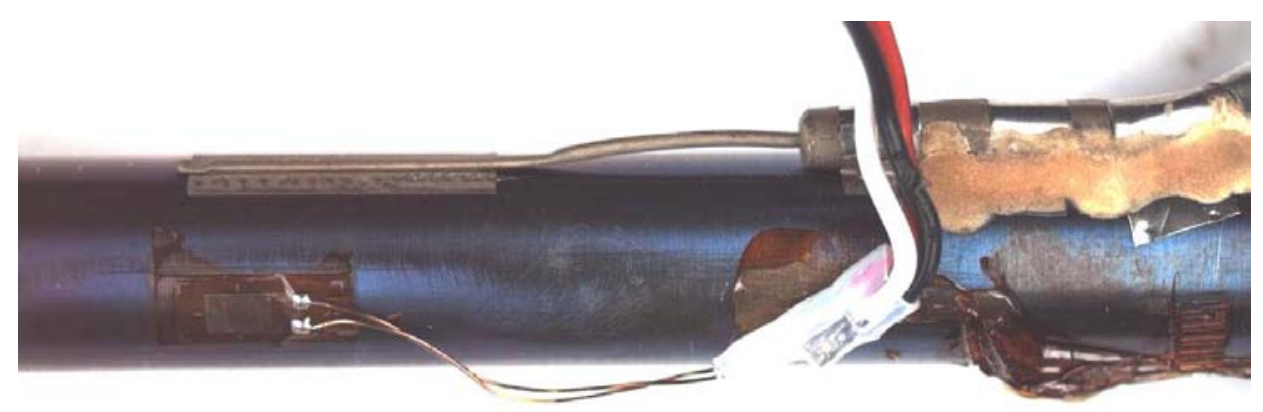

Figure 2-2

Bonded RT strain gauge

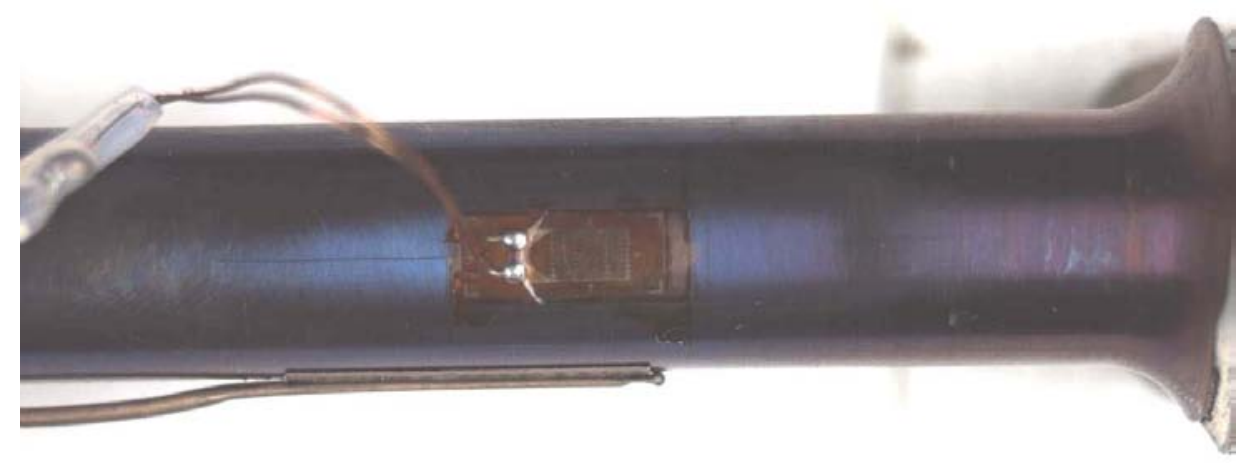

Figure 2-3

Bonded HT strain gauge 


\section{Procedure}

\section{Static Testing at Room Temperature}

In a first step, the specimen was statically loaded in steps up to a maximum of approximately $0.6 \%$ (strain recorded at the leading spot welded HT gauge) and then entirely unloaded. The corresponding strains, including the residual strain in the unloaded condition, were compared to the "most accurate" strain recorded by an annually calibrated high precision axial extensometer. The strain data generated by this extensometer was considered $100 \%$ if deviations in per cent are expressed in the following paragraphs.

\section{Dynamic Testing at $240^{\circ} \mathrm{C}$}

In a second step the tensile specimen was subject to cyclic loading. For this test, the bonded RT gauge was removed and the initial strain of all remaining instrumented gauges was adjusted to the same level recorded as residual plastic strain after the static load test. The cyclic loading was performed for approximately 10 cycles with an $\mathrm{R}$ ratio $>0$. Again the corresponding strain responses were compared to the numbers obtained with the high precision axial extensometer

\section{Findings}

\section{Static Testing}

The results are summarized in Table 2-1. The static load test conducted at room temperature showed very good agreement between the bonded HT strain gauge and the high precision clip gauge. The deviations found are considered negligible.

However, the leading spot welded HT strain gauge exhibited relative large deviations when compared to the high precision extensometer. The numbers recorded are too low. For strains up to $0.2 \%$ the deviation is approximately $-10 \%$ but for higher strains (up to $0.6 \%$ ) the maximum deviation was found to be $-26 \%$ from the nominal number determined with the extensometer.

The bonded RT gauge also exhibited large deviations if compared to the high precision extensometer. This gauge was reading too high and the average deviation was found to be approximately $20 \%$. 


\section{Cyclic Testing}

The cyclic load sequence conducted at $240^{\circ} \mathrm{C}$ confirmed the inaccuracy of the spot welded HT gauges since it showed a continuous negative deviation of approximately $-0.2 \%$. The average deviation determined at the peak loads was found to be $-23 \%$ as shown in Figure 2-4. However, the bonded HT stain gauges exhibited good agreement with the extensometer.

\begin{tabular}{|c|c|c|c|c|}
\hline \multicolumn{5}{|c|}{ Static Qualification Testing at Room Temperature } \\
\hline $\begin{array}{c}\text { Extensometer } \\
\text { (strain in \%) }\end{array}$ & $\begin{array}{c}\text { HT gauge } \\
\text { spot welded } \\
\text { (strain in \%) }\end{array}$ & $\begin{array}{c}\text { HT gauge } \\
\text { bonded } \\
\text { (strain in \%) }\end{array}$ & $\begin{array}{c}\text { RT gauge } \\
\text { bonded } \\
\text { (strain in \%) }\end{array}$ & $\begin{array}{c}\text { Force } \\
\text { (kN) }\end{array}$ \\
\hline- & 0 & 0 & - & - \\
\hline- & 0.05 & 0.057 & - & - \\
\hline- & 0.1 & 0.111 & - & - \\
\hline- & 0.15 & 0.165 & - & - \\
\hline- & 0.2 & 0.225 & - & - \\
\hline 0.618 & 0.525 & 0.735 & 0.89 & 32.29 \\
\hline 0.745 & - & - & & 33.11 \\
\hline 0.824 & 0.611 & 0.823 & 0.973 & 32.66 \\
\hline 0.83 & - & - & - & 29.86 \\
\hline 0.606 & 0.399 & 0.595 & 0.724 & 3.16 \\
\hline 0.564 & 0.372 & 0.57 & 0.701 & 0.21 \\
\hline
\end{tabular}

Table 2-1

Results from static testing during strain gauge qualification

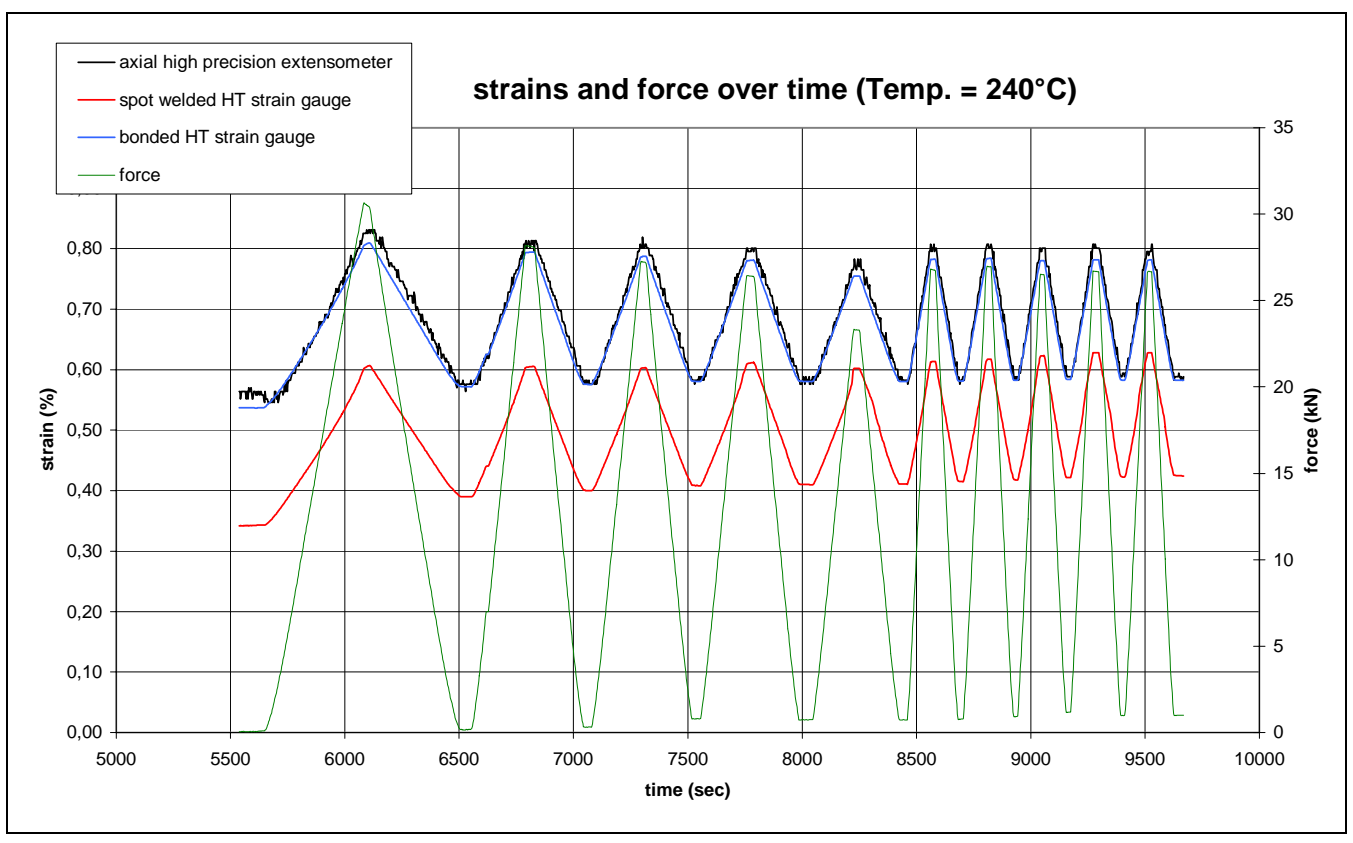

Figure 2-4

Results of dynamic load testing during strain gauge qualification 


\section{Conclusions from Strain Gauge Qualification}

The test set-up and wiring was inspected and considered sound.Thus, the large deviation above strains of $0.2 \%$ is caused by an unknown gauge behavior and could not have been foreseen prior to testing. This gauge characteristic might be attributed to the fact that the common operating range where extensive data/experience is available for this type of gauge is well below $0.2 \%$ strain. Any operating strain beyond this level, as it will be the case for all tests throughout this fatigue program, might result in deviations as observed. The following can be summarized:

- Test set-up considered sound

- Spot-welded gauge was reading too low. Deviation up to absolute strain of $0.2 \%$ was 10\%; beyond up to $26 \%$

- Error attributed to unexpected non-linear behavior of the spot welded HT gauge beyond absolute strains of $0.2 \%$

- Finding has some important implications for the evaluation of previous baseline test

- Good agreement between high precision extensometer and bonded HT strain gauge (to be used for all further work)

\section{Implications for BLT 1}

In the context of these results, the relatively strong drift of strain data that was recorded during BLT 1 (Chapter 7, Report 1007853, Phase A) is explainable. The implications for BLT1 are as follows:

- The new knowledge about the deviation and the drift of the spot welded HT strain gauge can explain the observed behavior of the bend during BLT1

- At the beginning, the strain amplitude was in the range of $0.8 \%$, drifting during the 36 cycles to $+1 \%$ or higher.

- On the other hand, reaching - $0.6 \%$ required higher negative displacement.

Hence, data from this test might not represent the actual strains present in the bend during testing and conclusions should not be drawn without carefully reviewing the raw data in the context of the above. In terms of comparability of tests within the regime of $\pm 0.6 \%$ strain amplitude, BLT 2 (described in Chapter 4) should be considered the decisive test. 



\section{3 \\ LOADING CONSIDERATIONS}

The task of stressing a small-scale component in the shape of a cold-formed, U-bend with a fully reversed load pattern is relatively complex. To facilitate proper evaluation of fatigue results, the following loading considerations are appropriate for the testing performed:

- The bend test is effectively strain controlled, with the axial strain at the outside surface (OD) of the bend intrados $\left(180^{\circ}\right.$ position) acting as the control strain.

- Despite the reduced wall thickness from fabrication at that location, axial strains at the OD of the bend extrados $\left(0^{\circ}\right.$ position) are considerably smaller than at the intrados, because of bend radius effects.

- Under the opening and closing moment (push-pull of the bend legs), compressive/tensile, cyclic axial strains are also created at the inside surface (ID) of the intrados, but their maximum values are much lower than the control strain at the OD.

- As a result of ovalization at the apex of the bend during cyclic loading, appreciable circumferential strains also arise in the $90^{\circ}$ and $270^{\circ}$ locations at the ID surface.

- The strains resulting from cyclic loading at the various locations around the bend apex cannot be expected to be entirely symmetrical, because of factors such as "out-ofroundness" and wall thickness variations arising from tube manufacture/bend fabrication, as well as bend residual stress.

From these considerations, mechanically dominated fatigue is expected to lead to circumferential cracking, starting at the outside surface of the intrados, whereas environmental effects should manifest themselves primarily as axial cracking at the inside surface in the so-called "neutral" bend positions (i.e. $90^{\circ}$ and $270^{\circ}$ ) around the apex of the test specimen.

A detailed finite-element analysis of the actual strains arising during bend loading is being performed by F-ANP as a voluntary addition to the test program and will be reported in 2005. This will facilitate comparison of the results obtained with both code design curves and literature data. However, despite the abovementioned complexity, the emphasis placed on quality control during bend fabrication, as well as on reproducibility of loading from test to test, ensures that a direct comparison of data for the main testing variable (flow rate) is possible prior to knowledge of these details. 



\section{4}

\section{BASE LINE TEST 2}

\section{Test Set-Up and Approach}

Baseline Test 2 (BLT 2) was conducted as a final step to optimize test procedures and gain meaningful data for later environmental testing under different flow conditions. The test parameters and bend instrumentation during BLT 2 were as follows:

- Inert $\mathrm{N}_{2}$ atmosphere inside the bend and around the bend

- Internal pressure adjusted to 50 bar (725 psi) representing the approximate primary water pressure at $240{ }^{\circ} \mathrm{C}$

- Testing temperature was monitored with NiCrNi thermocouple on external surface

- Three axial bonded HT strain gauges at the $0^{\circ}, 90^{\circ}$ and $180^{\circ}$ (intrados) locations

- $\quad$ Strain amplitude of $\pm 0.6 \%$ (total strain range of $1.2 \%$ )

- Strain rate of $1 \times 10^{-4} \mathrm{~s}^{-1}$

- Load pattern applied as both a triangular and a modified wave shape (for some cycles) with an $\mathrm{R}$ ratio of approximately -1 


\section{Results}

The test was started by applying an initial number of cycles (approximately 10) until the bend showed fairly stable behavior. During this sequence, the test was run displacement controlled with strain-triggered switch points at $\pm 0.6 \%$ strain. The displacements present at cycle 10 were explicitly determined and used as reference parameters for the remaining test sequence, performed under displacement control. Table 4-1 displays the basic mechanical test parameters and the mode of load application for the test.

\begin{tabular}{|c|c|c|c|c|c|}
\hline Cycle & $\begin{array}{l}\text { Wave } \\
\text { Shape }\end{array}$ & $\begin{array}{l}\text { Control } \\
\text { Channel }\end{array}$ & Strain rate & Switch Point & $\begin{array}{c}\text { Switch off } \\
\text { Criteria }\end{array}$ \\
\hline $1-5$ & triangular & displacement & $1 \times 10^{-5} \mathrm{~s}^{-1}$ & $\begin{array}{l}+0.6 \% \\
-0.6 \%\end{array}$ & \\
\hline $6-12$ & triangular & displacement & $1 \times 10^{-4} \mathrm{~s}^{-1}$ & $\begin{array}{l}+0.6 \% \\
-0.6 \%\end{array}$ & \\
\hline $13-815$ & triangular & displacement & $1 \times 10^{-4} \mathrm{~s}^{-1}$ & $\begin{array}{l}+6.9 \mathrm{~mm} \\
-4.7 \mathrm{~mm}\end{array}$ & $10700 \mathrm{~N}$ \\
\hline $816-865$ & $\begin{array}{c}\text { case } 4 \\
\text { mod. }\end{array}$ & displacement & $\begin{array}{l}0.2 \mathrm{~mm} / \mathrm{s} \\
1 \times 10^{-4} \mathrm{~s}^{-1} \\
0.2 \mathrm{~mm} / \mathrm{s} \\
1 \times 10^{-4} \mathrm{~s}^{-1}\end{array}$ & $\begin{array}{c}+1.75 \mathrm{~mm}(-0.06 \%) \\
+6.9 \mathrm{~mm} \\
+0.25 \mathrm{~mm}(+0.07 \%) \\
-4.7 \mathrm{~mm}\end{array}$ & $9700 \mathrm{~N}$ \\
\hline $866-1705$ & triangular & displacement & $1 \times 10^{-4} \mathrm{~s}^{-1}$ & $\begin{array}{l}+6.9 \mathrm{~mm} \\
-4.7 \mathrm{~mm}\end{array}$ & faillure \\
\hline
\end{tabular}

Table 4-1

Basic test parameters during BLT 2

During the first 12 cycles of loading the bend showed relatively uniform behavior with no anomalies to be observed (see Figure 4-1 and Figure 4-2). BLT 2 was performed to a maximum number of 1705 cycles. At this point, the bend exhibited a circumferential through wall crack and consequently the test was terminated.

Figure 4-3 shows the load and displacement over time response of the entire test. The displacement controlled testing exhibited a very uniform appearance for the entire test. The sudden decreases in load at the approximate testing time $4650 \mathrm{~min}$ and $6200 \mathrm{~min}$ were attributed to adjustments of the internal autoclave pressure. These adjustments were necessary because loss of the autoclave pressure resulted in deviations of the pressure differential to the internal bend atmosphere and consequently the loads on the bend would have varied.

The strain response of all instrumented gauges is displayed in Figure 4-4. The leading strain gauge at the $180^{\circ}$ intrados position delivered data until cycle 126 and then stopped working. Also, the other strain gauges at the $0^{\circ}$ and $90^{\circ}$ position were not considered past cycle 126 and the test was continued under displacement control. The load displacement hysteresis is shown in Figure 4-5 and Figure 4-6. It appears relatively uniform in shape indicating fairly stable bend behavior during testing. 


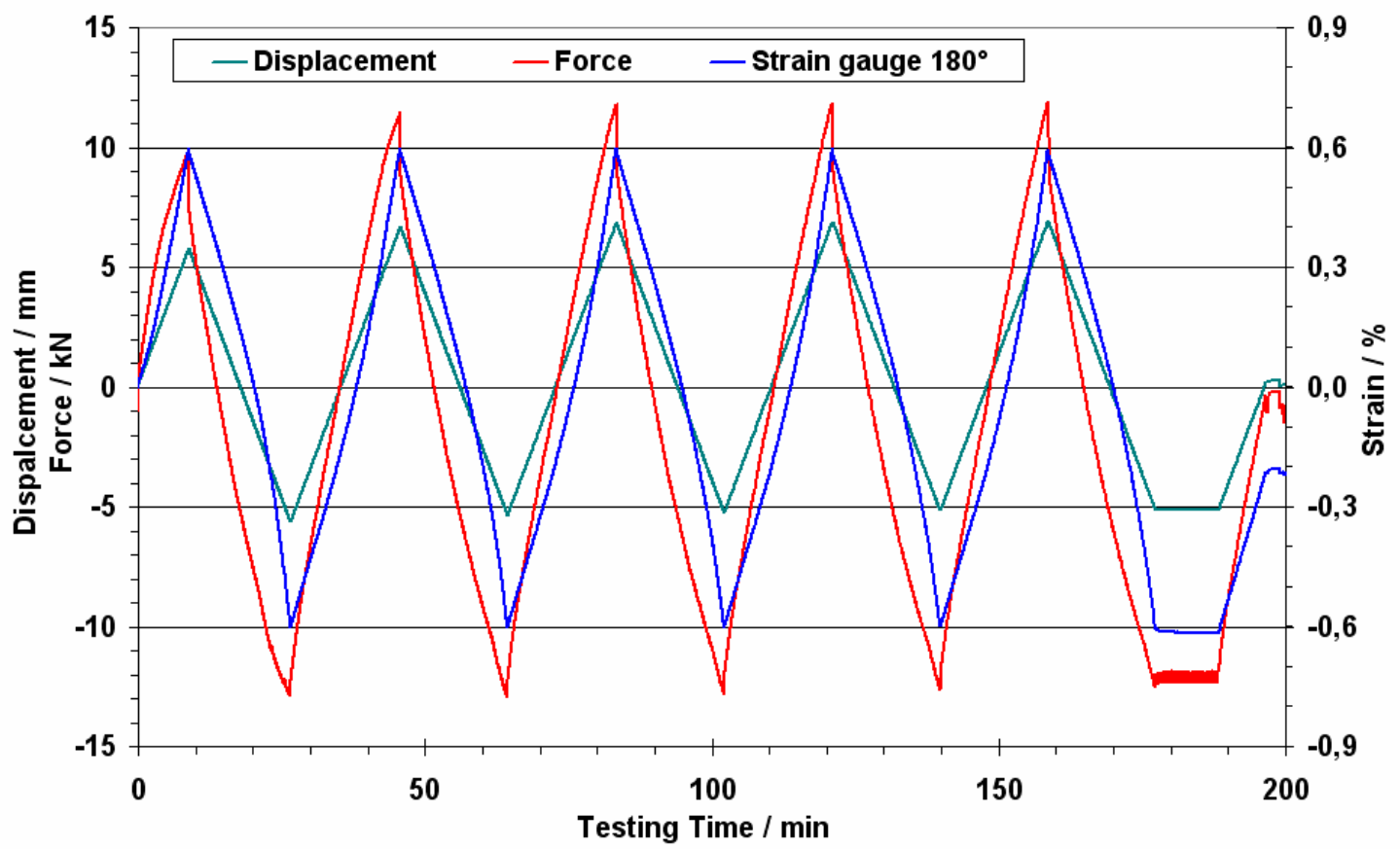

Figure 4-1

First 5 cycles of BLT 2 showing uniform behavior

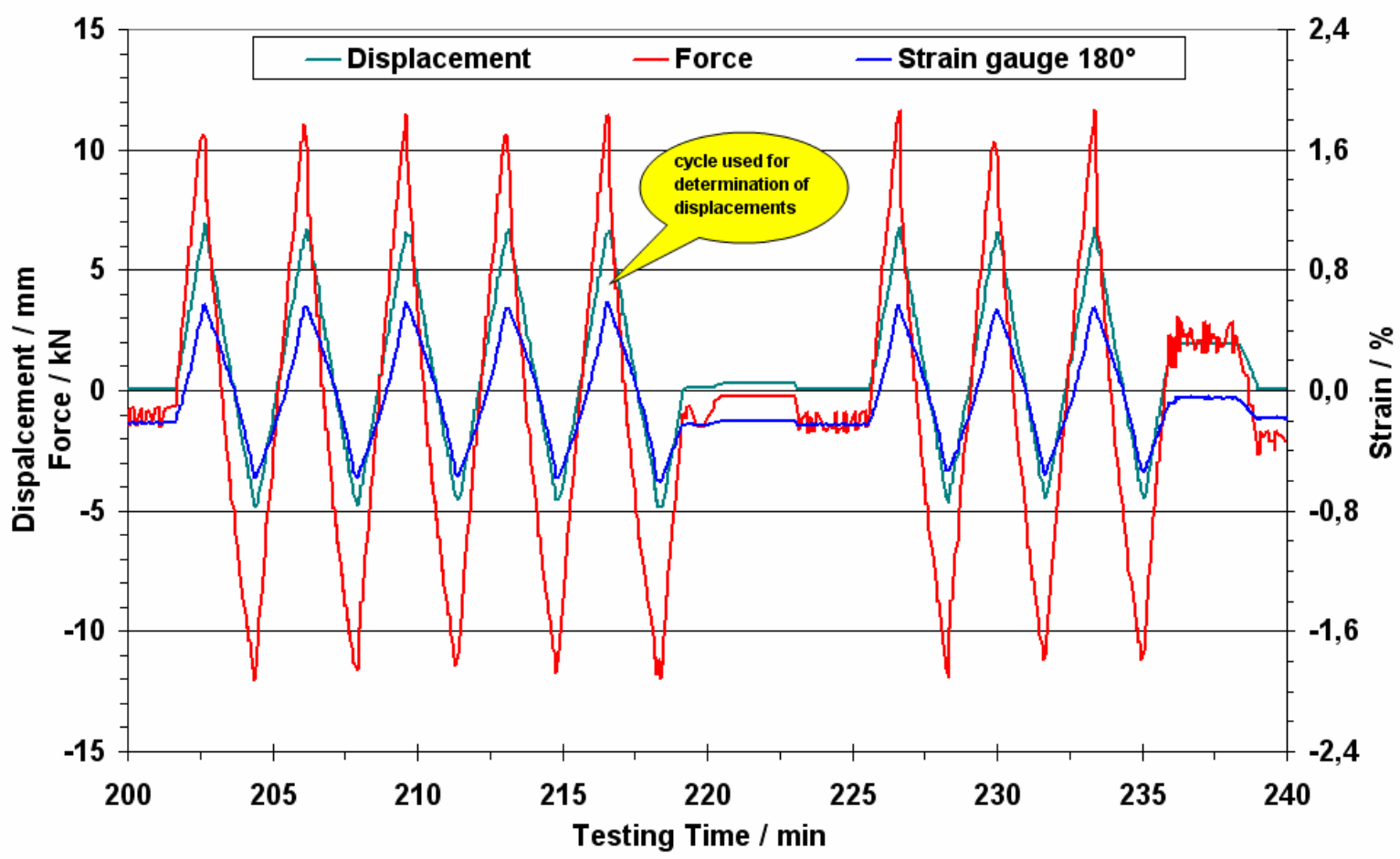

Figure 4-2

Cycle 6 to 13; Cycle 10 was used for determination of displacements for remaining test 


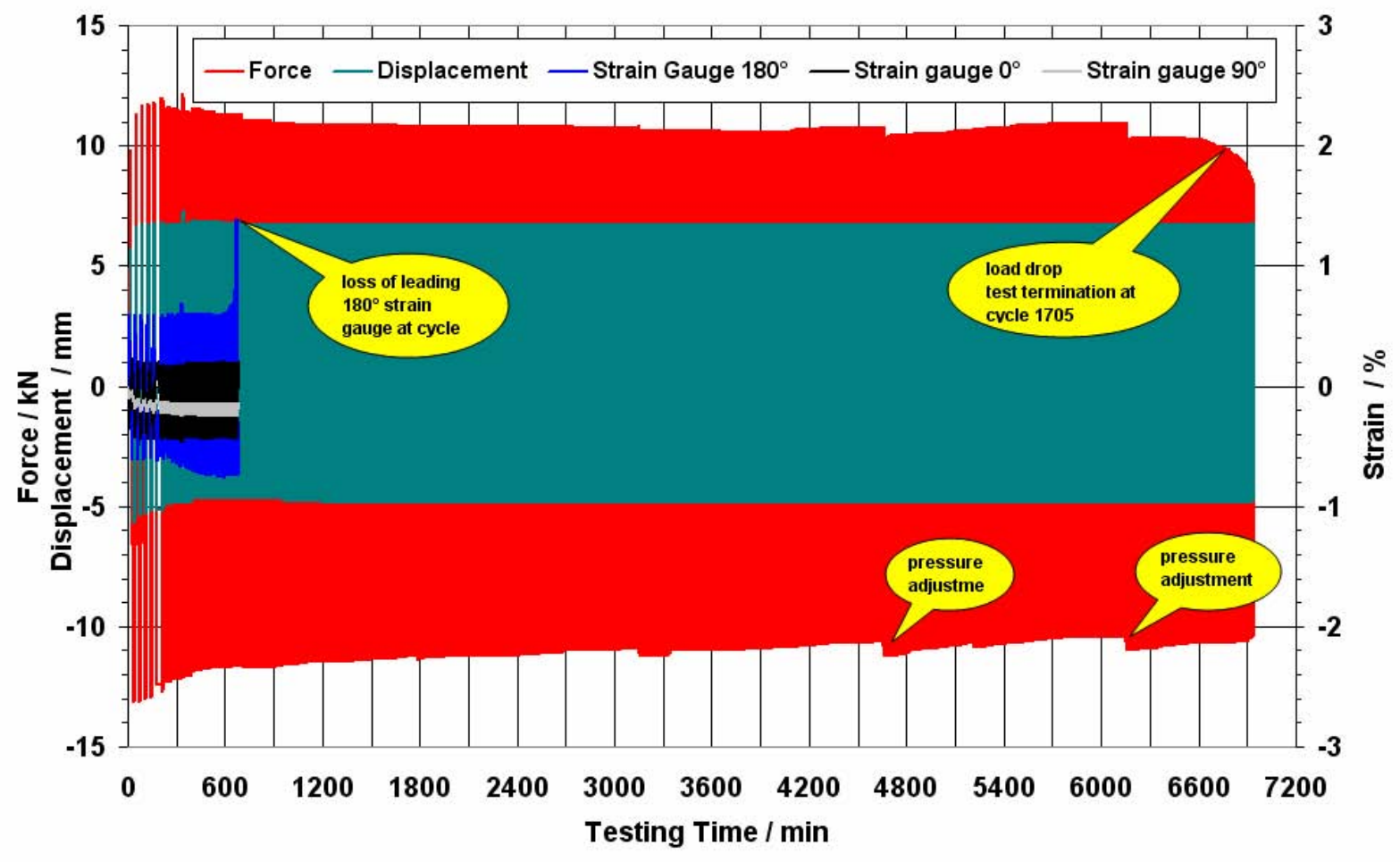

Figure 4-3

Entire test sequence of BLT 2 with the maximum of 1705 cycles

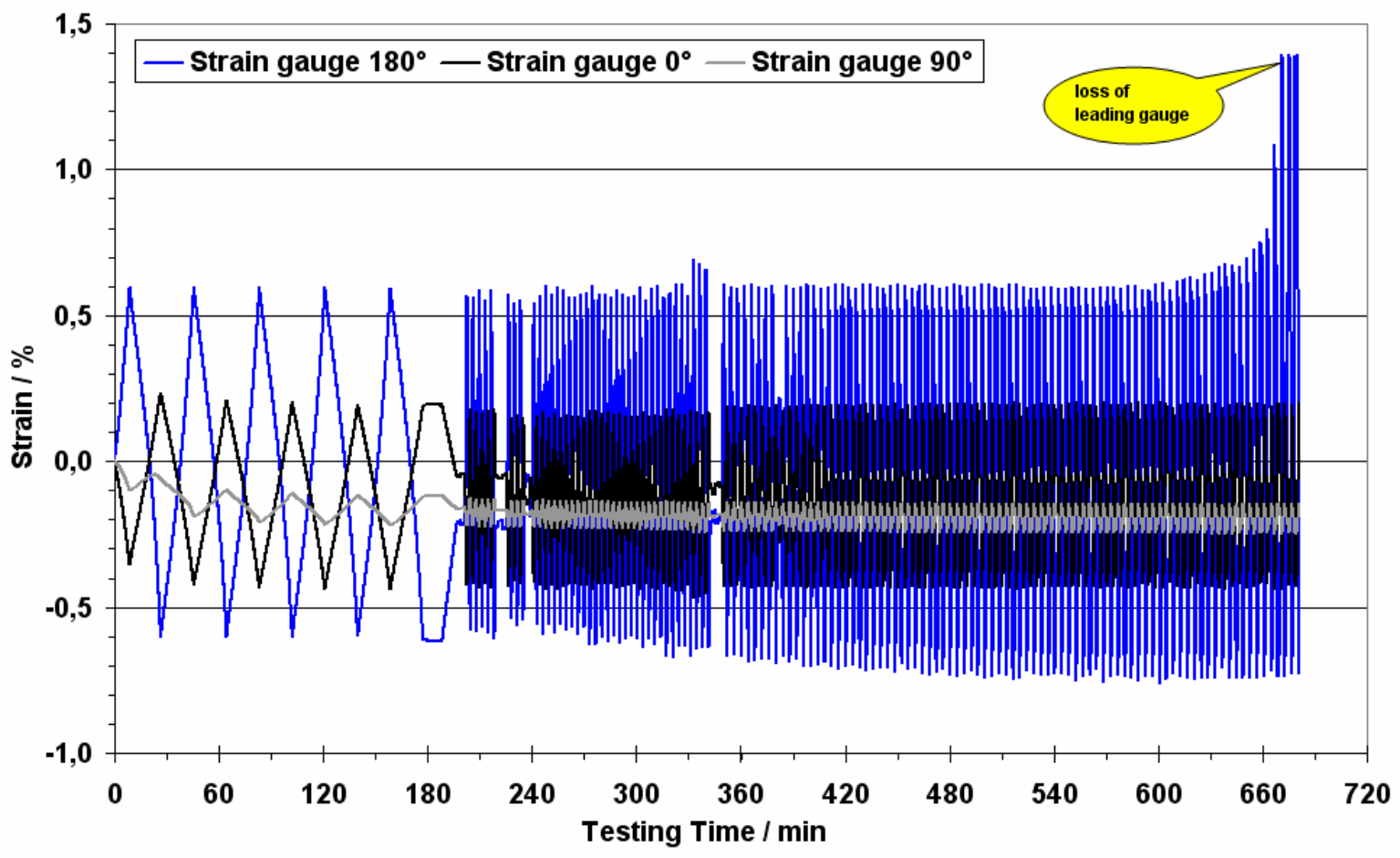

Figure 4-4

Strain response of all instrumented strain gauges to cycle 126 


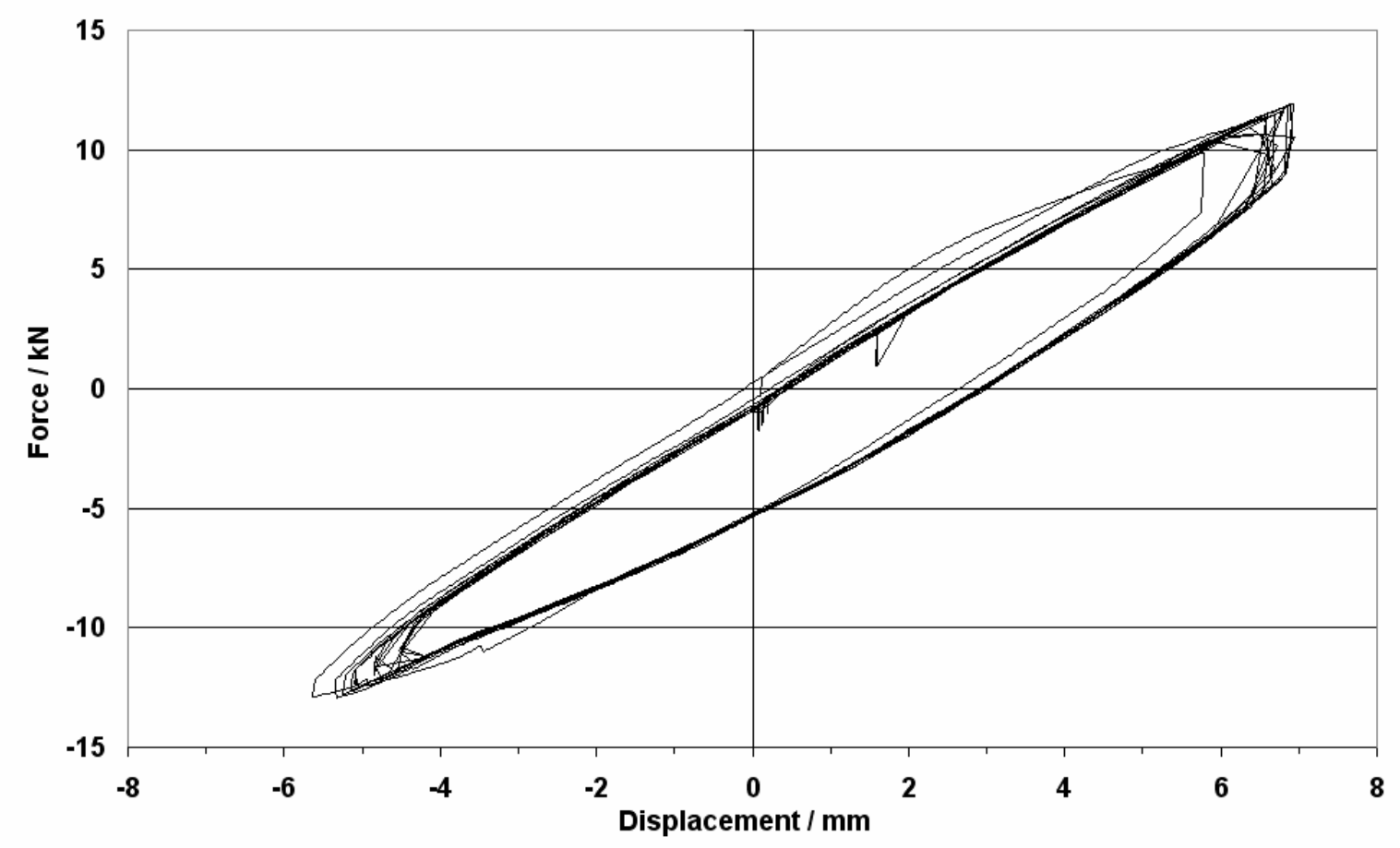

Figure 4-5

Force vs. displacement plot for cycles 1 to 10.

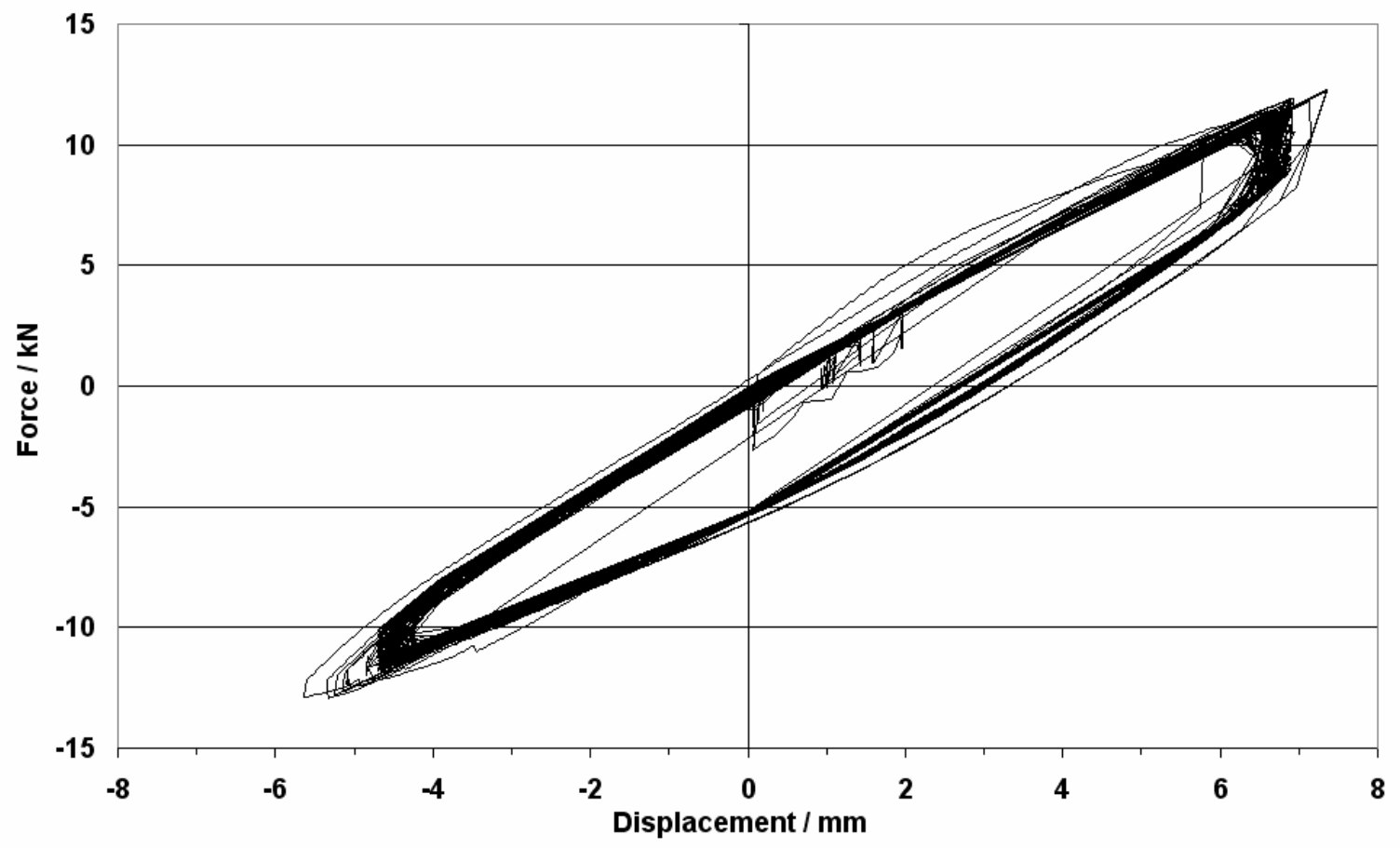

Figure 4-6

Force vs. displacement plot for cycles 1 to 126. 


\section{Post Test Characterization}

After the physical testing part of BLT 2 was accomplished, the U-bend was removed from the testing rig, the additional tubing for optimizing flow condition was cut off, and the bend was prepared for analysis. The post-test characterization entailed the following tasks:

- Visual inspection of tested U-bend

- Dye penetrant inspection (DPI)

- Fractography at high magnifications using scanning electron microscopy (SEM)

- Metallography of selected locations of interest

- Vickers micro hardness measurements

\section{Visual Inspection}

Visual inspection revealed one primary circumferential crack with an approximate length of $20 \mathrm{~mm}$ located at the intrados adjacent to the strain gauge. This defect had developed into a through wall crack as displayed in Figure 4-7. No other primary defects visible to the naked eye were found on the external surface during visual inspection.

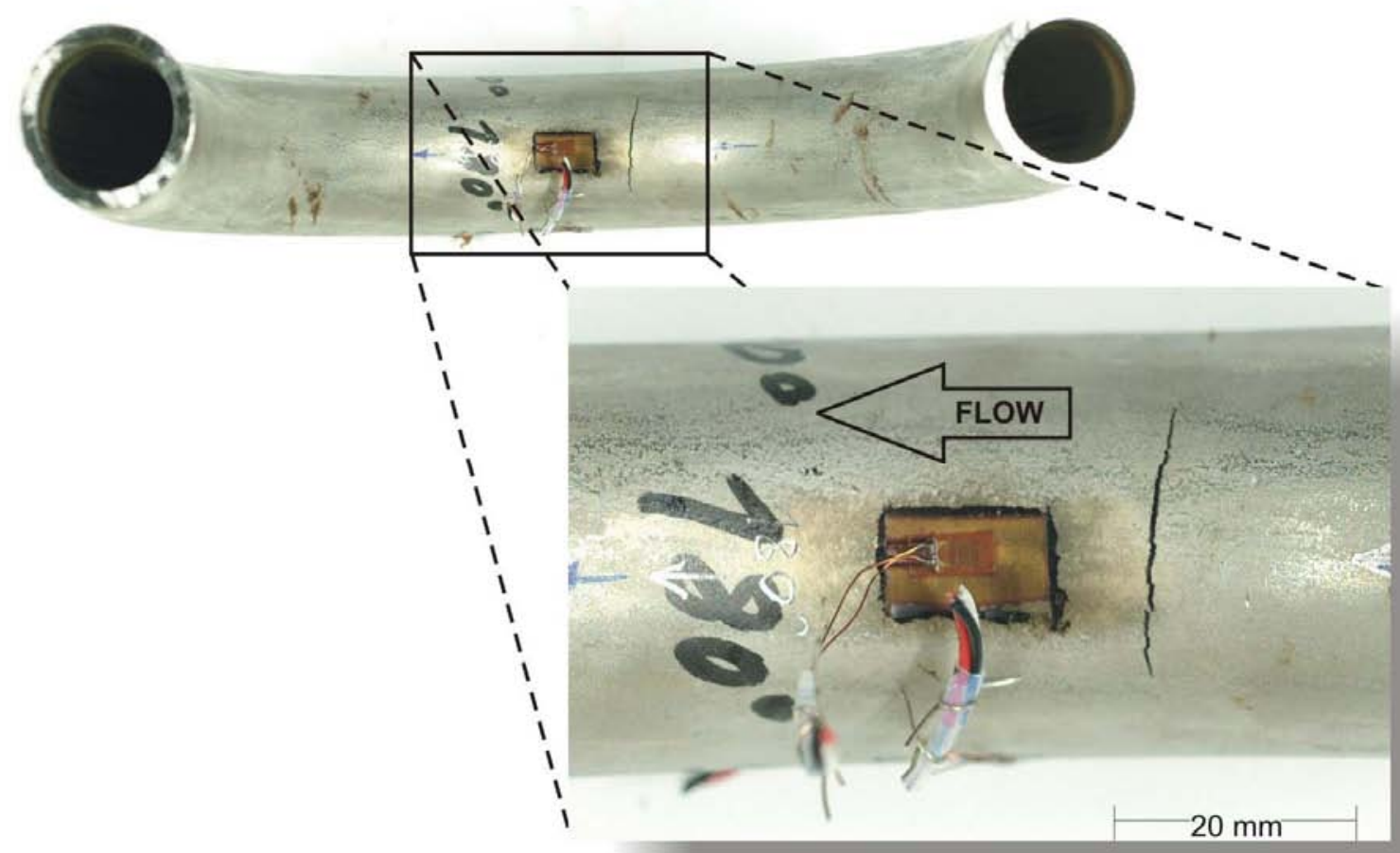

Figure 4-7

Visual inspection of BLT 2; primary failure in the form of circumferential crack 


\section{Dye Penetrant Inspection}

A narrow piece with an approximate length of $60 \mathrm{~mm}$ containing the bend apex was sectioned from the bend and split in two half shells for further inspection with dye penetrant. The external surface of the intrados exhibited an array of multiple circumferential crack indications as displayed in Figure 4-8. The internal surface of the intrados was free of indications with the exception of the primary failure formed by the circumferential through wall crack (see Figure 4-9).

Both the internal and external surface of the extrados were free from indications as displayed in Figure 4-10 and Figure 4-11.

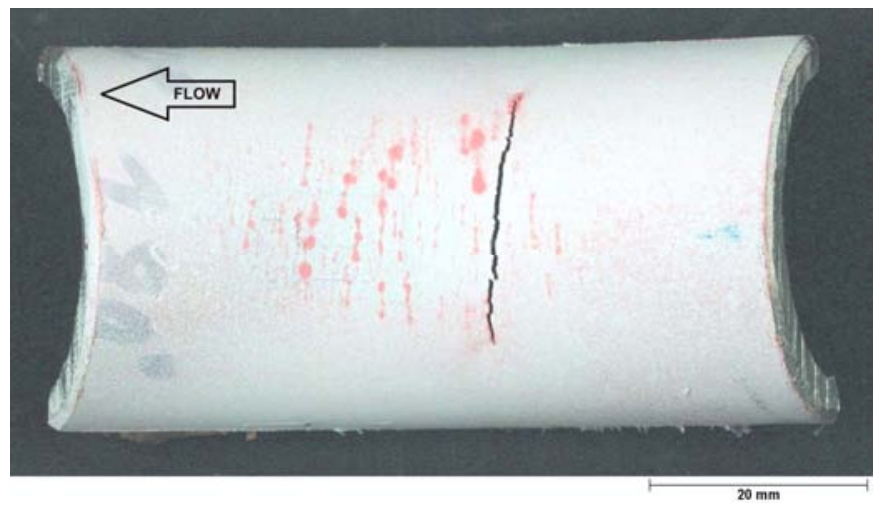

Figure 4-8

DPI of external surface at intrados revealing an array of circumferential cracks in the intrados area

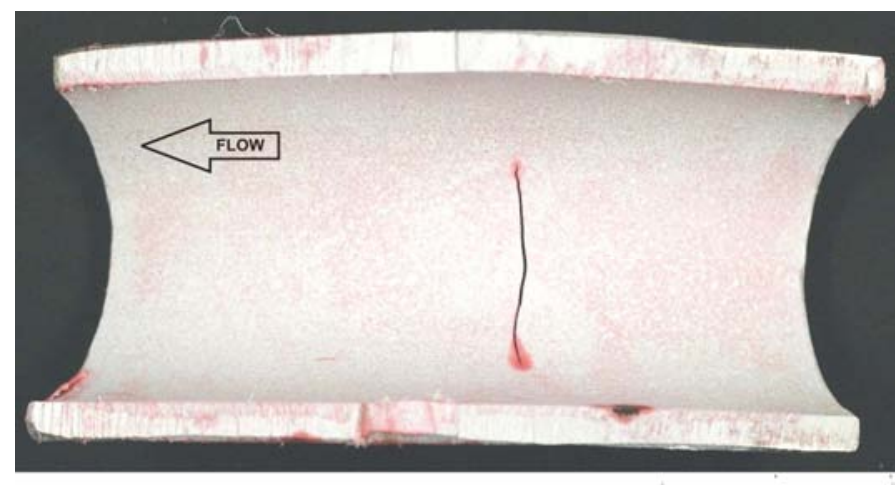

$20 \mathrm{~mm}$

Figure 4-9

DPI of internal surface at intrados showing that the primary circumferential crack had developed into a through wall defect. 


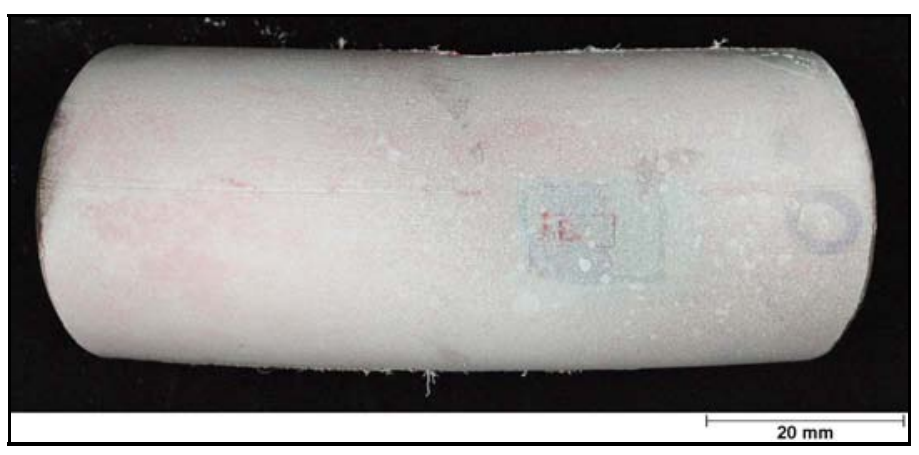

Figure 4-10

DPI of external surface of extrados free of indications

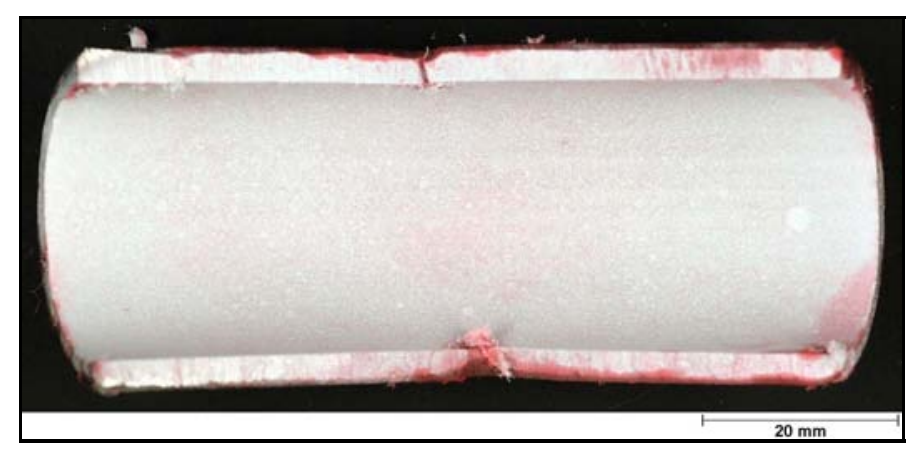

Figure 4-11

DPI of internal surface of extrados free of indications

\section{Scanning Electron Microscopy}

The primary circumferential fracture at the intrados was broken open for fractography at high magnifications using the scanning electron microscope. The fracture initiation area on the external surface, the wall thickness mid-section and the internal surface were of particular interest (see Figure 4-12).

The failure mechanism was confirmed as mechanical fatigue, indicated by striations as a result of step-wise crack progression under cyclic loading. As expected, the striation spacing increased with further propagation, since the decreasing wall thickness resulted in higher local loading. With the exception of pickling attack along grain boundaries, no other potential fracture initiating features were found. The initiation area and the mid section of the wall thickness exhibited striations with an average spacing of $1 \mu \mathrm{m}$ and $2 \mu \mathrm{m}$, respectively. In the last stages of the fracture however, the striations exhibited an average spacing of $20 \mu \mathrm{m}$. 


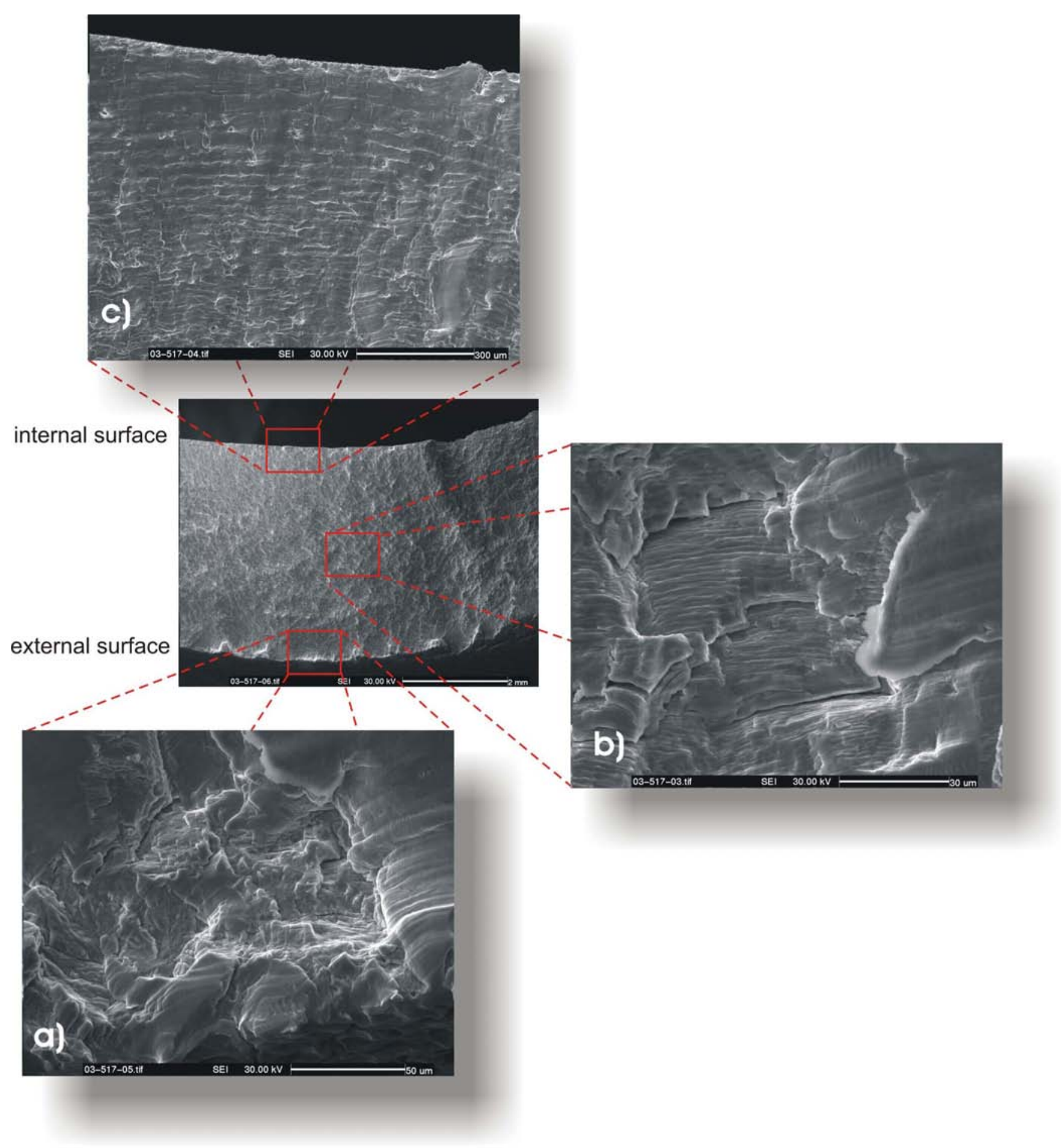

Figure 4-12

Views obtained during SEM examination; a) typical crack initiation site found along the external surface with average striation spacing of $1 \mu \mathrm{m}$; b) typical fracture appearance found in mid-section of fracture with average striation spacing of $2 \mu \mathrm{m}$; c) typical fracture appearance adjacent to internal surface with average striation spacing of $20 \mu \mathrm{m}$ 


\section{Metallography and Micro Hardness}

A cross-sectional specimen from the intrados containing multiple crack indications on the external surface was removed from the bend as indicated in Figure 4-13. After mounting into bakelite and polishing to a $1 \mu \mathrm{m}$ surface finish, the specimen was etched with stainless steel etchant (approximate composition: $25 \%$ Ethanol, $<5 \% \mathrm{HNO}_{3}, 16 \% \mathrm{HCl}$ ) and finally examined with a metallurgical microscope at different magnifications.

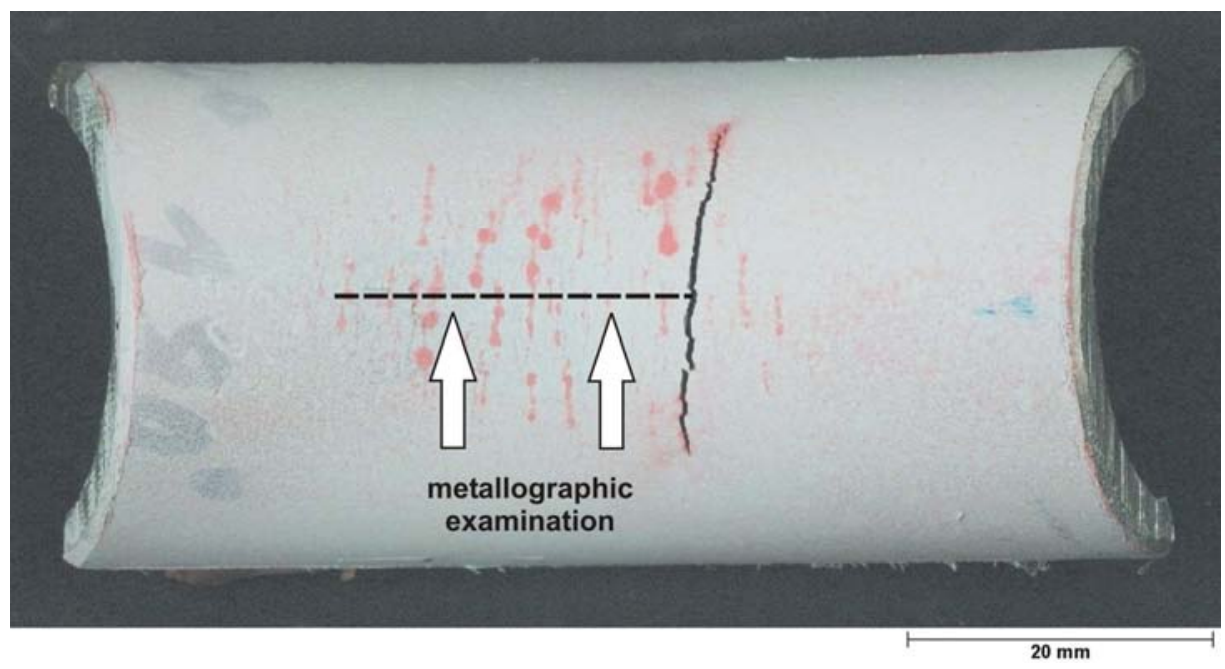

Figure 4-13

Location of specimen extraction for metallurgical examination.

Similar to all previously examined U-bends, metallography showed a generally sound austenitic microstructure. No anomalies were found. The examination confirmed the findings from visual and dye penetrant inspection. The intrados area exhibited multiple cracks all initiating from the external surface progressing towards the internal surface. All examined locations showed, that the crack progression was more or less perpendicular to the tube surface and exhibited a nonbranched, transgranular mode indicating a purely mechanical driven failure mechanism (see Figure 4-14 to Figure 4-16).

Cracking also occurred immediately underneath the intrados strain gauge, which was positioned centrally within the array of circumferential indications. In the course of examination, it was observed that the intrados strain gauge had fractured and disbonded from the tube's surface as shown in Figure 4-17. 


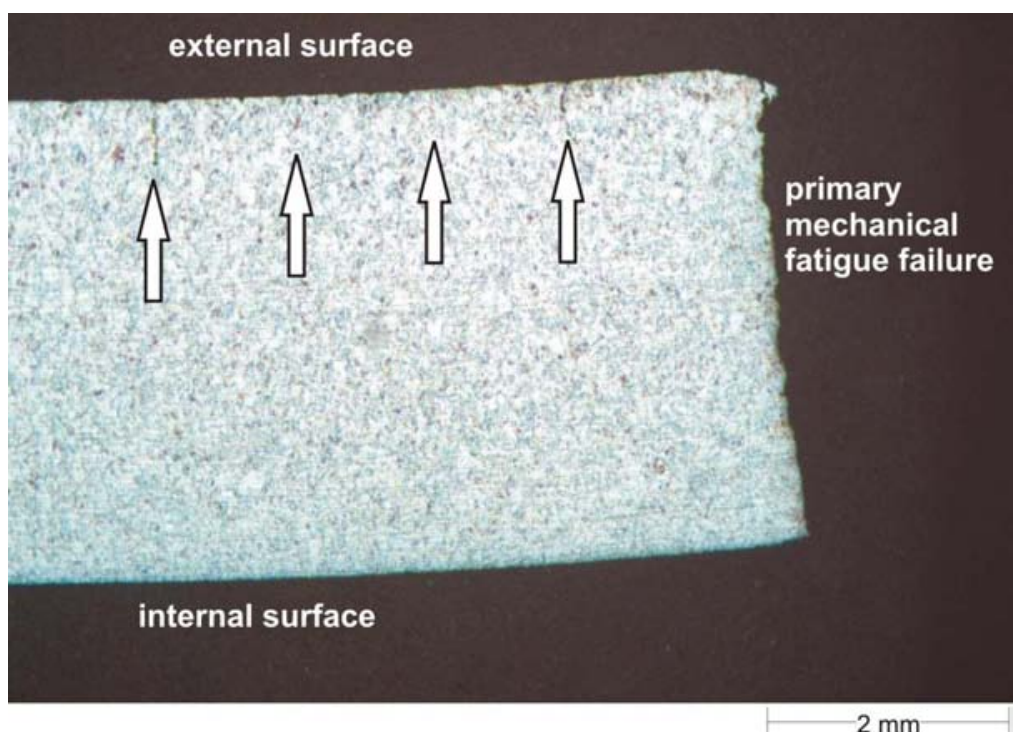

Figure 4-14

Overall view of prepared specimen; the white arrows indicate some of the multiple crack initiations on the external surface.

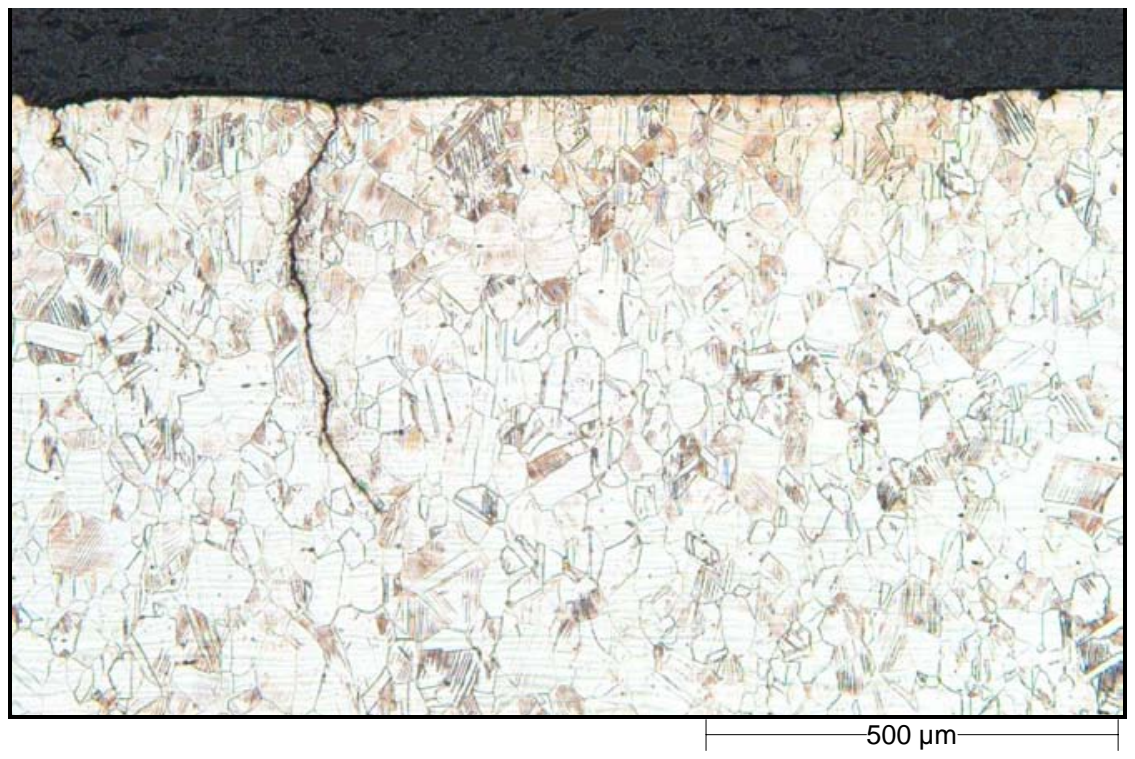

Figure 4-15

Typical view of microstructure with transgranular crack originating from external surface. 


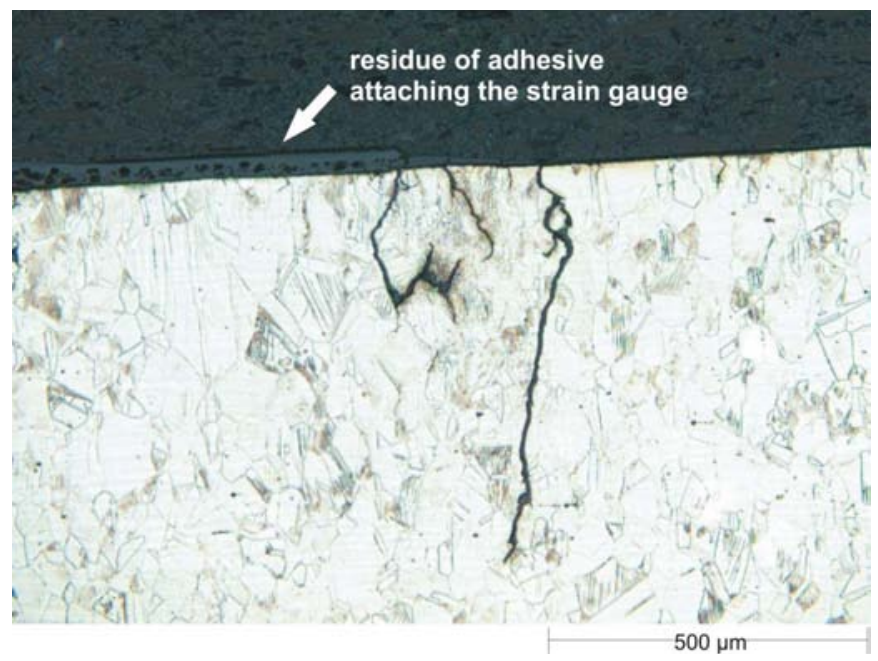

Figure 4-16

Transgranular cracking in area where strain gauge was positioned.

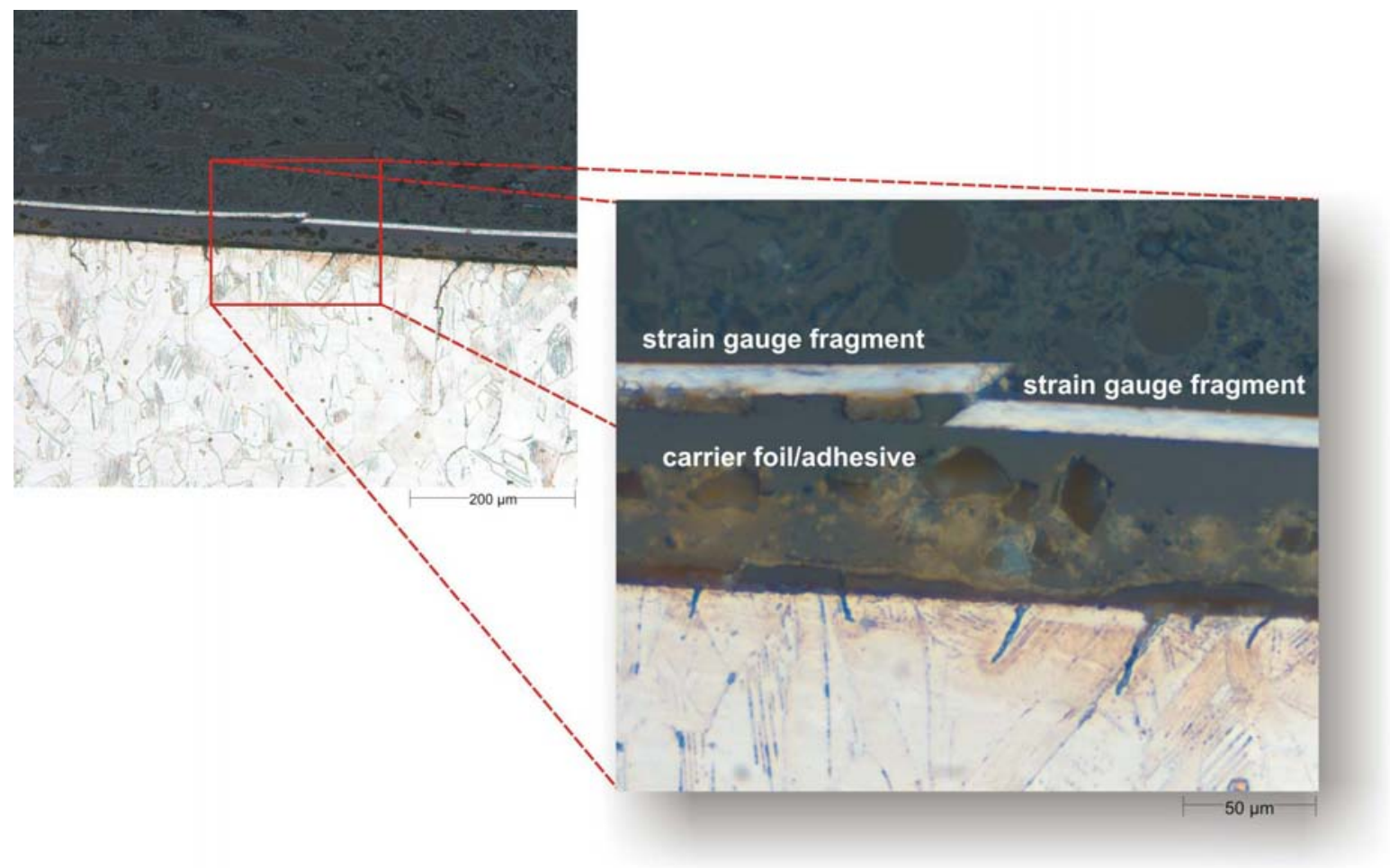

Figure 4-17

Micrograph showing cracked strain gauge; the separation of the strain gauge most likely occurred during sample preparation and is not associated with testing. 


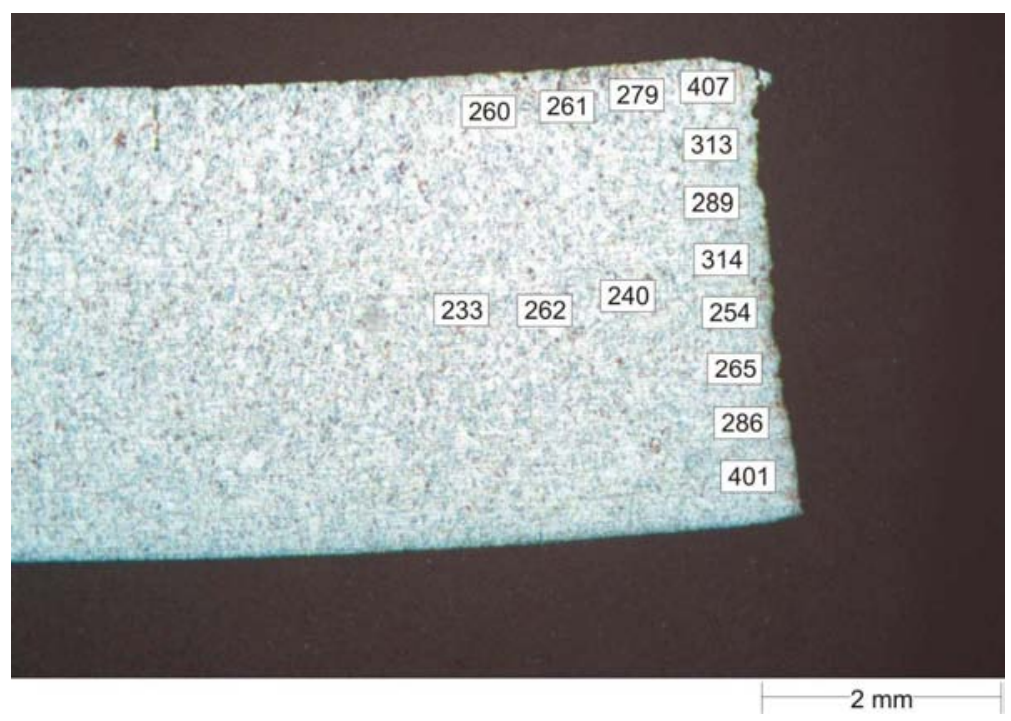

Figure 4-18

Hardness readings obtained.

Vickers micro hardness (100g load) measurements were conducted along the primary fracture and in the base metal of the prepared metallographic specimen, as displayed in Figure 4-18. Generally the readings ranged from $233 \mathrm{HV}$ to $314 \mathrm{HV}$ and corresponded with previously obtained results. However, the readings adjacent to the edges at the internal and external surface exhibited higher numbers with $401 \mathrm{HV}$ and $407 \mathrm{HV}$, respectively.

\section{Conclusions on BLT 2}

Similar to BLT 1 and BLT 2RT, the U-bend tested during BLT 2 suffered from multiple crack indications on the external surface arranged in an array at the highly strained intrados area. The primary failure occurred due to a circumferential through-wall defect that originated on the external surface of the intrados. The relatively straight crack progression in a transgranular manner and the fracture appearance with striations clearly indicated a mechanical driven fatigue failure. Corresponding to previously tested bends, the microstructure appeared to be sound, since no general microstructural effects negatively affecting the bend's fatigue behavior were observed. With the exception of two readings at the internal and external surfaces, the hardness readings also corresponded with previous results. Figure 4-19 graphically summarizes the results of BLT 2. 


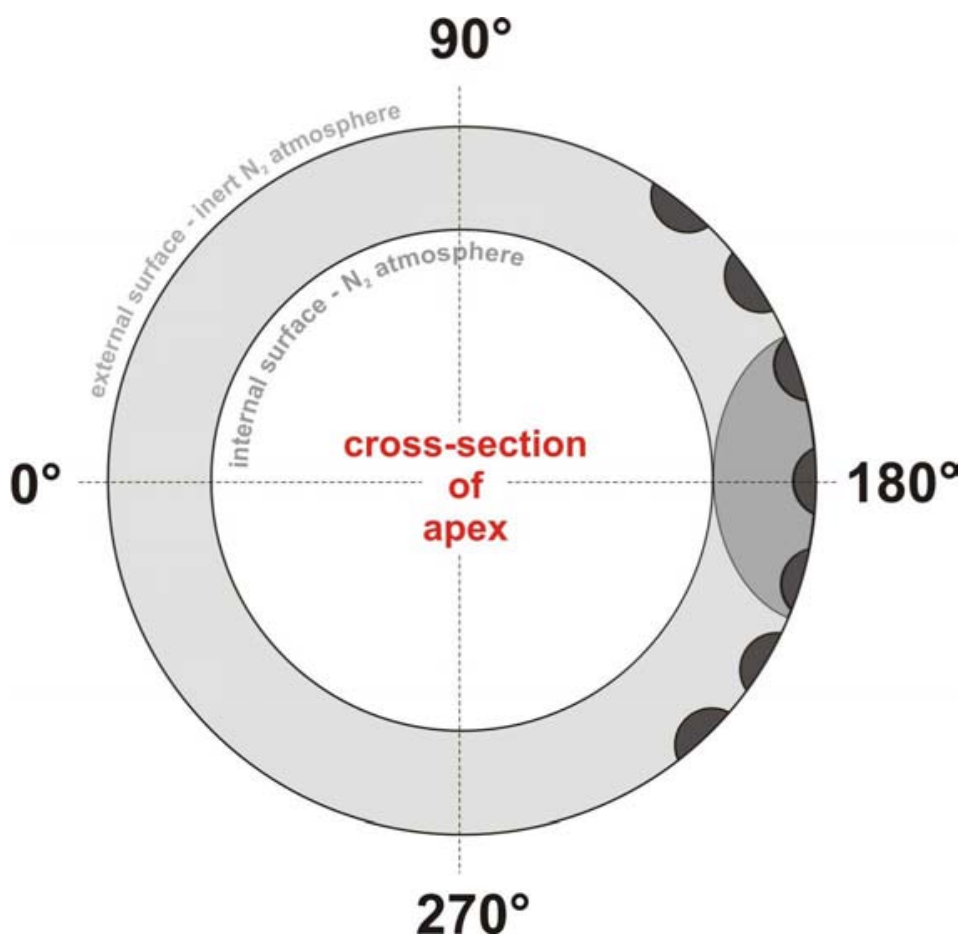

Figure 4-19

Schematic graphically summarizing the cracking locations of BLT 2. 


\section{5}

\section{ENVIRONMENTAL TEST 2A}

\section{Test Set-Up and Approach}

After having gained basic experimental data during Phase A by conducting several baseline tests and strain gauge qualification, the first environmental test of Phase B was performed. During Phase $\mathrm{B}$, the internal nitrogen atmosphere was replaced with simulated primary water subject to different flow rates. According to the text matrix, the first environmental test $2 \mathrm{a}$ was characterized as a low flow-rate test in conjunction with the following U-bend instrumentation and test parameters:

- $\quad$ pre-conditioning of the bend internal surface by lengthy exposure to simulated primary water

- $\quad$ instrumented U-bend with three bonded HT strain gauges at the $0^{\circ}, 90^{\circ}$ and $180^{\circ}$ position

- $\quad$ strain amplitude of $0.6 \%$ (total strain range of $1.2 \%$ )

- $\quad$ strain rate of $1 \times 10^{-4} \mathrm{~s}^{-1}$

- $\quad$ testing temperature $\mathrm{T}=240^{\circ} \mathrm{C}$, pressure $\mathrm{p}=50$ bar

- $\quad \mathrm{HT}$ water chemistry comprising 1200 ppm B as $\mathrm{H}_{3} \mathrm{BO}_{3}+2$ ppm Li as $\mathrm{LiOH}$

- oxygen content adjusted to $<<10 \mathrm{ppb}$, no $\mathrm{H}_{2}$ injection

- the impurity level adjusted to $\mathrm{Cl}^{-}+\mathrm{F}^{-}+\mathrm{SO}_{4}{ }^{2-}<100 \mathrm{ppb}$

- Water sampling and chemical analysis of $\mathrm{B}, \mathrm{Li}, \mathrm{Cl}^{-}, \mathrm{F}^{-}, \mathrm{SO}_{4}{ }^{2-}, \mathrm{pH}$ during start-up and before shut down

- flow rate adjusted to $<10 \mathrm{l} / \mathrm{h}$ (corresponds to $\approx 0.005 \mathrm{~m} / \mathrm{s}$ for an ID of $26.5 \mathrm{~mm}$ ) 


\section{Results}

\section{Water Chemistry}

The mechanical loading of the U-bend during testing was not commenced until the specified requirements with respect to test temperature, water chemistry/purity and electrochemical corrosion/redox potentials were met. Water sampling before start-up and loading assured this, as displayed in Table 5-1. After shut down at the end of the test water sampling was impossible due to loss of the medium overnight as a result of the through wall defect formed in the U-bend.

\begin{tabular}{|c|c|c|c|c|c|c|c|}
\hline $\begin{array}{c}\text { water } \\
\text { sampling }\end{array}$ & $\begin{array}{c}\text { B } \\
\text { ppm }\end{array}$ & $\begin{array}{c}\mathrm{Li} \\
\mathrm{ppm}\end{array}$ & pH & $\begin{array}{c}\text { chloride } \\
\text { ppb }\end{array}$ & $\begin{array}{l}\text { sulfate } \\
\text { ppb }\end{array}$ & $\begin{array}{l}\text { fluoride } \\
\text { ppb }\end{array}$ & remarks \\
\hline $\begin{array}{l}\text { before start-up } \\
\text { at RT }\end{array}$ & 1280 & 1,96 & & $<10$ & 12 & $<10$ & \\
\hline $\begin{array}{c}\text { before loading, } \\
\text { test } \\
\text { temperature } \\
\text { was reached }\end{array}$ & 1207 & 2,07 & 6,5 & $<10$ & $<10$ & $<10$ & $\begin{array}{c}\text { ion exchanger } \\
\text { cond.(out) }=21,6 \mu \mathrm{S} / \mathrm{cm} \\
\mathrm{O}_{2} \text { (out) } \approx 3 \mathrm{ppb}\end{array}$ \\
\hline $\begin{array}{l}\text { before shut } \\
\text { down }\end{array}$ & - & - & - & - & - & - & $\begin{array}{c}\text { water sampling not possible } \\
\text { due to through wall cracking } \\
\text { during night time }\end{array}$ \\
\hline
\end{tabular}

Table 5-1

Results from water sampling during environmental Test 2a.

During testing the water chemistry was monitored continuously with respect to test temperature, conductivity and electrochemical corrosion potential (ECP) and redox potential. Figure 5-1 and Figure 5-2 show the inlet and outlet conductivity, the test temperature, as well as ECP and the redox potential, for the entire duration of environmental test 2a. The ECP showed values of approximately $-600 \mathrm{mV}_{\mathrm{H}, \mathrm{T}}$ and the redox potential was measured at approximately $-500 \mathrm{mV}_{\mathrm{H}, \mathrm{T}}$. The target test temperature of $240{ }^{\circ} \mathrm{C}$ was held very stable for the entire test. The trend of a slightly increasing inlet and outlet conductivity during testing was attributed to increasing $\mathrm{Li}$ concentrations largely determining the conductivity of the simulated primary water. Li was released from the ion-exchanger trying to reach equilibrium with the test solution. Both the inlet and outlet conductivity ranged from $21.5 \mu \mathrm{S} / \mathrm{cm}$ at the beginning to approximately $22.2 \mu \mathrm{S} / \mathrm{cm}$ at the end of testing. These differences are insignificant. 


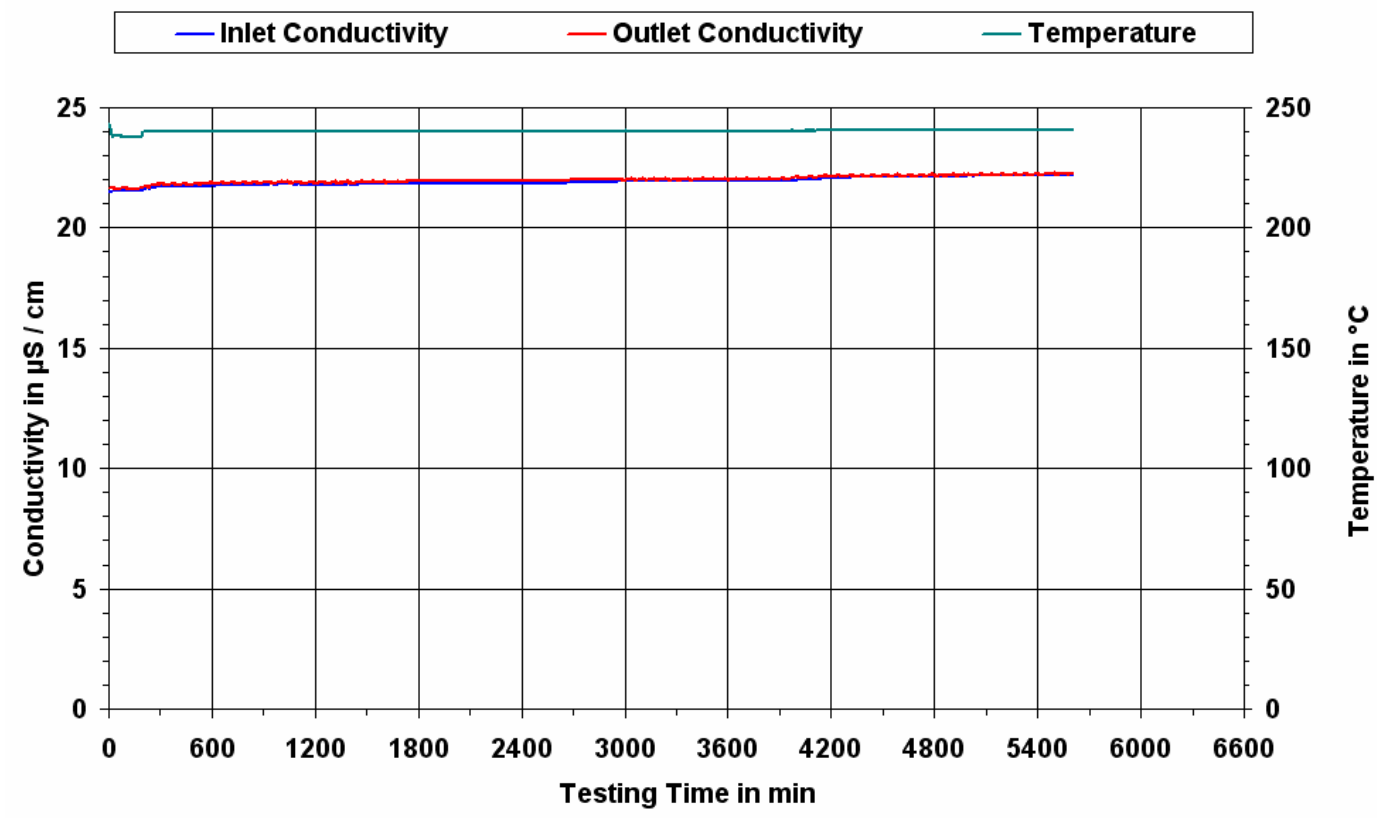

Figure 5-1

Water chemistry during environmental Test 2a.

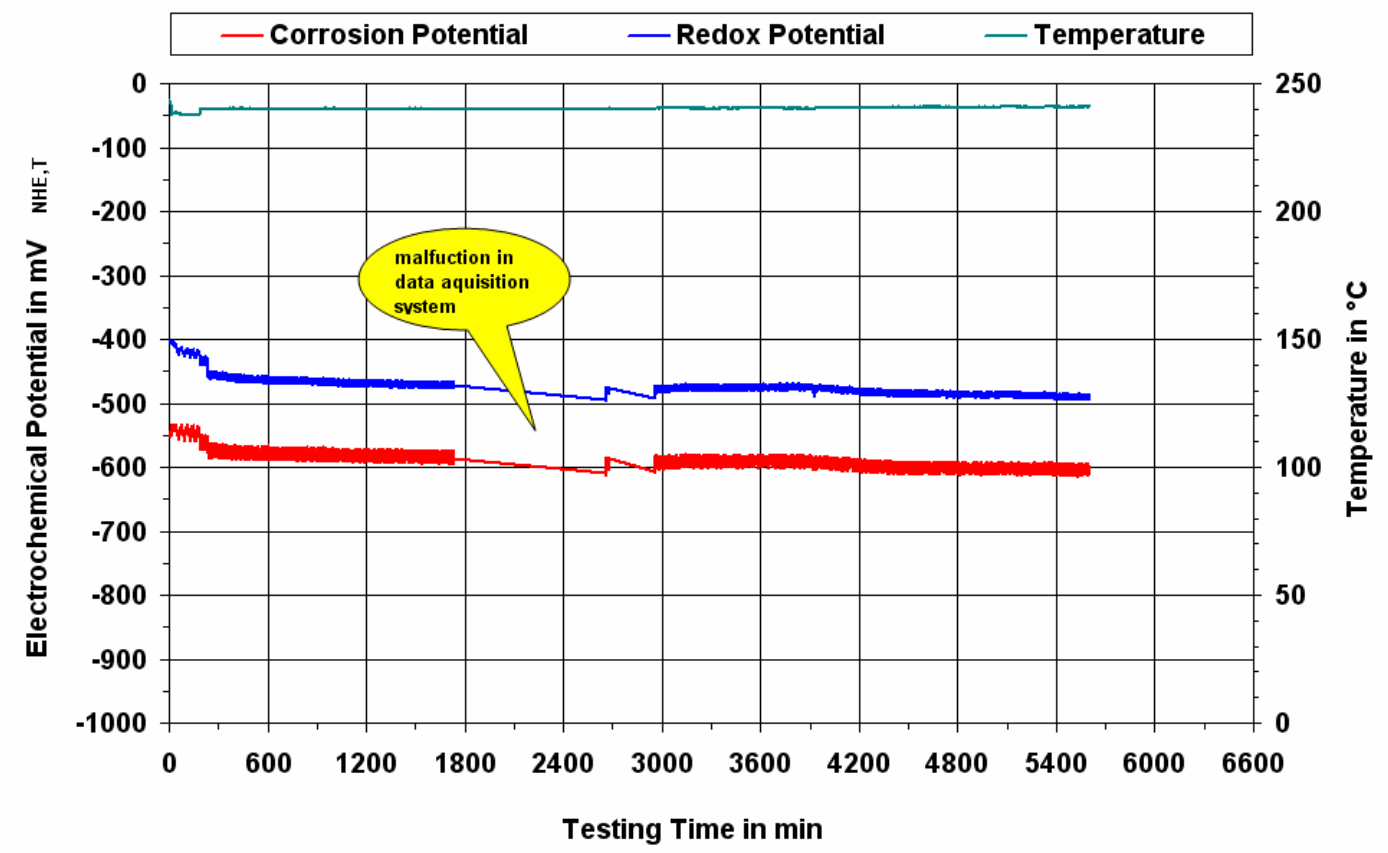

Figure 5-2

Electrochemical potentials during environmental Test 2a. 


\section{Mechanical Data}

Having reached the desired levels with regards to water chemistry and test temperature, the loading sequence was started. The basic test parameters used for mechanical loading of the Ubend are given in Table 5-2. Initially, the bend was loaded with a triangular wave shape for the first 5 cycles to evaluate the response. The first five cycles are displayed in Figure 5-3. Cycles 6 to 12 were then performed with a wave shape according to Case 4 modified. To this point, the test was performed displacement controlled with strain triggered switch points at $0.2 \%$ and $0.6 \%$ strain amplitude, respectively. The mechanical data of cycles 6 to 12 are displayed in Figure 5-4. The load over displacement hysteresis for the first 12 cycles is displayed in Figure 5-7 and indicated a fairly stable bend behavior. Cycle 12 was used to determine the displacements necessary for the remaining test, which was performed displacement controlled exclusively.

Cycle 13 to 48 were also performed according to Case 4 modified wave shape, however the bend exhibited unexpected non-stable behavior resulting in a system shut-down at cycle 33 due to reaching the shut-down criteria of a $5 \%$ load drop. At cycle 43 , the leading $180^{\circ}$ intrados strain gauge stopped working as a result of the cyclic loading. All available strain data is shown in Figure 5-6. After restarting and applying some additional cycles with the Case 4 modified wave shape, the bend behavior did not improve significantly and therefore it was decided in agreement with EPRI to continue testing from cycle 49 with a standard triangular wave shape and a less sensitive switch-off criterion of $10 \%$. It should be noted that this approach was also used for all later testing. Figure 5-8 displays the load vs. displacement hysteresis for cycles 1 to 61 . By reapplying a triangular wave shape, the bend exhibited stable behavior for the entire remaining test period until it was terminated at a total number of 1520 cycles, after having reached the shut down criteria. All mechanical data of the entire test are displayed in Figure 5-5.

\begin{tabular}{|c|c|c|c|c|c|}
\hline cycle & $\begin{array}{l}\text { wave } \\
\text { shape }\end{array}$ & $\begin{array}{l}\text { control } \\
\text { channel }\end{array}$ & strain rate & switch point & $\begin{array}{c}\text { switch off } \\
\text { criteria }\end{array}$ \\
\hline $1-5$ & triangular & displacement & $1 \times 10^{-5} \mathrm{~s}^{-1}$ & $\begin{array}{l}+0.6 \% \\
-0.6 \%\end{array}$ & \\
\hline $6-12$ & $\begin{array}{c}\text { Case } 4 \\
\text { mod. }\end{array}$ & displacement & $\begin{array}{l}0.2 \mathrm{~mm} / \mathrm{s} \\
1 \times 10^{-4} \mathrm{~s}^{-1} \\
0.2 \mathrm{~mm} / \mathrm{s} \\
1 \times 10^{-4} \mathrm{~s}^{-1}\end{array}$ & $\begin{array}{l}+0.2 \% \\
+0.6 \% \\
-0.2 \% \\
-0.6 \%\end{array}$ & \\
\hline $13-48$ & $\begin{array}{c}\text { Case } 4 \\
\text { mod. }\end{array}$ & displacement & $\begin{array}{l}0.2 \mathrm{~mm} / \mathrm{s} \\
1 \times 10^{-4} \mathrm{~s}^{-1} \\
0.2 \mathrm{~mm} / \mathrm{s} \\
1 \times 10^{-4} \mathrm{~s}^{-1}\end{array}$ & $\begin{array}{l}+4.1 \mathrm{~mm} \\
+6.5 \mathrm{~mm} \\
-2.4 \mathrm{~mm} \\
-4.85 \mathrm{~mm}\end{array}$ & $\begin{array}{l}\text { switched off } \\
\text { at } 11950 \mathrm{~N}\end{array}$ \\
\hline $49-1520$ & triangular & displacement & $\begin{array}{c}1 \times 10^{-4} \mathrm{~s}^{-1} \\
(0.115 \mathrm{~mm} / \mathrm{s})\end{array}$ & $\begin{array}{r}+6.5 \mathrm{~mm} \\
-4.85 \mathrm{~mm}\end{array}$ & failure \\
\hline
\end{tabular}

Table 5-2

Basic test parameters of mechanical loading during environmental Test $2 a$. 


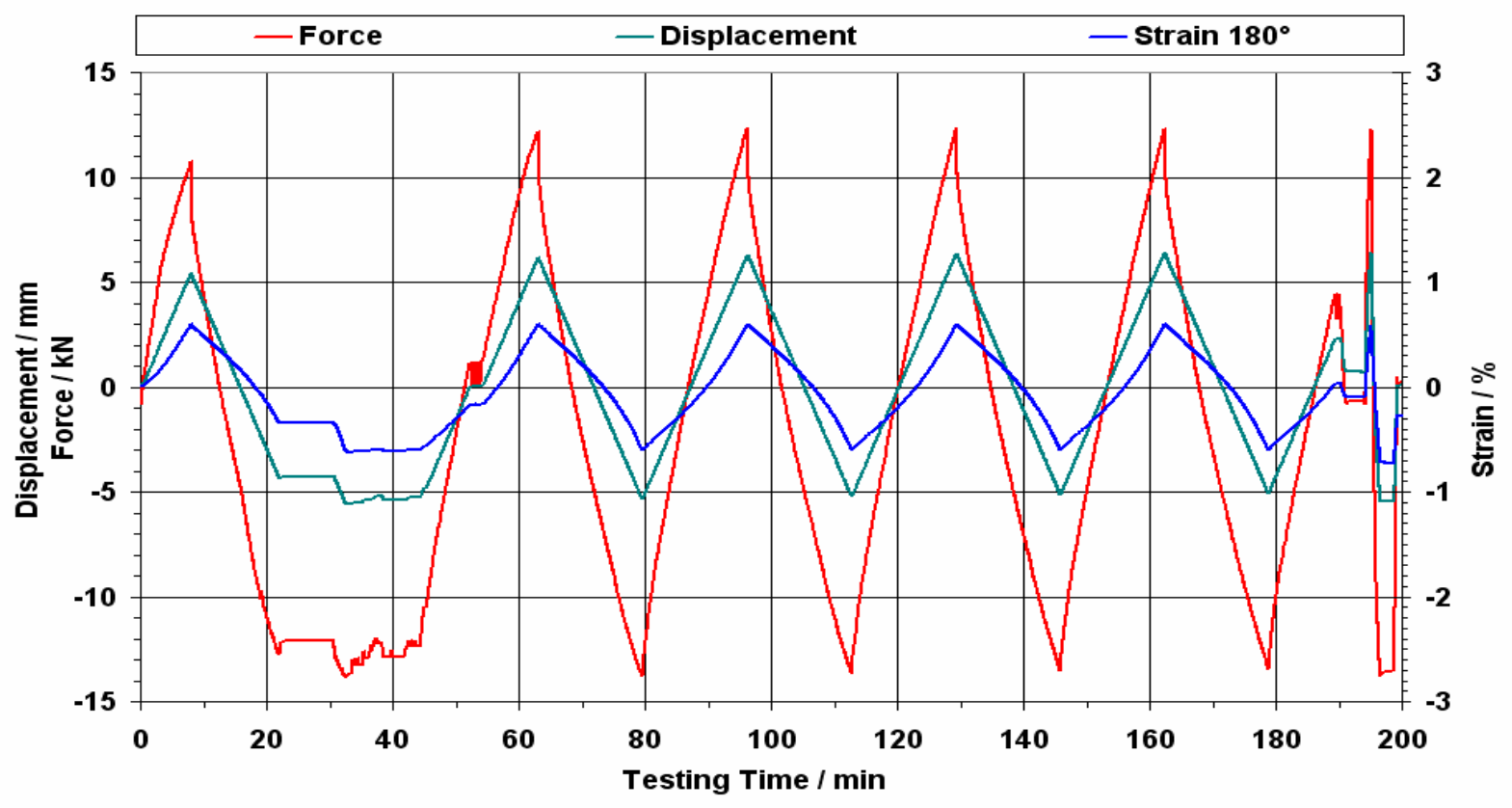

Figure 5-3

Cycles 1 to 5 of environmental Test 2a with triangular wave shape.

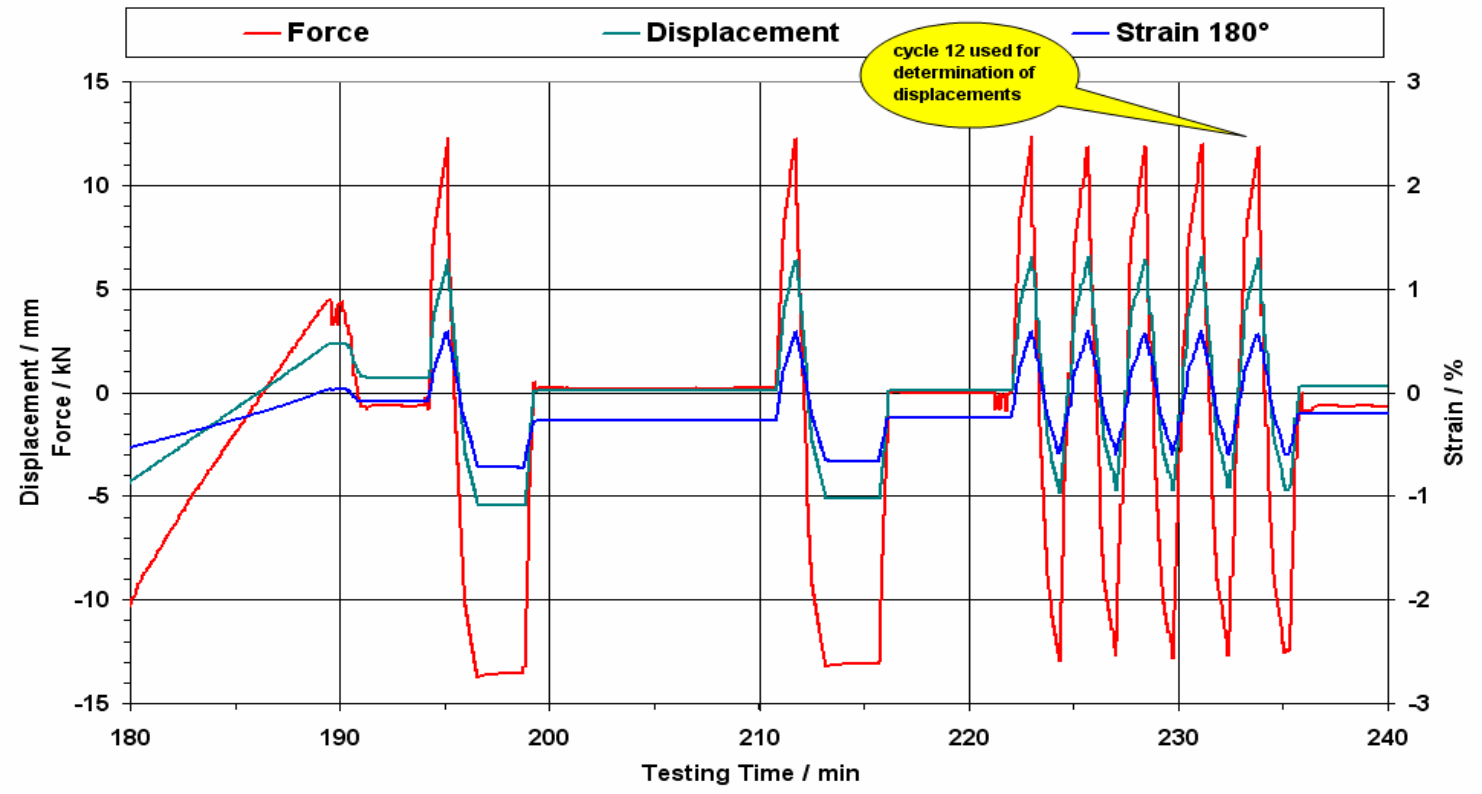

Figure 5-4

Cycles 6 to 12 of environmental Test 2a with wave shape according to Case 4 modified. 


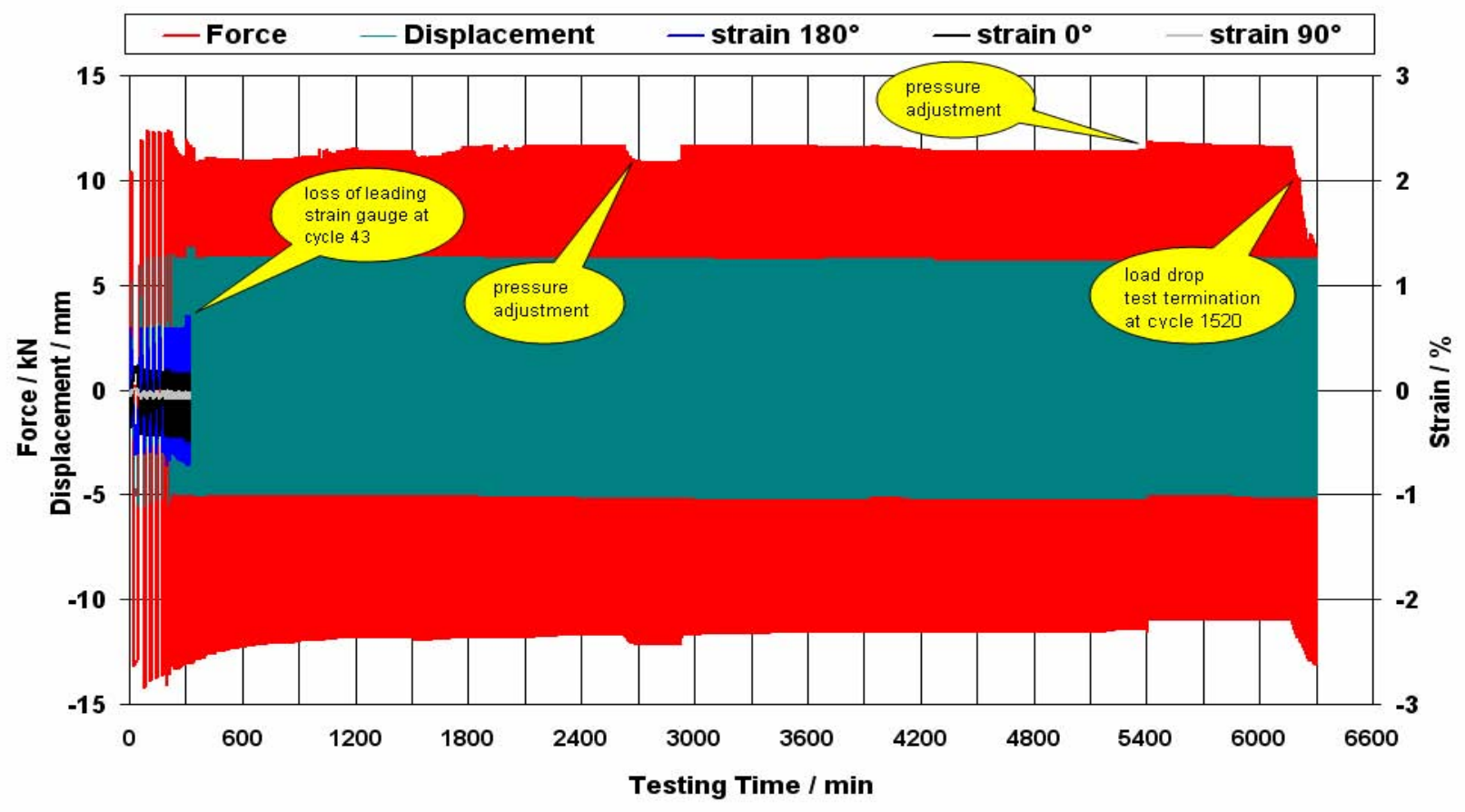

Figure 5-5

View of entire Test $2 a$.

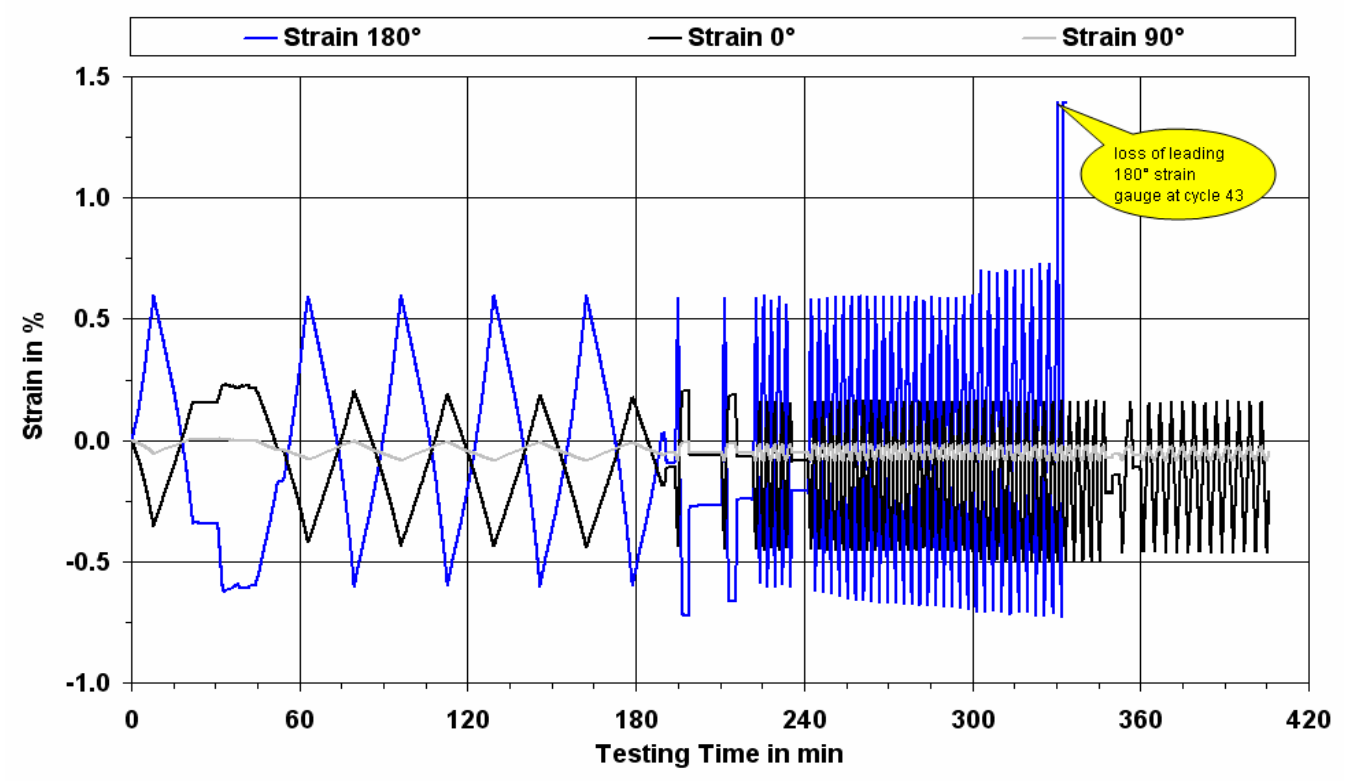

Figure 5-6

Strain response of all instrumented stain gauges. 


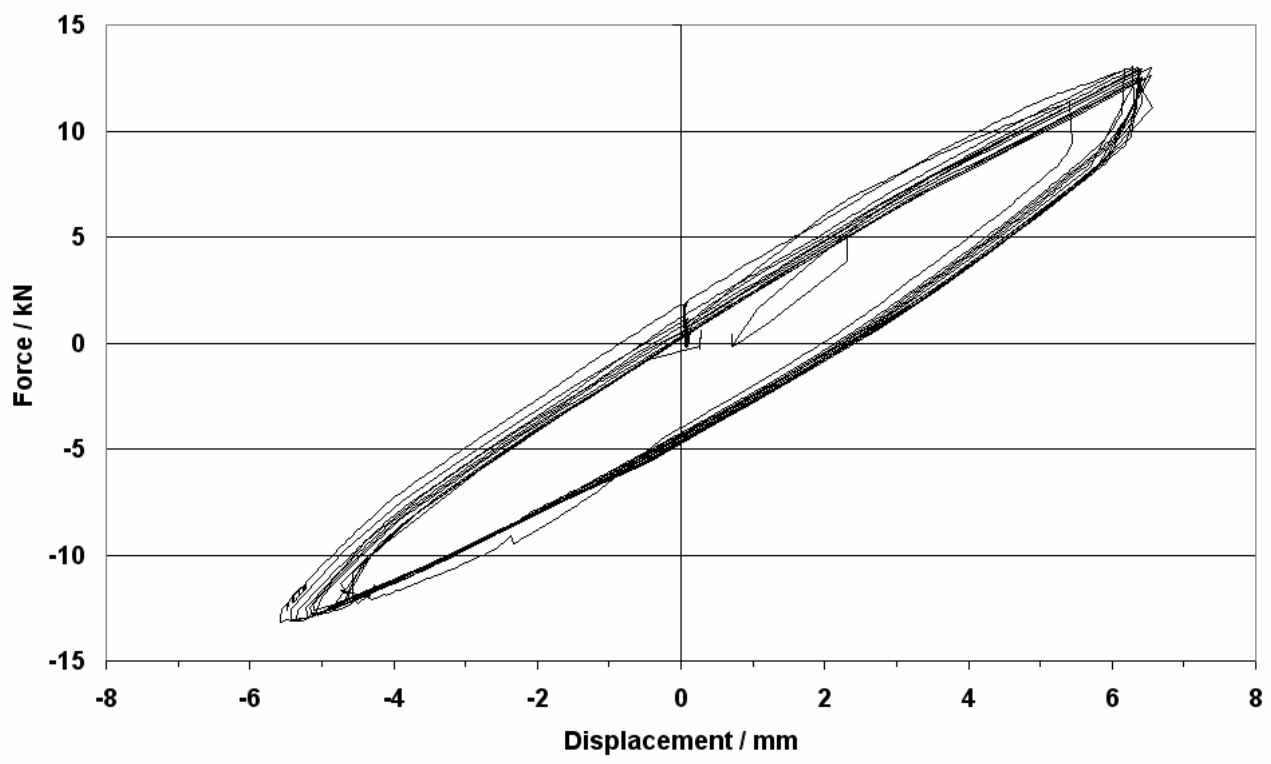

Figure 5-7

Force vs. displacement for cycles 1 to 12.

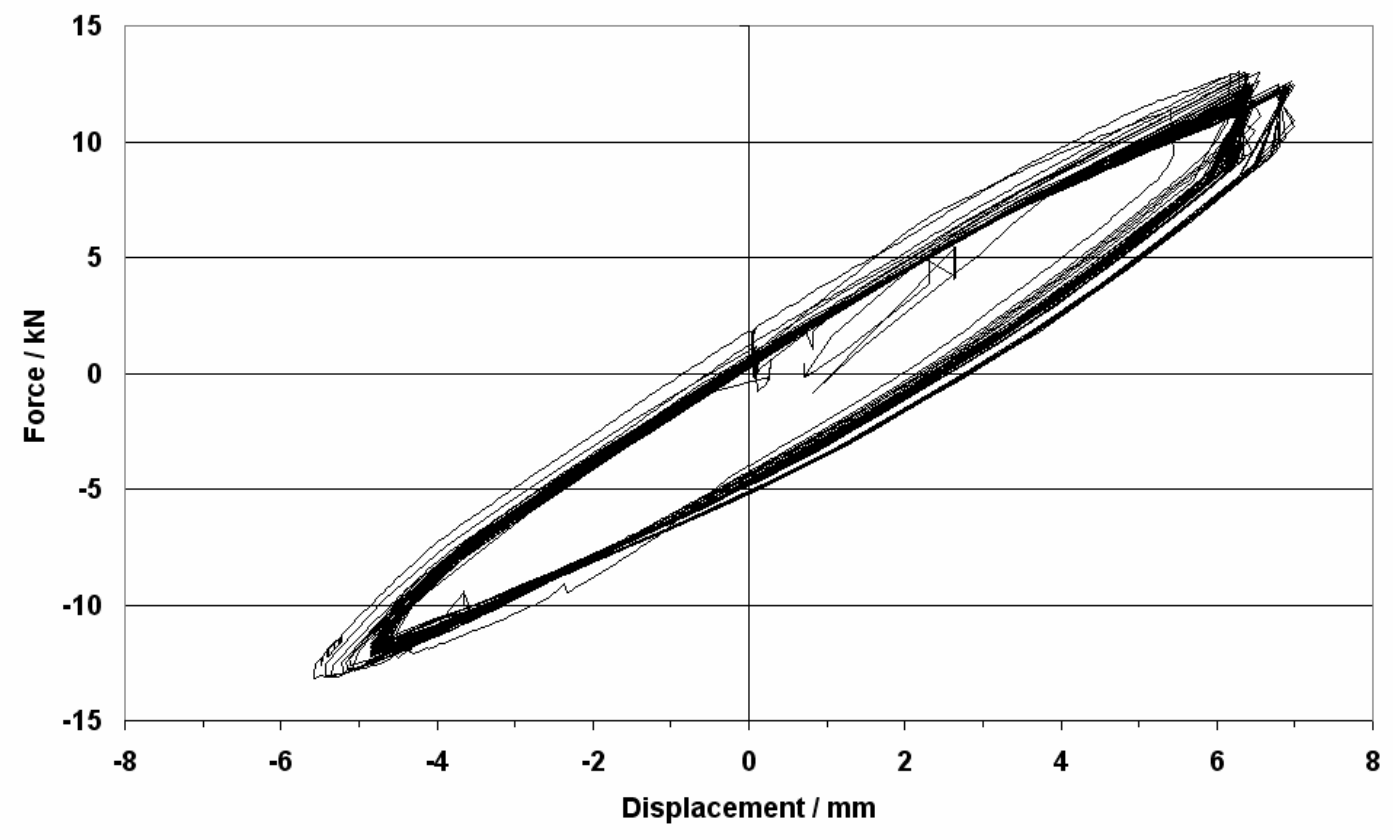

Figure 5-8

Force vs. displacement for cycles 1 to 61 . 


\section{Post Test Characterization}

After the physical testing part of environmental test 2a was accomplished, the U-bend was removed from the testing rig, the additional tubing for optimized flow condition was cut off, and the bend was prepared for post test characterization entailing the following tasks:

- Visual inspection of tested U-bend

- Dye penetrant inspection (DPI)

- Fractography of selected locations at high magnifications using scanning electron microscopy (SEM)

- Metallography of selected locations of interest

\section{Visual Inspection}

Visual inspection revealed one primary circumferential crack with an approximate length of $15 \mathrm{~mm}$. This defect was located at the intrados immediately underneath the strain gauge. This fracture had developed into a through wall defect causing the loss of most of the primary water environment into the autoclave. No other defects visible to the naked eye were found on the external surface during visual inspection. Figure 5-9 shows the intrados area of the bend with the primary fracture.

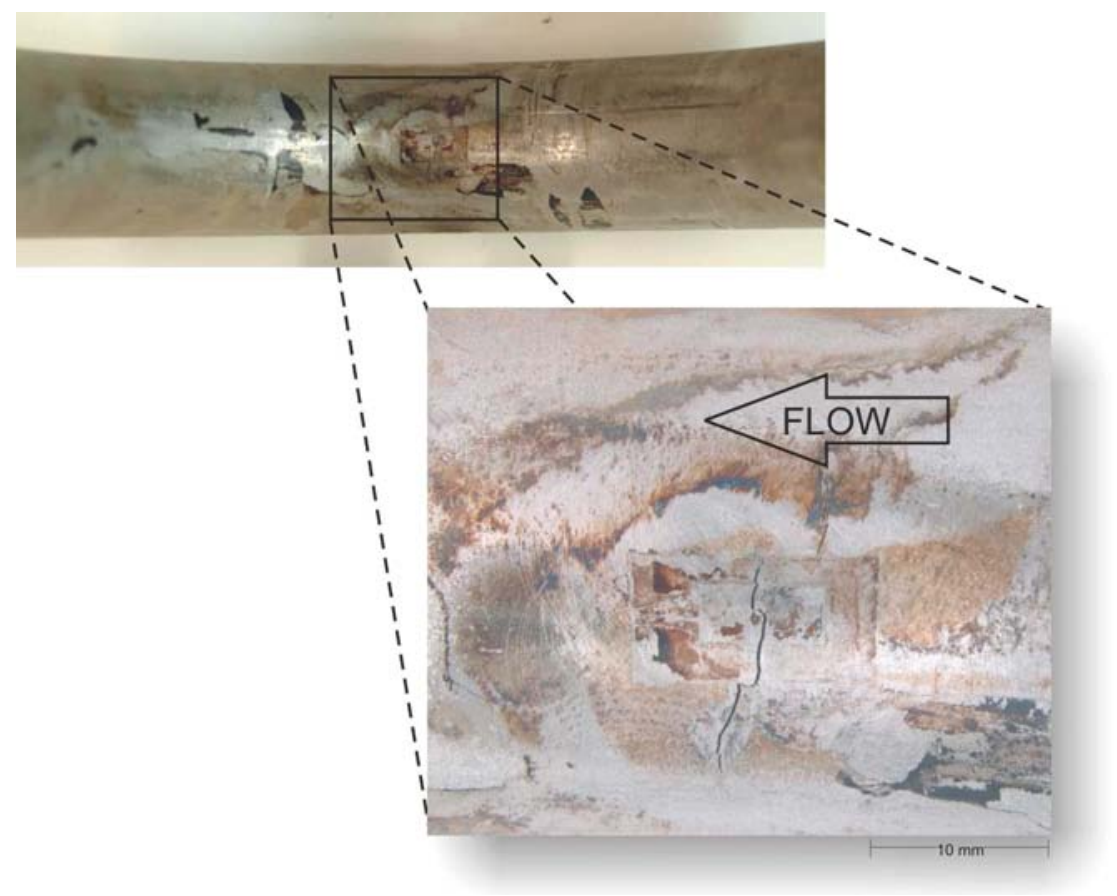

Figure 5-9

Visual inspection of U-bend revealing one primary circumferential crack at the intrados. 


\section{Dye Penetrant Inspection}

A narrow piece containing the bend apex with an approximate length of $60 \mathrm{~mm}$ was sectioned from the bend and split in two half shells for further inspection with dye penetrant. Both the internal and external surfaces were examined.

Similar to BLT 2, the external surface of the intrados exhibited an array of multiple circumferential crack indications as displayed in Figure 5-10. The internal surface of the intrados disclosed the through wall defect as well as multiple axial indications shown in Figure 5-11. The $90^{\circ}, 270^{\circ}$ position were free of cracking on the external surface, but revealed multiple axial indications on the internal surface as displayed in Figure 5-12 and Figure 5-13. The indications appeared to follow wear marks that most likely originated from the bending mandrel used during manufacturing. The extrados showed similar characteristics, since it was free of cracking on the external surface Figure 5-14 but revealed some weak axial indications as displayed in Figure 5-15.

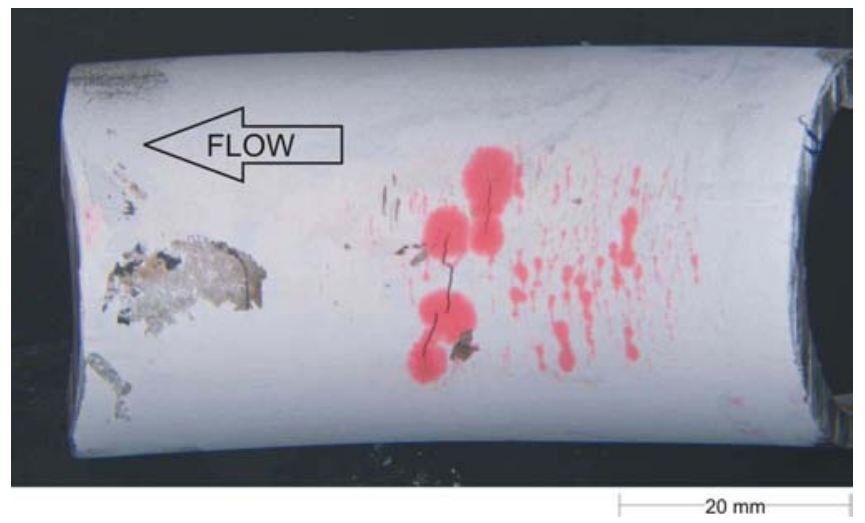

Figure 5-10

DPI of external surface of intrados exhibiting array of circumferential indications.

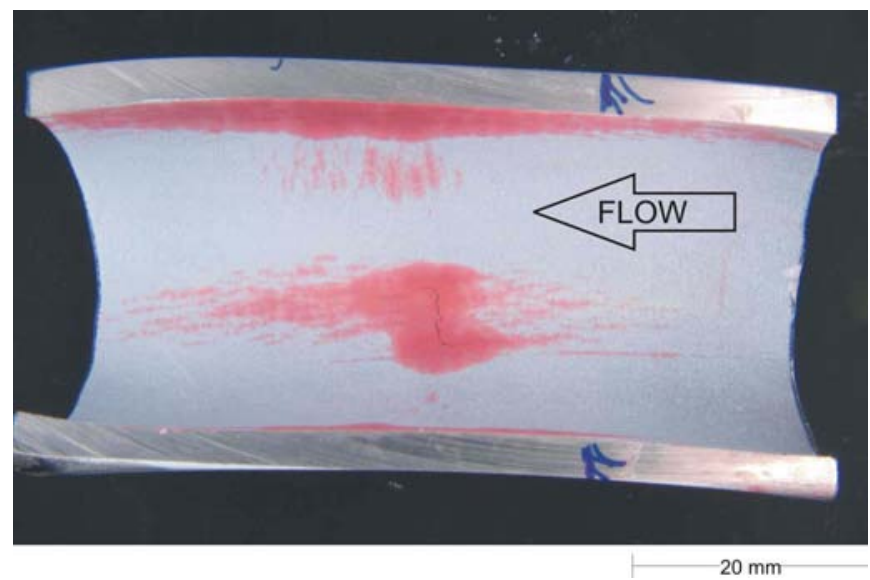

Figure 5-11

DPI of internal surface of intrados. 


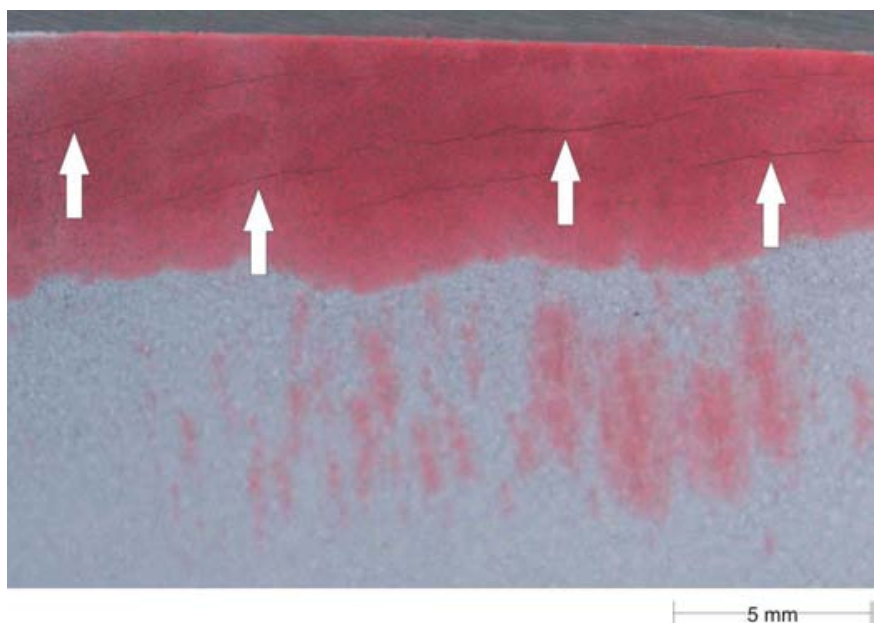

Figure 5-12

Axial crack indications found at the $90^{\circ}$ position; some of which are indicated by white arrows.

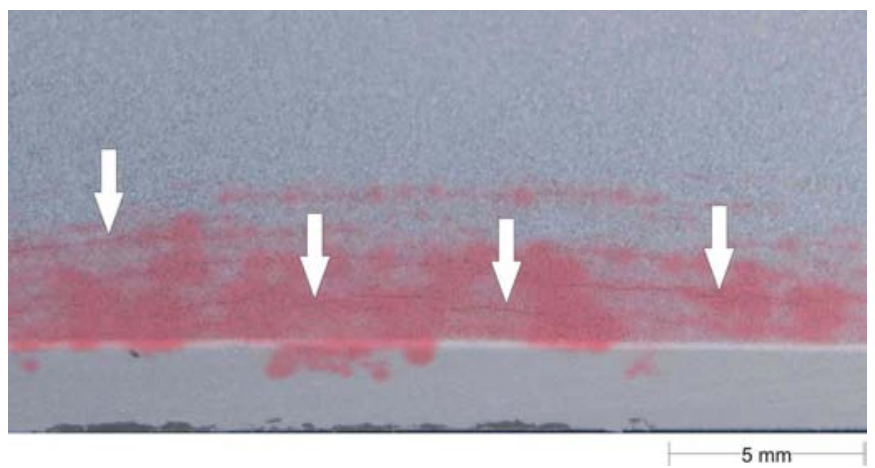

Figure 5-13

Axial crack indications found at the $270^{\circ}$ location; some of which are indicated by white arrows.

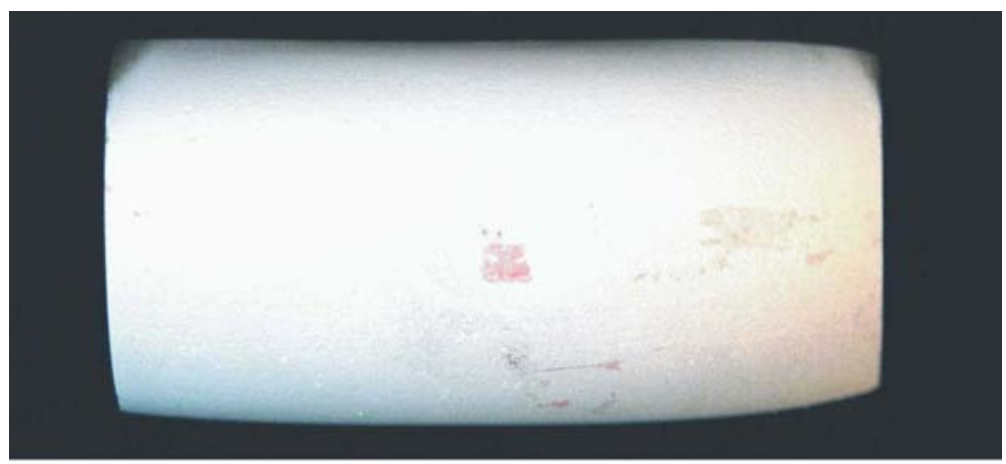

$20 \mathrm{~mm}$

Figure 5-14

No indications found on external surface of the extrados. 


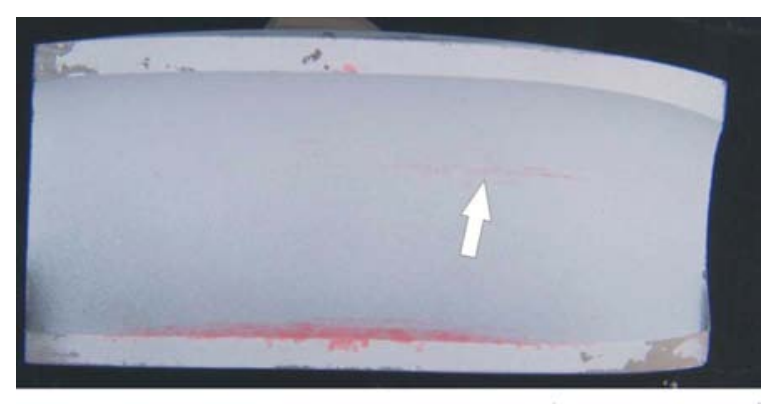

Figure 5-15

Axial crack found on internal surface of extrados as indicated by the white arrow.

\section{Scanning Electron Microscopy}

The internal surface of the intrados containing the circumferential through-wall crack was examined with the scanning electron microscope (SEM). The analysis confirmed the findings from visual inspection and DPI by revealing a predominantly circumferential crack. Smaller axial crack indications were found also. It appeared that all three crack indications followed a "given" path along grain boundaries provided by the texture from the picking attack (see Figure 5-16)

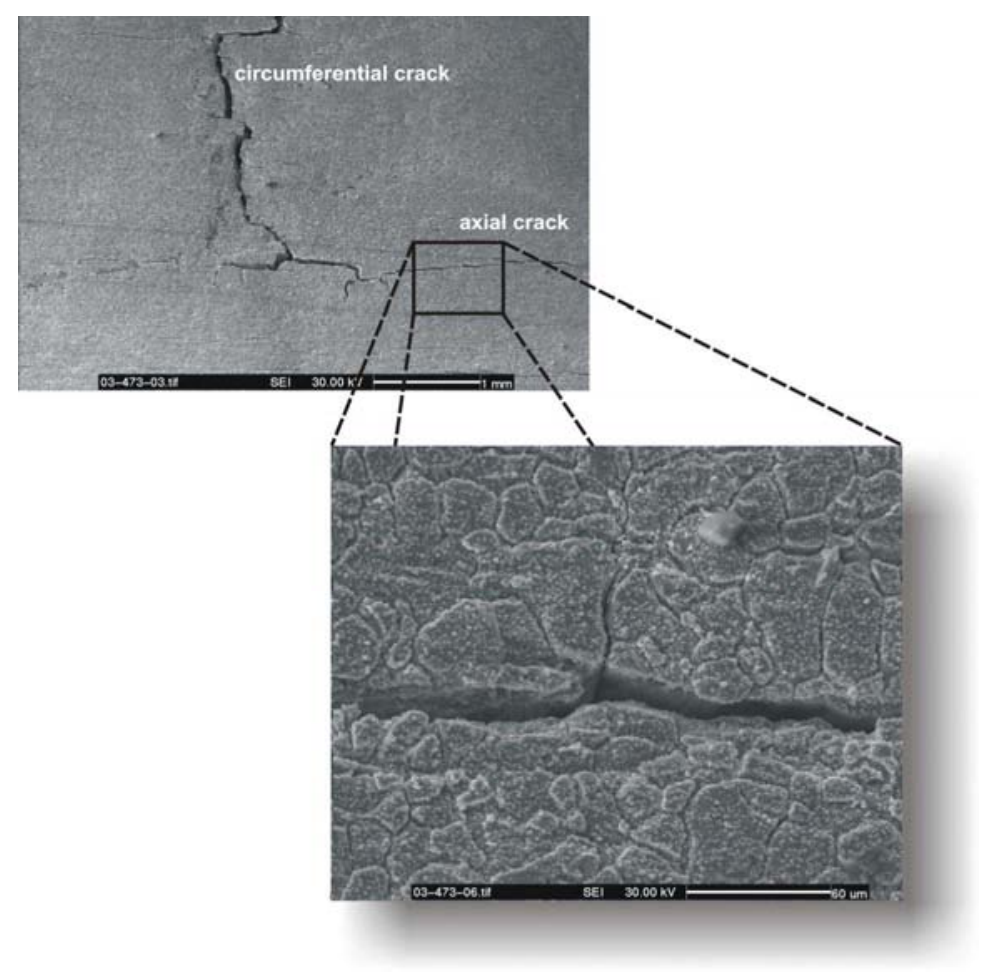

Figure 5-16

SEM examination of internal surface of intrados revealing circumferential and axial cracking. 
As a next step, the primary circumferential crack at the $180^{\circ}$ intrados position was broken open for detailed fractography. Figure 5-17 displays the specimen used during SEM examination.

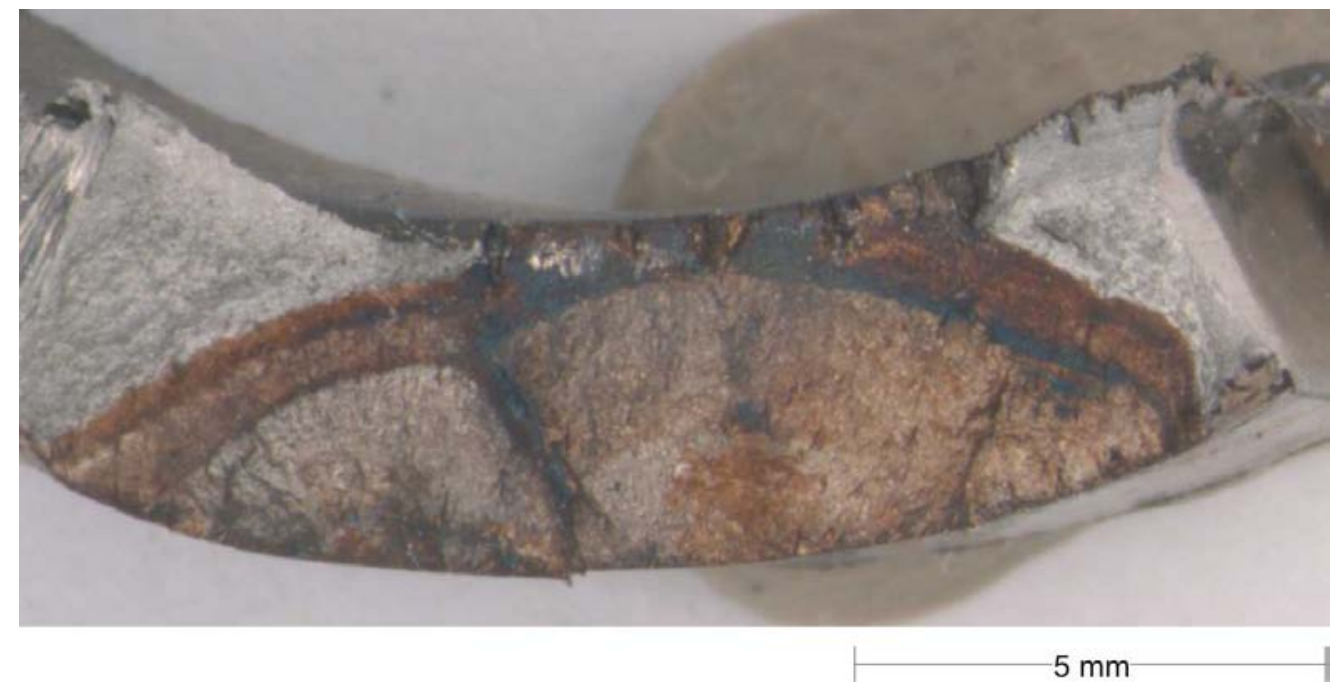

Figure 5-17

Broken open circumferential crack used for fractography.

The findings from visual inspection were confirmed, since the fracture surface was dominated by one primary circumferential crack progressing from the external to the internal surface of the intrados. The entire fracture surface exhibited evidence of mechanical fatigue, since striations as a result of step-wise crack propagation during cyclic loading of the bend were found. The initiation area exhibited a striation spacing of approximately $1 \mu \mathrm{m}$. With further progression of the crack front, the spacing increased to approximately $5 \mu \mathrm{m}$ in the mid fracture area and to approximately $20 \mu \mathrm{m}$ at the last stages of failure. Various stages of the failure are illustrated in Figure 5-18.

The internal surface of the intrados also disclosed multiple axial fissures as displayed in Figure 5-19. One representative axial fissure was broken open and analyzed with the SEM. The fracture surface also revealed a striation pattern indicating a step-wise crack progression under cyclic loading. However, the spacing was determined as $0.5 \mu \mathrm{m}$ to $1 \mu \mathrm{m}$ and thus found to be finer if compared to the primary mechanical driven fracture. The crack progression of this axial fissure occurred from the internal towards the external surface. The fracture surface was partly altered by the HT water during testing, but the morphology still indicated a combined environmental and mechanical effect as to be expected during corrosion fatigue (see Figure 5-20). 


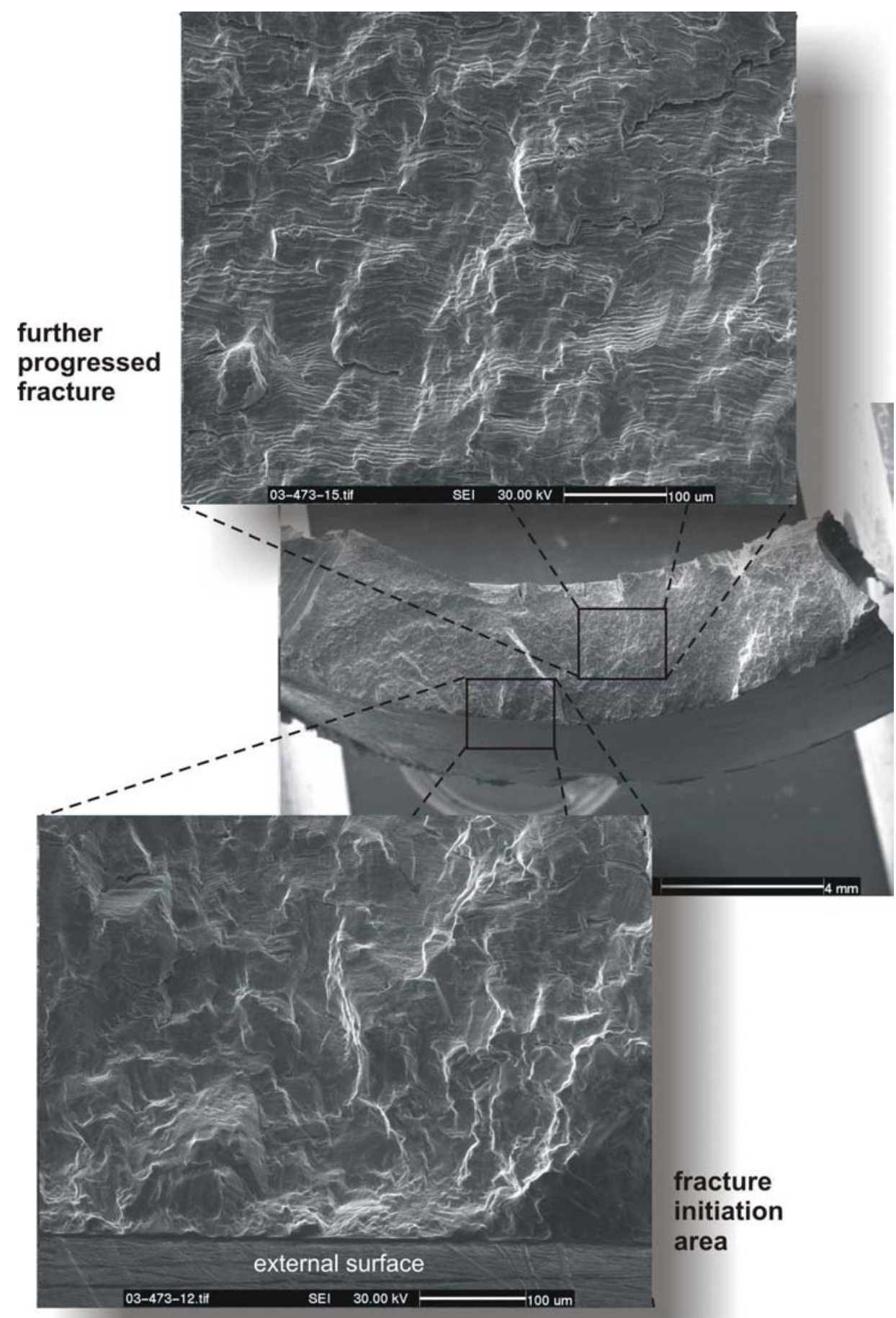

Figure 5-18

Broken open primary fracture used for SEM examination. 


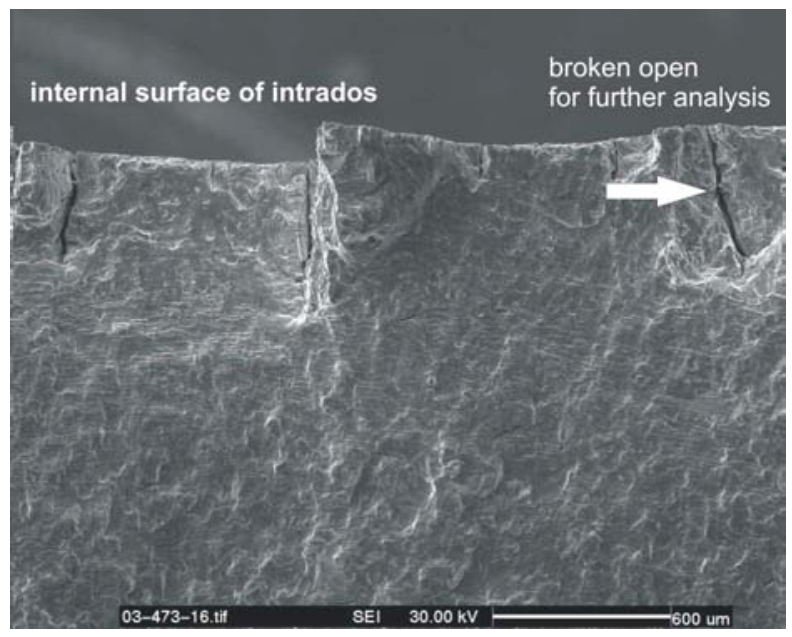

Figure 5-19

Axial cracking found on the internal surface of intrados.

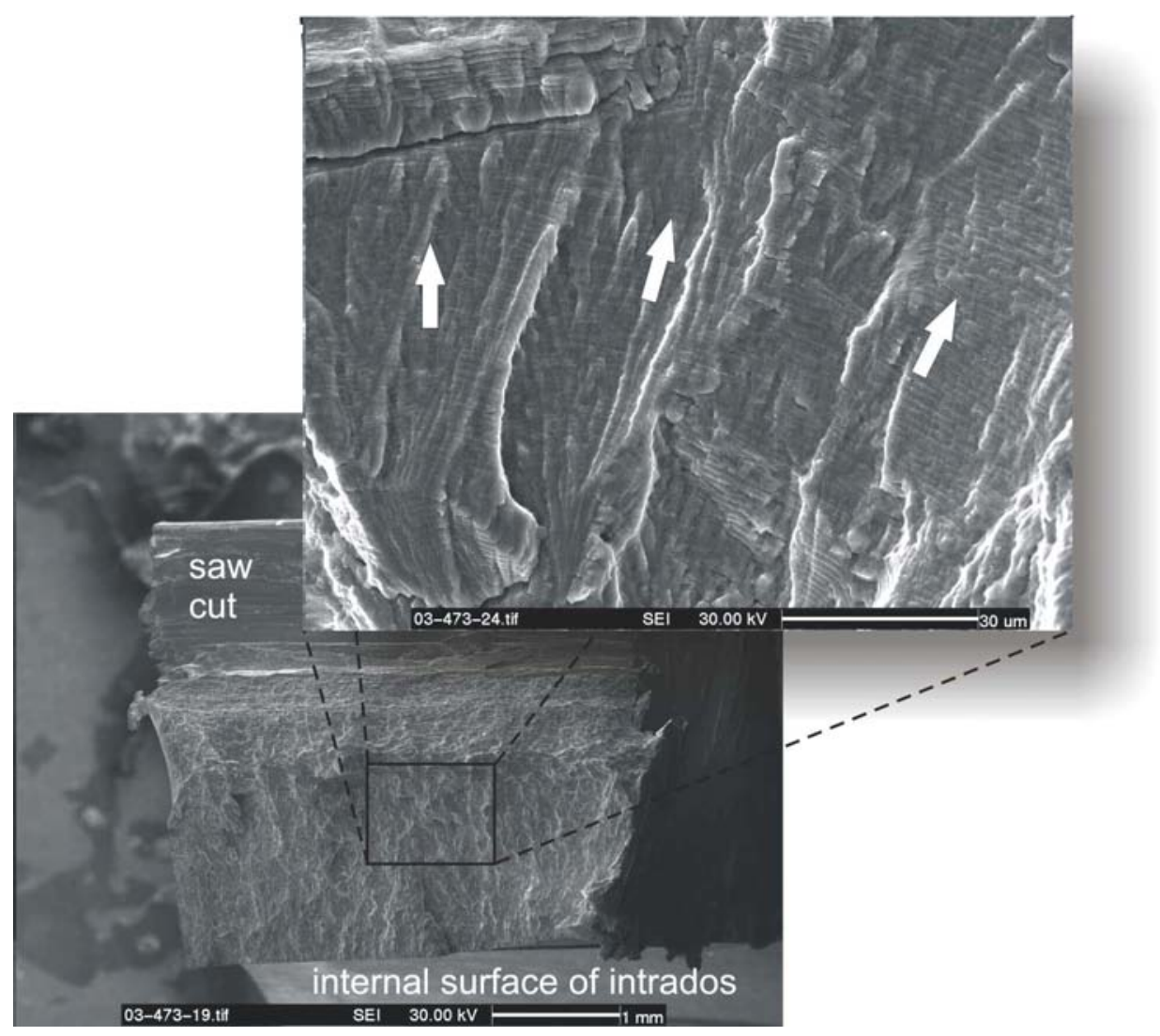

Figure 5-20

Broken open axial crack showing evidence of corrosion fatigue with a crack front progressing from the internal towards the external surface. 


\section{Metallography}

Selected locations labeled S1 to S4 (see Figure 5-21) were extracted from the U-bend for metallurgical analysis. The specimens were mounted into bakelite and polished to a $1 \mu \mathrm{m}$ surface finish and finally etched with appropriate agents. The examination was performed with a metallurgical microscope.

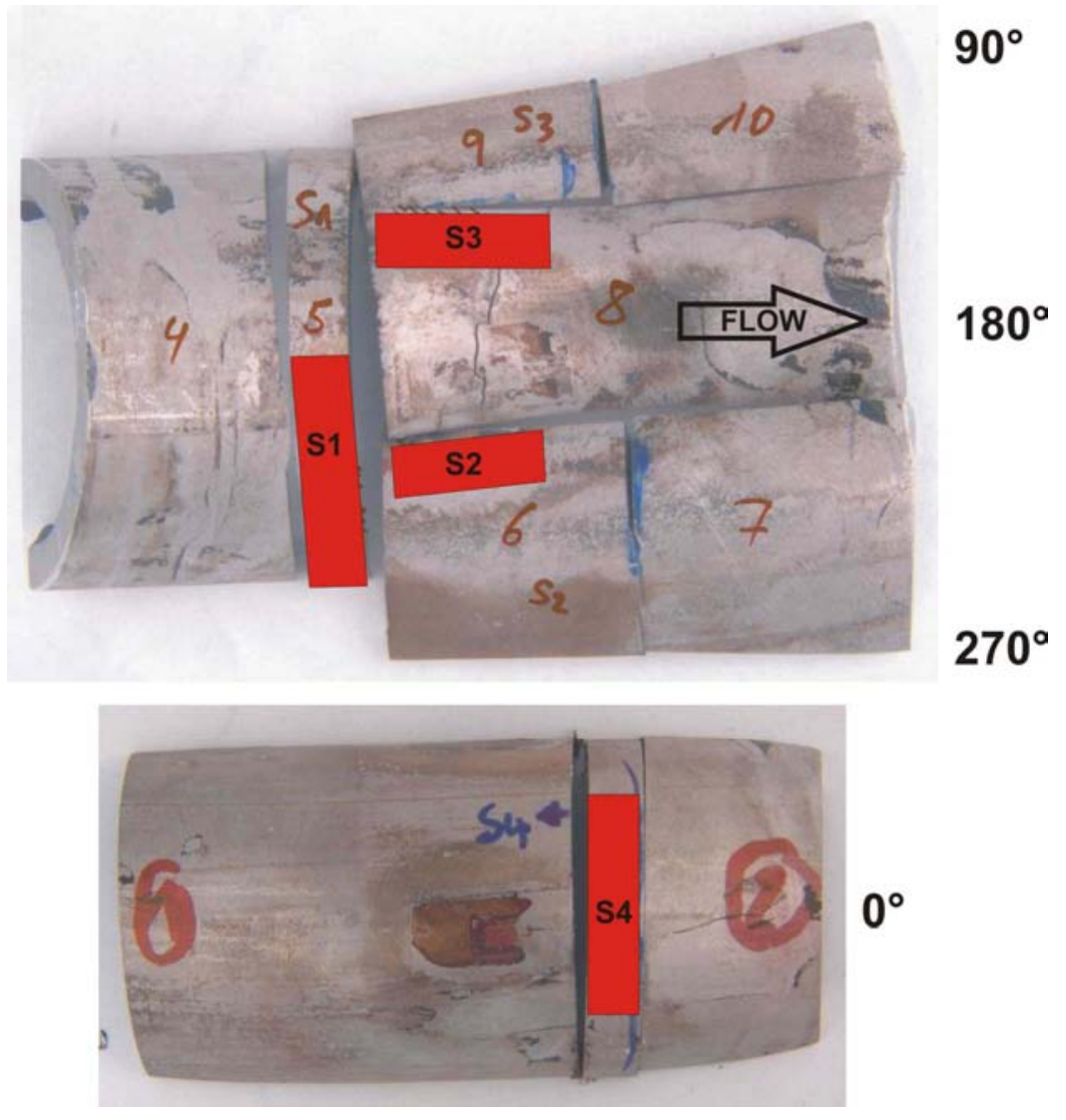

Figure 5-21

Specimen removal plan used for metallurgical analysis.

All examined microstructures appeared to be generally sound, since they exhibited features typical for austenitic stainless steels with no anomalies to be found. The indications from visual and dye penetrant inspection were confirmed and all corresponding locations exhibited cracking.

The $270^{\circ}$ position (Specimen S1) revealed axial cracking progressing in a transgranular manner from the internal towards the external surface as displayed in Figure 5-22. The cracking showed slight branching and exhibited a maximum depth of $500 \mu \mathrm{m}$, representing about $15 \%$ of the tube's nominal wall thickness. It appeared to have initiated at attacked grain boundaries from the pickling treatment during manufacturing.

The approximate $200^{\circ}$ position (Specimen S2) revealed circumferential cracking progressing in a transgranular manner from the external towards the internal surface as displayed in Figure 5-23. These non-branched cracks correspond to previous obtained results from BLT 2 where the 
external intrados area $\left(160^{\circ}\right.$ to $\left.200^{\circ}\right)$ also suffered from these type of defects. The maximum depth was determined as approximately $600 \mu \mathrm{m}$, representing about $18 \%$ of the tube's nominal wall thickness. Again the cracking appeared to have initiated on attacked grain boundaries from the pickling treatment during manufacturing.

The $110^{\circ}$ Position (Specimen S3) revealed circumferential cracking progressing in a transgranular manner from the internal towards the external surface as displayed in Figure 5-24. The cracking showed a maximum depth of $200 \mu \mathrm{m}$, representing about $6 \%$ of the nominal wall thickness.

The extrados (Specimen S4) exhibited axial cracking that propagated in a transgranular manner from the internal towards the external surface as displayed in Figure 5-25. The maximum crack depth was determined as approximately $200 \mu \mathrm{m}$ (approximately $6 \%$ of the tube's nominal wall thickness). At this location, too, the attacked grain boundaries appeared to have influenced the crack initiation process.
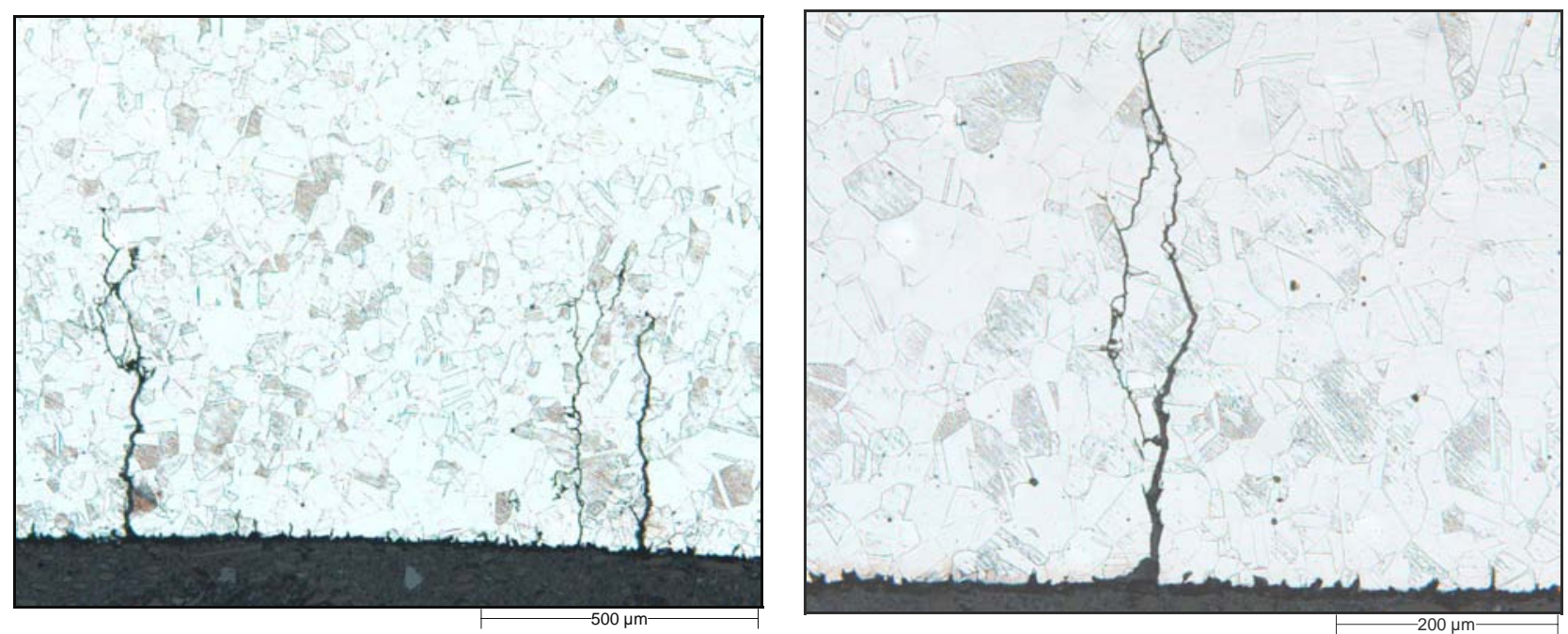

Figure 5-22

Typical views of cross-section in the $270^{\circ}$ position (Specimen S1) showing transgranular axial cracking progressing from the internal towards the external surface. 

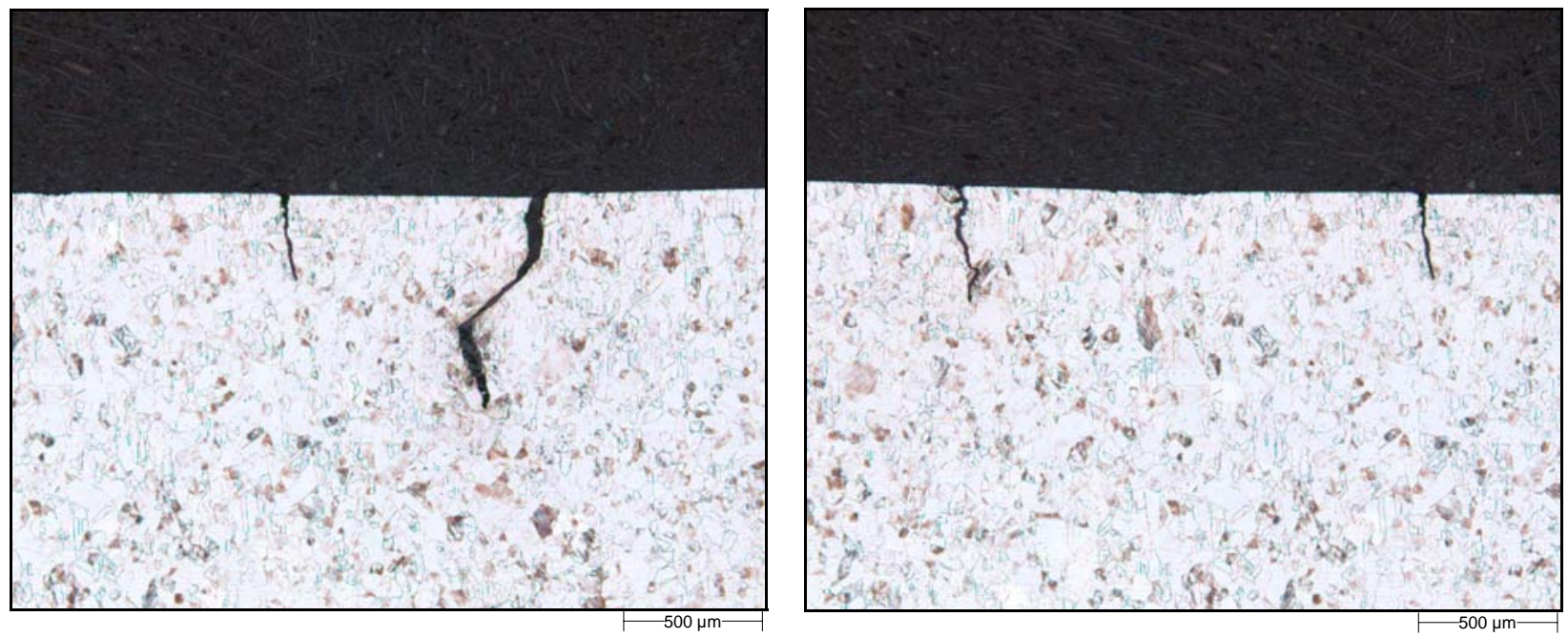

Figure 5-23

Typical views of cross-section in the approximate $200^{\circ}$ position (Specimen S2) showing transgranular circumferential cracking progressing from the External towards the internal surface.
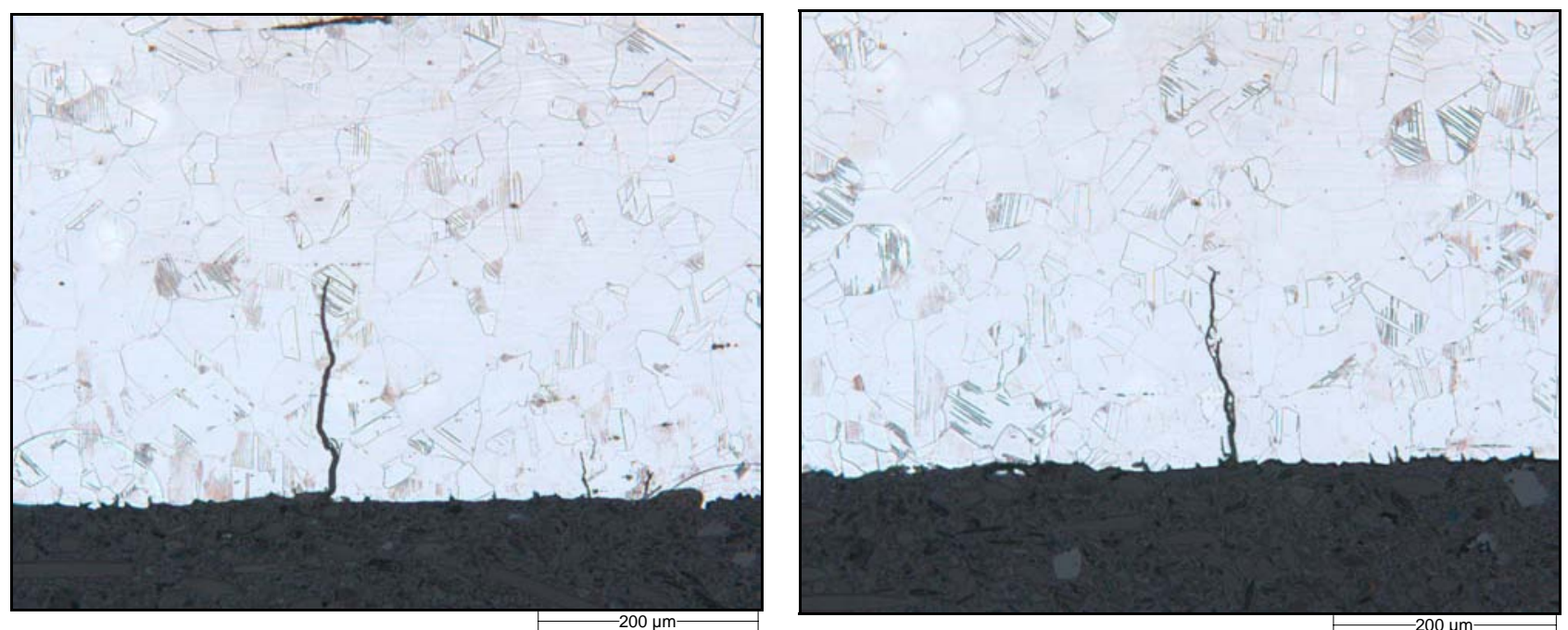

Figure 5-24

Typical views of cross-section in the approximate $110^{\circ}$ position (Specimen S3) showing transgranular circumferential cracking progressing from the internal towards the external surface. 


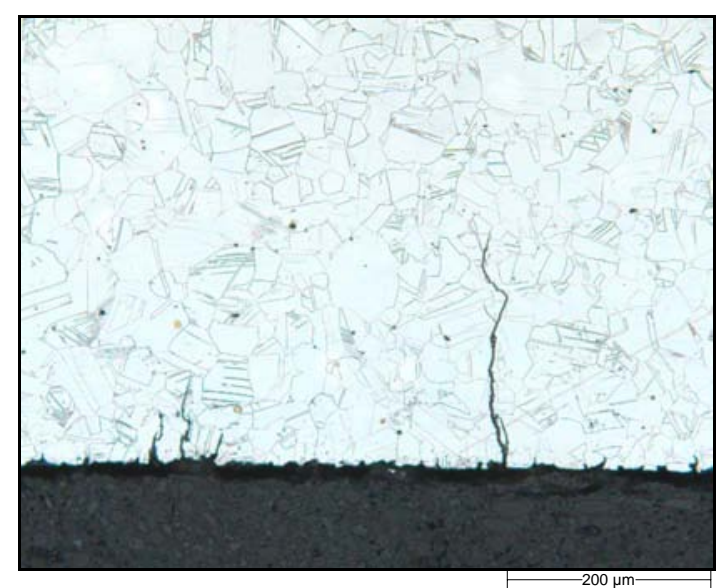

Figure 5-25

Typical view of cross-section at the extrados (Specimen S4) showing transgranular axial cracking progressing from the internal towards the external surface.

\section{Summary of Results}

The following results can be summarized from environmental test 2a:

- Water chemistry in the range of specified values, ECP -600 mV $\mathrm{H}_{\mathrm{H}, \mathrm{T}}$, Redox Pot. $-500 \mathrm{mV} \mathrm{H}_{\mathrm{H}, \mathrm{T}}$ for low flow rate.

- Cycles 13 to 48 performed with modified wave form before switching to triangular wave form due to unstable bend behavior and reaching switch-off criterion (load drop of 5\%) after 33 cycles.

- Total number of 1520 cycles resulting in circumferential through wall crack at intrados starting at the external surface; mechanical loading dominates the failure mechanism.

- Intrados exhibited an array of multiple small circumferential cracks at the external surface.

- At the $180^{\circ}, 90^{\circ}$ and $270^{\circ}$ positions axial cracks found at the internal surface as a result of corrosion fatigue; also a small amount of axial cracking at internal surface of the extrados.

- One additional crack field with circumferential cracks on the internal surface in the area of the $110^{\circ}$ position.

- All cracks found propagated in a transgranular manner.

- No microstructural effect was observed.

Figure 5-26 graphically summarizes the location and extent of crack indications found after evaluating environmental test 2a. 


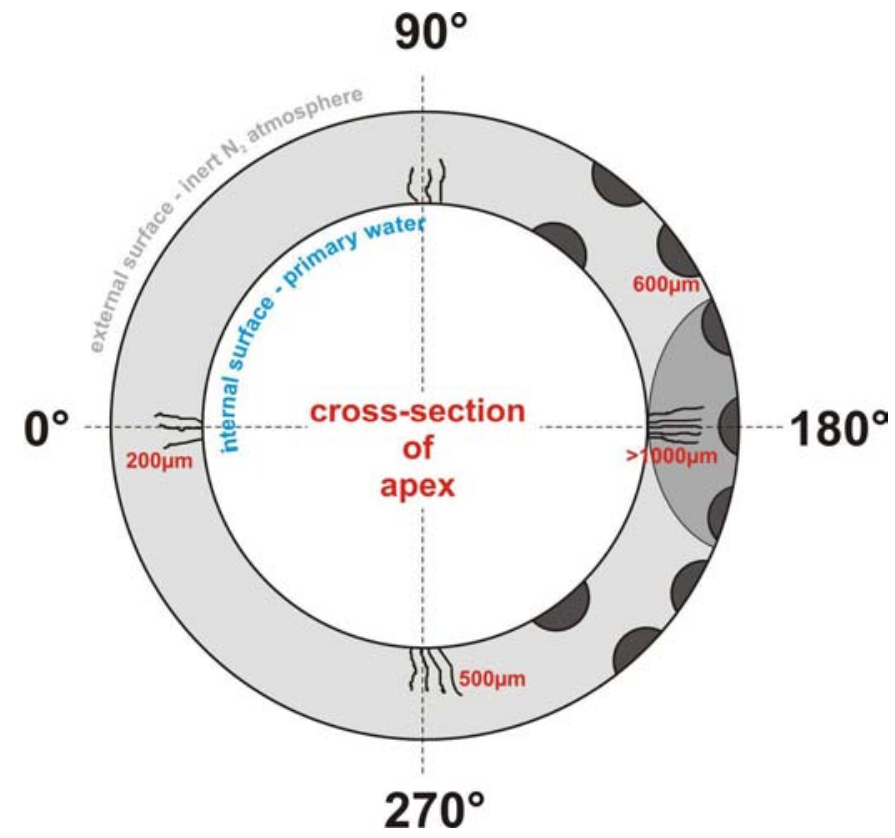

Figure 5-26

Cross-sectional sketch of apex schematically showing all crack indications and their depths (if available); please note that sketch is not to scale.

\section{Conclusions from Test 2a}

In clear contrast to BLT 2, the environmental test 2a at low flow rates showed the effect of primary water on the fatigue behavior of the U-bend under cyclic load, since multiple axial cracking at the internal surface of the apex was observed and characterized.

All fracture surfaces that had initiated on the internal surface exhibited evidence of combined efforts of mechanical loading and environmental impact, as commonly seen in corrosion fatigue. However, the primary failure causing leakage in the form of a circumferential through wall external defect was solely driven by cyclic mechanical loading, which was the dominant life time determining factor.

Independent from the location, either purely mechanical or combined mechanical/environmental cracking initiated at surface artifacts along grain boundaries resulting from the pickling attack during manufacturing. The internal surfaces of all bends are considered very similar, and therefore the impact on crack initiation is expected to be similar within domains of similar strain rate and strain amplitudes.

The modified wave-shape prooved to be too unstable and was therefore changed into a triangular wave shape. Furthermore, a less sensitive switch-off criterion of "loading to failure" will be implemented for all future tests. 



\section{6}

\section{ENVIRONMENTAL TEST 2B}

\section{Test Set-Up and Approach}

According to the text matrix, the environmental test $2 \mathrm{~b}$ was characterized as a high flow-rate test in conjunction with the following U-bend instrumentation and basic test parameters:

- $\quad$ pre-conditioning of the bend internal surface by lengthy exposure to simulated primary water

- $\quad$ instrumented U-bend with three bonded HT strain gauges at the $0^{\circ}, 90^{\circ}$ and $180^{\circ}$ position

- $\quad$ strain amplitude of $0.6 \%$ (total strain range of $1.2 \%$ )

- $\quad$ strain rate of $1 \times 10^{-4} \mathrm{~s}^{-1}$

- $\quad$ testing temperature $\mathrm{T}=240^{\circ} \mathrm{C}$, pressure $\mathrm{p}=50$ bar

- $\quad \mathrm{HT}$ water chemistry comprising 1200 ppm B as $\mathrm{H}_{3} \mathrm{BO}_{3}+2$ ppm Li as LiOH

- $\quad$ oxygen content was adjusted to $<<10 \mathrm{ppb}$, no $\mathrm{H}_{2}$ injection

- the impurity level was adjusted to $\mathrm{Cl}^{-}+\mathrm{F}^{-}+\mathrm{SO}_{4}{ }^{2-}<100 \mathrm{ppb}$

- Water sampling and chemical analysis of $\mathrm{B}, \mathrm{Li}, \mathrm{Cl}^{-}, \mathrm{F}^{-}, \mathrm{SO}_{4}{ }^{2-}, \mathrm{pH}$ during start-up and before shut down

- High flow rate: $4100 \mathrm{l} / \mathrm{h} \approx 2.2 \mathrm{~m} / \mathrm{s}$ for $26.5 \mathrm{~mm}$ ID 


\section{Results}

\section{Water Chemistry}

The mechanical loading of the U-bend during testing was not commenced until the specified requirements with respect to test temperature, water chemistry/purity and electrochemical corrosion/redox potentials were met. Water sampling before start-up and loading assured thisas displayed in Table 6-1.

\begin{tabular}{|c|c|c|c|c|c|c|c||}
\hline $\begin{array}{c}\text { water } \\
\text { sampling }\end{array}$ & $\begin{array}{c}\mathbf{B} \\
\mathbf{p p m}\end{array}$ & $\begin{array}{c}\mathbf{L i} \\
\mathbf{p p m}\end{array}$ & $\mathbf{p H}$ & $\begin{array}{c}\text { chloride } \\
\mathbf{p p b}\end{array}$ & $\begin{array}{c}\text { sulfate } \\
\mathbf{p p b}\end{array}$ & $\begin{array}{c}\text { fluoride } \\
\mathbf{p p b}\end{array}$ & remarks \\
\hline $\begin{array}{c}\text { before loading, test } \\
\text { temperature was } \\
\text { reached }\end{array}$ & 1168 & 1.98 & 6,5 & $<10$ & $<10$ & 21 & $\begin{array}{l}\text { lon exchanger } \\
\text { cond. (out) }=21.6 \mu \mathrm{S} / \mathrm{cm} \\
\mathrm{O}_{2}(\mathrm{out}) \approx 3 \mathrm{ppb}\end{array}$ \\
\hline during test & - & - & - & - & - & - & - \\
\hline before shut down & 1261 & 2.1 & - & 11 & $<10$ & 21 & $\begin{array}{c}\text { cond. (out) }=21.5 \mu \mathrm{S} / \mathrm{cm} \\
\text { O2 (out) } \approx 2 \mathrm{ppb}\end{array}$ \\
\hline
\end{tabular}

Table 6-1

Results from water sampling during environmental Test $\mathbf{2 b .}$

During testing the water chemistry was monitored continuously with respect to test temperature, conductivity and electrochemical corrosion potential (ECP) and redox potential. Figure 6-1 and Figure 6-2 show the inlet and outlet conductivity, the test temperature, as well as ECP and the redox potential, for the entire duration of environmental test $2 \mathrm{~b}$. The ECP showed values of approximately $-550 \mathrm{mV}$ H,T and the redox potential was measured at approximately $-500 \mathrm{mV}_{\mathrm{H}, \mathrm{T}}$. The target test temperature of $240^{\circ} \mathrm{C}$ was held very stable for the entire test. The inlet and outlet conductivity were at levels to be expected and did not show any anomalies.

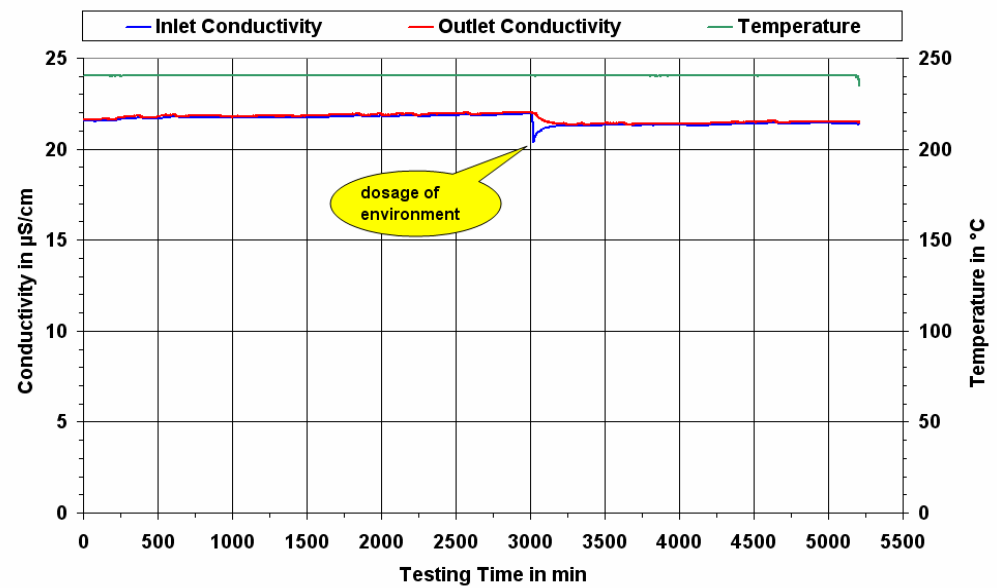

Figure 6-1

Conductivity and temperature vs. testing time. 


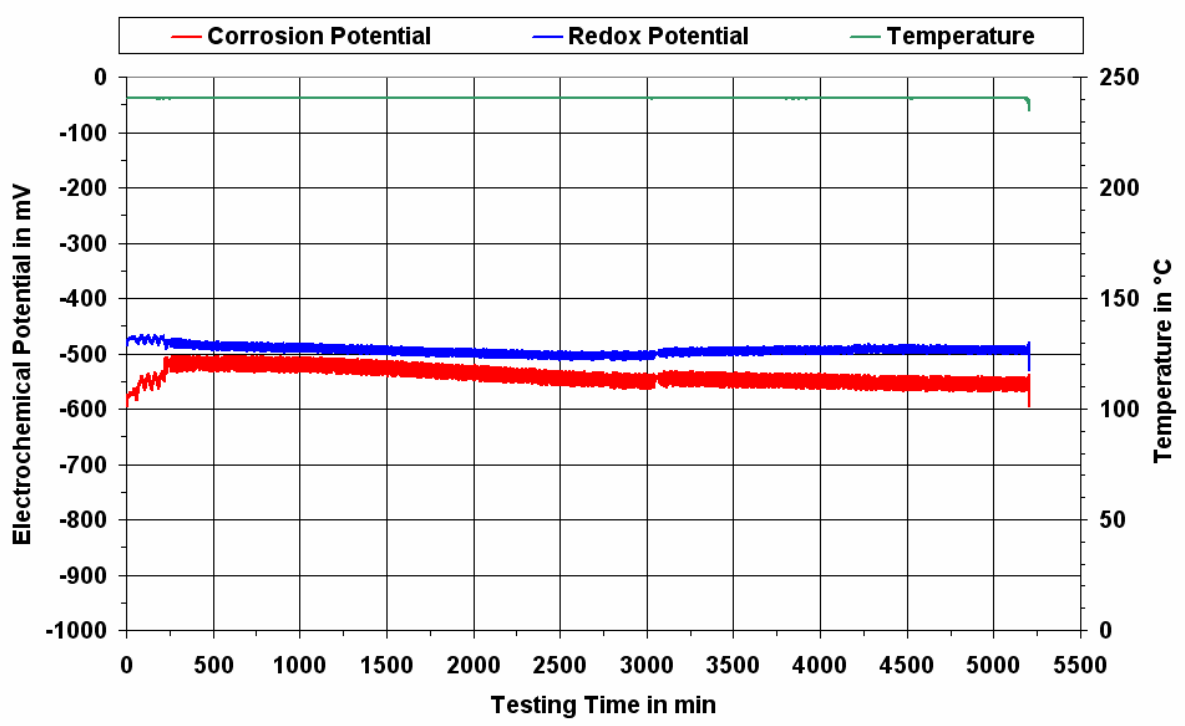

Figure 6-2

Electrochemical corrosion potential, redox potential and temperature vs. testing time.

\section{Mechanical Data}

Having reached the desired levels with regards to water chemistry and test temperature, the loading sequence was started. The basic test parameters used for mechanical loading of the Ubend are given in Table 6-2. The bend was loaded with a triangular wave shape for the first 10 cycles for evaluating itsresponse. With the exception of cycle one, where the signal was not recorded properly due to a malfunctioning displacement transducer (which was immediately replaced), the response of the bend was considered uniform. The load and strain response for this test sequence are displayed in Figure 6-3 to Figure 6-5.

Up to cycle 10, the test was performed displacement controlled with strain triggered switch points at $\pm 0.6 \%$ strain amplitude. The load vs.displacement hysteresis for the first 10 cycles is displayed in Figure 6-6 and also indicated fairlystable bend behavior. Cycle 10 was then used to determine the displacements necessary for the remaining test, which was performed exclusively under displacement control.

The complete test with all available mechanical data is displayed in Figure 6-7. The graph shows a uniform load response over the entire duration of the test. However, within about the first 1200 minutes, a slight softening of the bend can be observed as indicated by decreasing load amplitudes.

Due to the cyclic loading, the leading $180^{\circ}$ (intrados) strain gauge stopped working after a test duration of approximately 600 minutes. After having reached a total number of 1238 cycles, the test was terminated due to a defect causing leakage. The force vs.displacement hysteresis for the entire test is shown in Figure 6-8. 


\begin{tabular}{|c|c|c|c|c|c||}
\hline cycle & $\begin{array}{c}\text { wave } \\
\text { shape }\end{array}$ & $\begin{array}{c}\text { control } \\
\text { channel }\end{array}$ & strain rate & switch point & $\begin{array}{c}\text { switch off } \\
\text { criterion }\end{array}$ \\
\hline \multirow{2}{*}{$1-5$} & triangular & $\begin{array}{c}\text { displacement } \\
\text { strain triggered } \\
\text { switch point }\end{array}$ & $1 \times 10^{-5} \mathrm{~s}^{-1}$ & $\begin{array}{c}+0.6 \% \\
-0.6 \%\end{array}$ & \\
\hline $5-10$ & triangular & $\begin{array}{c}\text { displacement } \\
\text { strain triggered } \\
\text { switch point }\end{array}$ & $1 \times 10^{-4} \mathrm{~s}^{-1}$ & $\begin{array}{l}+0.6 \% \\
-0.6 \%\end{array}$ & failure \\
\hline $11-1238$ & triangular & displacement & $1 \times 10^{-4} \mathrm{~s}^{-1}$ & $+7.15 \mathrm{~mm}$ & $-5.4 \mathrm{~mm}$ \\
\hline
\end{tabular}

Table 6-2

Basic test parameters of mechanical loading during environmental Test $2 \mathrm{~b}$.

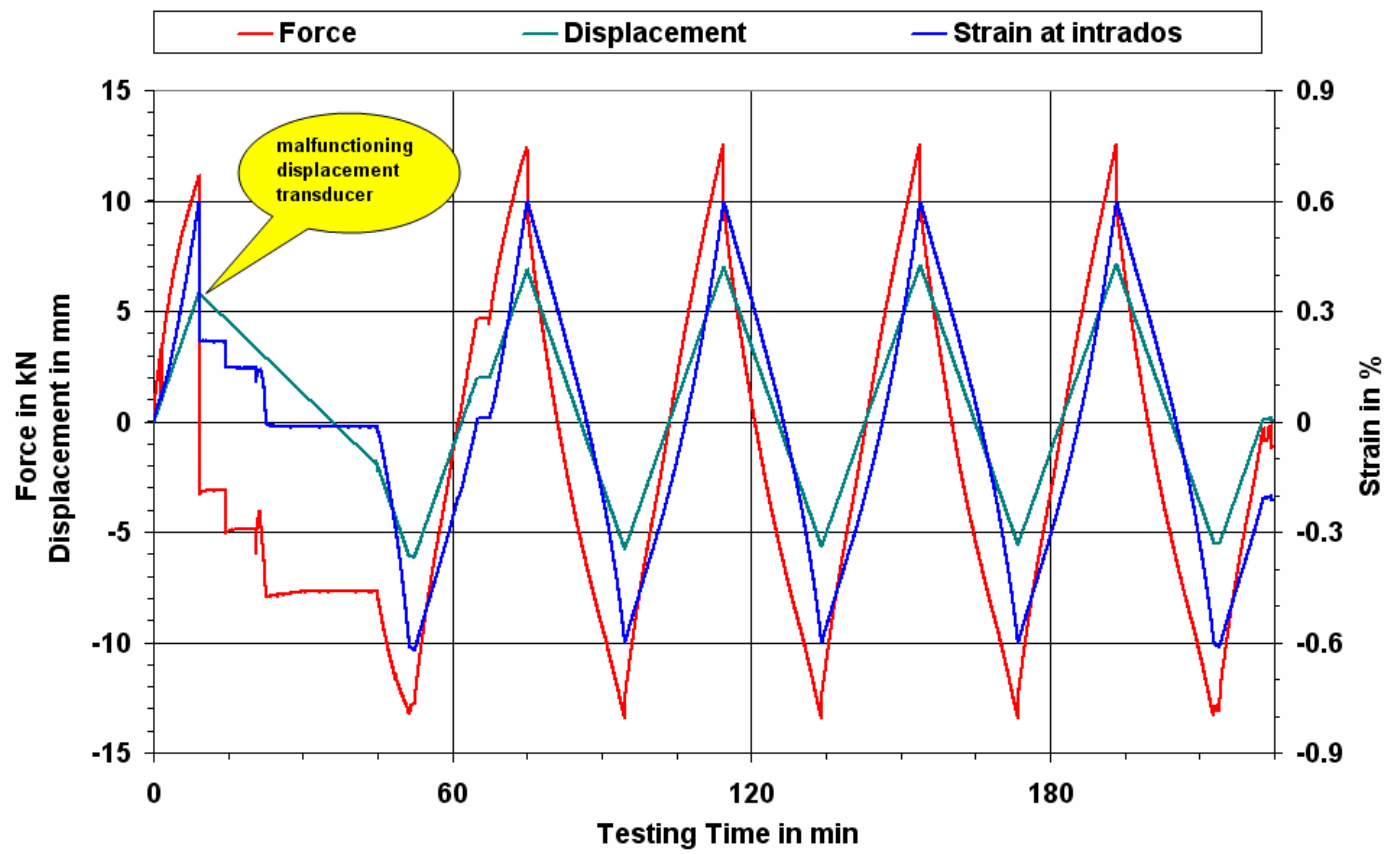

Figure 6-3

Mechanical data of Cycle 1 to 5. 


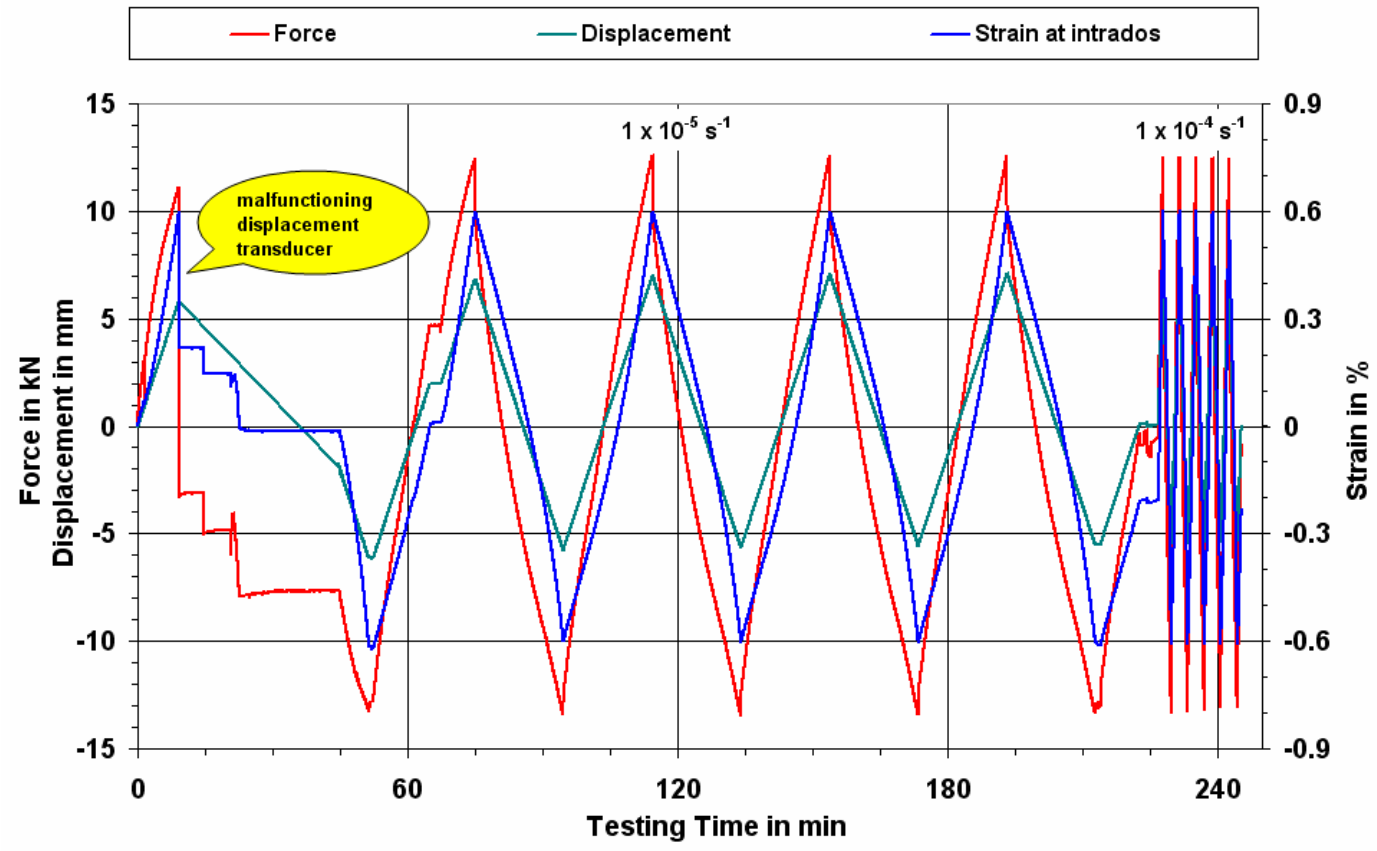

Figure 6-4

Mechanical data of Cycle 1 to 10.

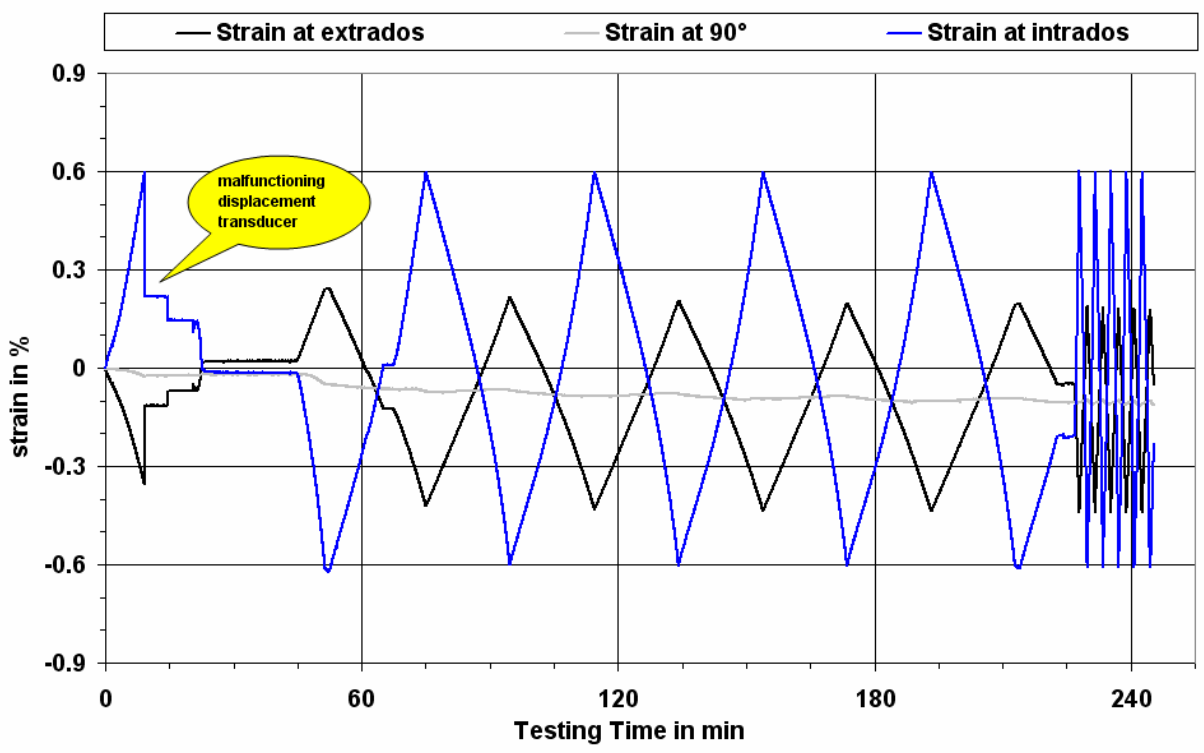

Figure 6-5

Response of all strains from Cycles 1 to 10. 


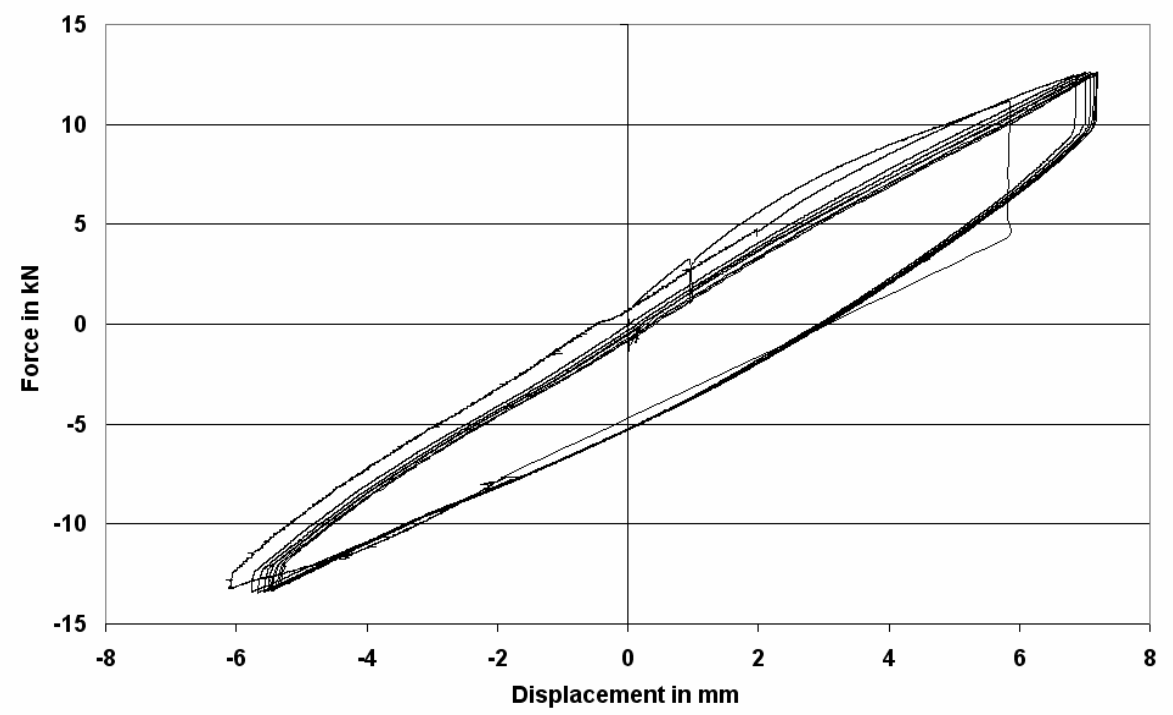

Figure 6-6

Load vs. displacement for Cycles 1 to 10.

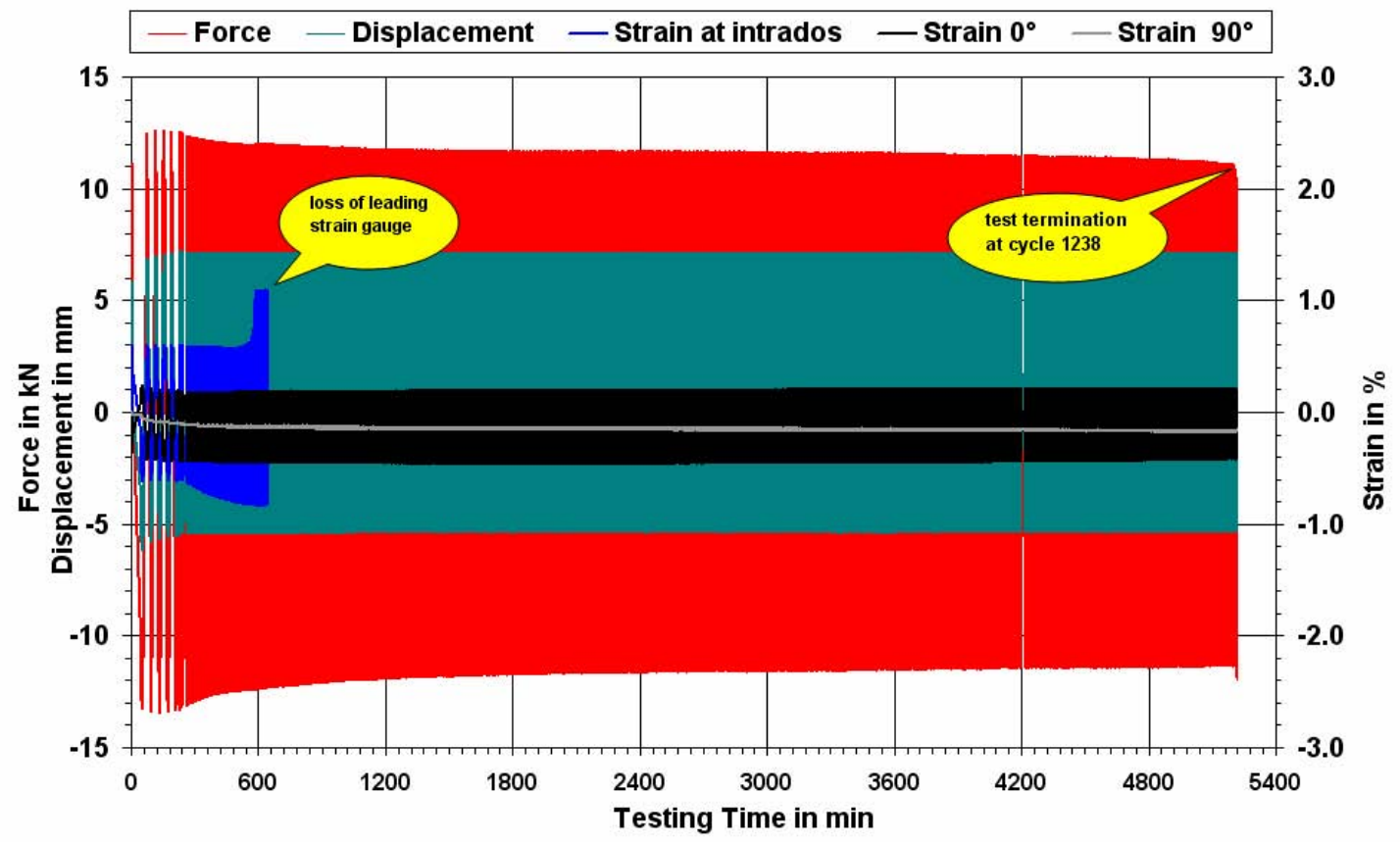

Figure 6-7

All mechanical data of Test $2 b$ for entire test duration. 


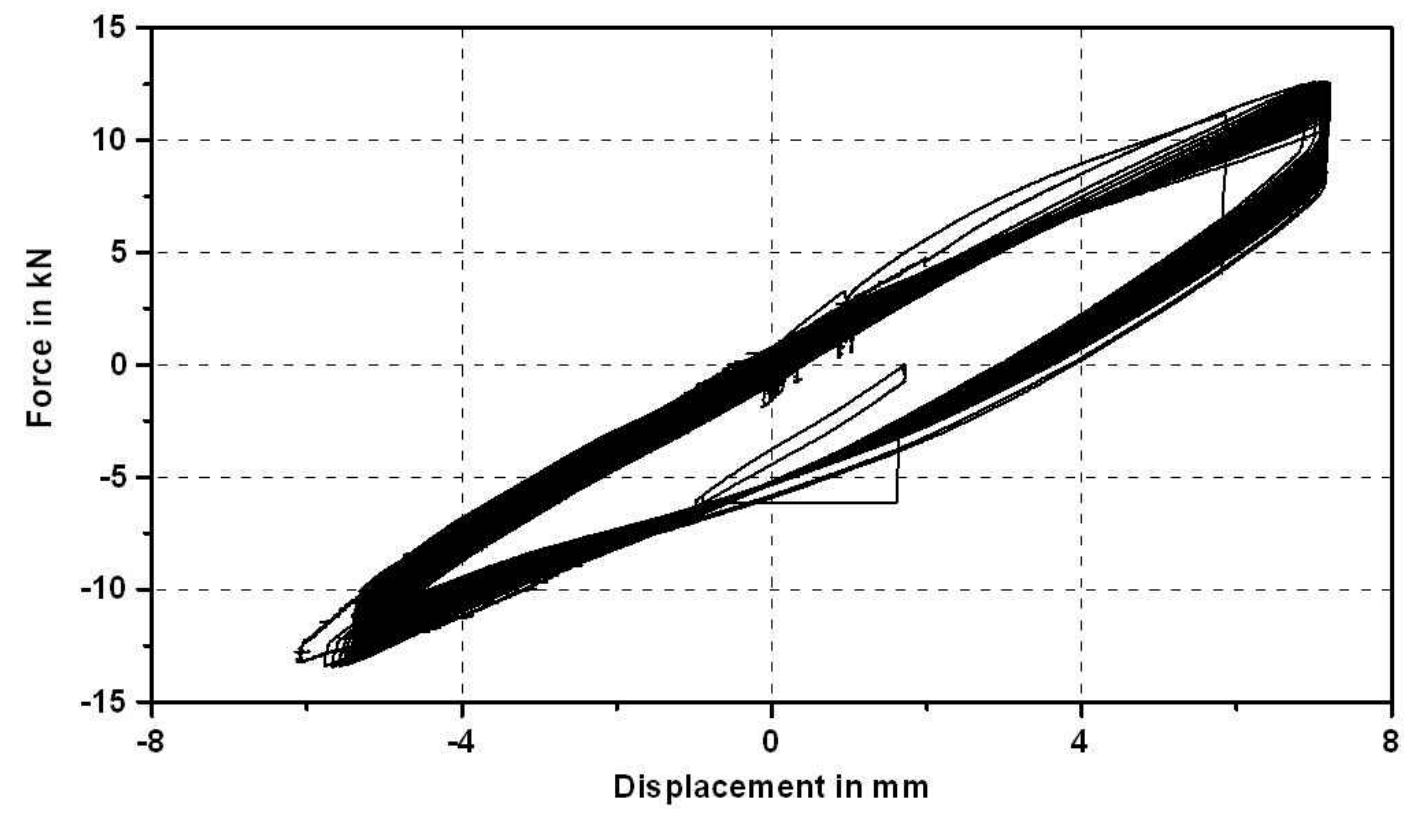

Figure 6-8

Force vs. displacement for entire test.

\section{Post Test Characterization}

After the physical testing part of environmental test 2a was accomplished, the U-bend was removed from the testing rig, the additional tubing for optimized flow condition was cut off, and the bend was prepared for post test characterization entailing the following tasks:

- Visual inspection of tested U-bend

- Dye penetrant inspection (DPI)

- Fractography of selected locations including examination at high magnifications using scanning electron microscopy (SEM)

- Metallography of selected locations

\section{Visual Inspection}

Visual inspection revealed one primary circumferential crack with an approximate length of $10 \mathrm{~mm}$ to $12 \mathrm{~mm}$ as displayed in Figure 6-9 and Figure 6-10. This defect was located in the intrados area (approximate $200^{\circ}$ position) and had developed into a through-wall defect causing leakage of the simulated primary water as also indicated by some boric acid that had crystallized along this fracture. The crack had initiated from the external surface at a circumferential scratch present on the bend. No other primary defects visible to the naked eye were found on the external surface during visual inspection. 


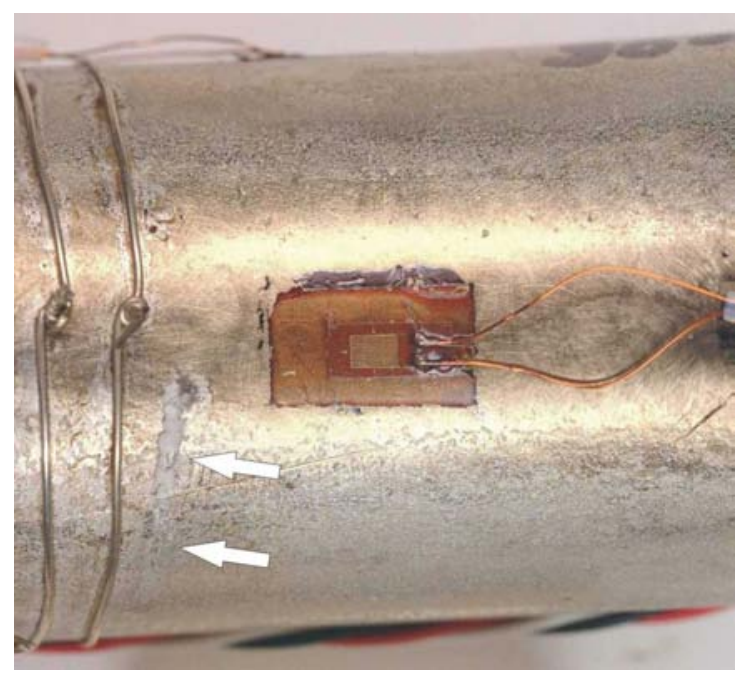

Figure 6-9

Circumferential intrados defect as observed after test termination; the white remnants originated from crystallized boric acid.

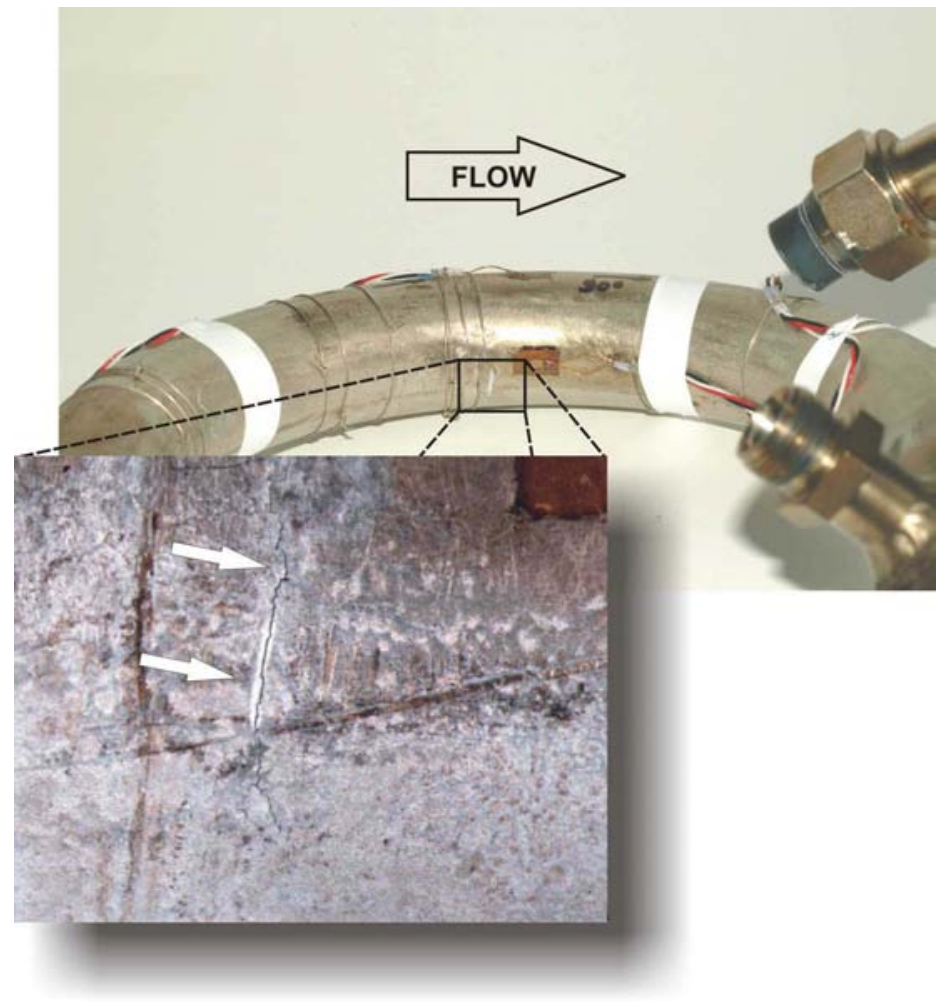

Figure 6-10

Close-up of leakage causing defect located in the intrados area. 


\section{Dye Penetrant Inspection}

A narrow piece containing the bend apex with an approximate length of $60 \mathrm{~mm}$ was sectioned from the bend and split in two half shells for further inspection with dye penetrant. Both the internal and external surfaces were examined.

The external surface of the intrados area exhibited an array of circumferential cracks including the defect causing leakage similar to previously tested bends (see Figure 6-11). No further indications were found on all other external positions of the bend.

DPI of the internal intrados surface showed multiple axial cracking and the through wall defect formed by the one circumferential fissure mentioned above (see Figure 6-12). Also fine circumferential cracking was found on the internal surface of the intrados. The internal surfaces of the extrados, the $90^{\circ}$ and the $270^{\circ}$ position all showed axial cracking to varying degrees as displayed in Figure 6-13 to Figure 6-15.

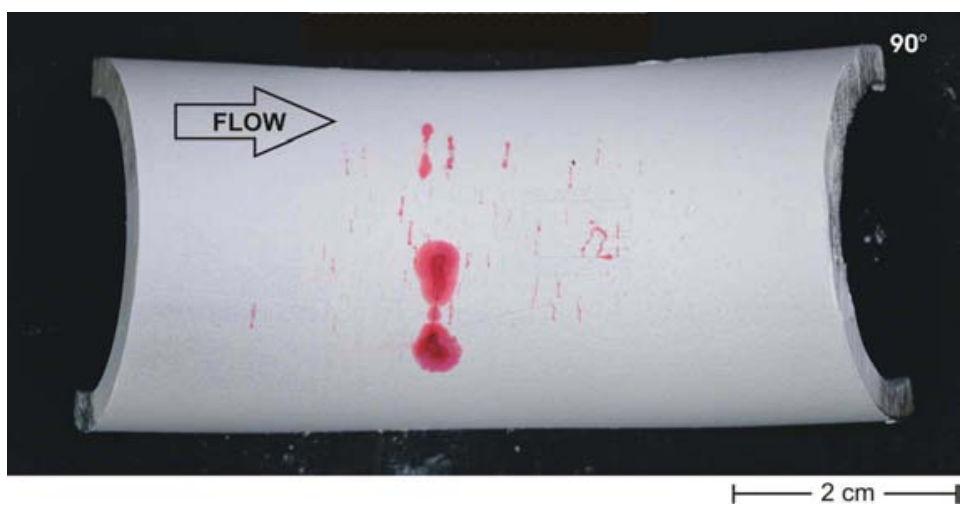

Figure 6-11

External surface of intrados showing array of circumferential cracks.

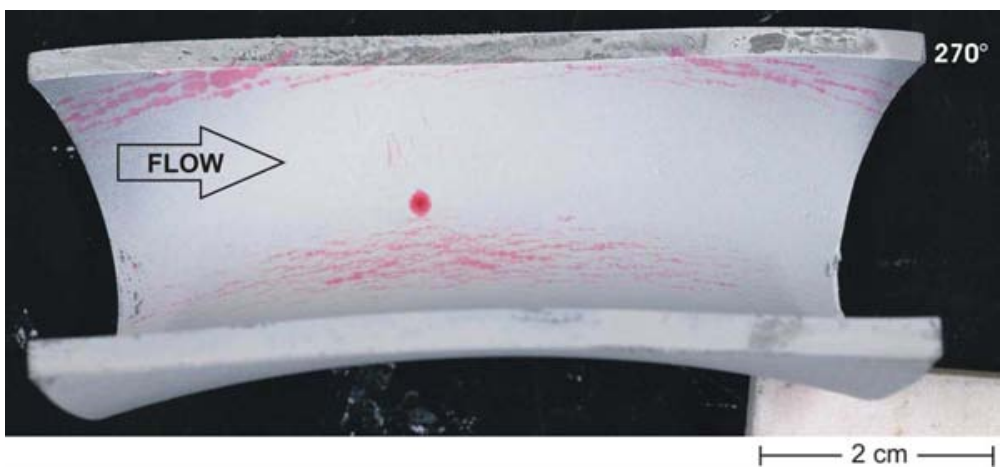

Figure 6-12

Internal surface of intrados showing multiple axial cracking and the defect causing leakage in the form of a spot-like indentation in the middle of the halfshell. 


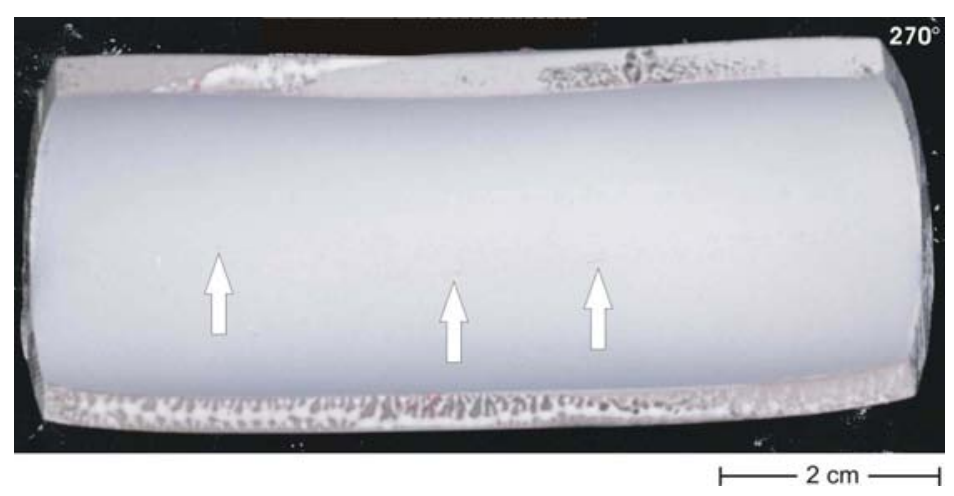

Figure 6-13

Internal surface of extrados showing very fine axial cracking.

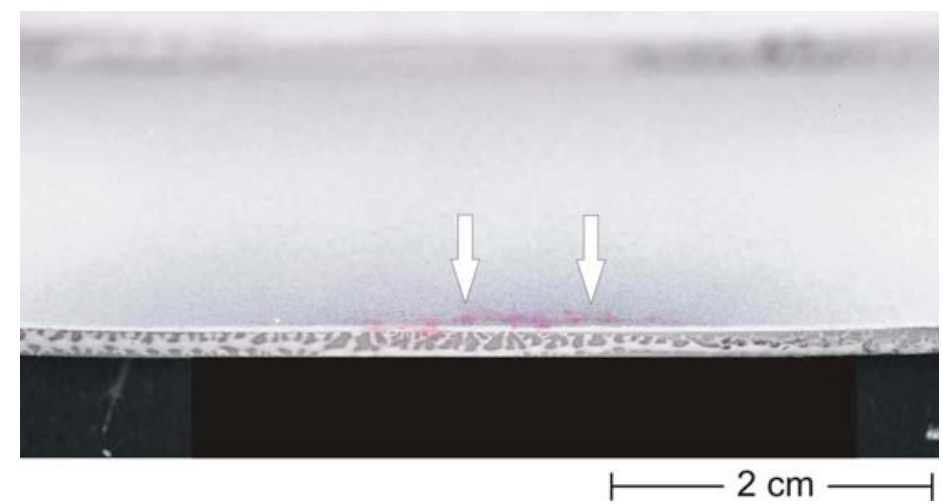

Figure 6-14p

Internal surface of $90^{\circ}$ position showing axial cracking.

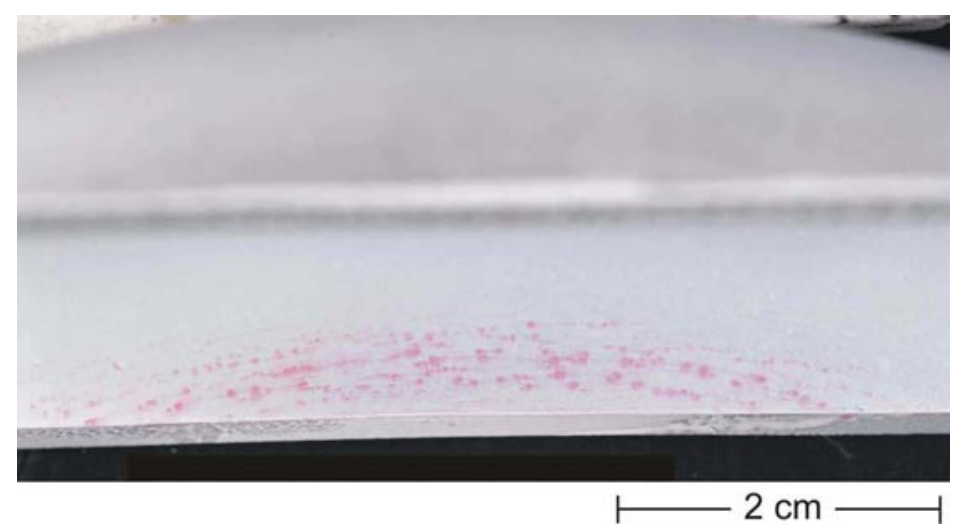

Figure 6-15

Internal surface of $270^{\circ}$ position showing axial cracking. 


\section{Scanning Electron Microscopy}

The external surface of the intrados adjacent to the defect causing leakage was examined by SEM. The results clearly showed, that the primary circumferential failure had initiated at a scratch formed by a circumferential dent as displayed in Figure 6-16 and Figure 6-17.

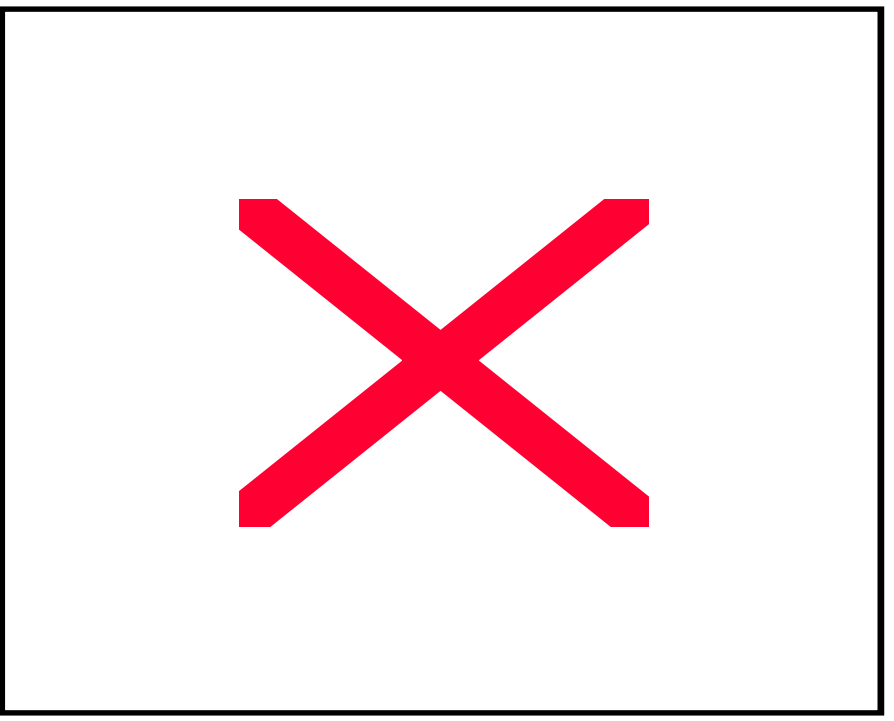

Figure 6-16

External intrados surface showing primary circumferential crack originating within circumferential dent/scratch.

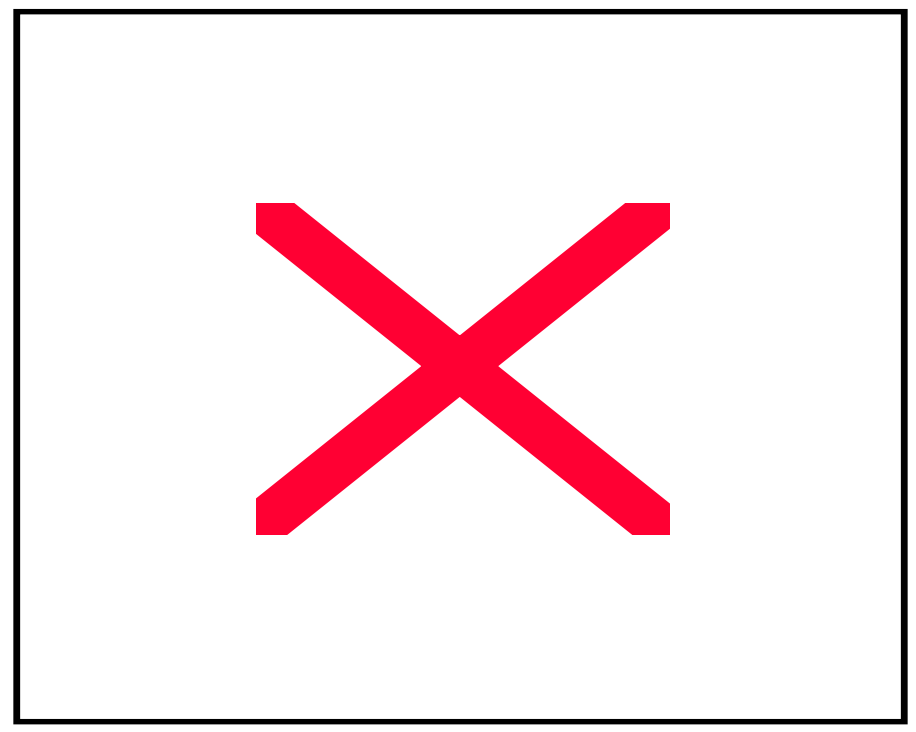

Figure 6-17

Close-up of Figure 6-16. 
The internal surface of the intrados was subject to SEM examination. The DPI findings were confirmed, since axial cracking was found as displayed in Figure 6-18. To a certain extent, circumferential cracking was also found on the internal surface, but to a lesser degree in terms of number and extension if compared to the axial cracking (see Figure 6-19). In all cases the crack progression along the surface tended to follow an intergranular "texture" provided by the pickling attack.

The primary circumferential crack was broken open for fractography. Figure 6-20 displays the specimen used for analysis. The defect causing leakage was characterized as mechanical fatigue indicated by striations typical for step-wise crack progression under cyclic loading as displayed in Figure 6-21. The crack progression occurred from the external towards the internal surface. The area typically considered a mid fracture area revealed a striation spacing of approximately $2.5 \mu \mathrm{m}$, whereas the final stages of this facture exhibited numbers greater then $20 \mu \mathrm{m}$.

The internal surface exhibited both internally initiated axial and circumferential cracking as shown in Figure 6-22. The striation spacing for both types of cracking was determined to range between $0.5 \mu \mathrm{m}$ to $1 \mu \mathrm{m}$. The morphology of both types of cracks was similar and indicated environmentally assisted crack progression under cyclic loading. Figure 6-23 and Figure 6-24 show typical fracture surfaces of axial and circumferential cracks, respectively.

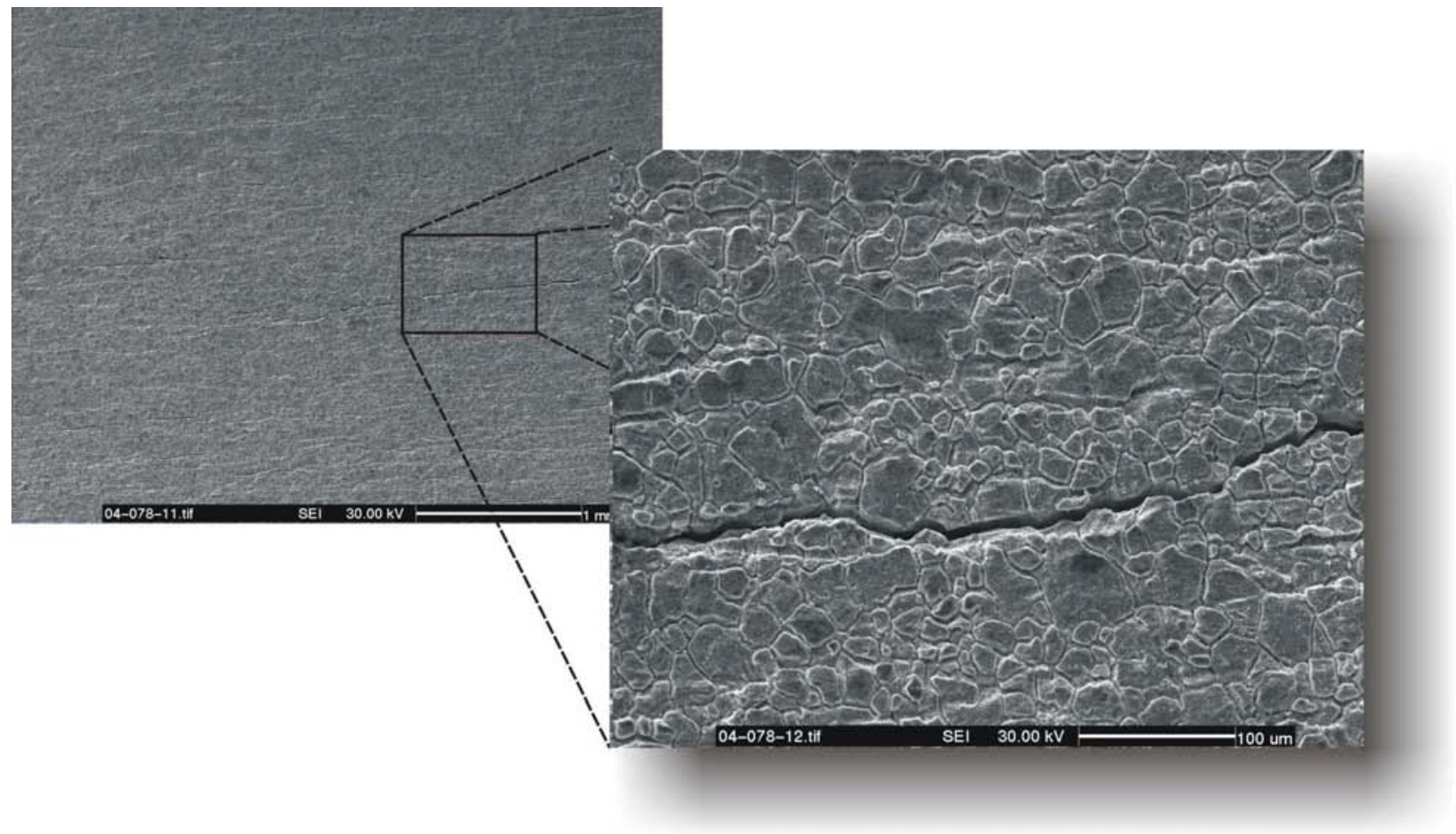

Figure 6-18

Internal surface of intrados showing axial cracking along the texture provided by the pickling attack. 


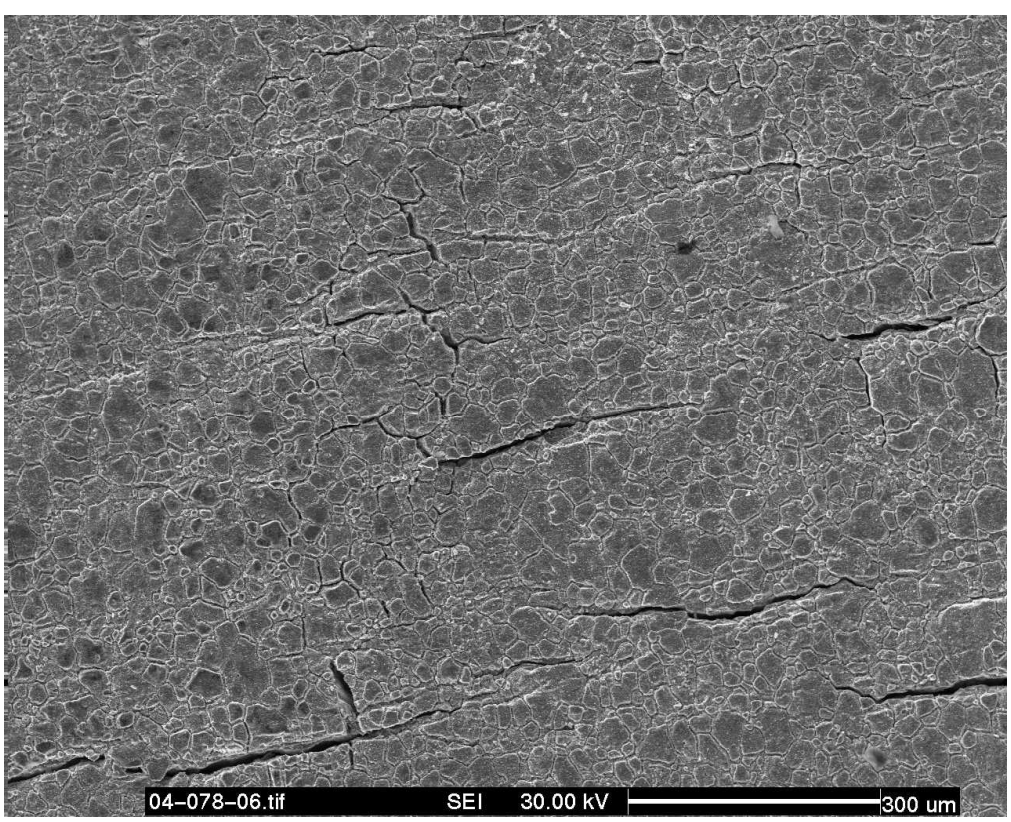

Figure 6-19

SEM of internal intrados surface also showing circumferential cracking to a certain degree.

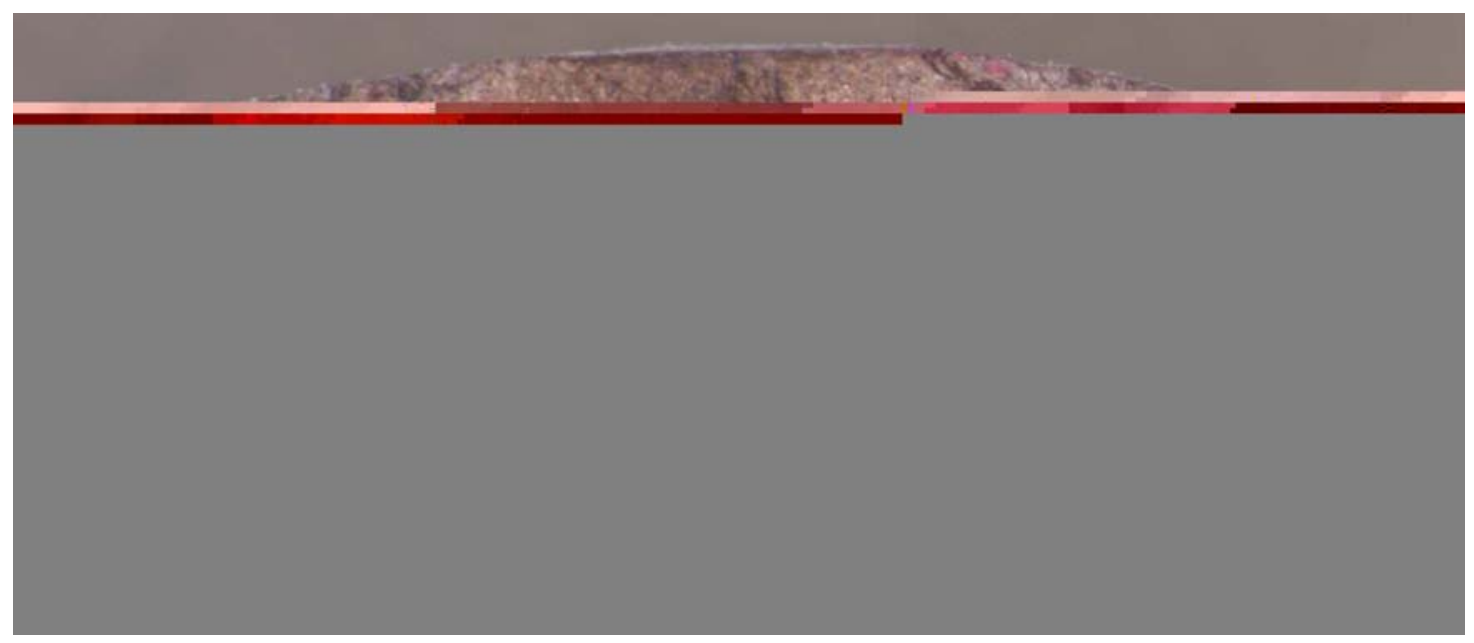

Figure 6-20

Broken open circumferential crack used for fractography. 


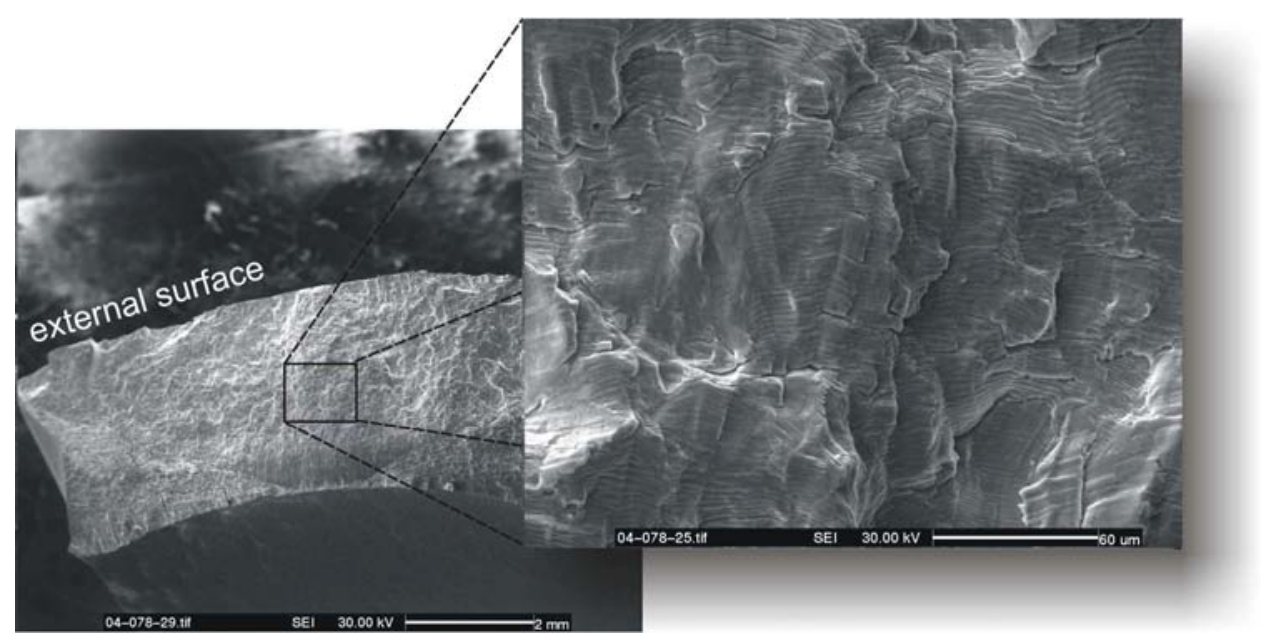

Figure 6-21

Typical view of circumferential mid fracture area; the striations clearly indicate step-wise crack progression typical for mechanical fatigue.

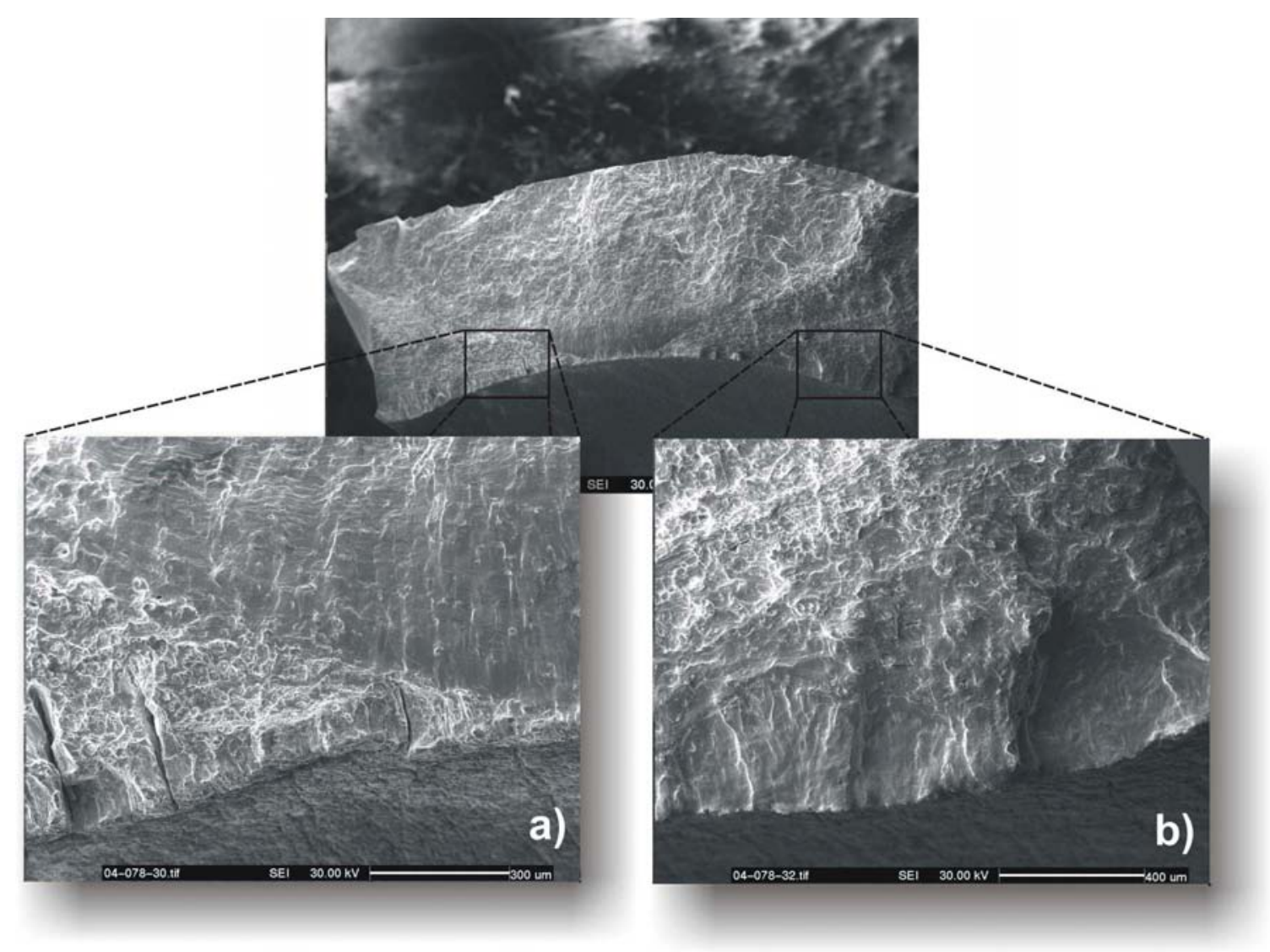

Figure 6-22

Typical fracture appearance found on the internal surface of the intrados; a) axial cracking initiating from the internal surface; b) circumferential cracking initiating from the internal surface. 


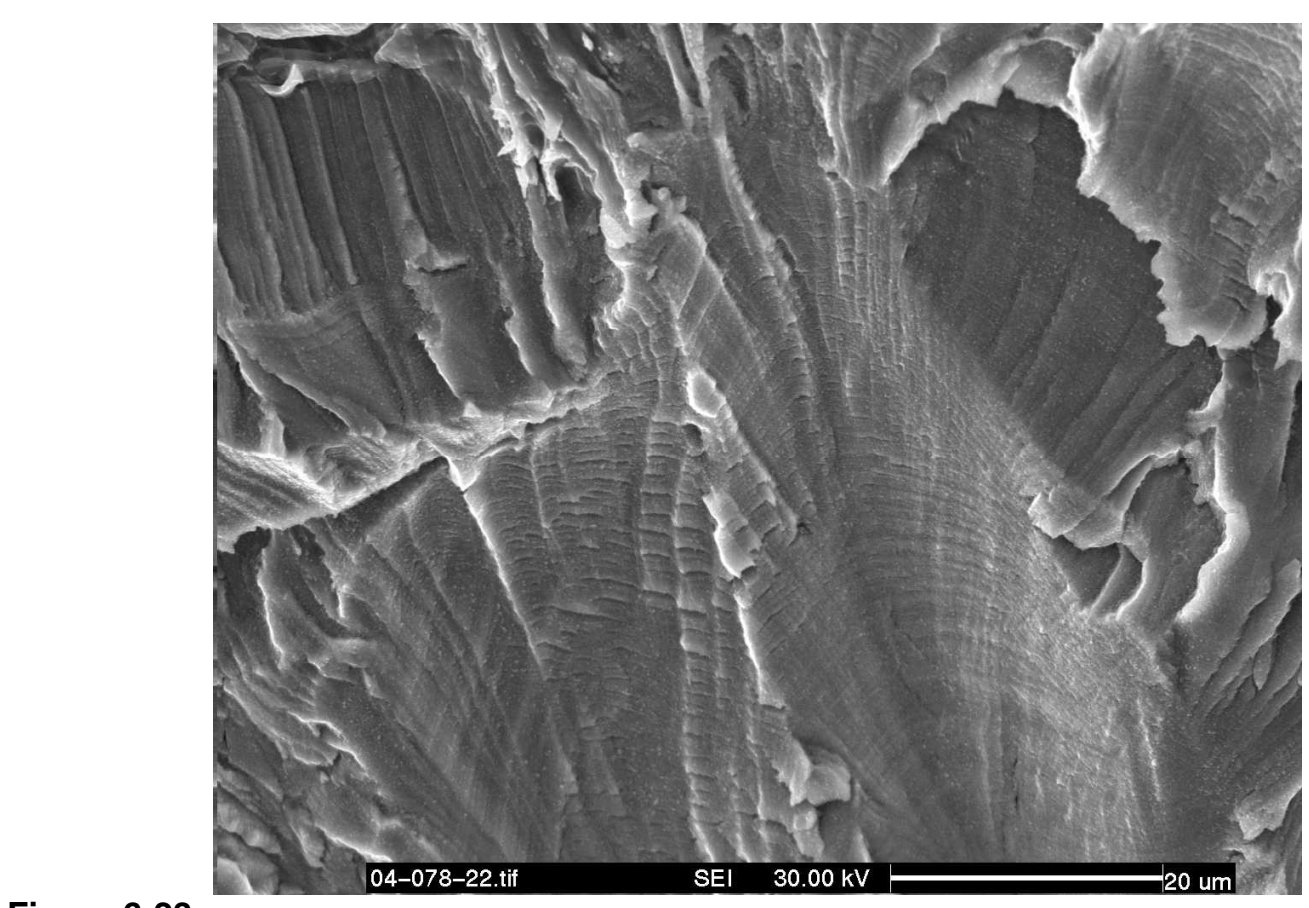

Figure 6-23

Typical crack morphology found on axial cracks that had initiated on internal surface.

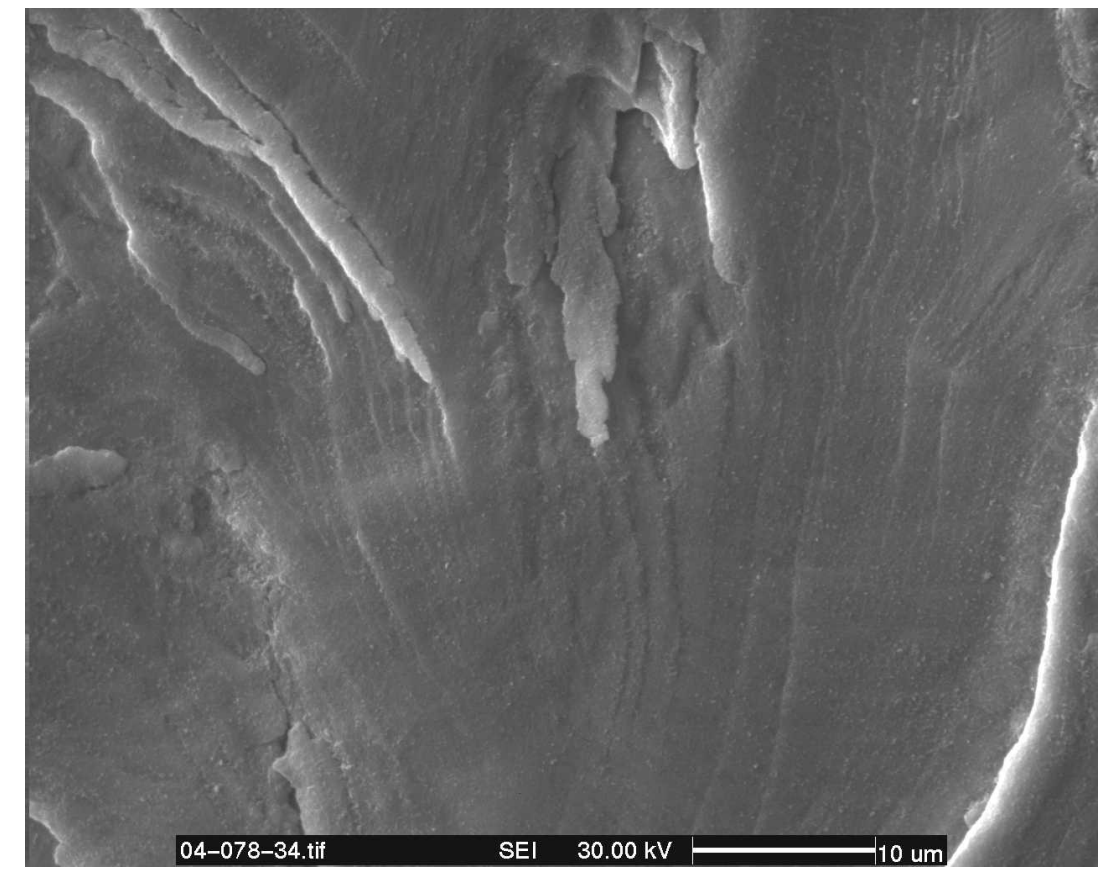

Figure 6-24

Typical crack morphology found on circumferential cracks that had initiated on internal surface. 


\section{Metallography}

The selected locations S1 to S4 (see Figure 6-25) were extracted from the U-bend for metallurgical analysis. The specimens were mounted into bakelite and polished to a $1 \mu \mathrm{m}$ surface finish and etched with appropriate agents. The examination was performed with a metallurgical microscope. All examined specimens appeared to be have sound microstructures, since they exhibited features typical for austenitic stainless steels with no anomalies to be found. The indications from visual and dye penetrant inspection were confirmed and all corresponding locations exhibited cracking.

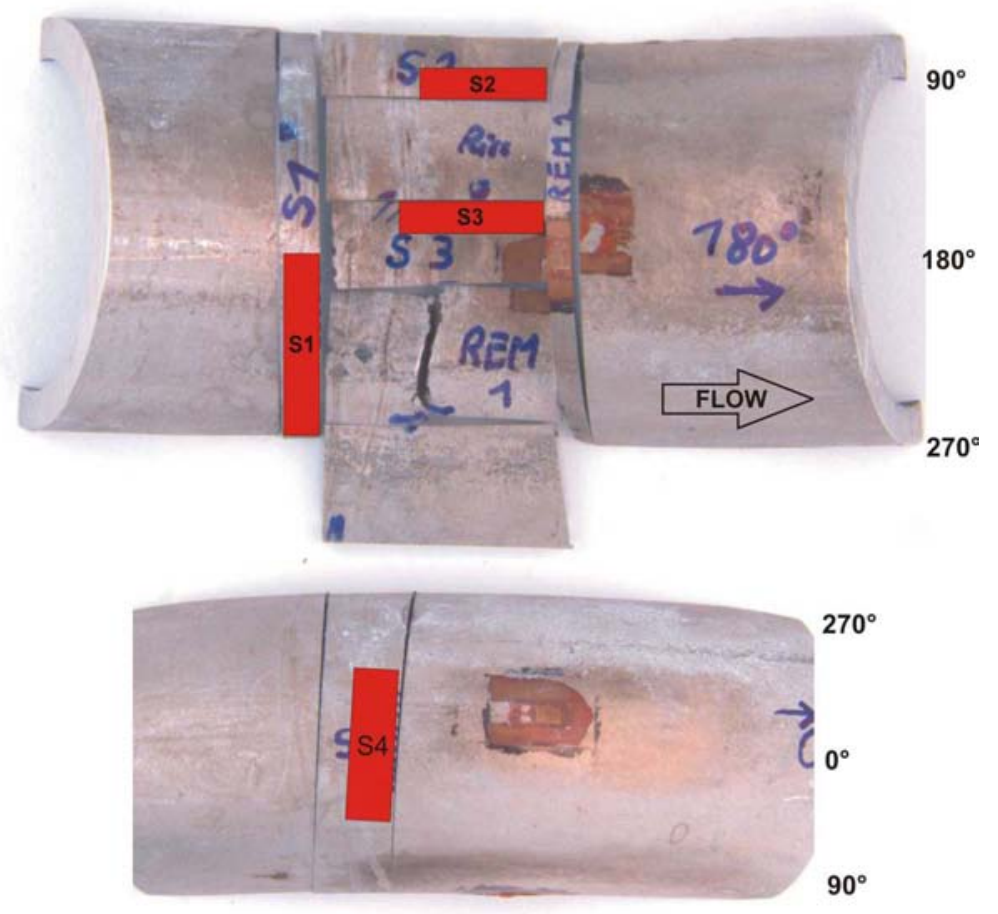

Figure 6-25

Specimen removal for metallographic examination; the red squares numbered from $\mathrm{S} 1$ to S4 indicate the locations of specimen extraction.

The external $180^{\circ}$ intrados position exhibited circumferential cracking, propagating in a transgranular manner from the external to the internal surface (see Figure 6-26). At this particular location, the crack depth was determined to be approximately $100 \mu \mathrm{m}$ (about $3 \%$ of the nominal wall thickness). The internal $180^{\circ}$ intrados position also exhibited circumferential cracking as displayed in Figure 6-27. There the maximum observed crack depth was approximately $250 \mu \mathrm{m}$ (approx. $7 \%$ of the nominal wall thickness).

The $270^{\circ}$ position exhibited slightly branched transgranular axial cracking that progressed from the internal towards the external surface as shown in Figure 6-28. The crack appearance suggested an environmental effect on the failure mechanism, confirming the results from SEM 
examination. This cross-section showed a maximum crack depth of approximately $400 \mu \mathrm{m}$ representing about $12 \%$ of the nominal wall thickness.

The $110^{\circ}$ position exhibited circumferential cracking on both the external and internal surface as shown in Figure 6-29 and Figure 6-30. Again the environmentally assisted cracks found at the internal surface revealed evidence of crack initiation at attacked grain boundaries.

The $0^{\circ}$ extrados position revealed axial, transgranular cracking propagating from the internal towards the external surface as shown in Figure 6-31. The crack appearance also suggested an environmental effect on the propagation, with initiation predominantly occurring at attacked grain boundaries. The approximate crack depth was determined to be $200 \mu \mathrm{m}$, representing about $6 \%$ of the nominal wall thickness.
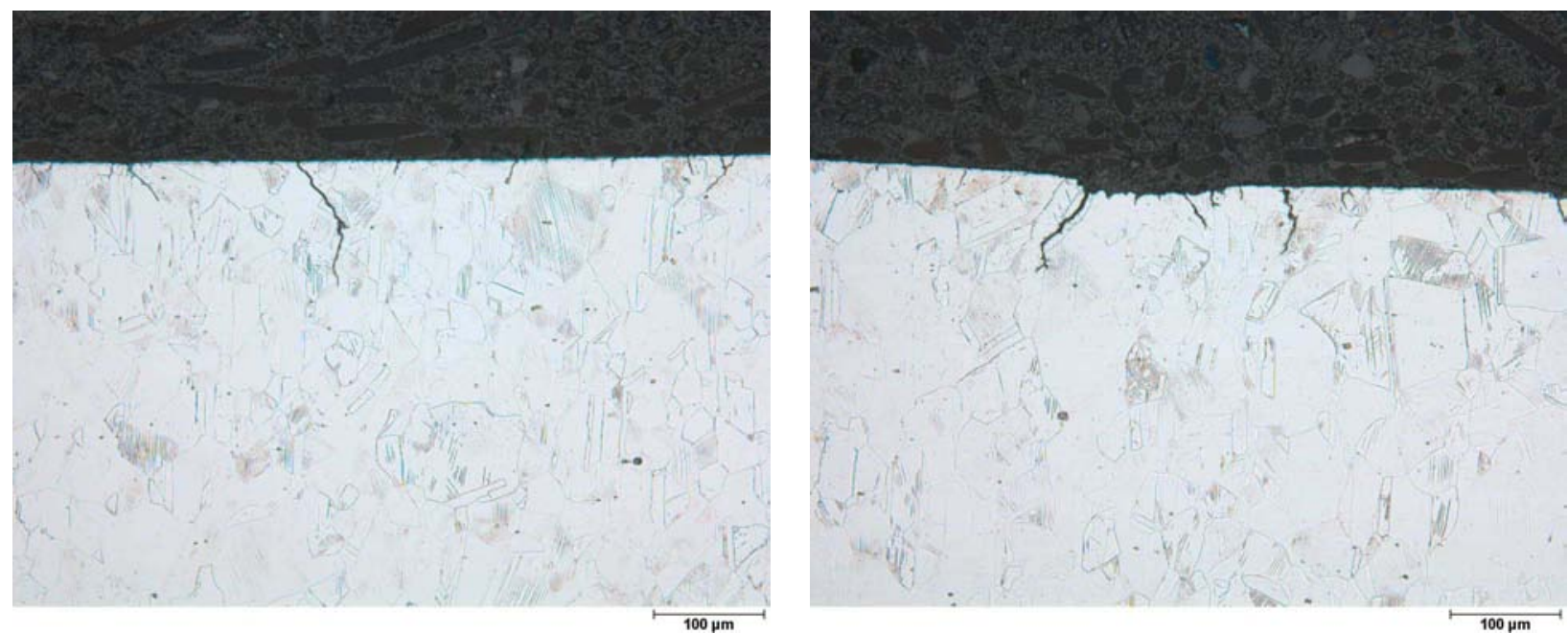

Figure 6-26

Typical views of cross section of the external $180^{\circ}$ intrados position (Specimen S3); transgranular, circumferential cracks propagating from the external towards the internal surface. 

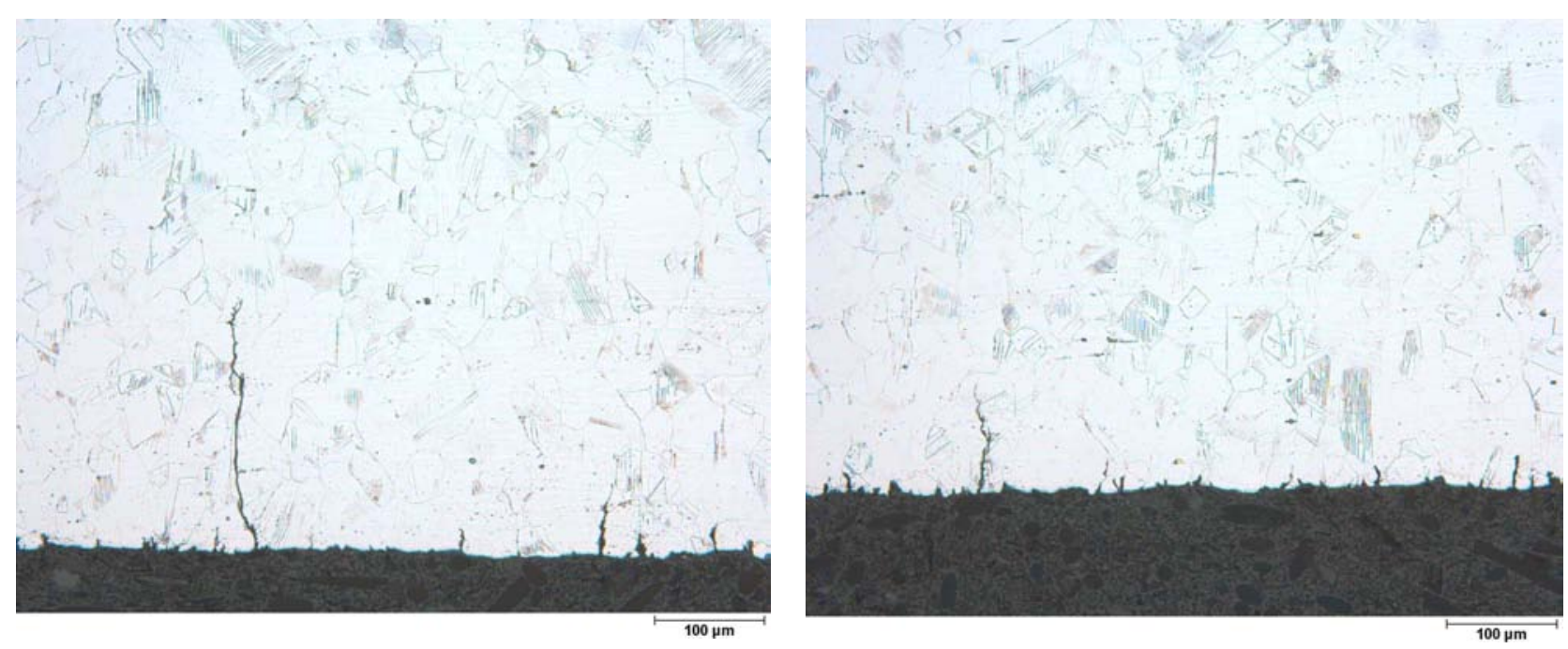

Figure 6-27

Typical views of cross section of the internal $180^{\circ}$ intrados position (Specimen S3); transgranular, circumferential cracks propagating from the internal towards the external surface.
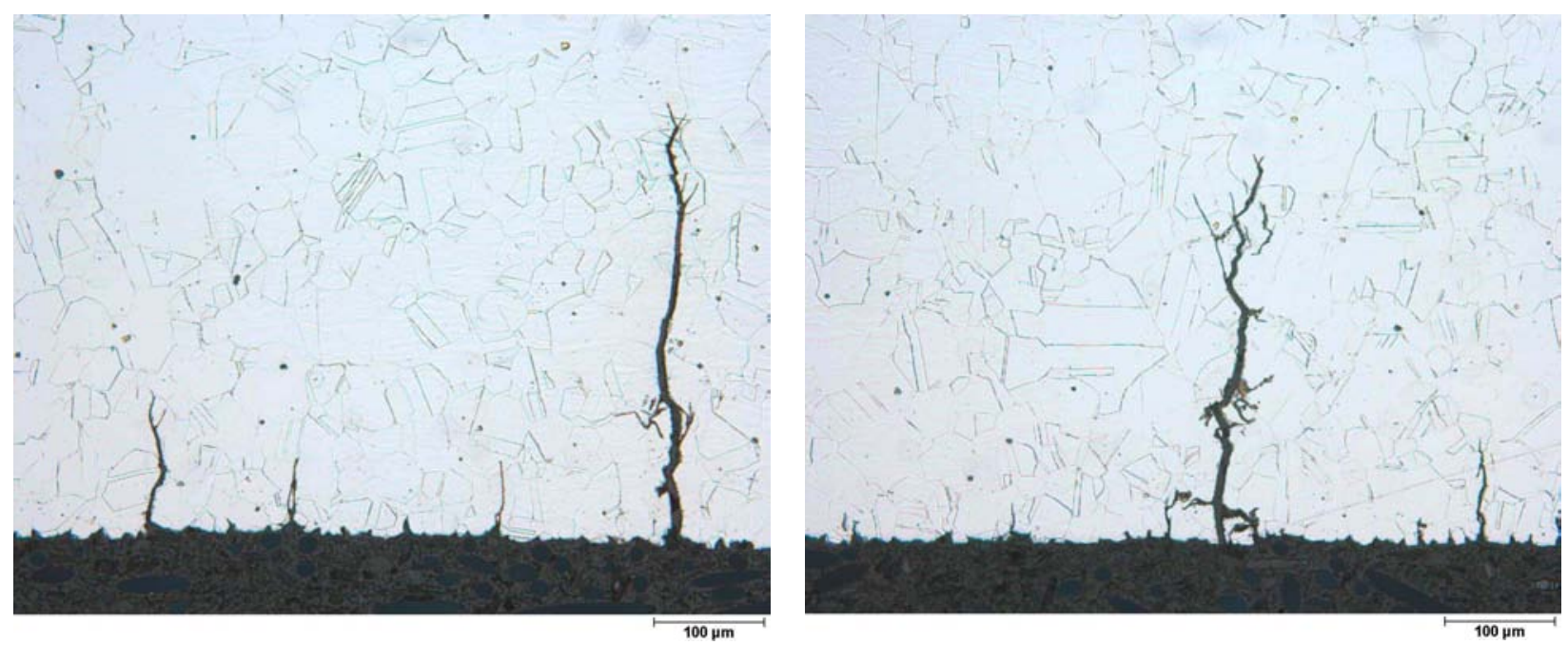

Figure 6-28

Typical views of cross section of the internal $270^{\circ}$ position (Specimen S1); environmental, axial cracks propagating from the internal towards the external surface in a transgranular manner; crack initiation appeared to have occurred at attacked grain boundaries from pickling treatment. 

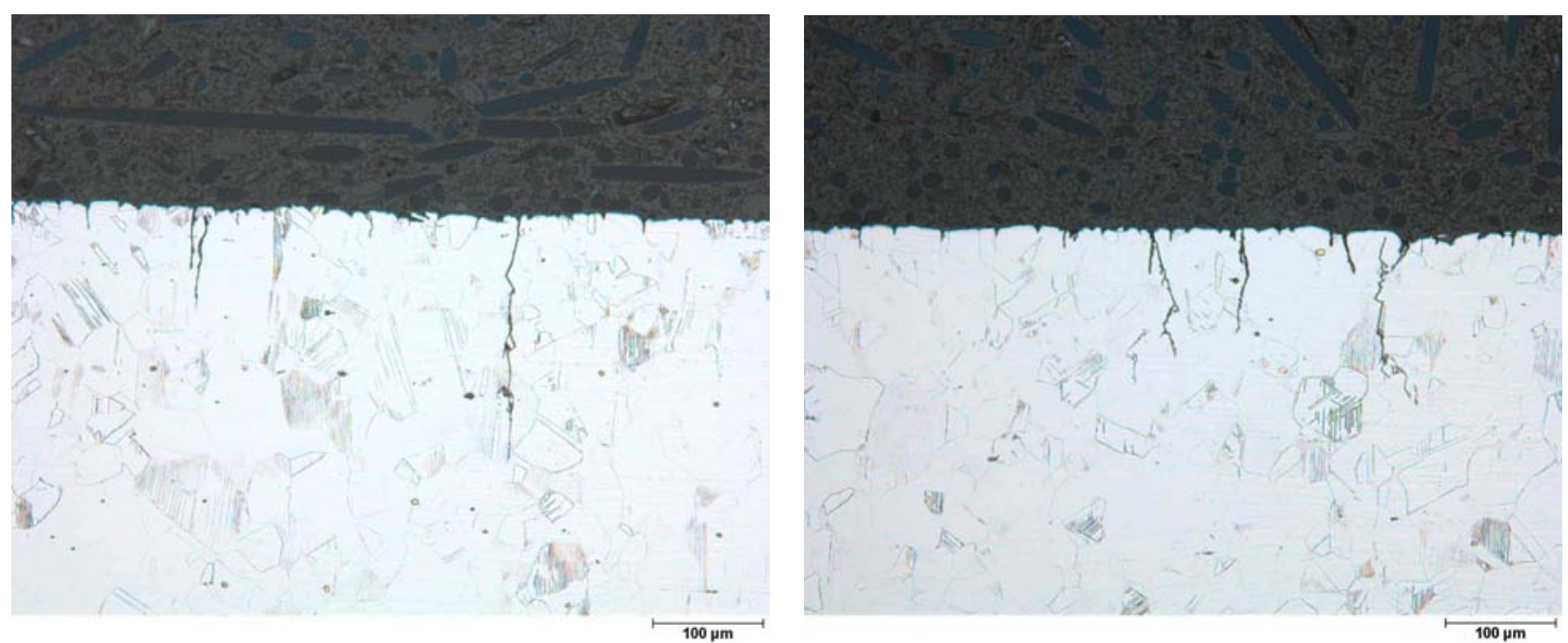

Figure 6-29

Typical views of external $110^{\circ}$ position (Specimen S2) showing transgranular crack propagation from the external towards the internal surface; crack initiation appeared to have occurred at attacked grain boundaries from pickling treatment.
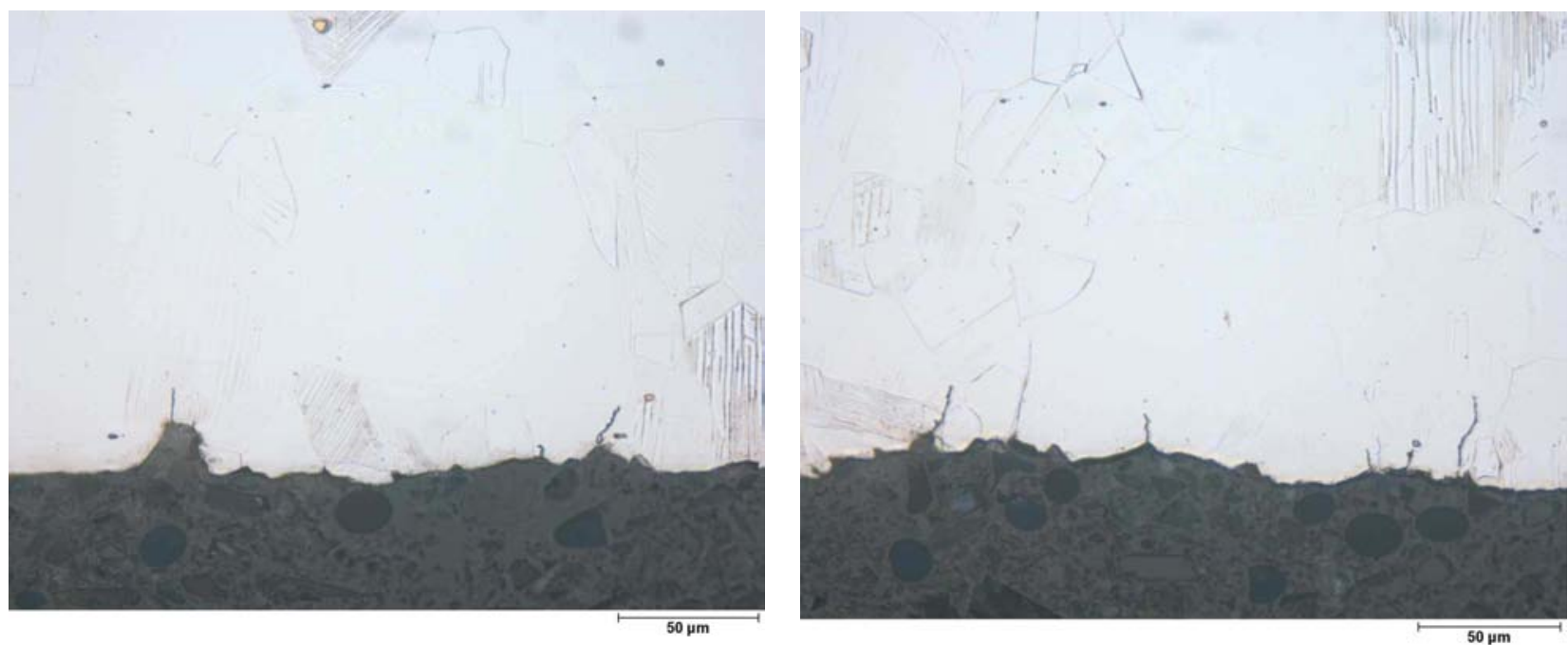

Figure 6-30

Typical views of cross section of the internal $110^{\circ}$ position (Specimen S2); environmental, circumferential cracks propagating from the internal towards the external surface in a transgranular manner; crack initiation appeared to have occurred at attacked grain boundaries from pickling treatment. 

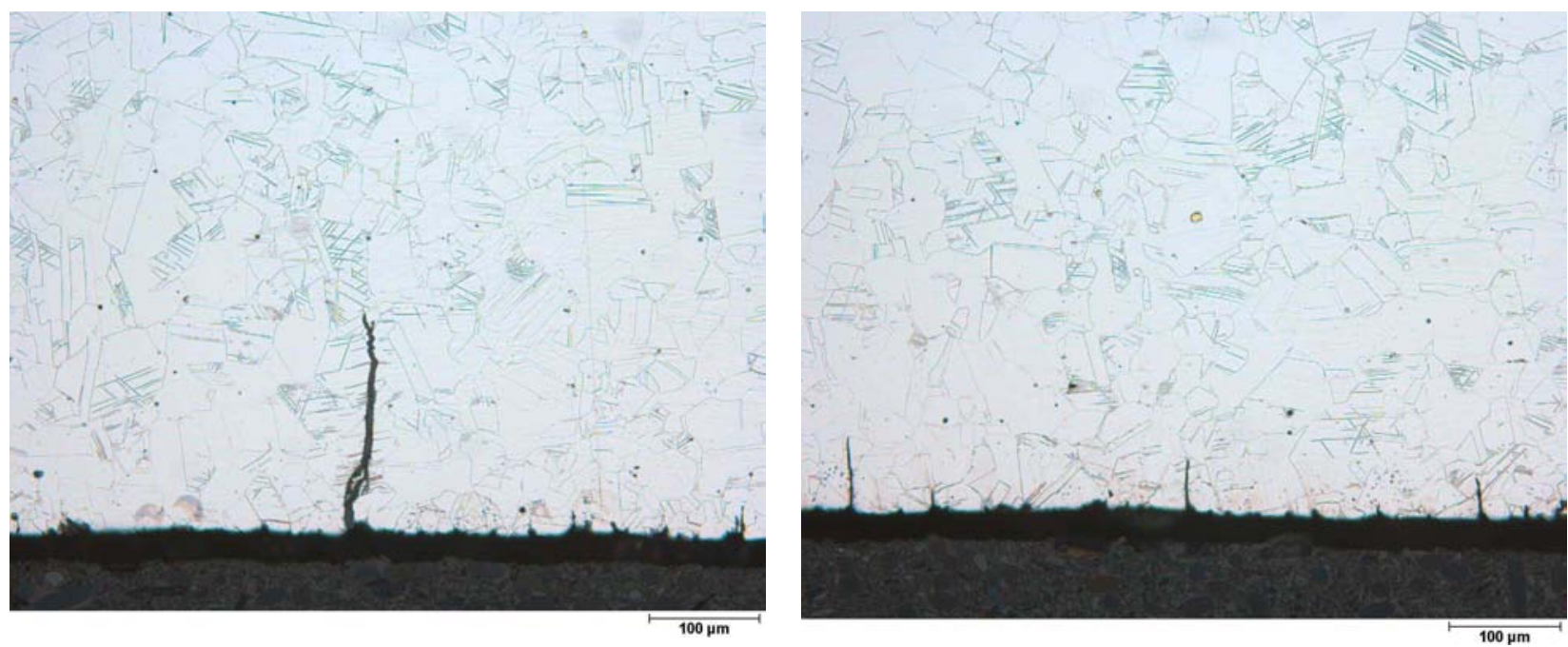

Figure 6-31

Typical views of the internal $0^{\circ}$ extrados position (Specimen S4); environmental, axial cracks propagating from the internal towards the external surface in a transgranular manner; crack initiation appeared to have occurred at attacked grain boundaries from pickling treatment.

\section{Summary of Results}

The following results can be summarized from environmental test $2 \mathrm{~b}$ :

- Water chemistry in the range of specified values; ECP $-550 \mathrm{mV}_{\mathrm{H}, \mathrm{T}}$, redox potential $-500 \mathrm{mV}_{\mathrm{H}, \mathrm{T}}$ for high flow rate $(2.1 \mathrm{~m} / \mathrm{s})$.

- Total number of 1238 cycles resulting in circumferential through-wall crack at intrados, starting within a notch at the external surface.

- Array of small circumferential mechanical cracks at the external surface of intrados; small amount of circumferential cracking at internal surface of intrados.

- Multiple axial cracking found on internal intrados surface.

- Environmentally assisted axial cracking at extrados, $90^{\circ}$ and $270^{\circ}$ positions from internal surface.

- All cracks found were transgranular showing the typical features of fatigue.

- No microstructural effects were observed.

Figure 6-32 graphically summarizes the extent of cracking and crack locations. 


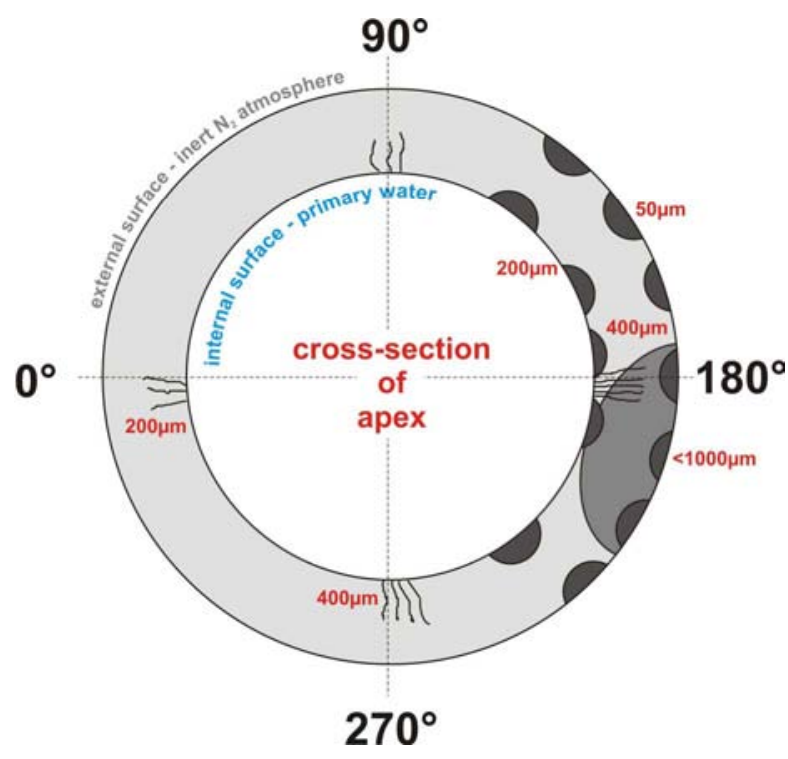

Figure 6-32

Schematic summary of crack locations, orientation and approximate crack depths (if available); schematic provides a cross-sectional view of the apex looking down-stream; please note that schematic is not to scale.

\section{Conclusions from Test $\mathbf{2 b}$}

In a similar manner to environmental test $2 \mathrm{a}$, this test $2 \mathrm{~b}$ at high flow rates clearly showed the effect of primary water on the fatigue behavior of the U-bend under cyclic load, since multiple axial cracking at the internal surface of the apex was observed and characterized. All axial fracture surfaces exhibited evidence of mechanical and environmental impact, typical for corrosion fatigue.

However, the primary failure in the form of a circumferential through-wall defect was again solely driven by cyclic mechanical loading, this remaining the dominant life time determining factor. Furthermore, this primary fracture initiated in a stress-riser (notch) in the form of a pronounced circumferential scratch/groove on the external surface, negatively affecting the bend's fatigue life. Therefore, a beneficial effect of high flow rates could not have been observed anyway. The total number of 1238 cycles in this test was even lower than the total number of 1520 achieved in environmental test 2a under low flow conditions.

Independent from the location all cracking initiated at surface artifacts along grain boundaries resulting from the pickling attack during manufacturing. The internal surfaces of all bends are relatively similar. As expected after accomplishing test $2 \mathrm{a}$, the impact of the internal surface quality on the bend's fatigue life is very similar within the same domain of strain rate and strain amplitude. 



\section{SUMMARY OF TEST RESULTS WITH $\pm 0.6 \%$ STRAIN AMPLITUDE}

For BLT 2 and the test series 2, all performed with a strain amplitude of $\pm 0.6 \%$ strain at a rate of $1 \times 10^{-4} \mathrm{~s}^{-1}$, the following statements can be made.

Mechanical fatigue dominates failure of bend under cyclic loading:

- Circumferential through-wall cracks at intrados initiating from the external surface

- Cycles to failure in the range of 1200 to 1700 (with apparent notch effects at OD surface probably more important than interaction with environmentally assisted cracks from ID surface)

- Many additional, circumferential cracks at the external surface of intrados

However, simulated primary water also has a pronounced effect:

- Internal surface shows multiple, deep, axial cracking at $0^{\circ}, 90^{\circ}, 180^{\circ}$ and $270^{\circ}$ positions

- ID circumferential cracking of limited depth also found in the intrados region

- All cracks still transgranular, but metallographic \& fractographic evidence for environmental effects on both crack initiation and growth from ID surface

No real effect of flow rate discernible, but comparison possibilities are limited

Figure 7-1 to Figure 7-3 graphically compare and summarize BLT 2 and test series 2 of Phase B. 


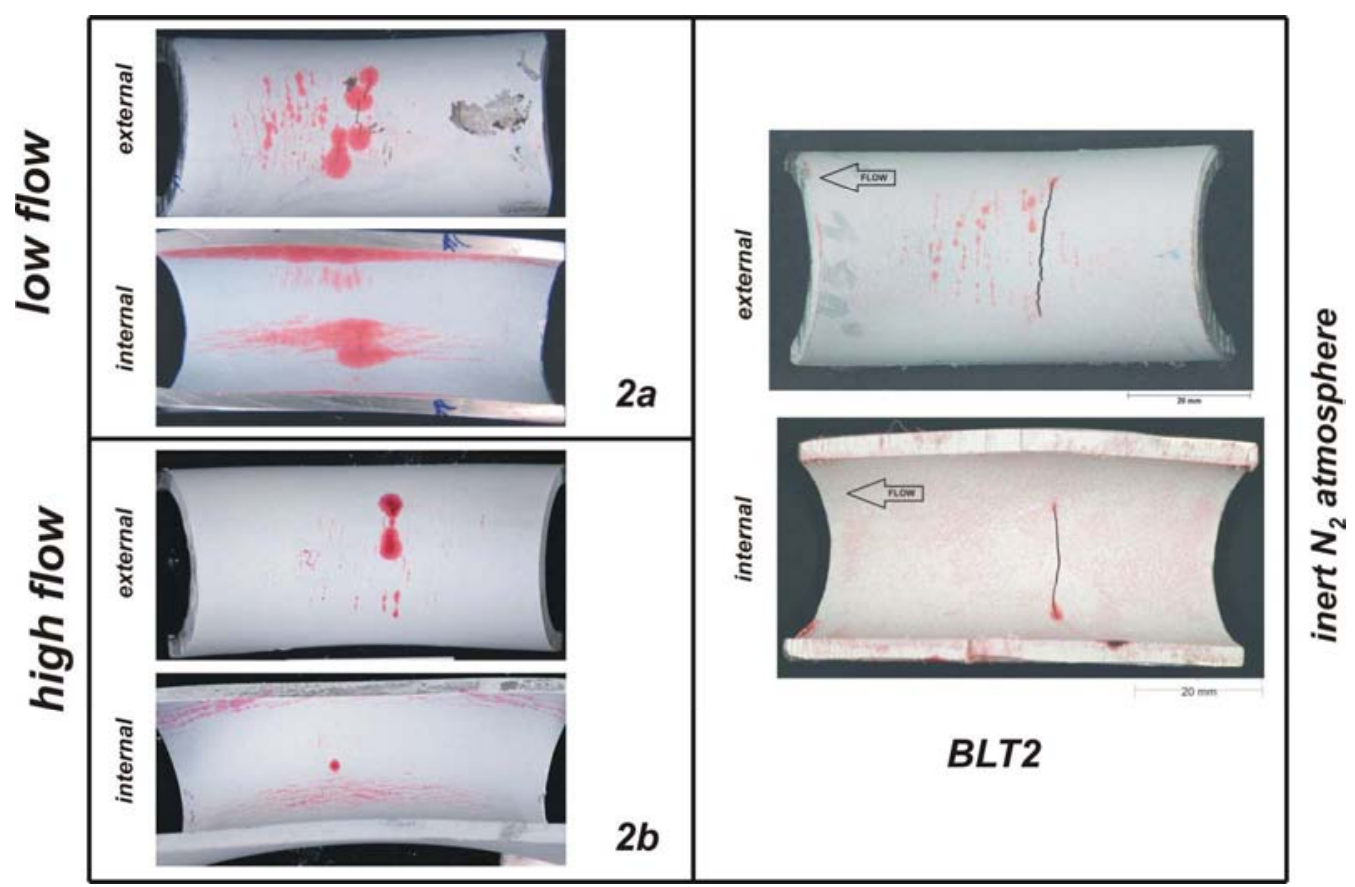

Figure 7-1

Summary of DPI results.

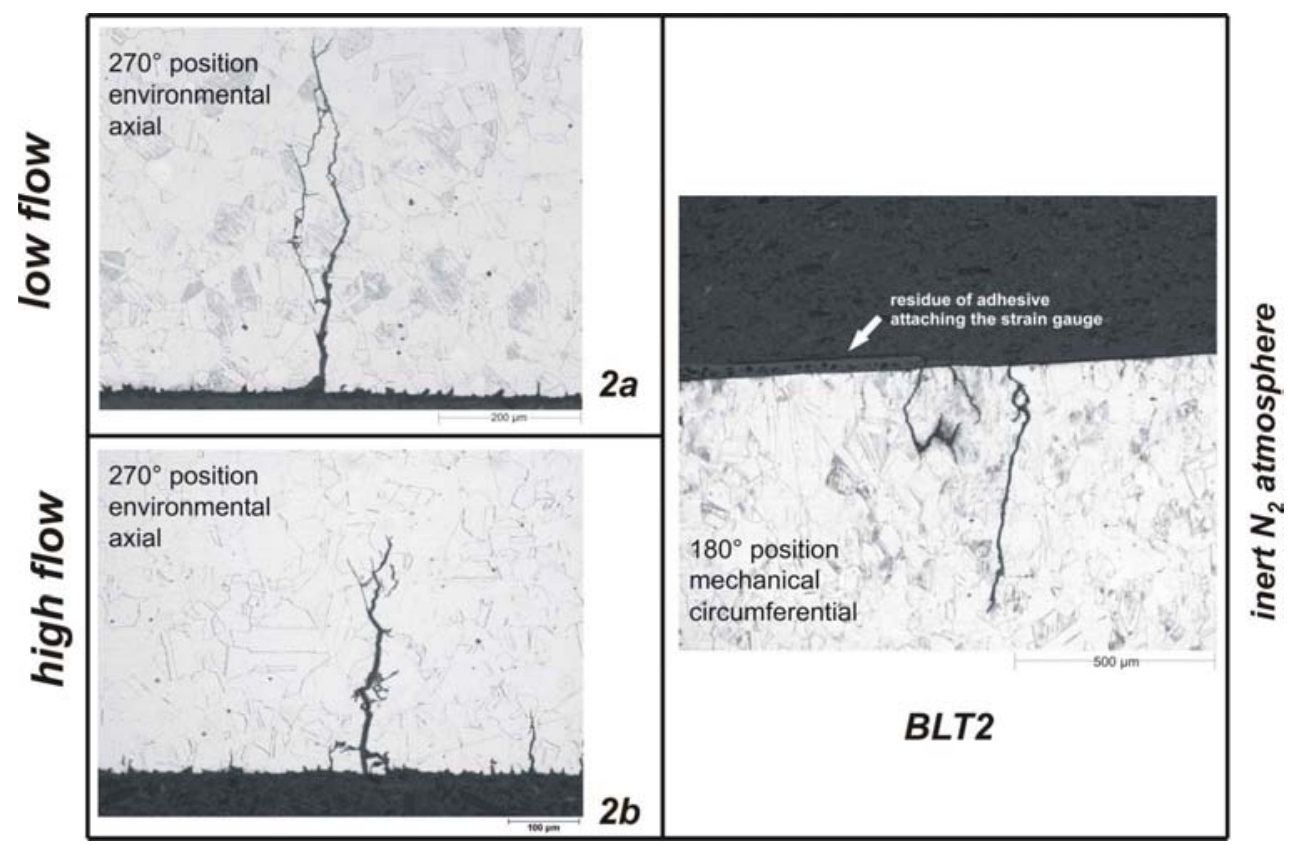

Figure 7-2

Summary of metallographic examination. 


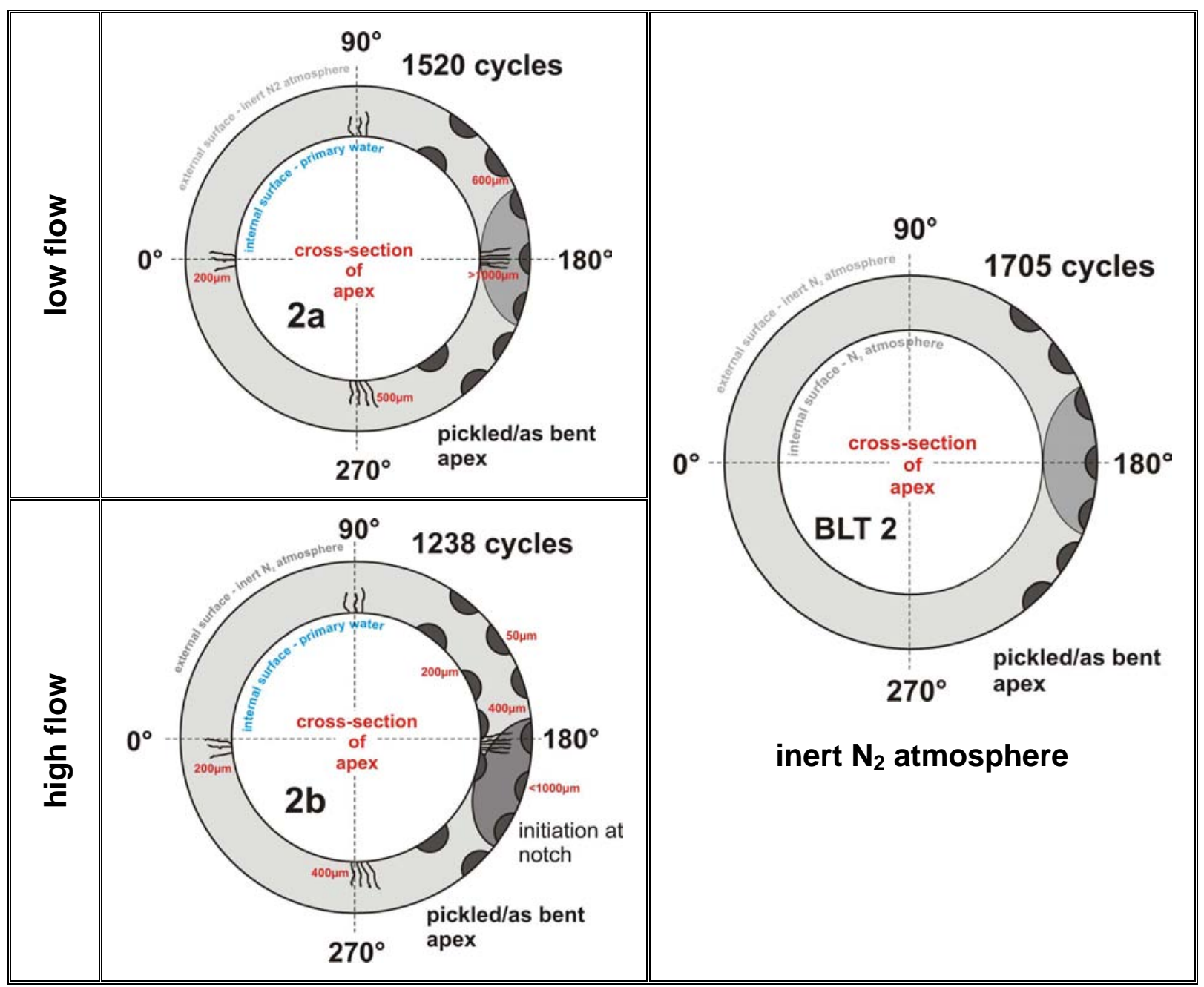

Figure 7-3

Summary of crack locations, depths and achieved cycles. 



\section{8}

\section{ENVIRONMENTAL TEST 4A}

\section{Test Set-Up and Approach}

After having completed Phase B with the first two environmental tests, test series 4 of Phase C was performed. The primary difference to Phase B is that the strain amplitude here was $0.4 \%$ rather than $0.6 \%$. The remaining test parameters are similar. According to the text matrix, environmental test 4a was characterized as a low flow rate test in conjunction with the following U-bend instrumentation and test parameters:

- $\quad$ pre-conditioning of the bend internal surface by lengthy exposure to simulated primary water

- instrumented U-bend with three bonded HT strain gauges at the $0^{\circ}, 90^{\circ}$ and $180^{\circ}$ position

- $\quad$ strain amplitude of $\pm 0.4 \%$ (total strain range of $0.8 \%$ )

- $\quad$ strain rate of $1 \times 10^{-4} \mathrm{~s}^{-1}$

- $\quad$ testing temperature $\mathrm{T}=240^{\circ} \mathrm{C}$, pressure $\mathrm{p}=50 \mathrm{bar}$

- $\quad \mathrm{HT}$ water chemistry comprising 1200 ppm B as $\mathrm{H}_{3} \mathrm{BO}_{3}+2$ ppm Li as $\mathrm{LiOH}$

- $\quad$ oxygen content adjusted to $<<10 \mathrm{ppb}$, no $\mathrm{H}_{2}$ injection

- the impurity level adjusted to $\mathrm{Cl}^{-}+\mathrm{F}^{-}+\mathrm{SO}_{4}{ }^{2-}<100 \mathrm{ppb}$

- water sampling and chemical analysis of $\mathrm{B}, \mathrm{Li}, \mathrm{Cl}^{-}, \mathrm{F}^{-}, \mathrm{SO}_{4}{ }^{2-}, \mathrm{pH}$ during start-up and before shut down

- flow rate adjusted to $<10 \mathrm{l} / \mathrm{h}$ (corresponds to $\approx 0.005 \mathrm{~m} / \mathrm{s}$ for an ID of $26.5 \mathrm{~mm}$ ) 


\section{Results}

\section{Water Chemistry}

The mechanical loading of the U-bend during testing was not commenced until the specified requirements with respect to test temperature, water chemistry/purity and electrochemical corrosion/redox potentials were met. Water sampling before start-up and loading assured this as displayed in Table 8-1.

\begin{tabular}{|c|c|c|c|c|c|c|c||}
\hline $\begin{array}{c}\text { water } \\
\text { sampling }\end{array}$ & $\begin{array}{c}\text { B } \\
\mathbf{p p m}\end{array}$ & $\begin{array}{c}\mathbf{L i} \\
\mathbf{p p m}\end{array}$ & $\mathbf{p H}$ & $\begin{array}{c}\text { chloride } \\
\mathbf{p p b}\end{array}$ & $\begin{array}{c}\text { sulfate } \\
\mathbf{p p b}\end{array}$ & $\begin{array}{c}\text { fluoride } \\
\mathbf{p p b}\end{array}$ & remarks \\
\hline $\begin{array}{c}\text { before loading test } \\
\text { temperature was } \\
\text { reached }\end{array}$ & 1261 & 2.13 & - & 20 & $<10$ & 20 & cond. outlet: $20.1 \mu \mathrm{S} / \mathrm{cm}$ \\
\hline during testing & 1221 & 2.14 & 6.5 & 13 & $<10$ & 16 & $\begin{array}{c}<\text { cond.(out) }=22.1 \mu \mathrm{S} / \mathrm{cm} \\
\mathrm{O}_{2} \text { (out) } \approx 3 \mathrm{ppb}\end{array}$ \\
\hline before shut down & 1214 & 2.18 & - & 20 & $<10$ & 32 & $\begin{array}{c}\text { iond.(out) }=22.2 \mu \mathrm{S} / \mathrm{cm} \\
\mathrm{O}_{2} \text { (out) } \approx 2 \mathrm{ppb}\end{array}$ \\
\hline
\end{tabular}

Table 8-1

Results from water sampling during environmental Test $4 a$.

During testing, the water chemistry was monitored continuously with respect to test temperature, conductivity and electrochemical corrosion potential (ECP) and redox potential. Figure 8-1 and Figure 8-2 show the inlet and outlet conductivity, the test temperature as well as ECP and the redox potential for the entire duration of environmental test 4a. The ECP showed values of approximately $-575 \mathrm{mV}_{\mathrm{H}, \mathrm{T}}$ and the redox potential was measured at approximately $-525 \mathrm{mV}_{\mathrm{H}, \mathrm{T}}$. The target test temperature of $240{ }^{\circ} \mathrm{C}$ was held very stable for the entire test.

The disturbances within the water chemistry data presented in Figure 8-1 and Figure 8-2 are attributed to a system shut down caused by unusual noises emitted from the autoclave during early stages of testing. Since this anomaly also affected the mechanical data, more detailed explanations and remedial actions follow in the paragraph describing the mechanical data. 


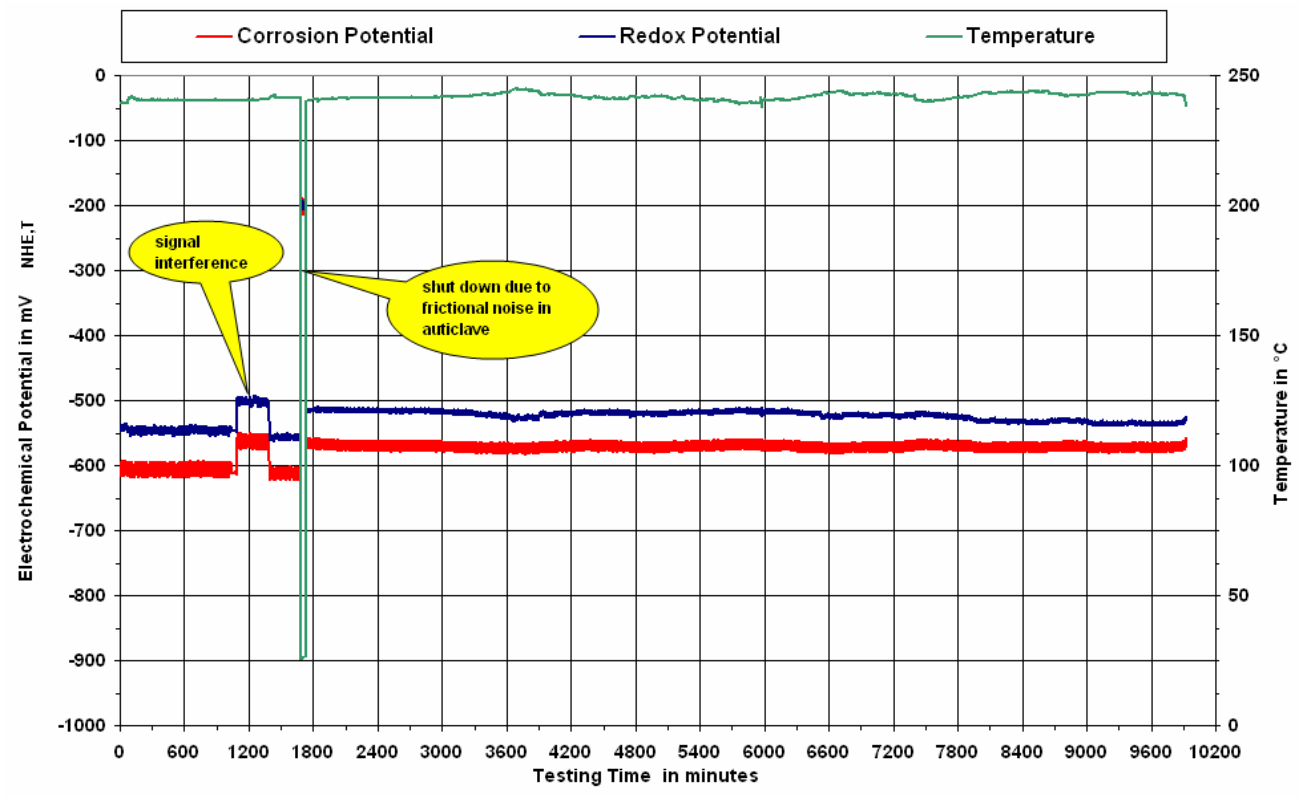

Figure 8-1

Temperature, electrochemical and redox potential vs. testing time.

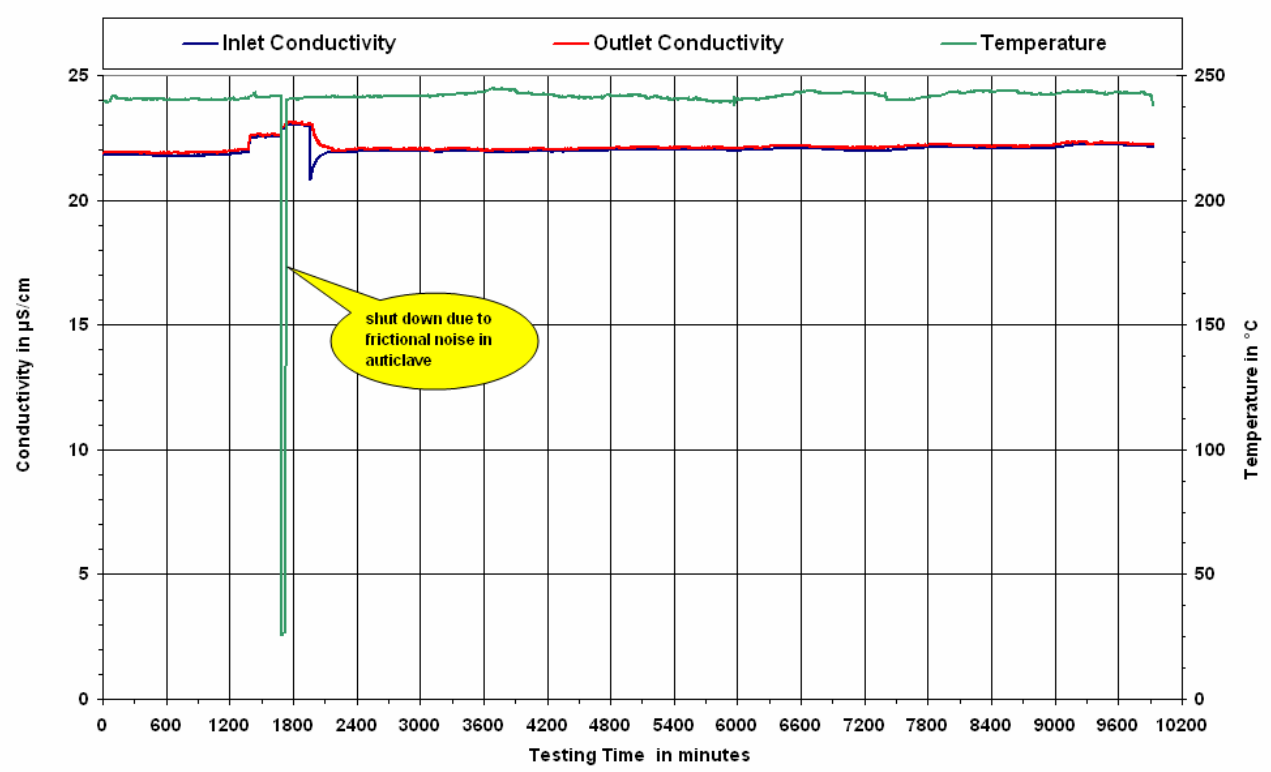

Figure 8-2

Conductivity and temperature vs. testing time. 


\section{Mechanical Data}

The basic test parameters used for mechanical loading of the U-bend are given in Table 8-2. Initially the bend was loaded with a triangular wave shape for the first 5 cycles to evaluate the Ubend response. For unknown reasons, the $0^{\circ}$ strain gauge stopped working shortly after starting the load sequence. The strain rate used for the first 5 cycles was $1 \times 10^{-5} \mathrm{x} \mathrm{s}^{-1}$. Cycles 6 to 10 were performed with a strain rate of $1 \times 10^{-4} \mathrm{x} \mathrm{s}^{-1}$. To this point the test was performed displacement controlled with strain triggered switch points at $\pm 0.4 \%$ strain amplitude. The load vs. displacement hysteresis for the first 10 cycles is displayed in Figure 8-9 and Figure 8-9 and indicated a fairly stable bend behavior. Cycle 10 was used to determine the displacements necessary for the remaining test, which was performed only under displacement control. Figure 8-3 and Figure 8-4 illustrate the mechanical data for cycles 1 to 5 and 6 to 10, respectively. The strain response for cycles 1 to 10 is provided in Figure 8-6.

The leading $180^{\circ}$ intrados strain gauge stopped working at cycle 340 as a result of the cyclic loading. The available strain data is shown in Figure 8-7. Generally, the bend showed a relatively stable behavior throughout the entire test, since the load response to the given displacements was uniform, as displayed in Figure 8-5. The load vs. displacement hysteresis for the entire test is displayed in Figure 8-10.

However, in the early stages of testing a groaning noise was noticed emitting from the autoclave. The noise constantly increased until it was decided to stop testing at cycle 452 (approximate testing time: 1686 minutes). The autoclave was opened and the test assembly inspected thoroughly. It was found that one of the flexible, steel mesh covered outlet hoses had been in contact with the inner autoclave wall. The bend itself had no signs of degradation related to the noise. After re-arranging the outlet hose the autoclave was closed again. After ensuring noise and trouble free operation it was decided, in mutual agreement with EPRI, to resume testing. A through-wall defect at cycle 3609 resulted in termination of testing.

\begin{tabular}{|c|c|c|c|c|c||}
\hline cycle & $\begin{array}{c}\text { wave } \\
\text { shape }\end{array}$ & $\begin{array}{c}\text { control } \\
\text { channel }\end{array}$ & strain rate & switch point & $\begin{array}{c}\text { switch off } \\
\text { criteria }\end{array}$ \\
\hline \hline $\mathbf{1}-\mathbf{5}$ & triangular & $\begin{array}{c}\text { displacement } \\
\text { strain triggered } \\
\text { switching point }\end{array}$ & $1 \times 10^{-5} \mathrm{~s}^{-1}$ & $\begin{array}{c}+0.4 \% \\
-0.4 \%\end{array}$ & - \\
\hline $\mathbf{5}-\mathbf{1 0}$ & triangular & $\begin{array}{c}\text { displacement } \\
\text { strain triggered } \\
\text { switching point }\end{array}$ & $1 \times 10^{-4} \mathrm{~s}^{-1}$ & $\begin{array}{l}+0.4 \% \\
-0.4 \%\end{array}$ & - \\
\hline $\mathbf{1 0 - 4 5 2 ^ { * }}$ & triangular & displacement & $1 \times 10^{-4} \mathrm{~s}^{-1}$ & $\begin{array}{l}+4.82 \mathrm{~mm} \\
-5.25 \mathrm{~mm}\end{array}$ & - \\
\hline $\mathbf{4 5 2} \mathbf{- 3 6 0 9}$ & triangular & displacement & $1 \times 10^{-4} \mathrm{~s}^{-1}$ & $\begin{array}{l}+4.82 \mathrm{~mm} \\
-5.25 \mathrm{~mm}\end{array}$ & failure \\
\hline \hline
\end{tabular}

*) long term shut down (approximately 3 days) at cycle 452 due to frictional noise in autoclave.

Table 8-2

Basic test parameters of mechanical loading during environmental Test $4 a$. 


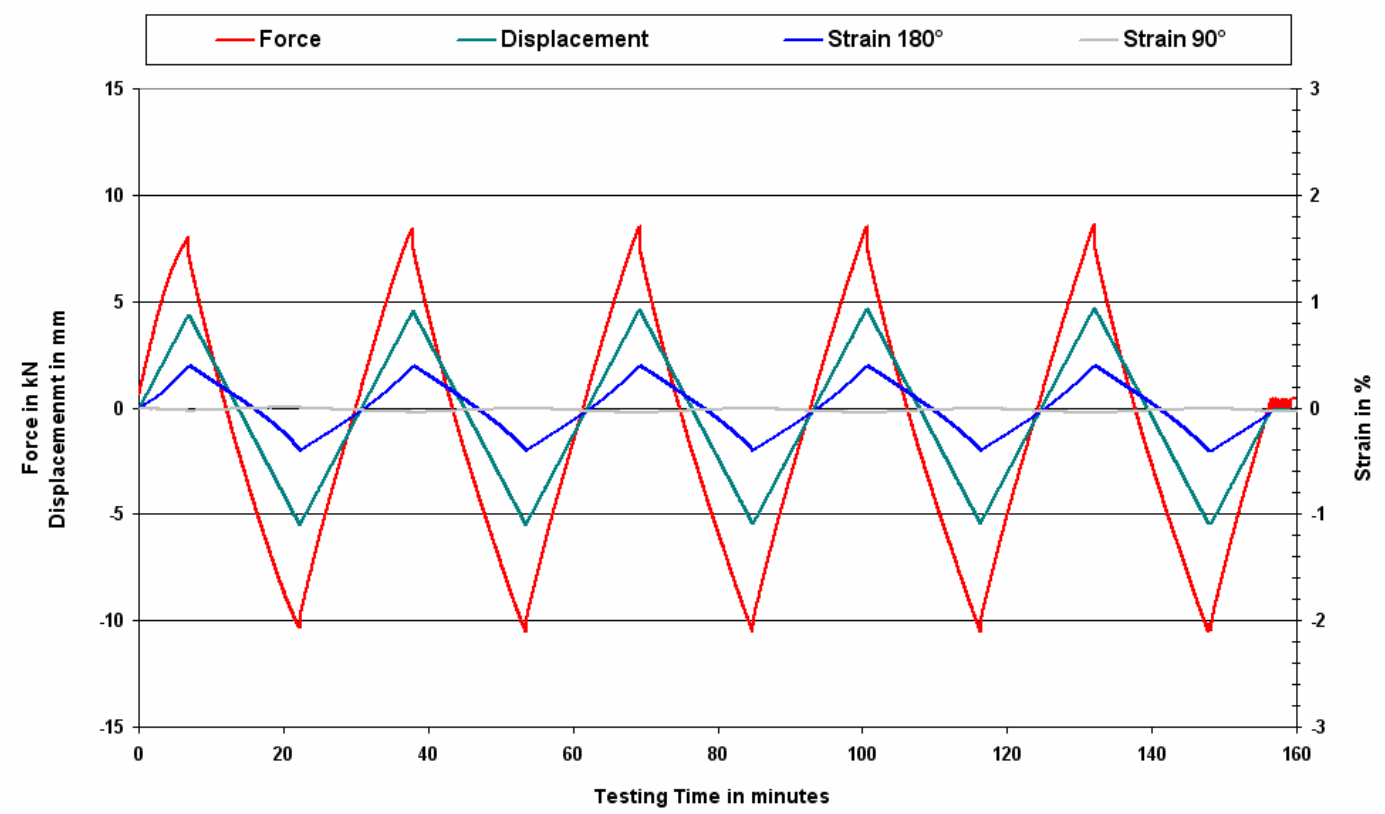

Figure 8-3

Mechanical data for Cycles 1 to 5 .

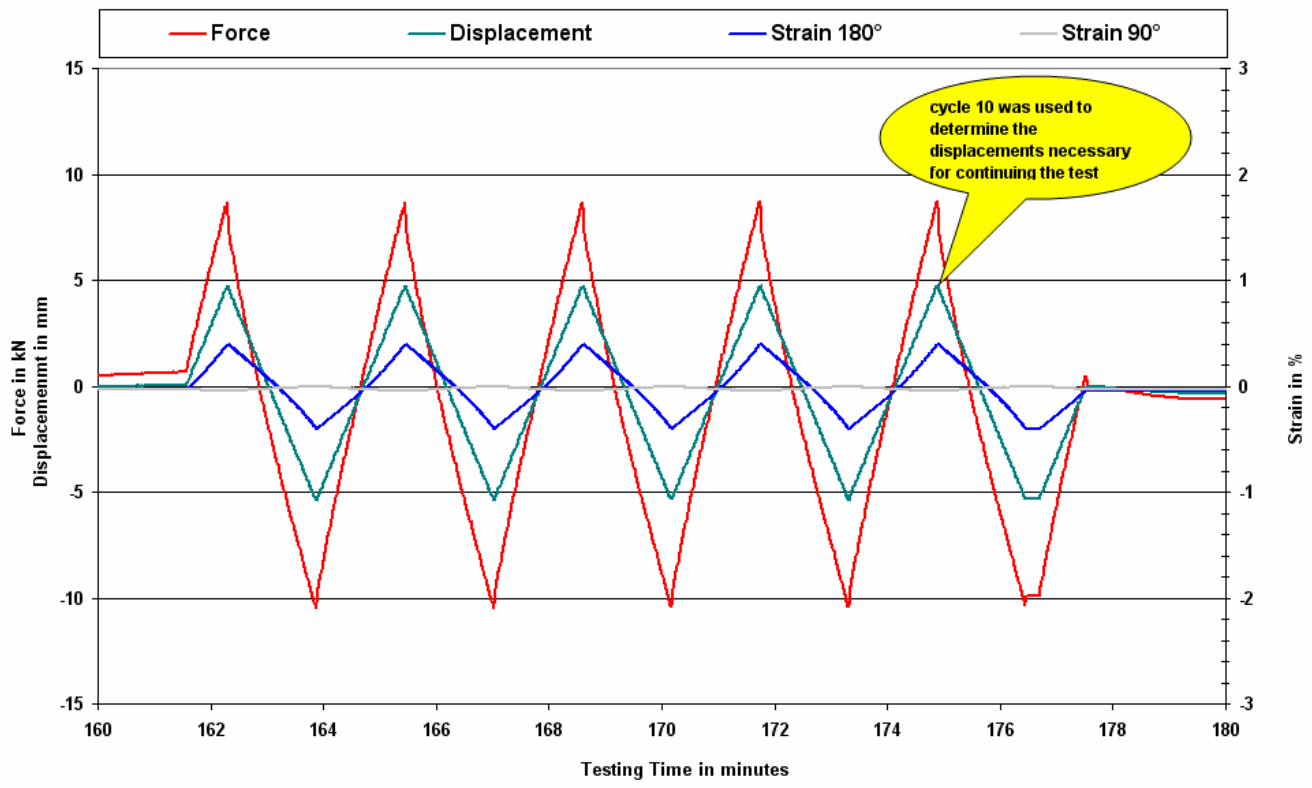

Figure 8-4

Mechanical data for Cycles 6 to 10. 


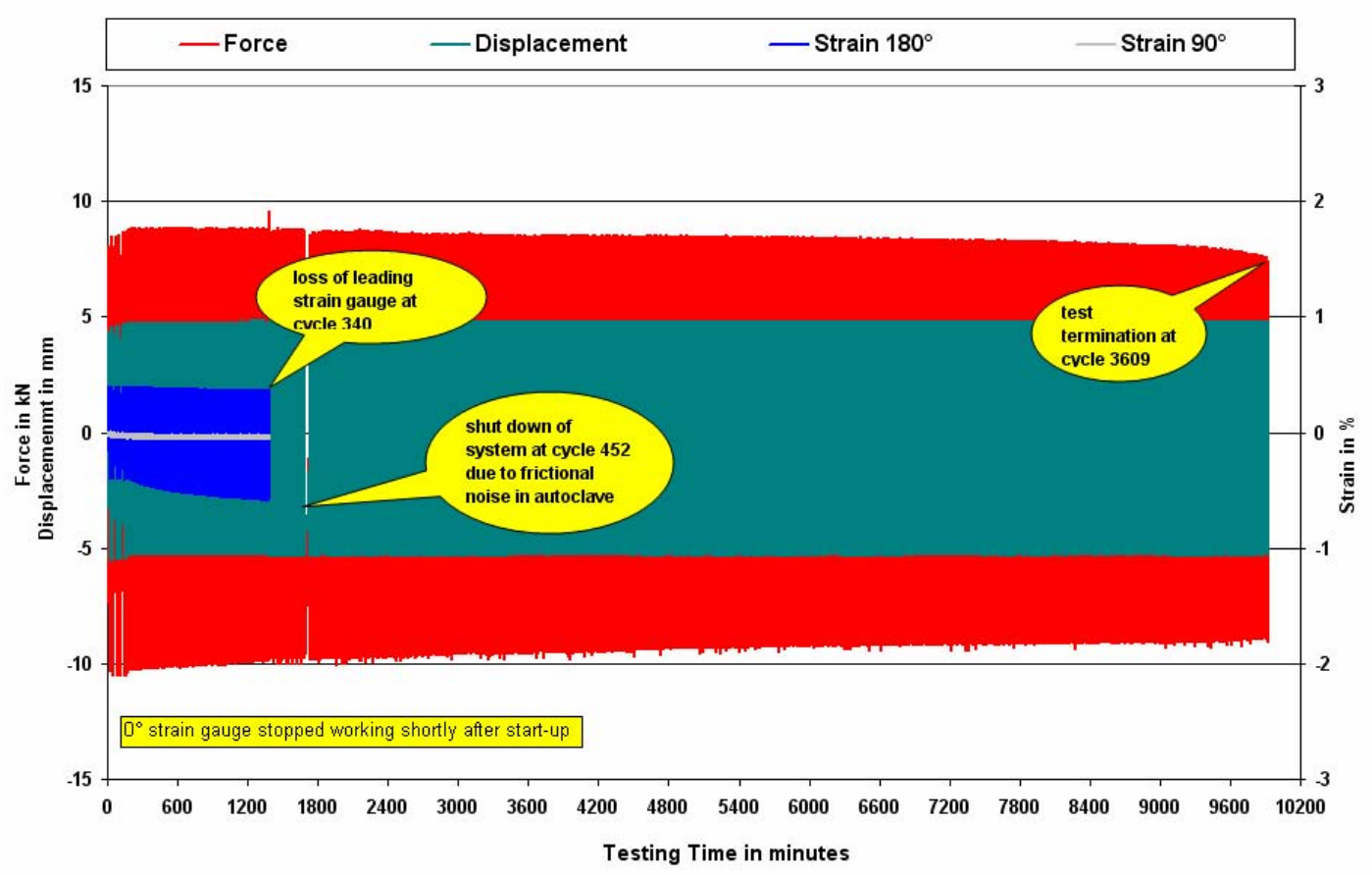

Figure 8-5

All mechanical data for the entire duration of Test $4 a$.

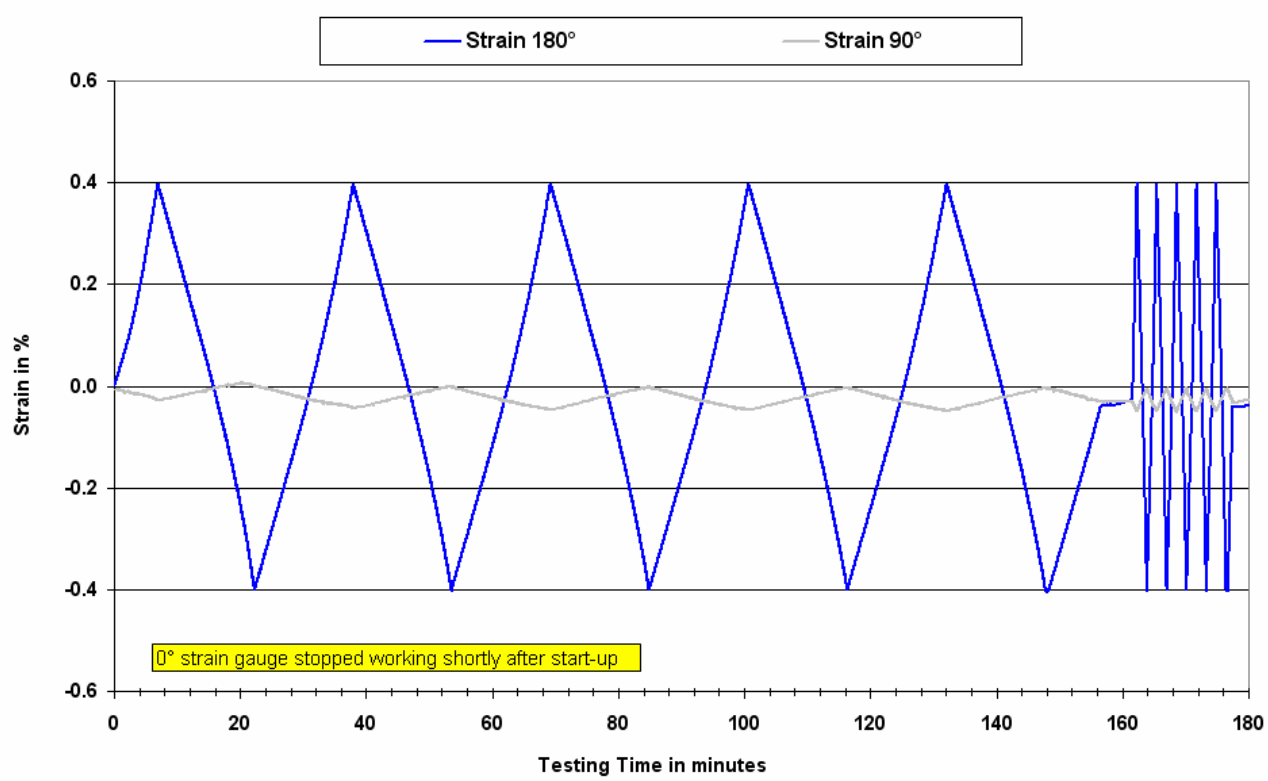

Figure 8-6

Strain data for Cycles 1 to 10. 


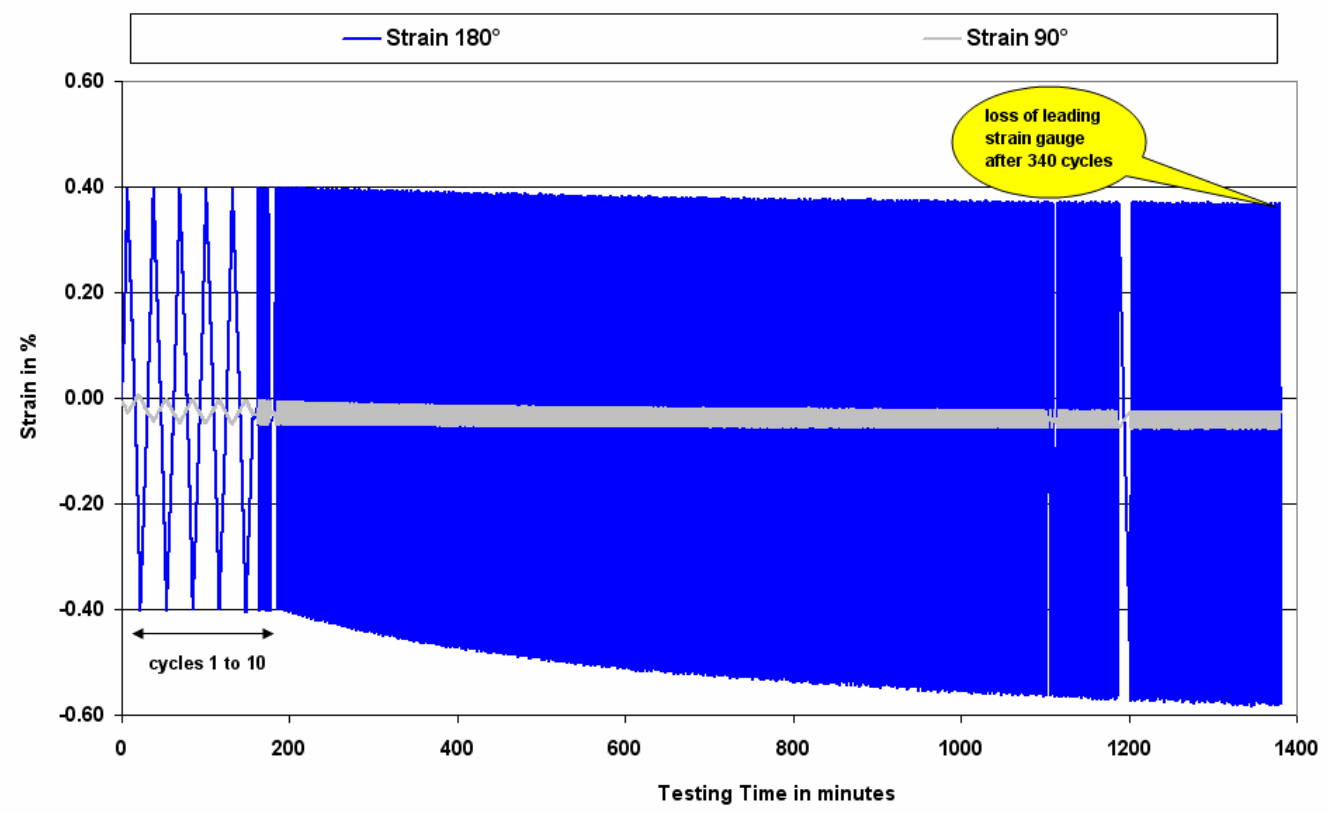

Figure 8-7

All available strain data.

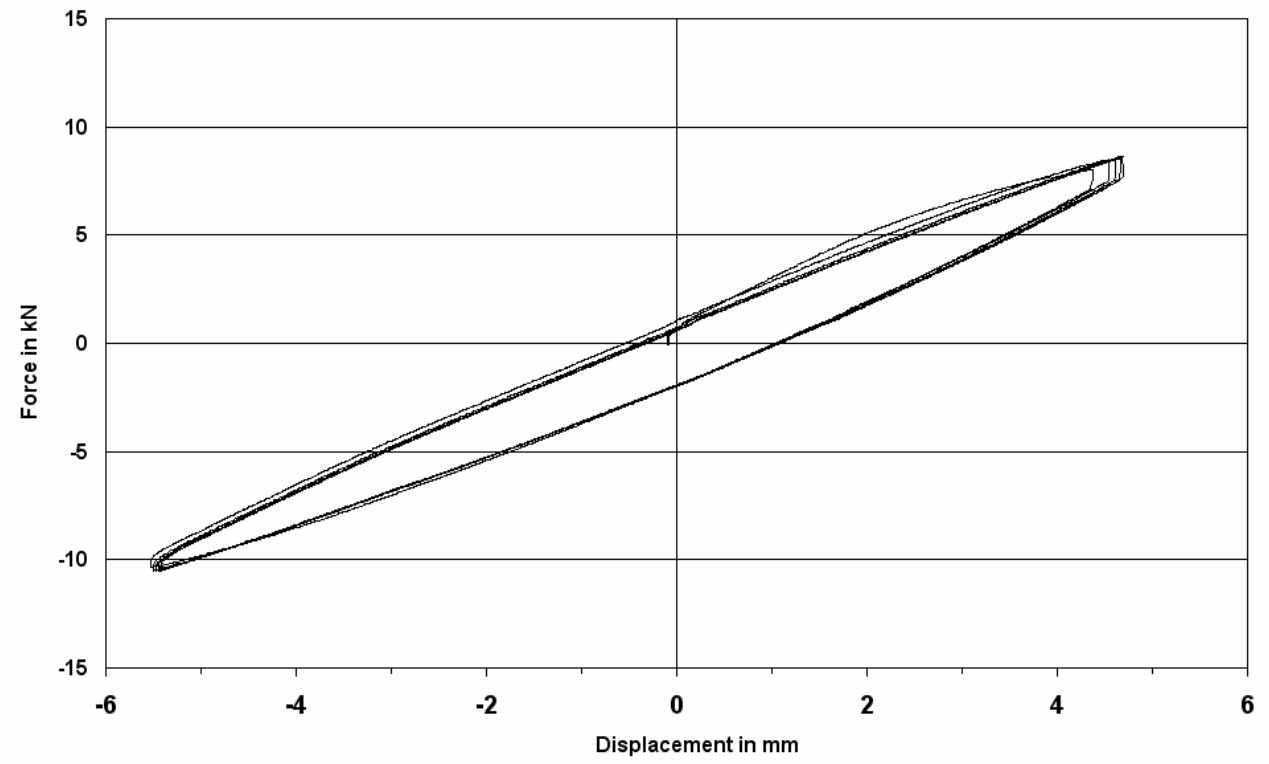

Figure 8-8

Force vs. displacment hysteresis for Cycles 1 to 5 (Strain Rate: $1 \times 10^{-5} \mathrm{xs}^{-1}$ ). 


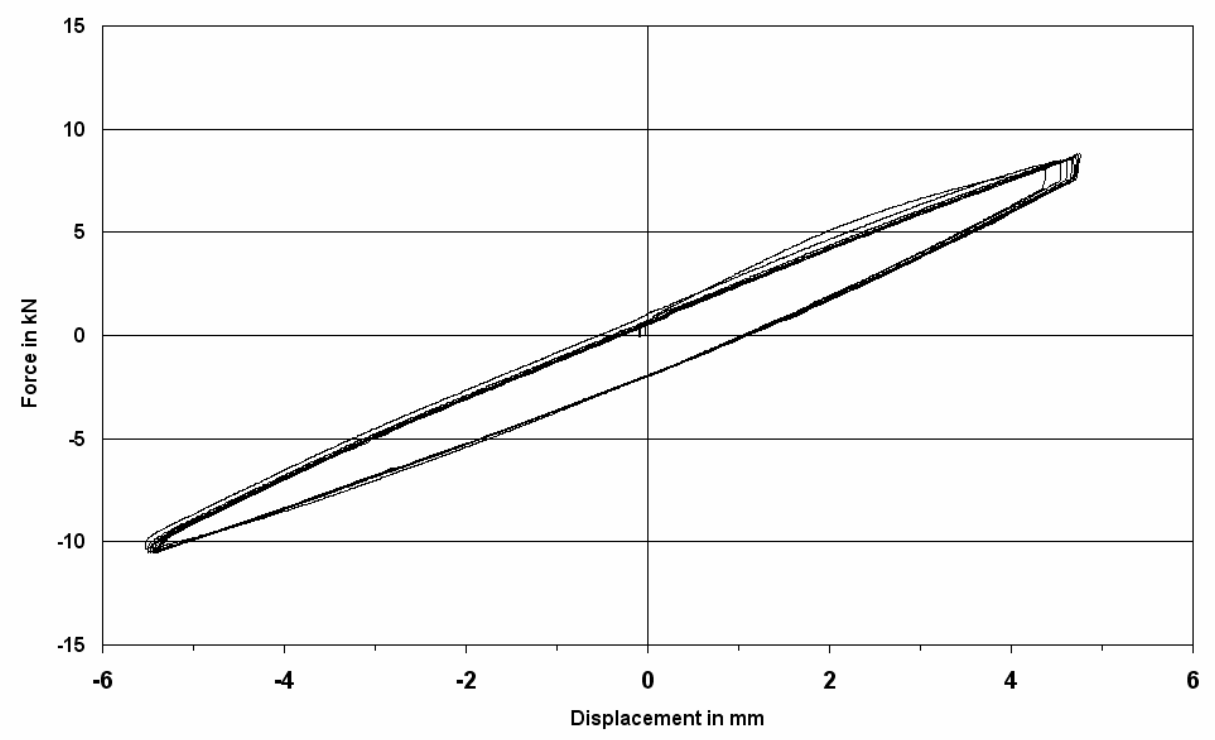

Figure 8-9

Force vs. displacement hysteresis for cycles 1 to 10 (Strain Rate Cycle 6 to $10: 1 \times 10^{-4} \mathrm{xs}^{-1}$ ).

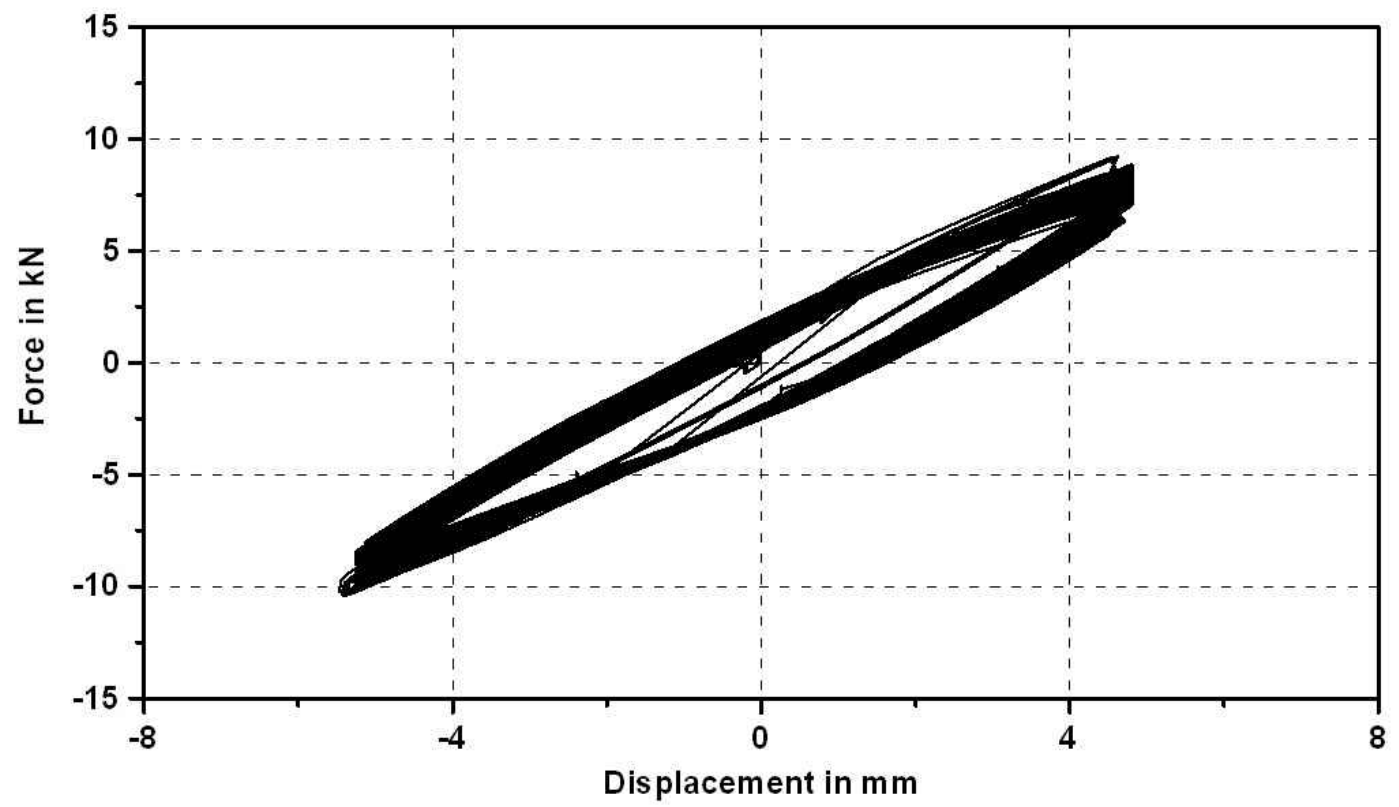

Figure 8-10

Force vs. displacement hysteresis for entire test. 


\section{Post Test Characterization}

After the physical testing part of environmental test $4 \mathrm{a}$ was accomplished the U-bend was removed from the testing rig, the additional tubing for optimized flow condition was cut off and the bend was prepared for post test characterization entailing the following tasks:

- Visual inspection of tested U-bend

- Dye penetrant inspection (DPI)

- Fractography of selected locations at high magnifications using scanning electron microscopy (SEM)

- Metallography of selected locations of interest

\section{Visual Inspection}

Visual inspection revealed one primary defect in the form of a narrow band of axial cracks. This band had an approximate length of $20 \mathrm{~mm}$ and was located in the $270^{\circ}$ position as shown in Figure 8-11. Remnants of crystallized boric acid were found adjacent to the leakage indicating that this defect had developed into a through wall fissure causing the loss of environment. No other primary defects visible to the naked eye were found on the external surface during visual inspection.
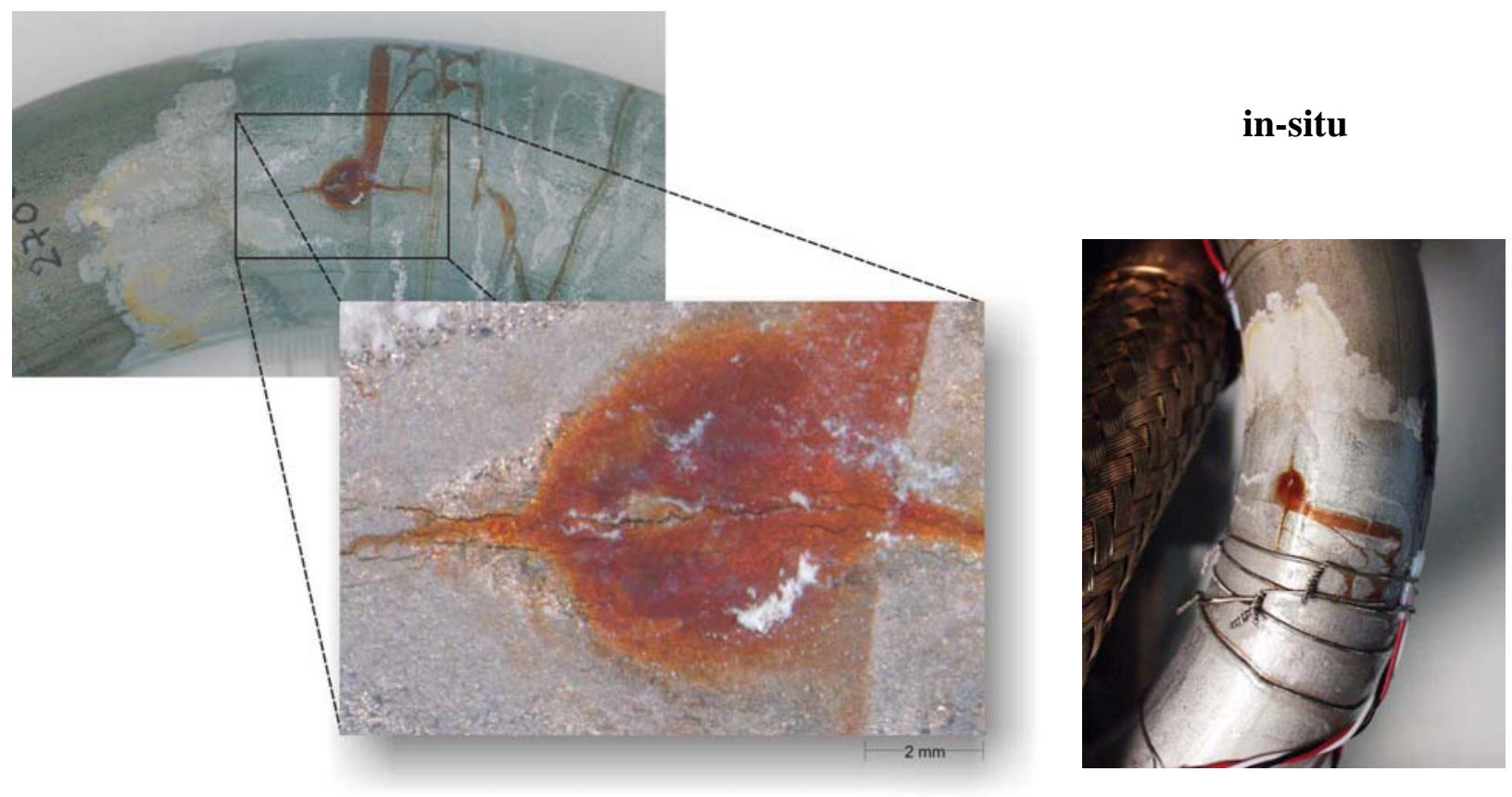

Figure 8-11

Primary leakage causing failure in the $270^{\circ}$ position. 


\section{Dye Penetrant Inspection}

A narrow piece containing the bend apex with an approximate length of $100 \mathrm{~mm}$ was sectioned from the bend and split in two half shells for further inspection with dye penetrant. Both the internal and external surfaces were examined.

Findings from visual inspection were confirmed, since the $270^{\circ}$ position revealed multiple axial cracking on both the internal and external surface (see Figure 8-12). With an approximate length of $70 \mathrm{~mm}$, the extent of axial cracking on the internal surface was greater if compared to the external surface.

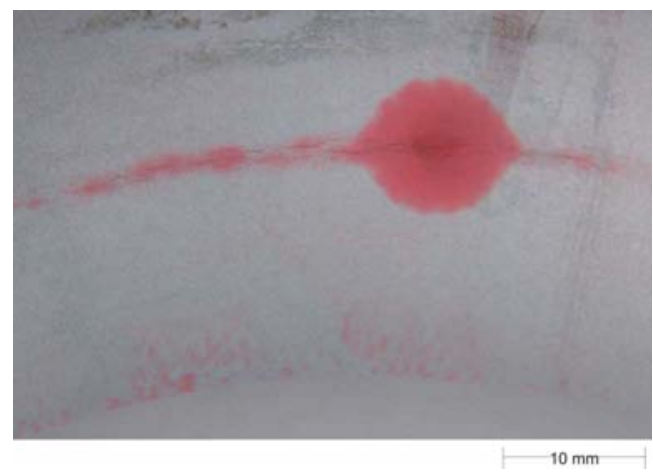

external surface

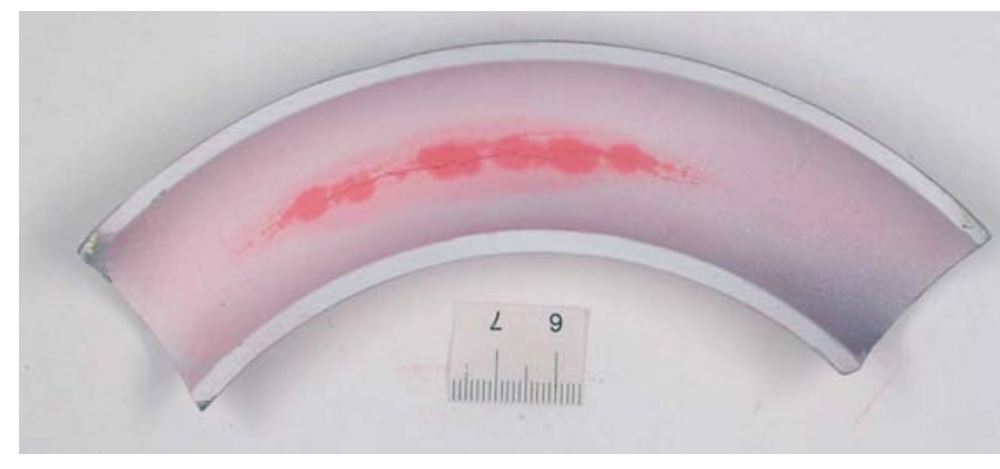

internal surface

Figure 8-12

DPI surface inspection of $270^{\circ}$ position showing multiple axial cracking at both locations.

The $90^{\circ}$ Position disclosed a similar failure appearance with a narrow band of multiple axial cracking on the internal surface, as shown in Figure 8-13. However, the cracking at this bend location had not developed into a through-wall defect, since the external surface was free of indications.

The $180^{\circ}$ intrados position revealed an array of circumferential cracking on the external surface, whereas the internal surface suffered from very fine axial cracking. Views of the internal and external findings are displayed in Figure 8-14. The internal defects of the $180^{\circ}$ position were much finer and less pronounced if compared to the $270^{\circ}$ and $90^{\circ}$ positions, respectively.

The $0^{\circ}$ extrados position was free of cracking both on the internal and external surfaces. 


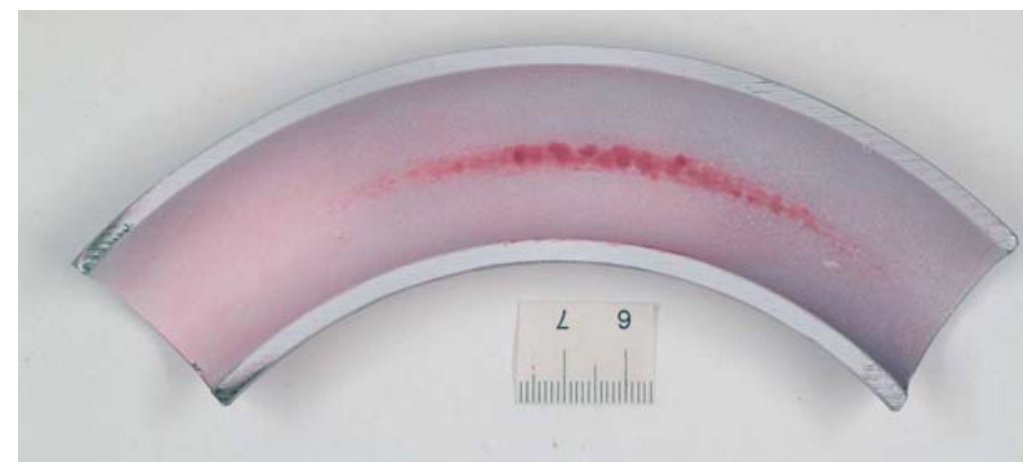

Figure 8-13

Internal surface of $90^{\circ}$ position showing multiple axial cracking.

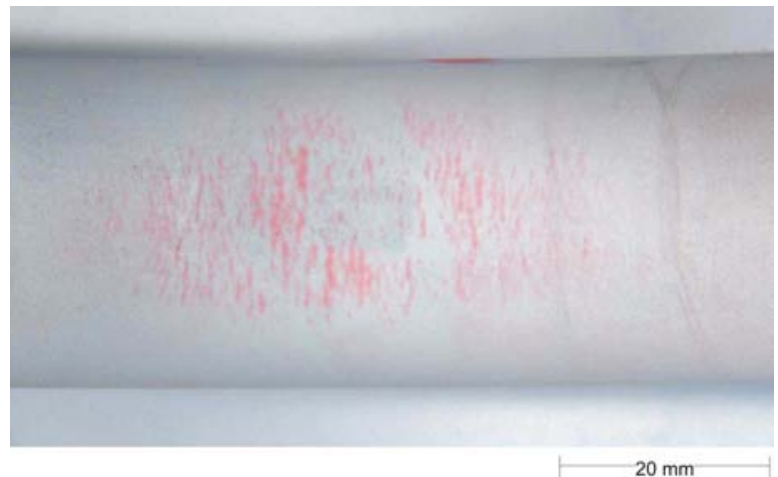

external surface

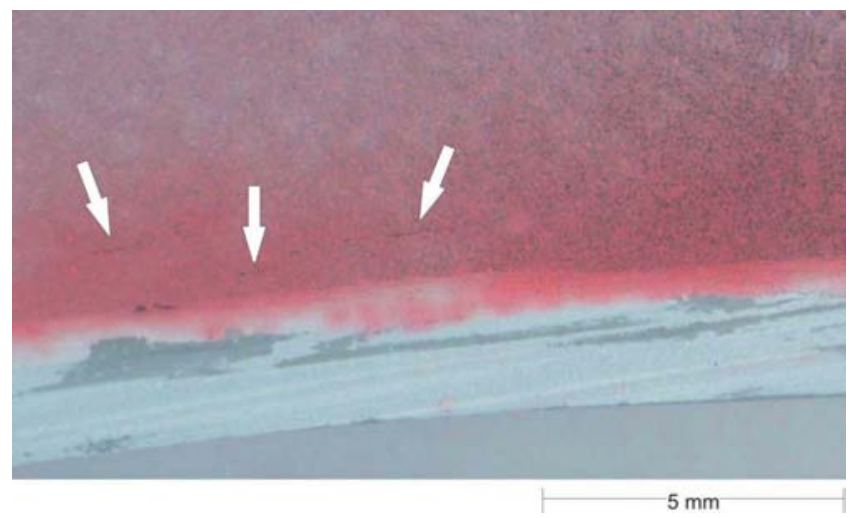

internal surface

Figure 8-14

$180^{\circ}$ intrados position showing array of fine circumferential cracking on external surface and fine multiple axial cracking on the internal surface.

\section{Scanning Electron Microscopy}

Locations of interest of the external and internal surfaces were also examined at higher magnifications using the SEM. The findings from DPI were confirmed since the $180^{\circ}$ intrados location revealed very fine circumferential cracking. It appeared that most of the cracks had initiated on surface defects that acted as stress rising notches. A typical example of circumferential cracking of the $180^{\circ}$ intrados position is displayed in Figure 8-15. The Internal surface of the $180^{\circ}$ intrados position is shown in Figure 8-16. Axial cracking exclusively following the attacked grain boundaries from the pickling treatment characterizes this location. The internal surfaces of the $90^{\circ}$ and $270^{\circ}$ position also confirmed the findings from DPI. Both locations exhibited multiple axial cracking as shown in Figure 8-17 and Figure 8-18. 


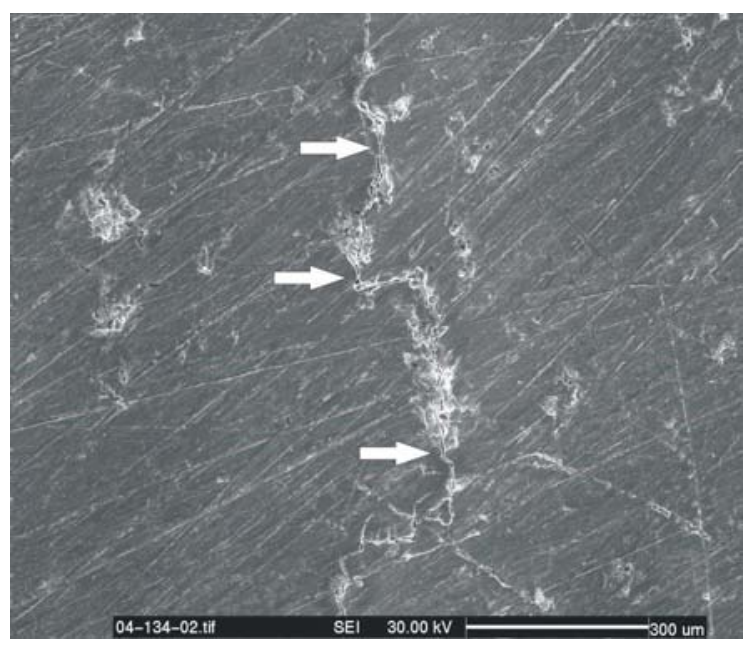

Figure 8-15

External surface of intrados showing fine circumferential cracking.

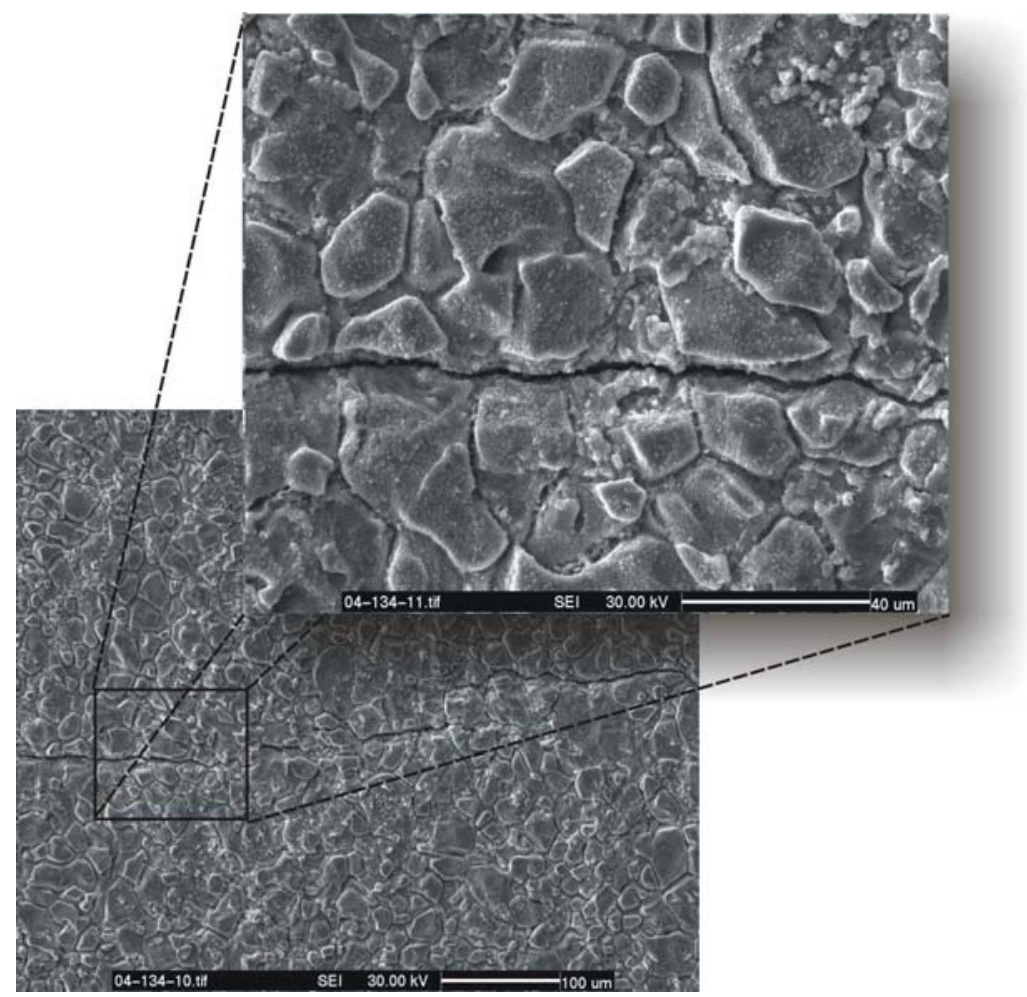

Figure 8-16

Internal surface of $180^{\circ}$ intrados position showing axial cracking following attacked grain boundaries from the pickling treatment. 


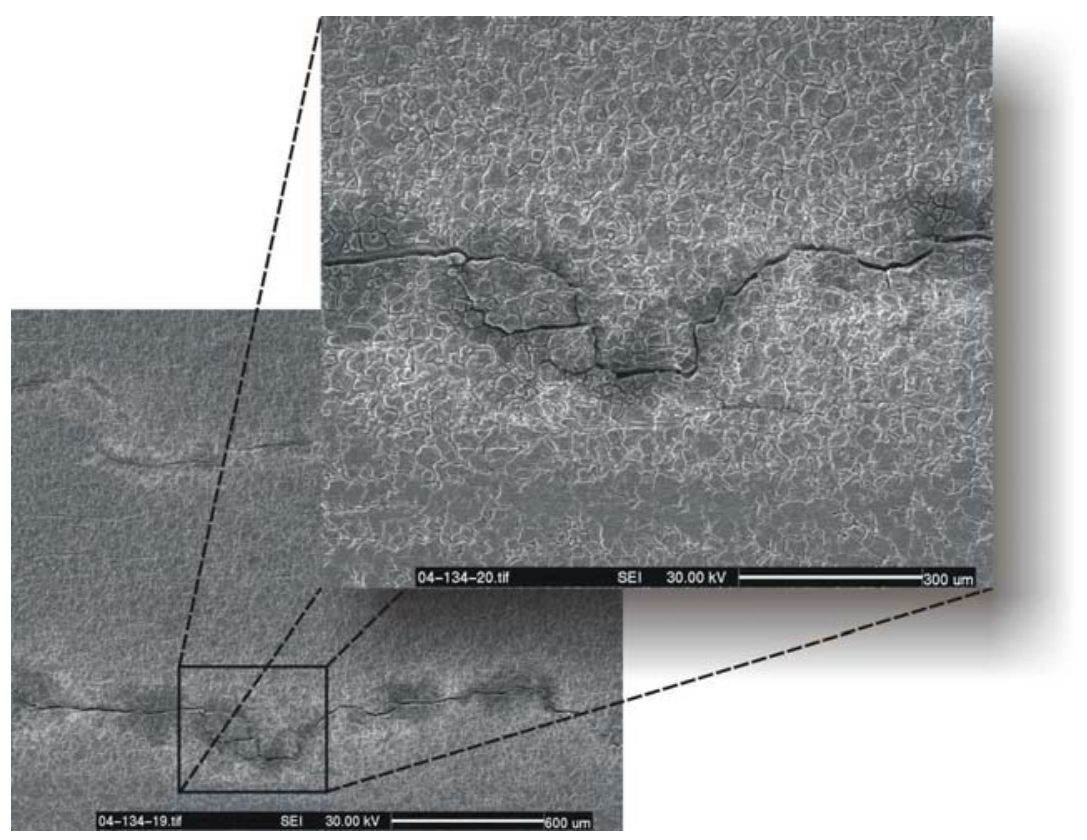

Figure 8-17

Internal surface of $90^{\circ}$ position showing axial cracking following attacked grain boundaries from pickling attack.

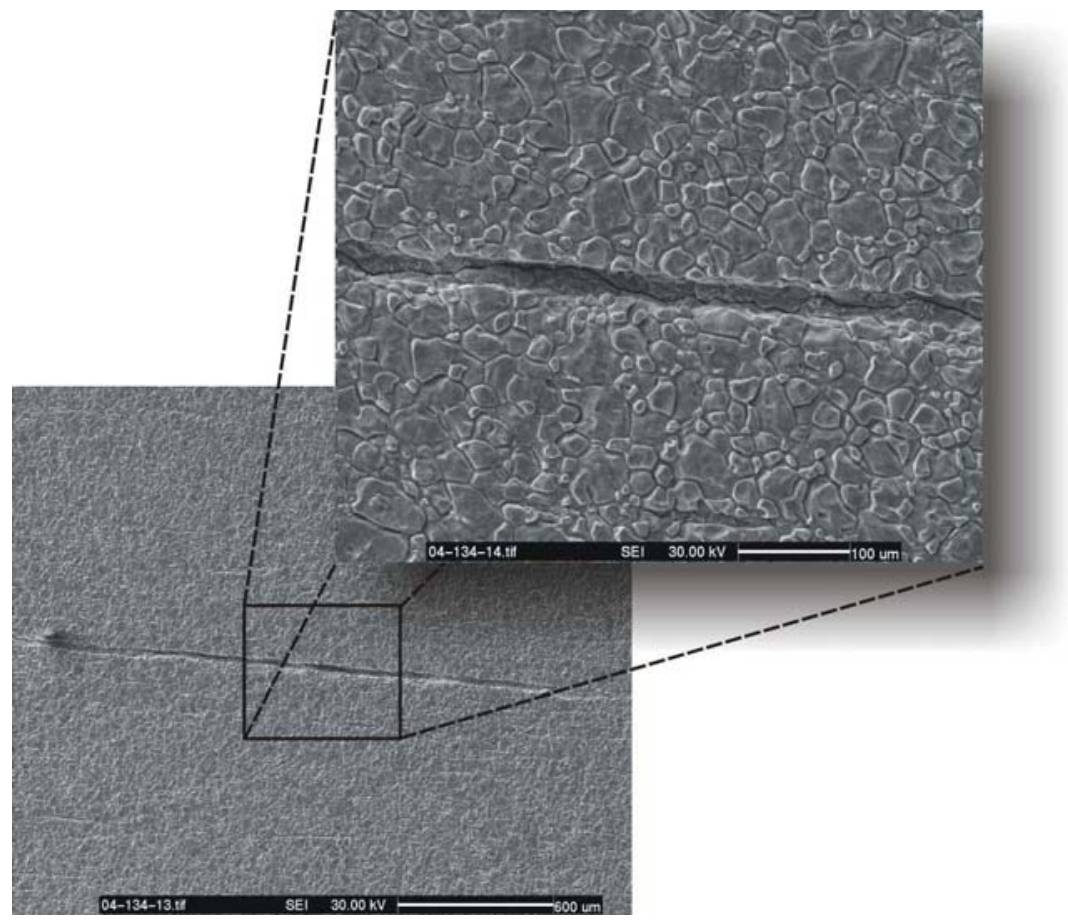

Figure 8-18

Internal surface of $270^{\circ}$ position showing defect causing leakage in the form of axial cracking. 
One external circumferential crack found on the $180^{\circ}$ intrados position was broken open for detailed fractography at higher magnifications. Figure 8-19 illustrates the saw cut area, the laboratory fracture as well as the actual fracture surface to be investigated.

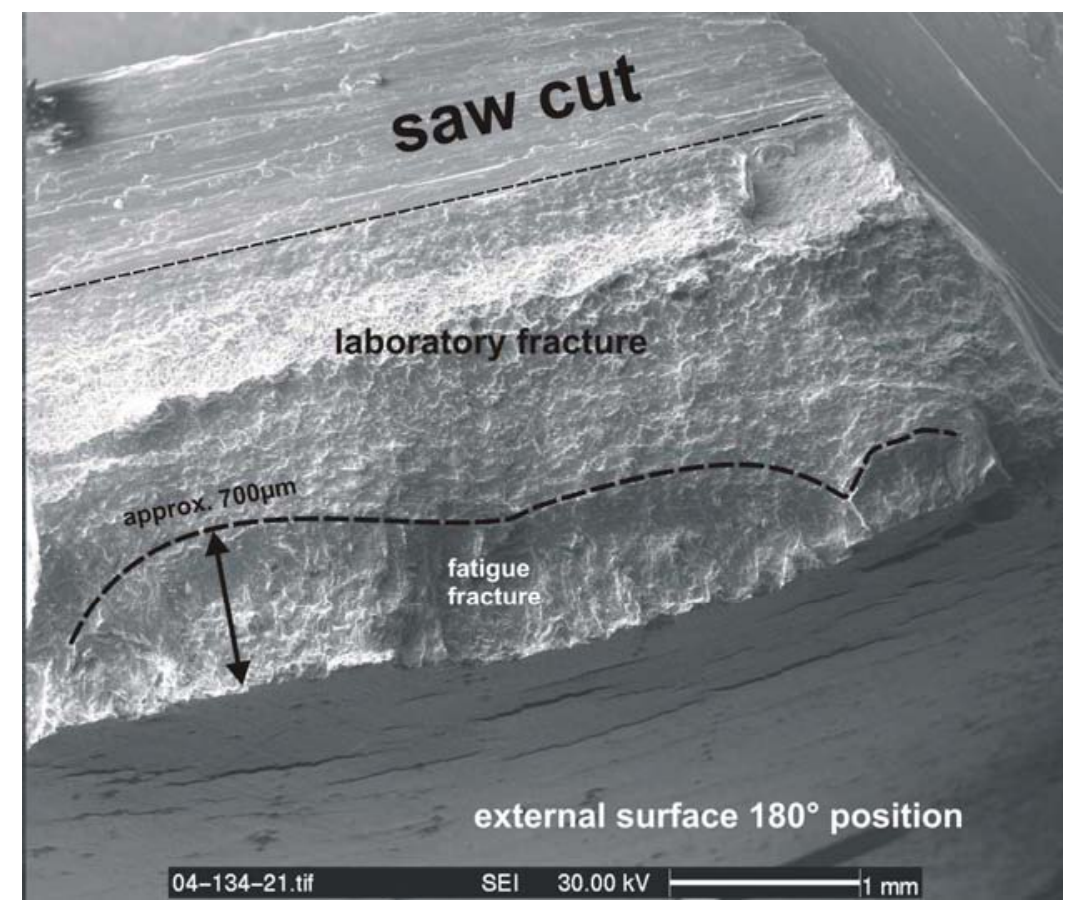

Figure 8-19

Broken open external circumferential crack at $180^{\circ}$ intrados position.

The crack front of this particular crack had a maximum depth of approximately $700 \mu \mathrm{m}$. The morphology revealed a striation pattern with varying spacing indicating a step wise crack progression under cyclic loading as displayed in Figure 8-20. The appearance indicated a purely mechanical driven fatigue crack that had progressed from the external towards the internal surface.

The striation spacing was then determined by evaluating corresponding images of the fracture surface. The spacing in the area associated to crack initiation was determined as approximately $1 \mu \mathrm{m}$. The mid fracture area showed a spacing of approximately $0.5 \mu \mathrm{m}$ to $1 \mu \mathrm{m}$. The final stages of the crack revealed a spacing of approximately $2 \mu \mathrm{m}$. 


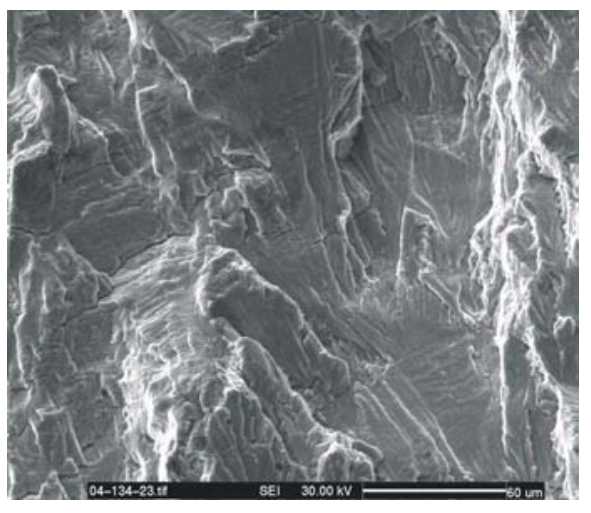

fracture initiation

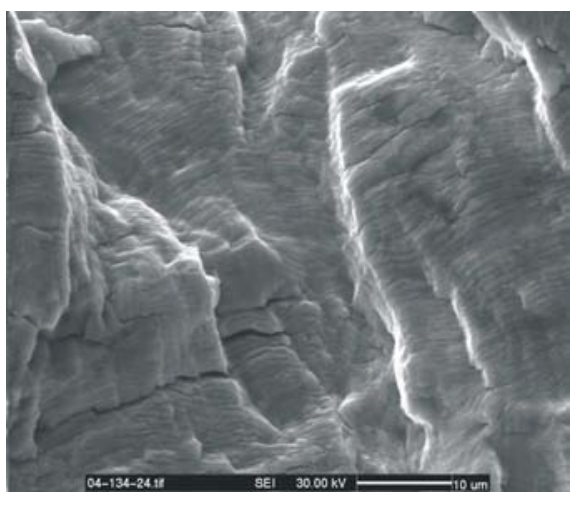

mid fracture

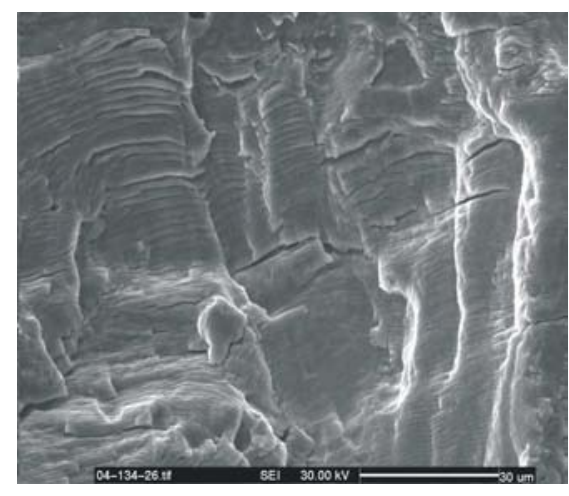

final stages

Figure 8-20

Typical views of circumferential crack at $180^{\circ}$ intrados position.

As a next step, one representative axial crack found in the $270^{\circ}$ position was broken open for analysis. Figure 8-21 illustrates the laboratory fracture as well as the actual fracture surface to be investigated. Similar to the $180^{\circ}$ circumferential crack, this location also revealed a fracture appearance with striations indicating a step-wise crack progression under cyclic loading. However, the generally flatten morphology and the fact of the multiple crack presence at this location indicated corrosion fatigue. Additionally, this is confirmed by the fact that the fracture progressed from the internal towards the external surface.

The striation spacing was then determined by evaluating corresponding images of the fracture surface. The spacing in the area associated to crack initiation was determined as approximately $1 \mu \mathrm{m}$. The mid fracture area showed a spacing of approximately $3 \mu \mathrm{m}$. The final stages of the crack revealed a striation spacing of approximately $7 \mu \mathrm{m}$.

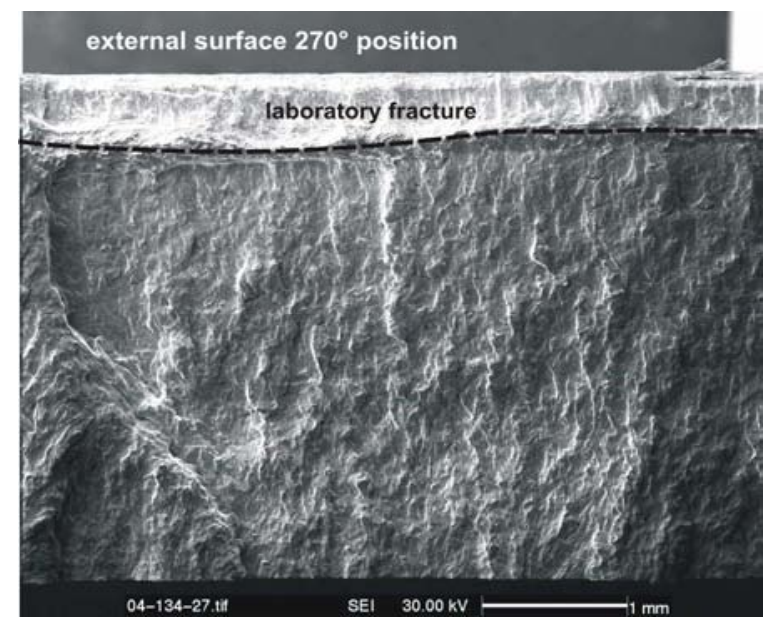

Figure 8-21

Broken open axial crack at $270^{\circ}$ position. 


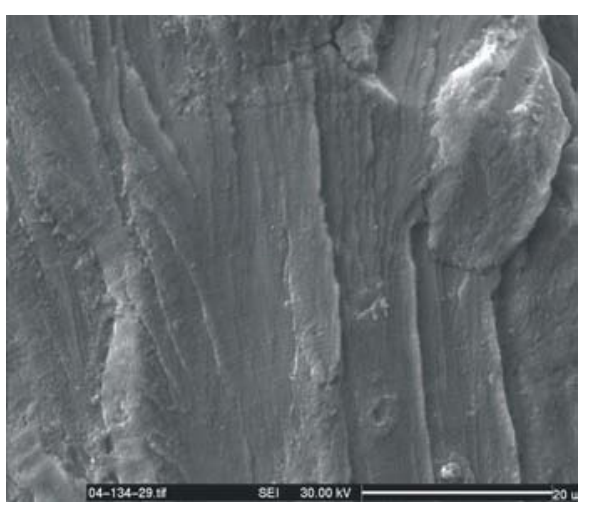

fracture initiation

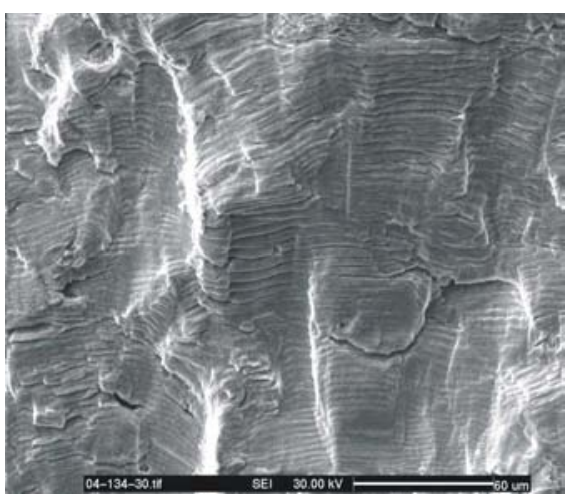

mid fracture

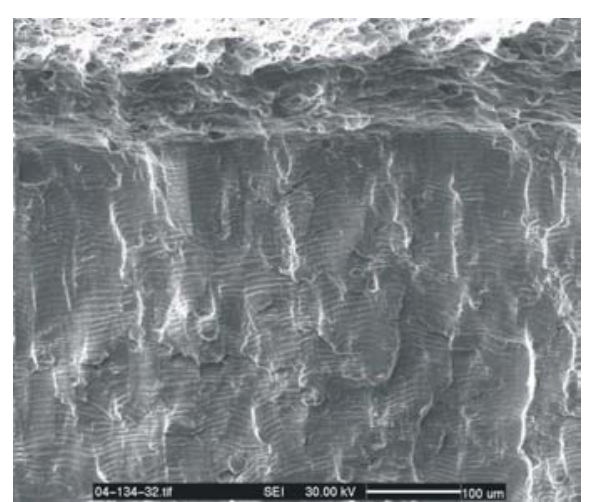

final stages

Figure 8-22

Typical views of fracture surface found at the $270^{\circ}$ position; the morphology indicates step-wise crack progression under the combined influence of mechanical loading and environment.

\section{Metallography}

The Microstructure of selected locations labeled S1 to S3 as displayed in Figure 8-23 below, was evaluated. The specimens were extracted from the bend, mounted and polished to a $1 \mu \mathrm{m}$ surface finish and etched with appropriate agents. The evaluation was conducted with a metallurgical microscope at varying magnifications.

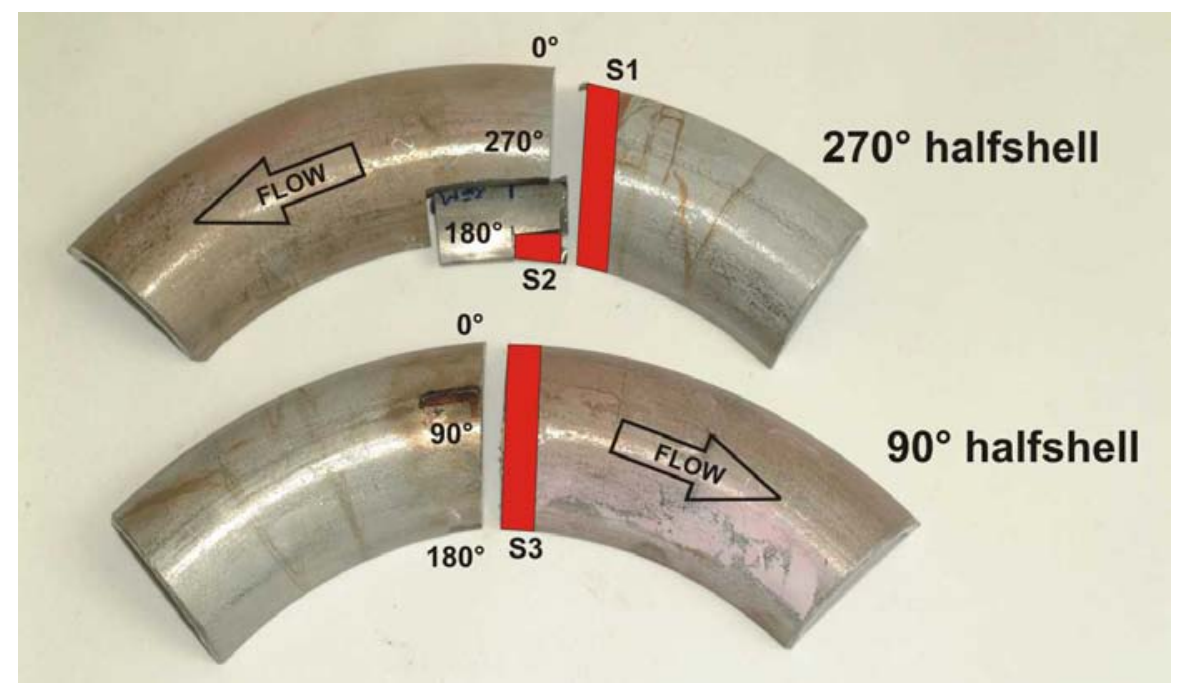

Figure 8-23

Specimen removal plan for Test $4 a$. 
All examined microstructures appeared to be generally sound, since they exhibited features typical for austenitic stainless steels with no anomalies to be found. The indications from visual and dye penetrant inspection were confirmed since all corresponding locations exhibited cracking.

The $270^{\circ}$ position suffered from an axially oriented through-wall defect that had initiated on the internal surface and propagated under the combined efforts of mechanical loading and environmental effects towards the external surface (see Figure 8-24). The propagation mode was found to be entirely. Again it was observed that the crack initiation had occurred at attacked grain boundaries originating from the pickling treatment.

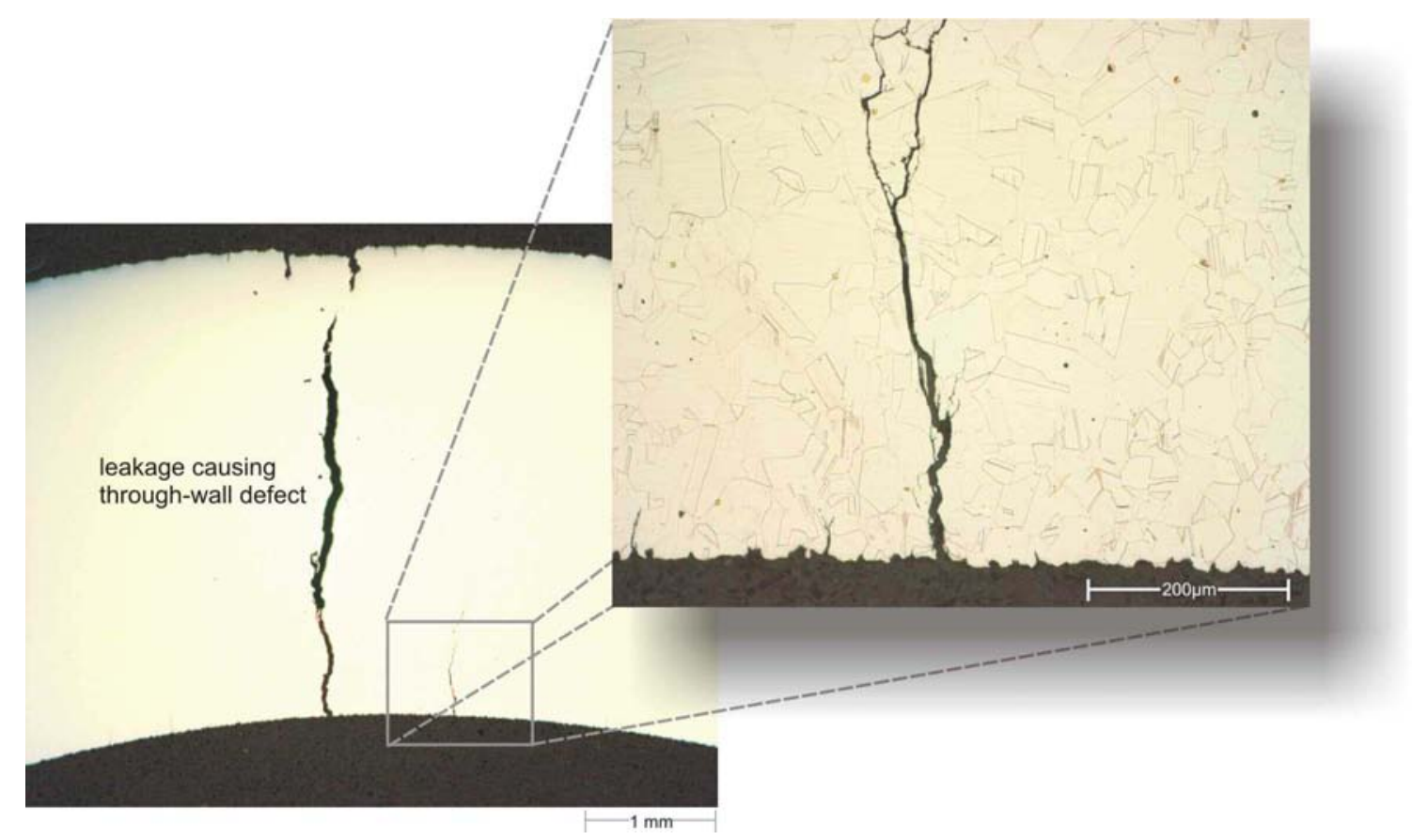

Figure 8-24

Typical view of $270^{\circ}$ position showing axial through-wall crack progressing from the internal towards the external surface (Specimen S1).

The $90^{\circ}$ position exhibited a very similar appearance with multiple axially oriented cracks propagating from the internal towards the external surface in a transgranular manner. Identical to previous examined locations the crack initiation had occurred at attacked grain boundaries. The maximum crack depth within this prepared specimen was determined to be $1700 \mu \mathrm{m}$, representing approximately 50\% of the nominal wall thickness as shown in Figure 8-25. 


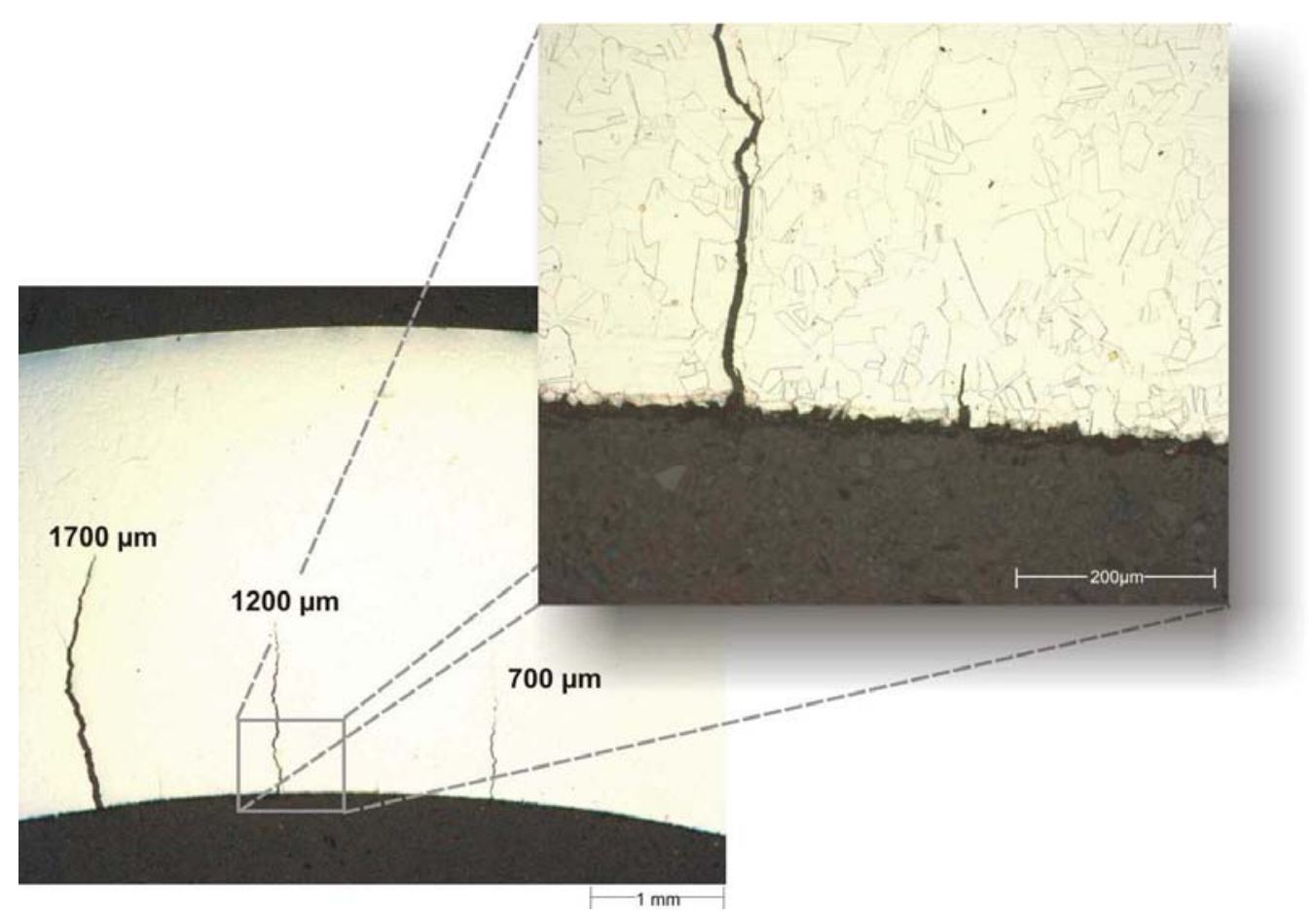

Figure 8-25

Typical view of $90^{\circ}$ position showing multiple axial cracking progressing from the internal towards the external surface (Specimen S3); the numbers represent approximate crack depths.

The $180^{\circ}$ position exhibited circumferentially oriented cracking, originating on the external surface. The propagation mode was transgranular and the maximum depth within this prepared cross-section was determined to be $295 \mu \mathrm{m}$, representing approximately $9 \%$ of the tube's nominal wall thickness. A typical view of this circumferential cracking is displayed in Figure $8-26$.

The internal surface of the $180^{\circ}$ intrados position exhibited features indicating an apparent multidirectional cracking without a clear circumferential or axial orientation. However, keeping the results from SEM examination in mind, where forked axial cracking on this location was observed, the principal crack orientation for this location is axial. Figure 8-27 displays both the metallurgical observations as well as a previously obtained SEM image from the same location. The maximum crack depth of these axial cracks was determined to be $580 \mu \mathrm{m}$, representing approximately $17 \%$ of the nominal wall thickness. 


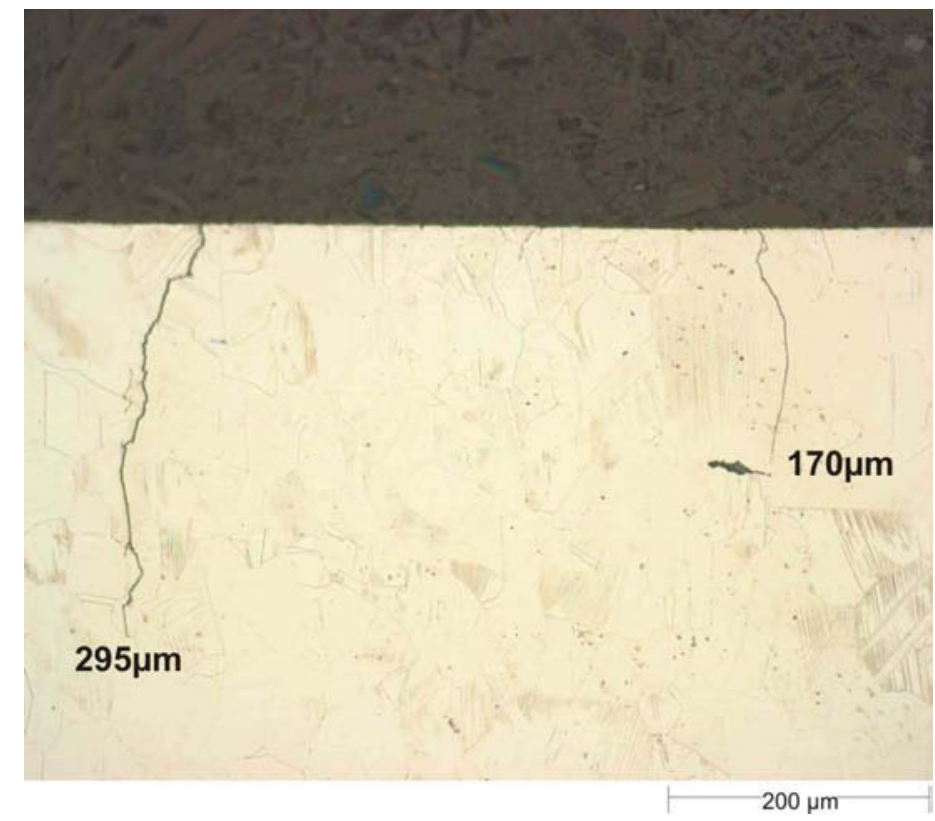

Figure 8-26

Typical views from the $180^{\circ}$ position showing circumferential cracking progressing from the external towards the internal surface.

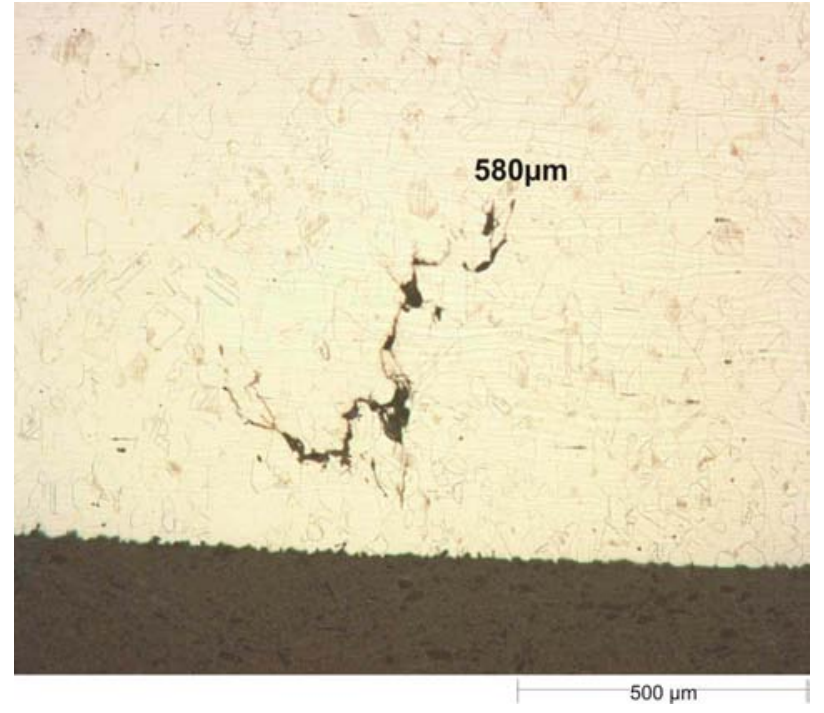

a)

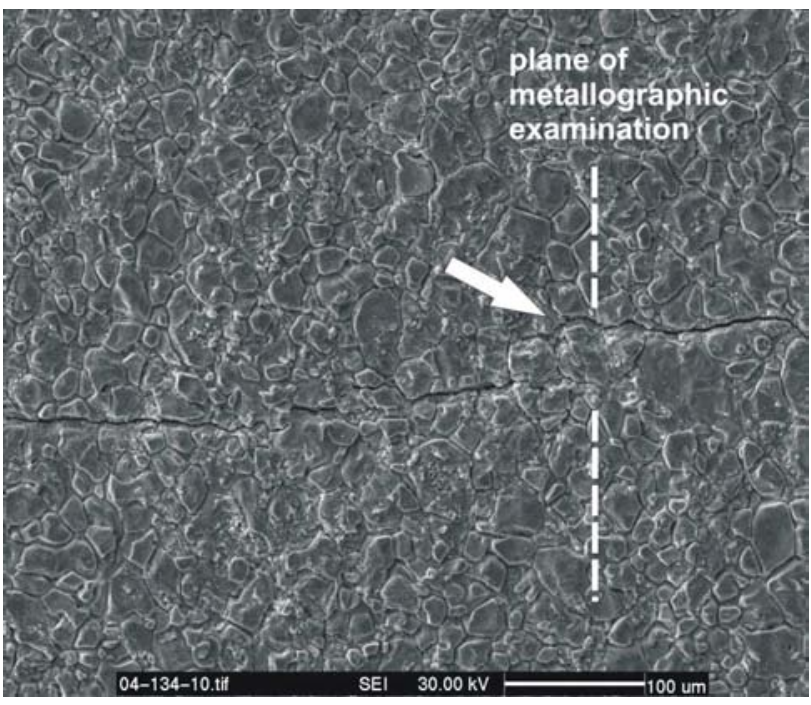

b)

Figure 8-27

Axial cracking found on the internal surface of the $180^{\circ}$ intrados position; apparent multidirectional character resulted from forked progression in combination with the plane the specimen was viewed in. 


\section{Summary of Results}

The following results can be summarized from environmental test 4a:

- Water chemistry within the range of specified values

- ECP -575 mVH,T, Redox Pot. $-525 \mathrm{mVH}, \mathrm{T}$ for low flow rate $(\approx 0.005 \mathrm{~m} / \mathrm{s})$

- Total number of cycles: 3609

- Frictional noise in autoclave led to long term shut down (approximately 3 days) at cycle 452; after re-arranging autoclave internals testing was resumed.

- Leakage due to internally initiated axial through-wall cracking in the $270^{\circ}$ position;

- At $90^{\circ}, 180^{\circ}$ and position axial cracking on internal surface

- Array of multiple circumferential cracks on the external surface of intrados $\left(180^{\circ}\right.$ position)

- No circumferential internal cracking

- The extrados position was free of cracking both internally and externally

- All cracks were transgranular and showed features typical of fatigue; all internal axially initiated cracks showed evidence of environmental assisted progression (corrosion fatigue)

- No microstructural effects were observed

Figure 8-28 graphically summarizes the extent and locations of cracking. 


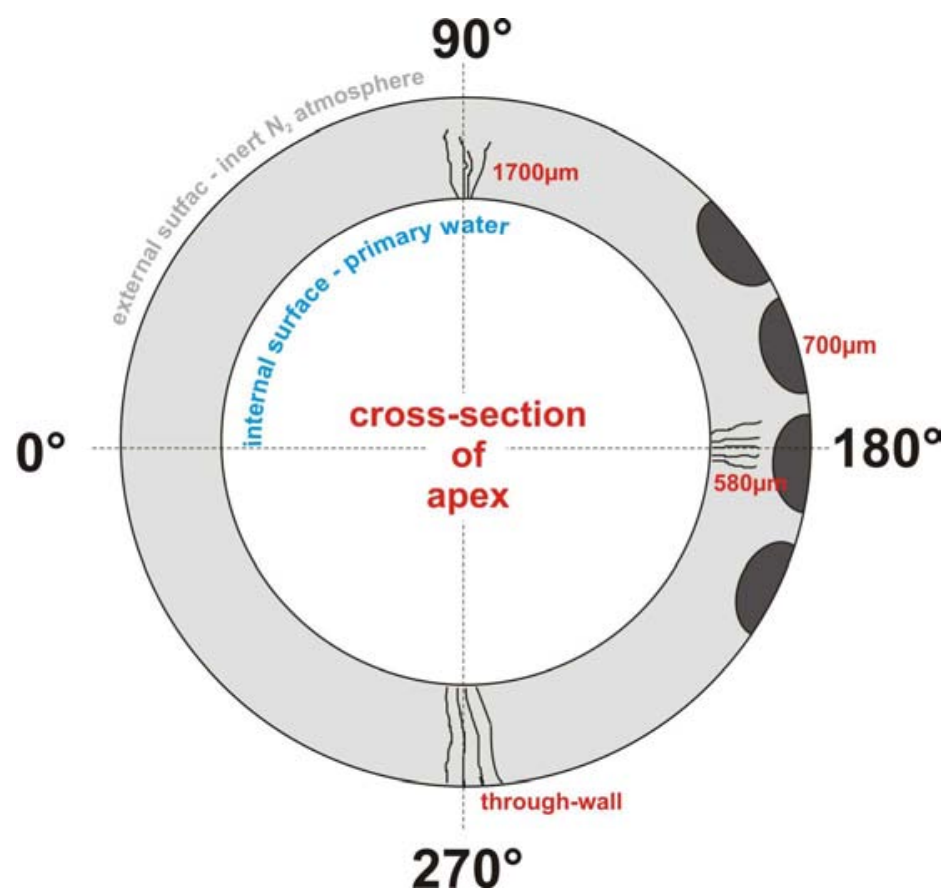

Figure 8-28

Schematic summary of crack locations, orientation and approximate crack depths (if available) of Test 4a; schematic provides a cross-sectional view of the apex looking downstream; please note that schematic is not to scale.

\section{Conclusions from Test $4 a$}

This test clearly showed an effect of primary water on the fatigue behavior of the U-bend under cyclic load, since multiple axial cracking at the internal surface of the apex was observed and characterized. Having implemented a less severe strain amplitude $(0.4 \%$ versus $0.6 \%$ of test series 2) the mechanical dominance that had led to failure in all previously conducted tests was no longer observed. The circumferential cracking in the external intrados area was attributed to pure mechanical loading and present only to a limited degree. The bend of test 4a definitely failed from internally initiating cracks due to combined efforts of mechanical loading and environment, since all axial fracture surfaces exhibited evidence of corrosion fatigue. This resulted in a total number of approximately 3609 cycles. 



\section{9 \\ ENVIRONMENTAL TEST 4B}

\section{Test Set-Up and Approach}

According to the text matrix, environmental test $4 \mathrm{~b}$ is characterized as a high flow rate test with a strain amplitude of $\pm 0.4 \%$. Deviating from previous practice, it was decided to mechanically polish the external surface of the apex to minimize surface effects on the external crack initiation. This approach was intended to allow "environmental dominance" of the cycles to failure during fatiguing the bend. The test was performed with the following U-bend instrumentation and basic test parameters:

- $\quad$ pre-conditioning of the bend internal surface by lengthy exposure to simulated primary water

- Instrumented U-bend with three bonded HT strain gauges at the $0^{\circ}, 90^{\circ}$ and $180^{\circ}$ position

- externally polished apex area to minimize surface effects on external crack initiation

- $\quad$ strain amplitude of $\pm 0.4 \%$ (total strain range of $0.8 \%$ )

- $\quad$ strain rate of $1 \times 10^{-4} \mathrm{~s}^{-1}$

- $\quad$ testing temperature $\mathrm{T}=240^{\circ} \mathrm{C}$, pressure $\mathrm{p}=50$ bar

- $\mathrm{HT}$ water chemistry comprised 1200 ppm B as $\mathrm{H}_{3} \mathrm{BO}_{3}+2$ ppm Li as $\mathrm{LiOH}$

- oxygen content was adjusted to $<<10 \mathrm{ppb}$, no $\mathrm{H}_{2}$ injection

- the impurity level was adjusted to $\mathrm{Cl}^{-}+\mathrm{F}^{-}+\mathrm{SO}_{4}{ }^{2-}<100 \mathrm{ppb}$

- water sampling and chemical analysis of $\mathrm{B}, \mathrm{Li}, \mathrm{Cl}^{-}, \mathrm{F}^{-}, \mathrm{SO}_{4}{ }^{2-}, \mathrm{pH}$ during start-up and before shut down

- high flow rate: $4100 \mathrm{l} / \mathrm{h} \approx 2.2 \mathrm{~m} / \mathrm{s}$ for $26.5 \mathrm{~mm}$ ID 


\section{Results}

\section{Water Chemistry}

The mechanical loading of the U-bend during testing was not commenced until the specified requirements with respect to test temperature, water chemistry/purity and electrochemical corrosion/redox potentials were met. Water sampling before start-up and loading assured thisas displayed in Table 6-1.

\begin{tabular}{|c|c|c|c|c|c|c|c||}
\hline $\begin{array}{c}\text { water } \\
\text { sampling }\end{array}$ & $\begin{array}{c}\text { B } \\
\mathbf{p p m}\end{array}$ & $\begin{array}{c}\mathbf{L i} \\
\mathbf{p p m}\end{array}$ & $\mathbf{p H}$ & $\begin{array}{c}\text { chloride } \\
\mathbf{p p b}\end{array}$ & $\begin{array}{c}\text { sulfate } \\
\mathbf{p p b}\end{array}$ & $\begin{array}{c}\text { fluoride } \\
\mathbf{p p b}\end{array}$ & remarks \\
\hline $\begin{array}{c}\text { before loading, test } \\
\text { temperature was } \\
\text { reached }\end{array}$ & 1232 & 2.2 & - & 20 & $<10$ & $<10$ & $\begin{array}{c}\text { conductivity } \\
\text { outlet: } 22.5 \mu \mathrm{S} / \mathrm{cm}\end{array}$ \\
\hline during test & 1218 & 2.15 & 6.5 & 34 & $<10$ & $<10$ & $\begin{array}{c}\text { conductivity } \\
\text { outlet: } 21.9 \mu \mathrm{S} / \mathrm{cm} \\
\mathrm{O}_{2} \approx 2 \mathrm{ppb}\end{array}$ \\
\hline before shut down & 1193 & 2.18 & - & 37 & $<10$ & $<10$ & $\begin{array}{c}\text { conductivity } \\
\text { outlet: } 22.4 \mu \mathrm{S} / \mathrm{cm} \\
\mathrm{O}_{2} \approx 3 \mathrm{ppb}\end{array}$ \\
\hline
\end{tabular}

Table 9-1

Results from water sampling during environmental Test $4 \mathrm{~b}$.

During testing the water chemistry was monitored continuously with respect to test temperature, conductivity and electrochemical corrosion potential (ECP) and redox potential. Figure 9-1 and Figure 9-2 show the inlet and outlet conductivity, the test temperature as well as ECP and the redox potential for the entire duration of environmental test $4 \mathrm{~b}$. The ECP showed values of approximately $-550 \mathrm{mV}_{\mathrm{H}, \mathrm{T}}$ and the redox potential was measured at approximately $-450 \mathrm{mV}_{\mathrm{H}, \mathrm{T}}$. The target test temperature of $240{ }^{\circ} \mathrm{C}$ was held very stable for the entire test.

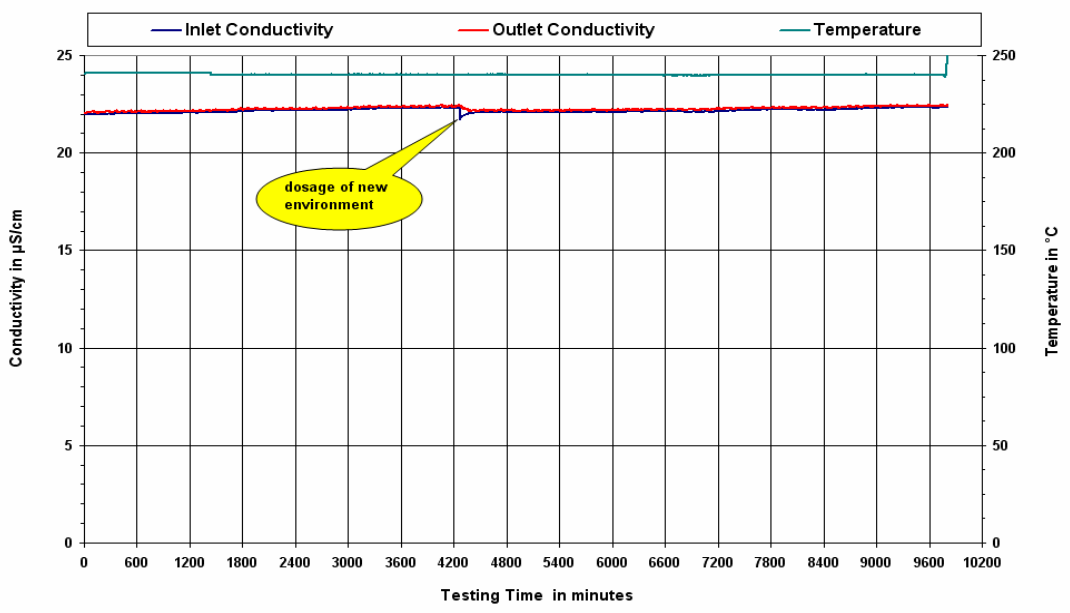


Figure 9-1

Temperature and conductivity over entire testing time.

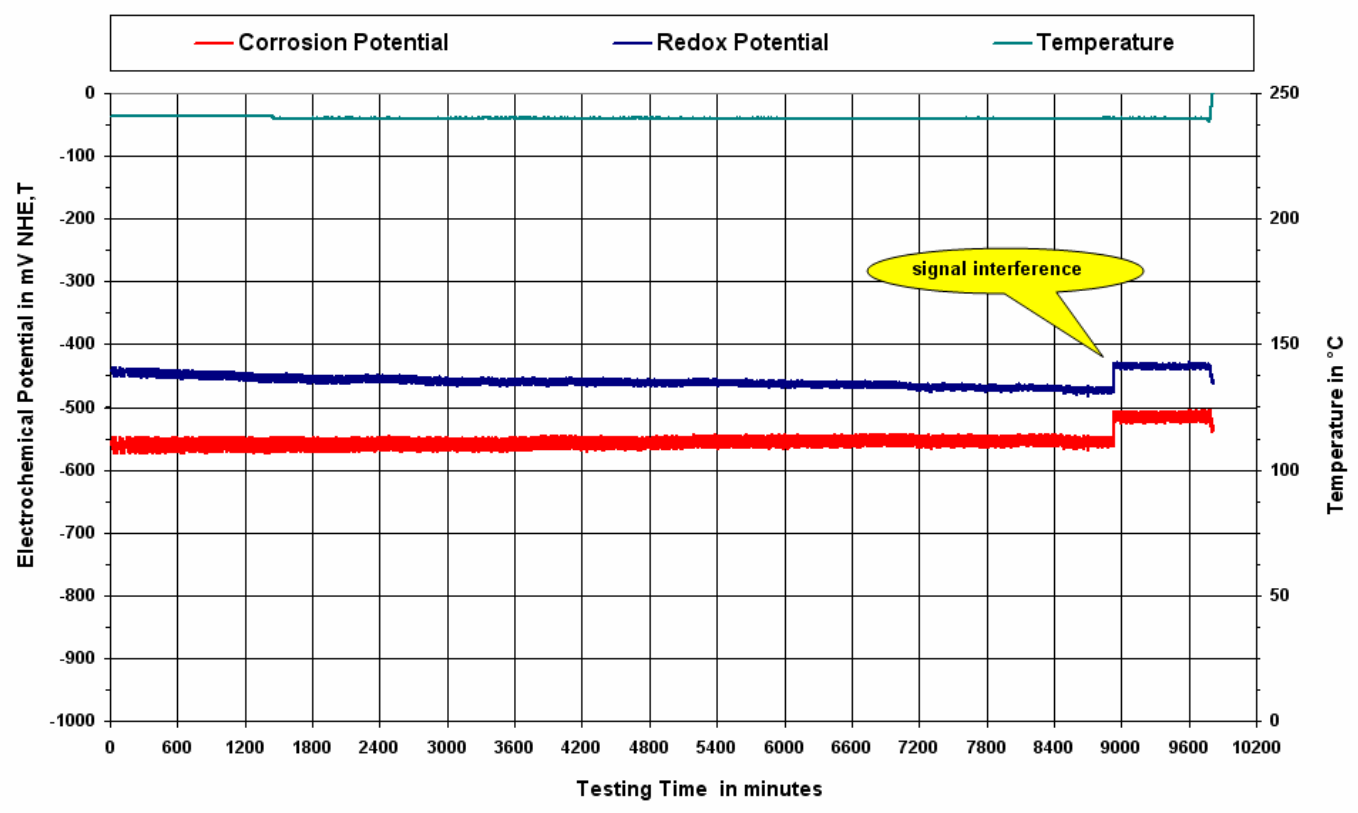

Figure 9-2

Temperature, electrochemical corrosion and redox potential vs. testing time.

\section{Mechanical Data}

Having reached the desired levels with regards to water chemistry and test temperature, the loading sequence was started. The basic test parameters used for mechanical loading of the Ubend are given in Table 9-2. Initially, the bend was loaded with a triangular wave shape for the first 5 cycles to evaluate the response. The strain rate used for the first 5 cycles was $1 \times 10^{-5} \mathrm{x} \mathrm{s}^{-1}$. Cycles 6 to 10 were performed with a strain rate of $1 \times 10^{-4} \mathrm{x} \mathrm{s}^{-1}$. To this point the test was performed displacement control with strain triggered switch points at $\pm 0.4 \%$ strain amplitude. Cycle 10 was used to determine the displacements necessary for the remaining test, which was performed displacement control. Figure 9-3 and Figure 9-4 illustrate the mechanical data for cycles 1 to 5 and 6 to 10, respectively. The strain response for the cycles 1 to 10 is provided in Figure 9-6. The load over displacement hysteresis for the first 10 cycles is displayed in Figure 9-8 and Figure 9-9 and indicated a fairly stable bend behavior.

The leading $180^{\circ}$ intrados strain gauge stopped working at approximately cycle 1500 as a result of the cyclic loading. The available strain data is shown in Figure 9-7. Generally, the bend showed a relatively stable behavior throughout the entire test since the load response to the given displacements was uniform, as displayed in Figure 9-5. The load vs. displacement hysteresis for the entire test is displayed in Figure 9-10. After having reached the shut down criterion, the test was terminated at cycle 3616. 


\begin{tabular}{||c|c|c|c|c|c||}
\hline cycle & $\begin{array}{c}\text { wave } \\
\text { shape }\end{array}$ & $\begin{array}{c}\text { control } \\
\text { channel }\end{array}$ & strain rate & switch point & $\begin{array}{c}\text { switch off } \\
\text { criterion }\end{array}$ \\
\hline \hline $\mathbf{0 - 5}$ & triangular & $\begin{array}{c}\text { displacement } \\
\text { strain triggered } \\
\text { switching point }\end{array}$ & $1 \times 10^{-5} \mathrm{~s}^{-1}$ & $\begin{array}{l}+0.4 \% \\
-0.4 \%\end{array}$ & \\
\hline $\mathbf{5}-\mathbf{1 0}$ & triangular & $\begin{array}{l}\text { displacement } \\
\text { strain triggered } \\
\text { switching point }\end{array}$ & $1 \times 10^{-4} \mathrm{~s}^{-1}$ & $\begin{array}{l}+0.4 \% \\
-0.4 \%\end{array}$ & failure \\
\hline $\mathbf{1 0 - 3 6 1 6}$ & triangular & displacement & $1 \times 10^{-4} \mathrm{~s}^{-1}$ & $\begin{array}{l}+5.07 \mathrm{~mm} \\
-5.08 \mathrm{~mm}\end{array}$ & \\
\hline
\end{tabular}

Table 9-2

Basic test parameters of mechanical loading during environmental Test $4 \mathrm{~b}$.

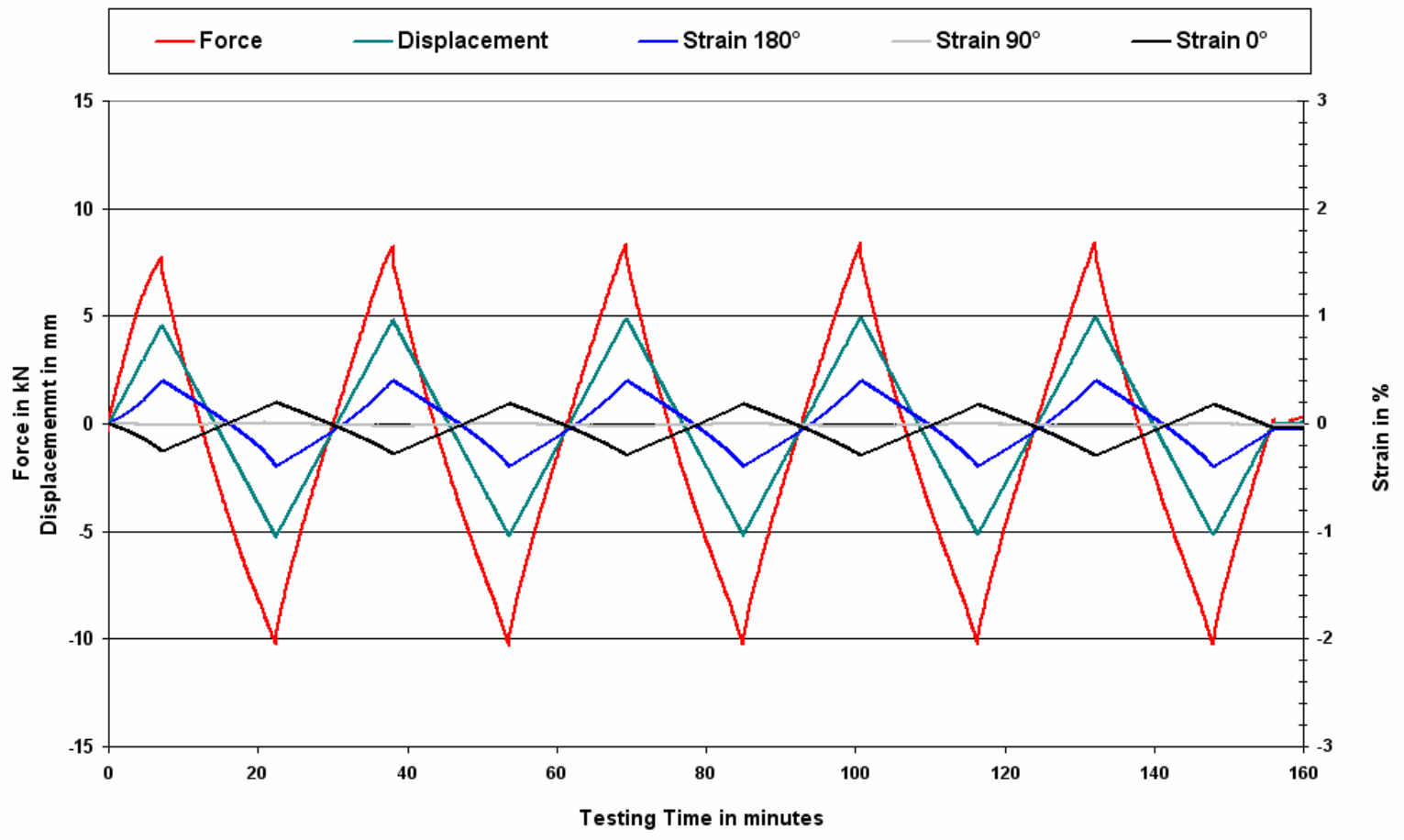

Figure 9-3

All mechanical data for Cycles 1 to 5 . 


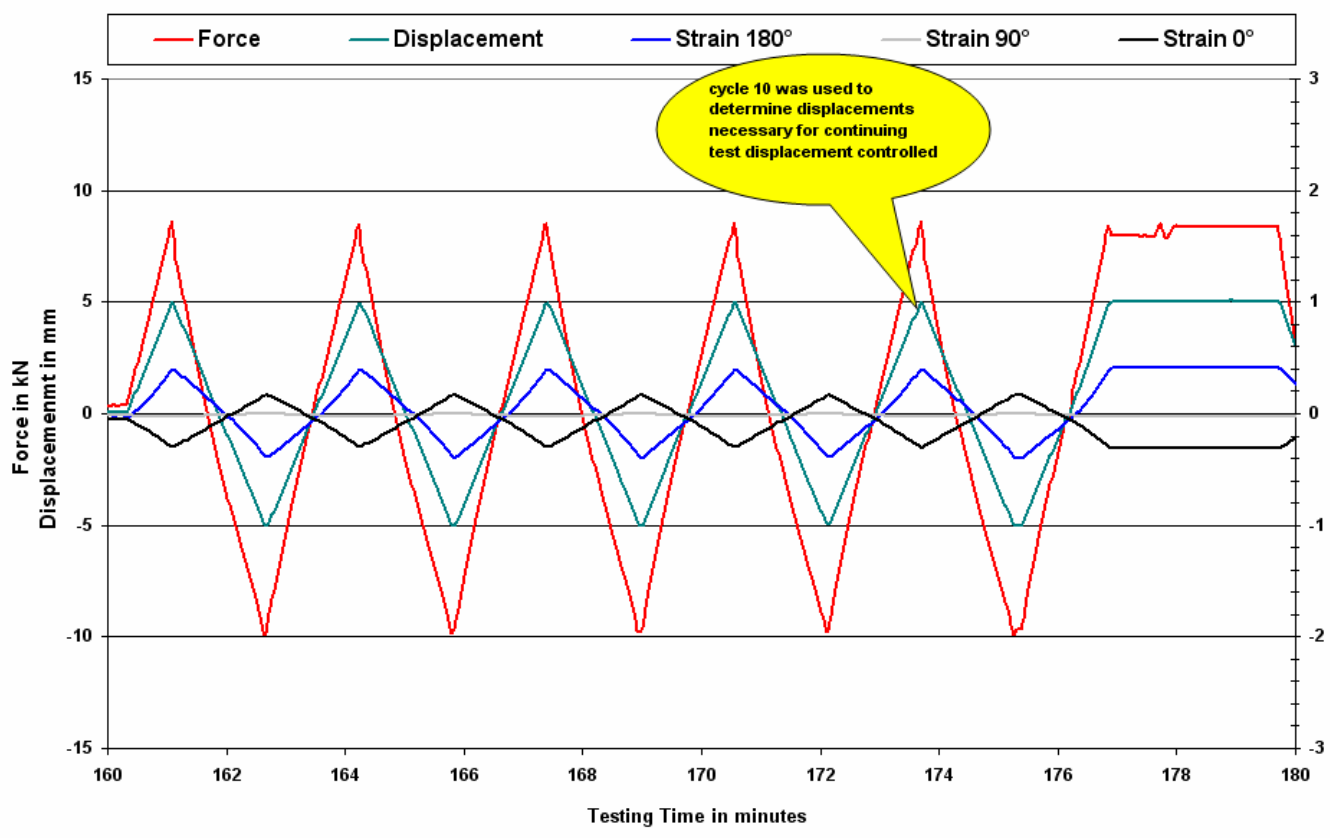

Figure 9-4

Mechanical data of Cycles 6 to 10.

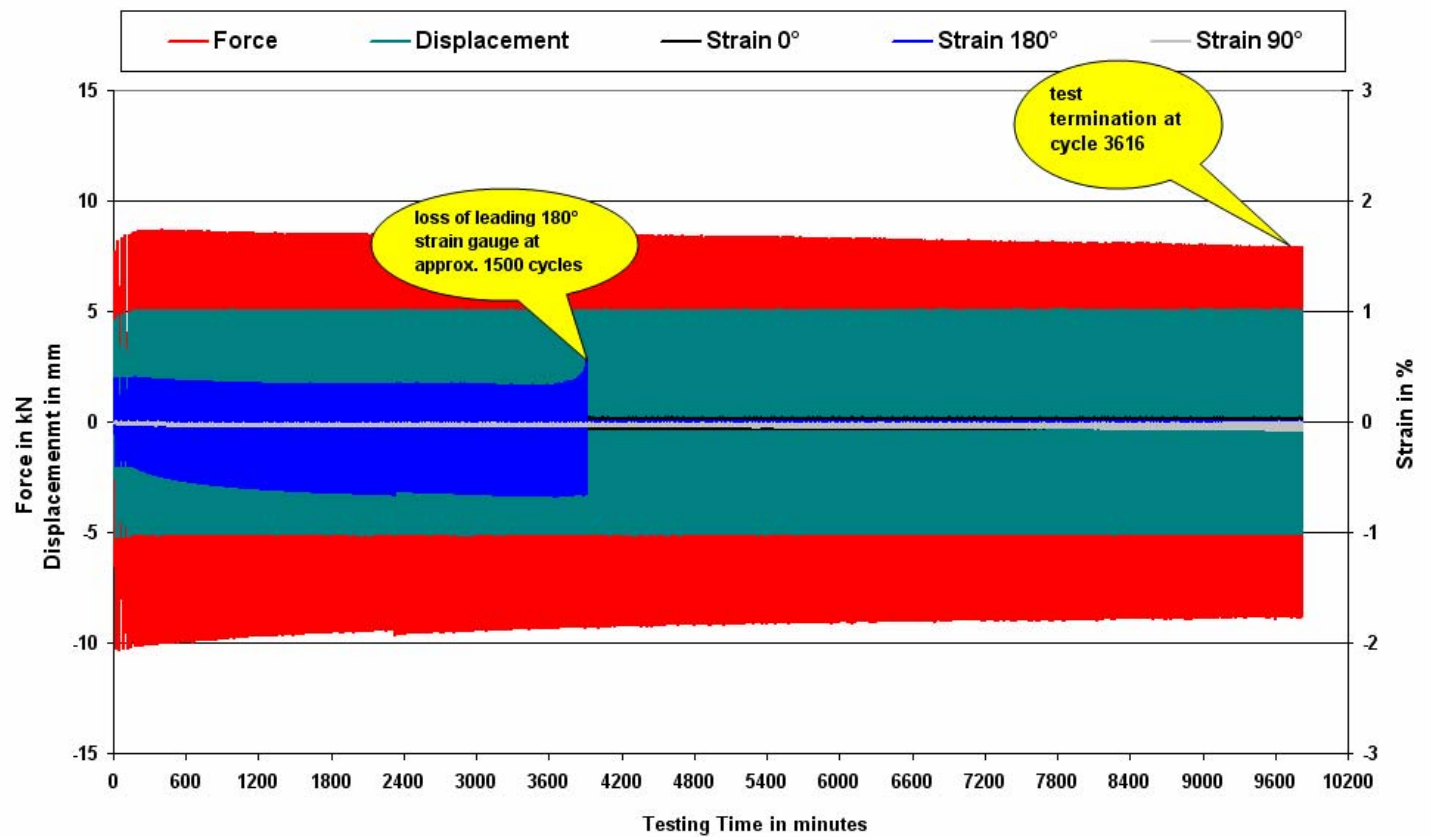

Figure 9-5

All mechanical data vs. testing time. 


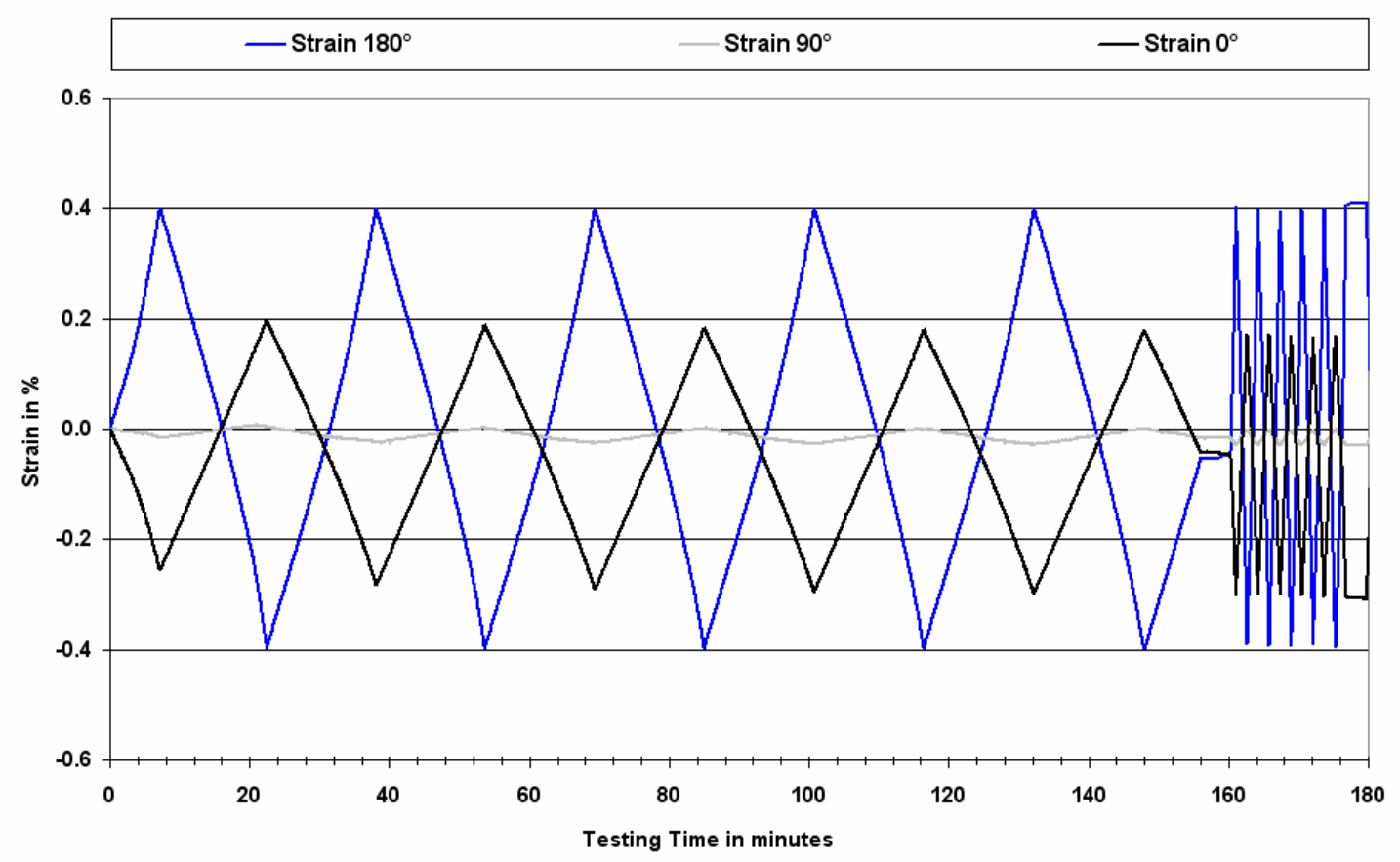

Figure 9-6

Strain data for Cycles 1 to 10 .

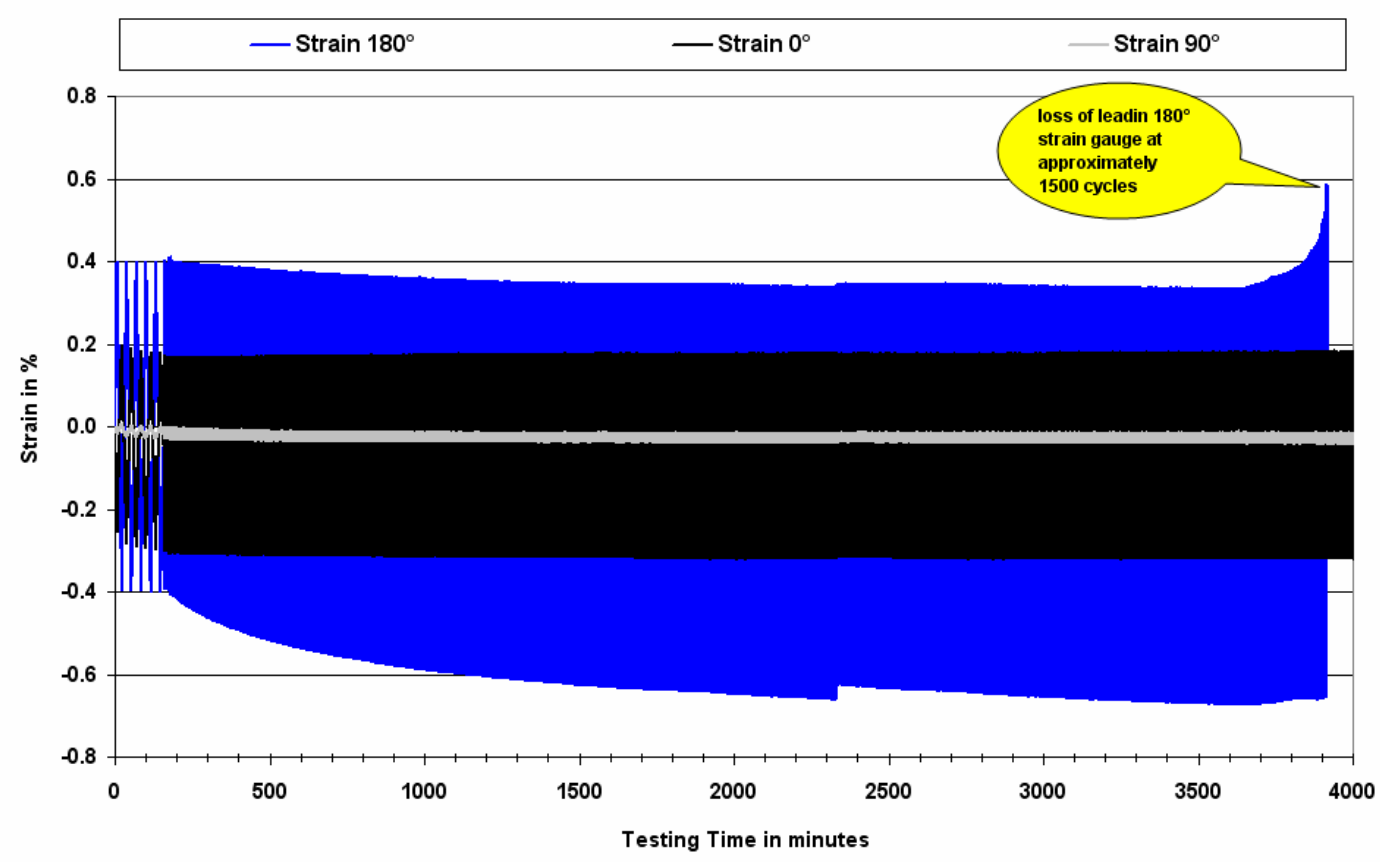

Figure 9-7

All available strain data. 


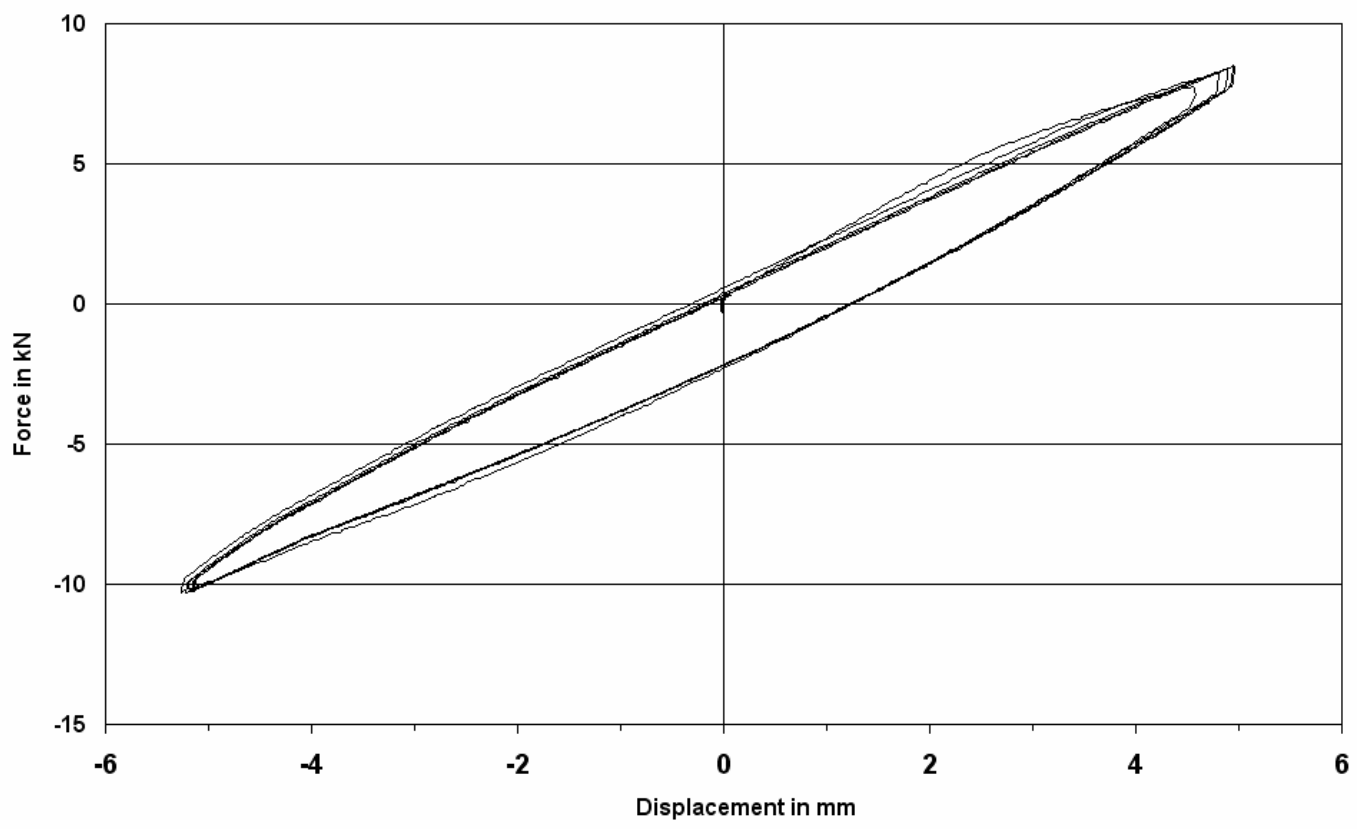

Figure 9-8

Load vs. displacement for Cycles 1 to 5.

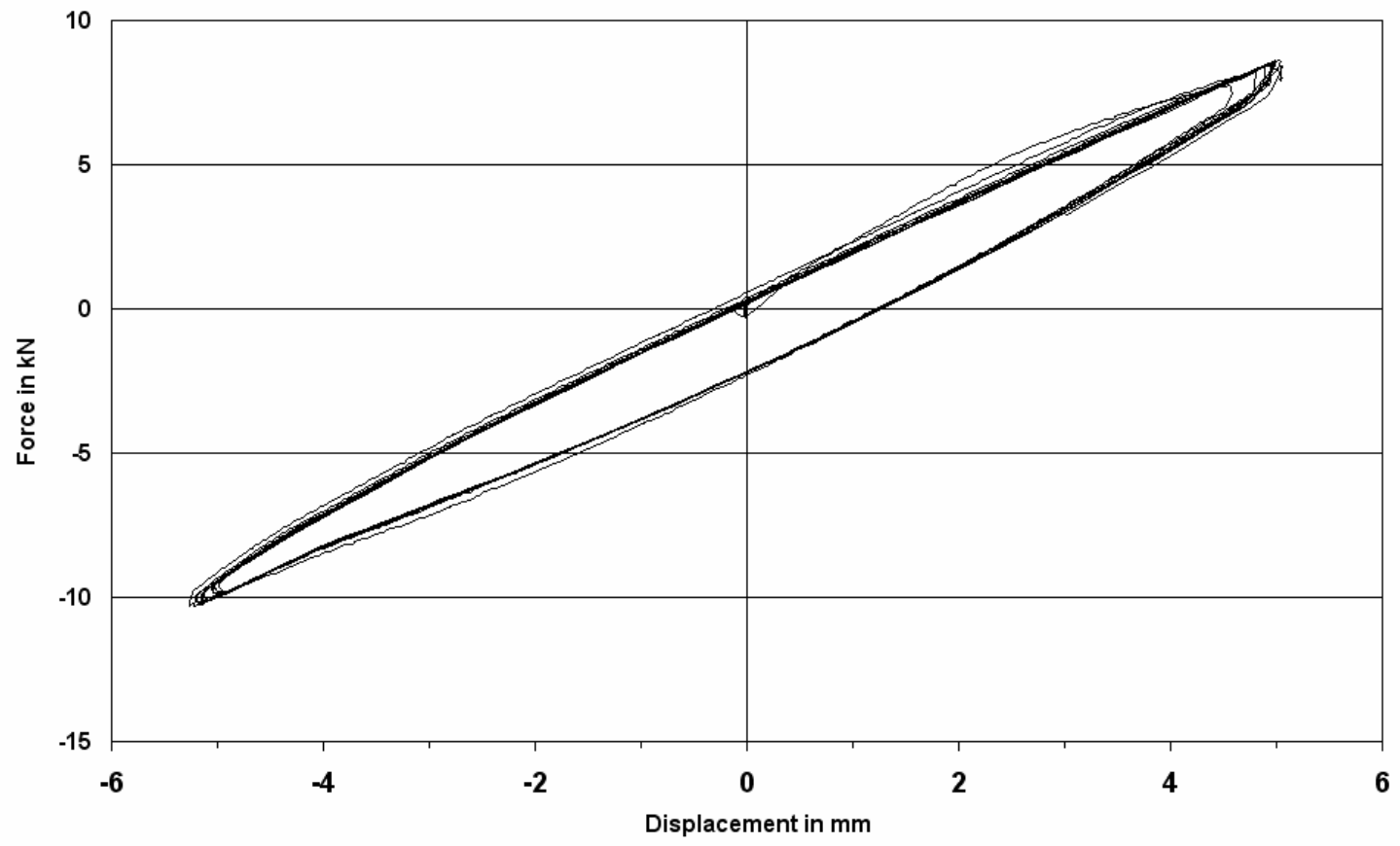

Figure 9-9

Load vs. displacement for Cycles 1 to 10. 


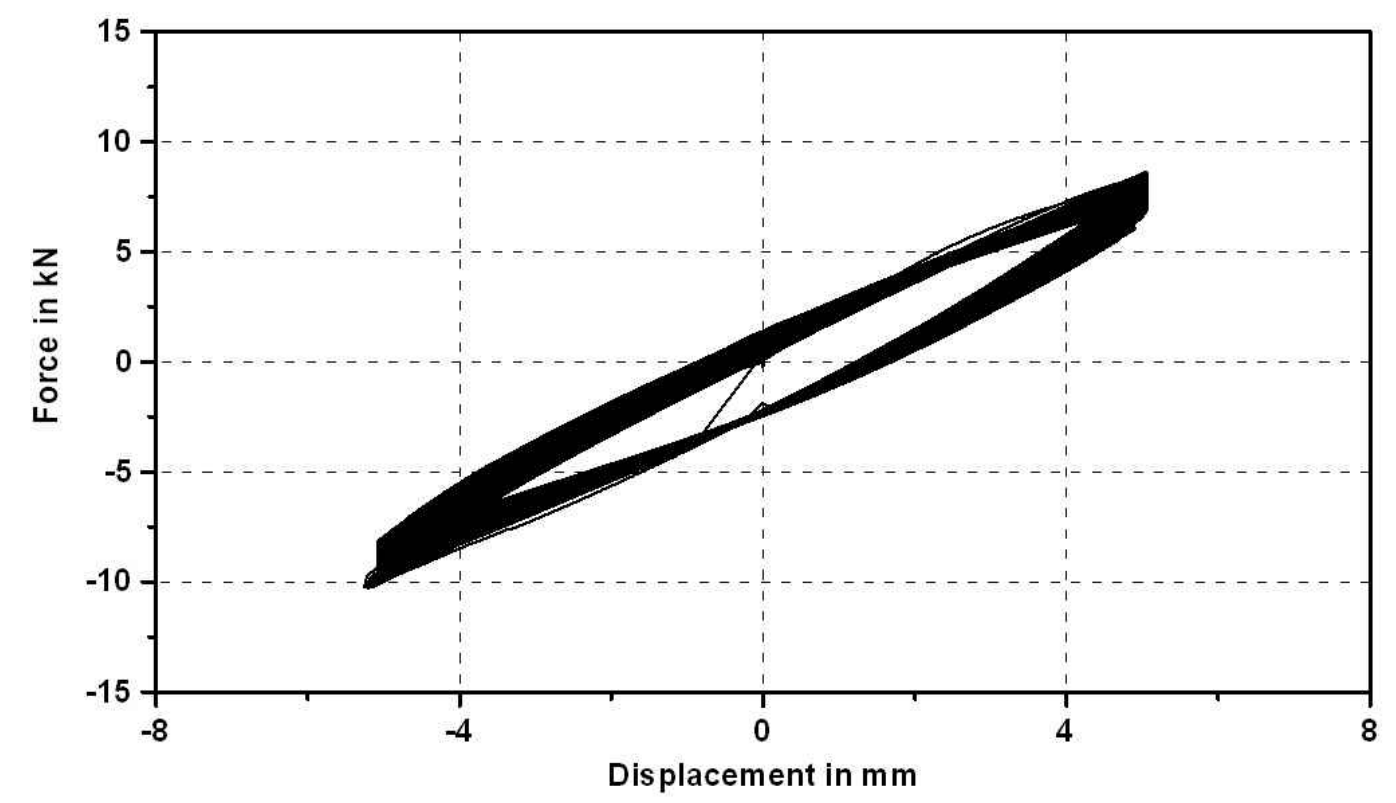

Figure 9-10

Load vs .displacement for the entire test

\section{Post Test Characterization}

After the physical testing part of environmental test $4 \mathrm{~b}$ was accomplished, the U-bend was removed from the testing rig, the additional tubing for optimized flow condition was cut off and the bend was prepared for post test characterization entailing the following tasks:

- Visual inspection of tested U-bend

- Dye penetrant inspection (DPI)

- Fractography of selected locations including examination at high magnifications using scanning electron microscopy (SEM)

- Metallography of selected locations of interest

\section{Visual Inspection}

Visual inspection revealed one primary axial defect with an approximate length of $10 \mathrm{~mm}$. The crack was located in the $270^{\circ}$ position as shown in Figure 9-11. Small remnants of crystallized boric acid were found adjacent to the leakage indicating that this defect had developed into a through wall fissure causing the loss of some environment. No other primary defects visible to the naked eye were found on the external surface during visual inspection. 


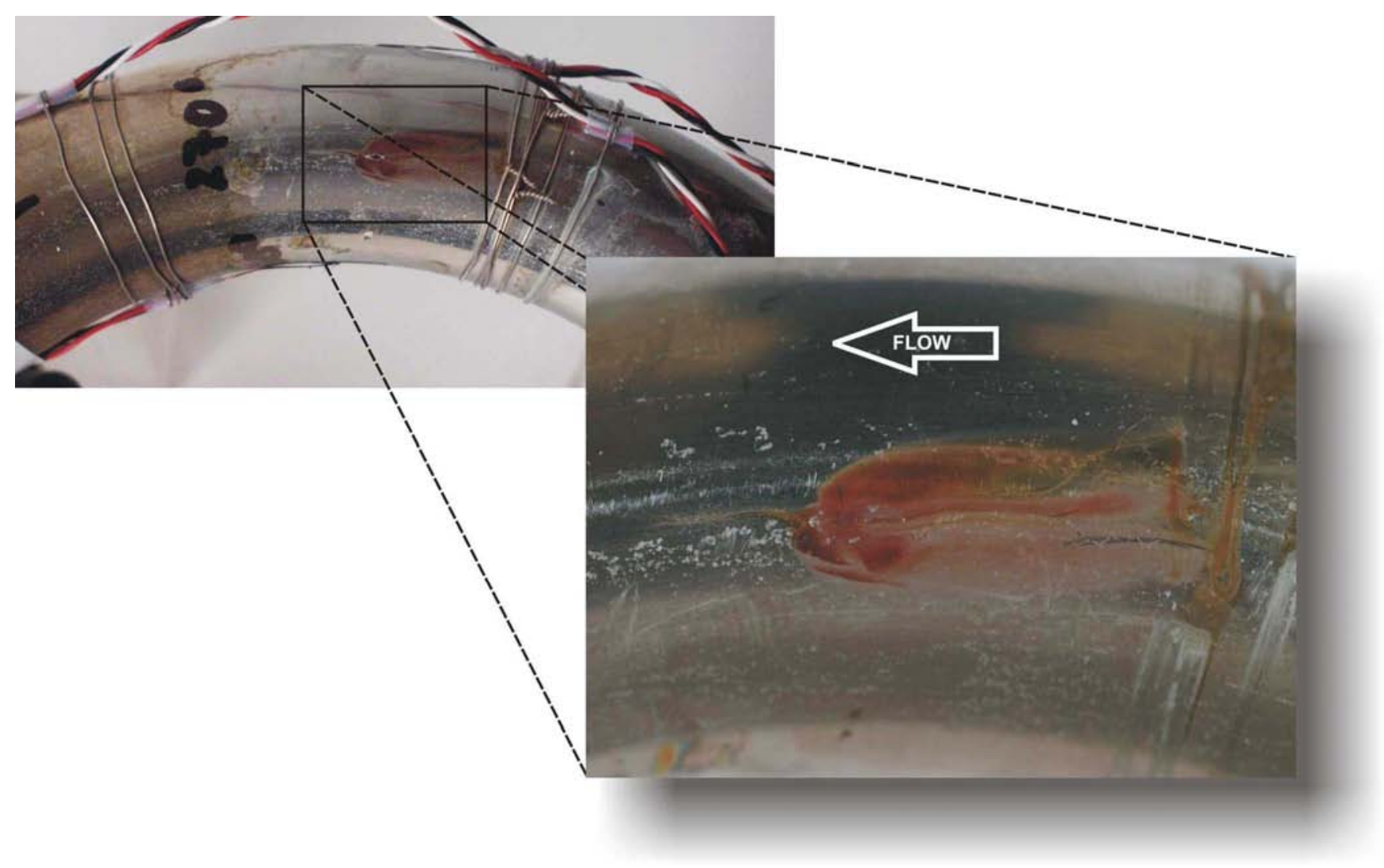

Figure 9-11

Visual inspection revealed leakage in the $270^{\circ}$ position.

\section{Dye Penetrant Inspection}

A narrow piece containing the bend apex with an approximate length of $100 \mathrm{~mm}$ was sectioned from the bend and split in two half shells for further inspection with dye penetrant. Both the internal and external surfaces were examined.

The findings from visual inspection were confirmed, since the $270^{\circ}$ position exhibited an axial fissure on the external surface as shown in Figure 8-12. The internal surface of the same location exhibited a narrow band of multiple axial cracking, which extended over a length of approximately $70 \mathrm{~mm}$ as displayed in Figure 9-13.

Also, the internal surface at the $90^{\circ}$ position revealed a narrow band of axial cracking showing similar extensions. However, the cracking was less pronounced if compared to the $270^{\circ}$ position (see Figure 9-14). The external surface at the $90^{\circ}$ position was free of indications. 


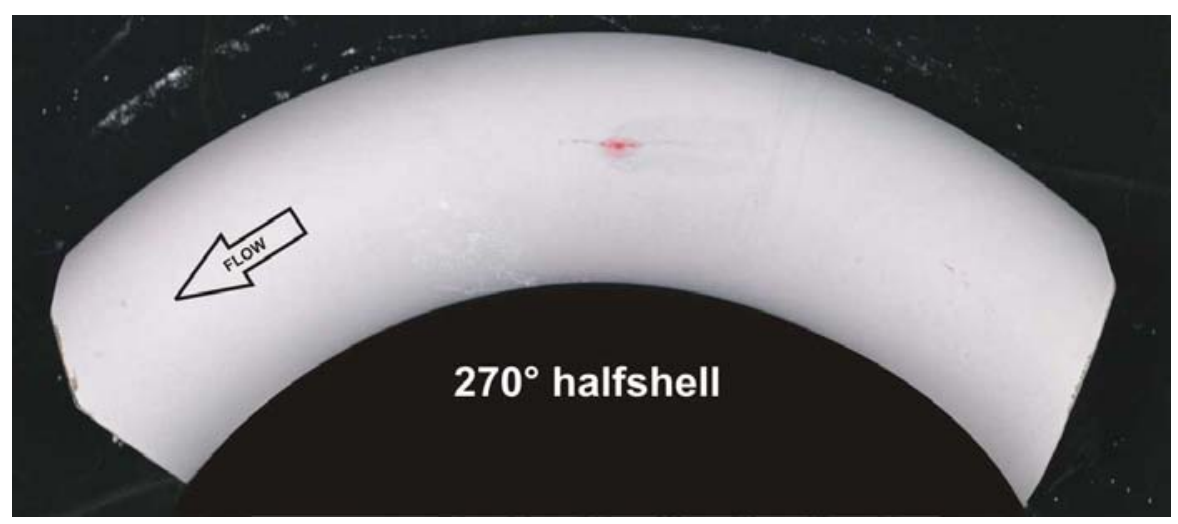

Figure 9-12

External surface at $270^{\circ}$ position revealing axial through-wall defect.

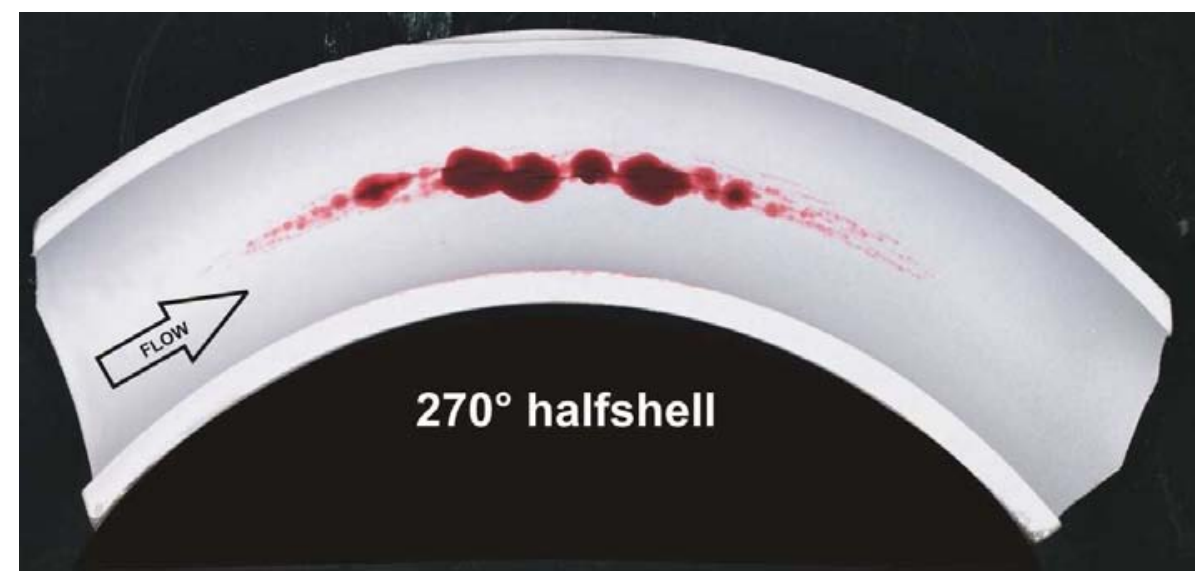

Figure 9-13

Internal surface at $270^{\circ}$ position revealing multiple axial cracking.

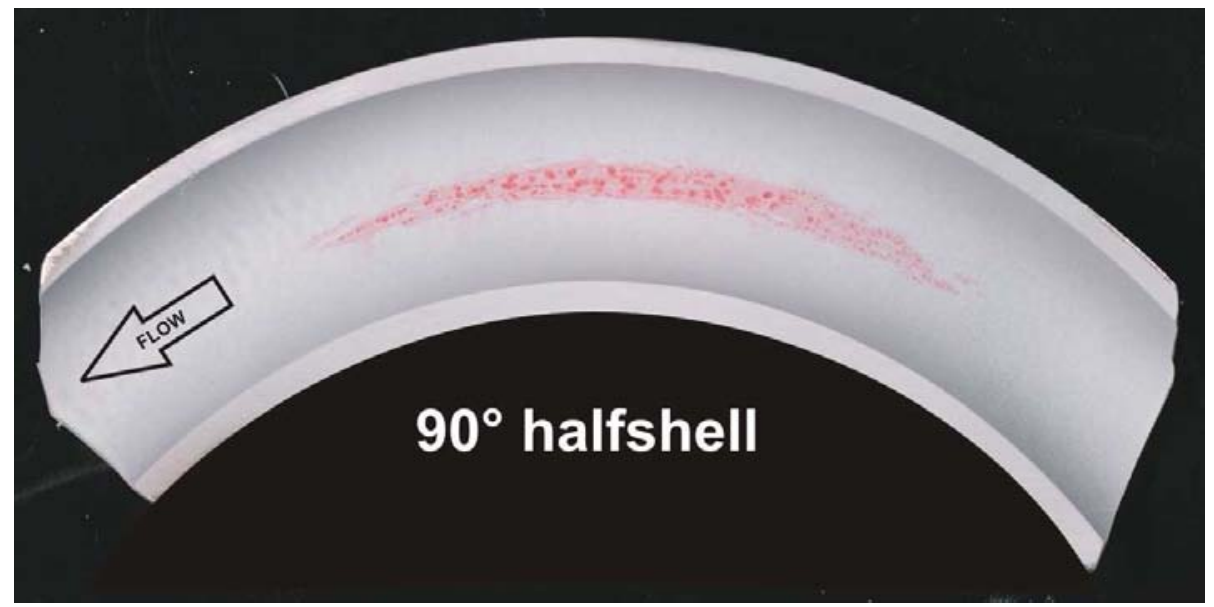

Figure 9-14

Internal surface at $90^{\circ}$ position revealing multiple axial cracking. 
The $180^{\circ}$ intrados position also revealed a narrow band of multiple axial cracking on the internal surface as shown in Figure 9-15. The external surface of this location was free of cracking. The $0^{\circ}$ extrados position was free of cracking both on the internal and external surfaces.

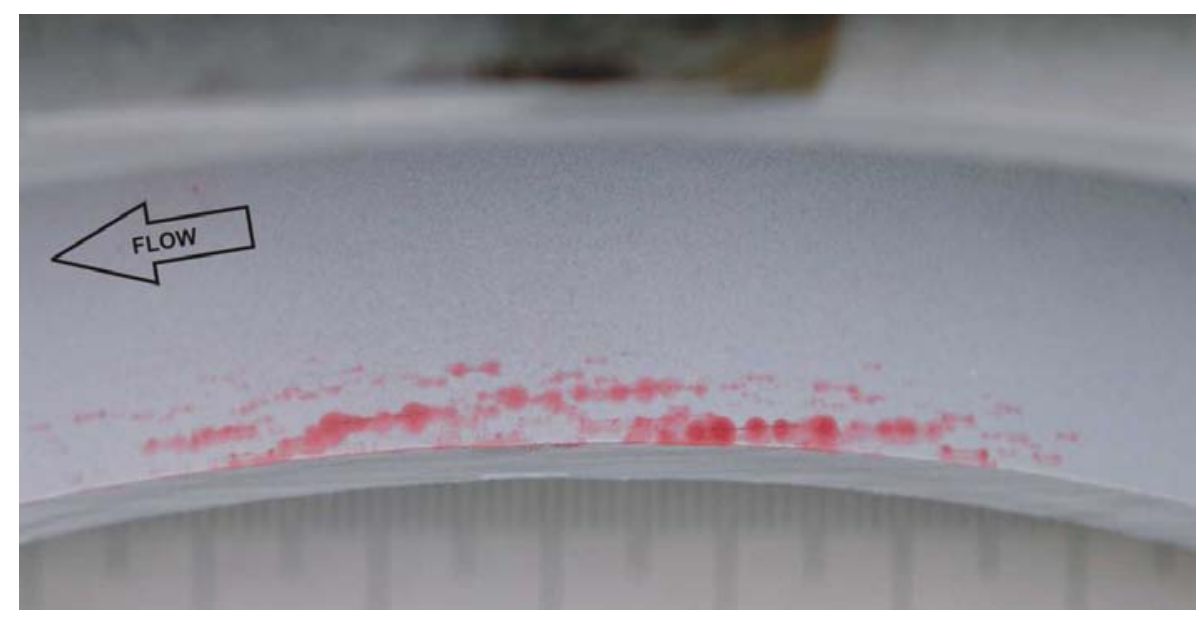

Figure 9-15

Internal surface at $180^{\circ}$ intrados position revealing multiple axial cracking.

\section{Scanning Electron Microscopy}

The internal surfaces of locations of interest were examined at higher magnifications using the SEM. Findings from DPI were confirmed since the $270^{\circ}$ position revealed multiple axial cracking that had initiated on the internal surface along attacked grain boundaries. A typical example of cracking found at the internal $270^{\circ}$ position is shown in Figure 9-16.

Also the $90^{\circ}$ and $180^{\circ}$ positions showed axial cracking, but, as already shown during DPI, the extent of cracking in both cases were less pronounced if compared to the $270^{\circ}$ position. The crack initiation again seemed to be associated with attacked grain boundaries. A typical example of axial cracking found at the internal $90^{\circ}$ and $180^{\circ}$ positions is displayed in Figure 9-17 and Figure 9-18, respectively. 


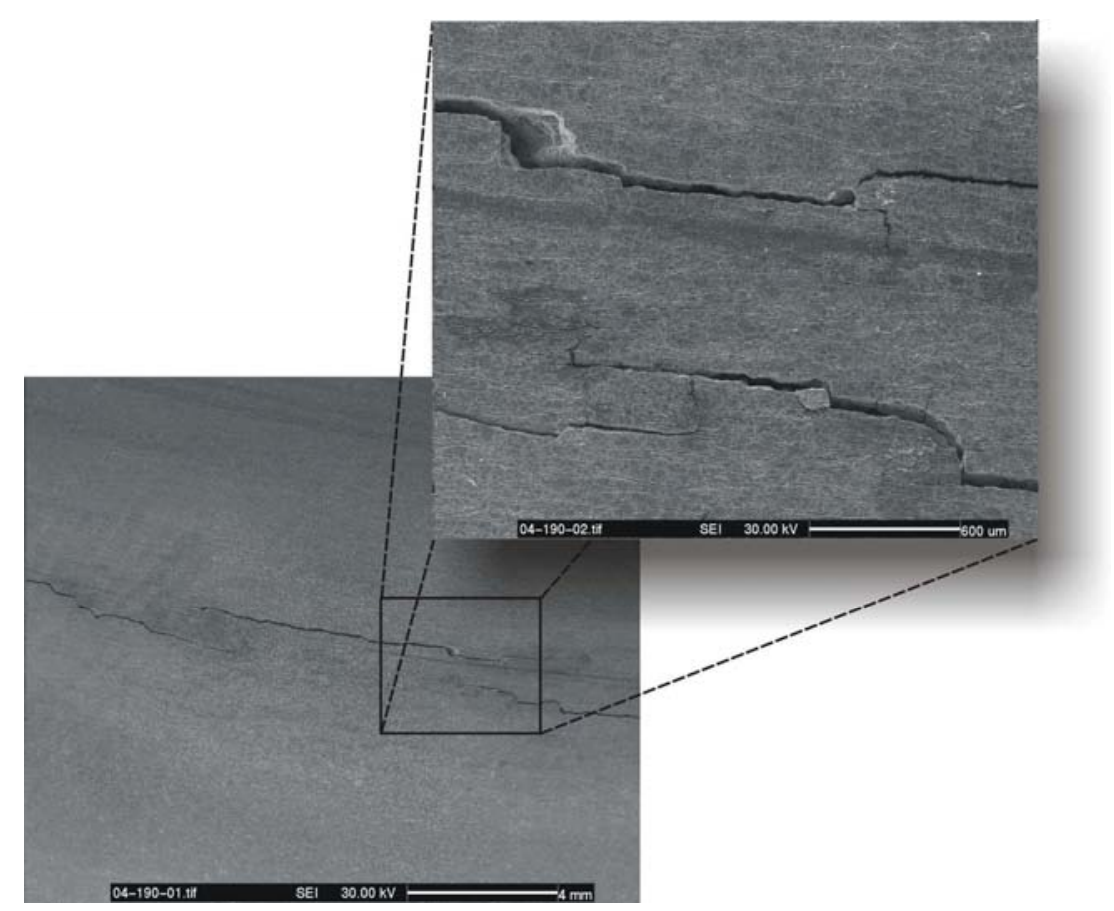

Figure 9-16

Internal surface examination of $270^{\circ}$ position showing axial cracking that followed attacked grain boundaries from pickling treatment.

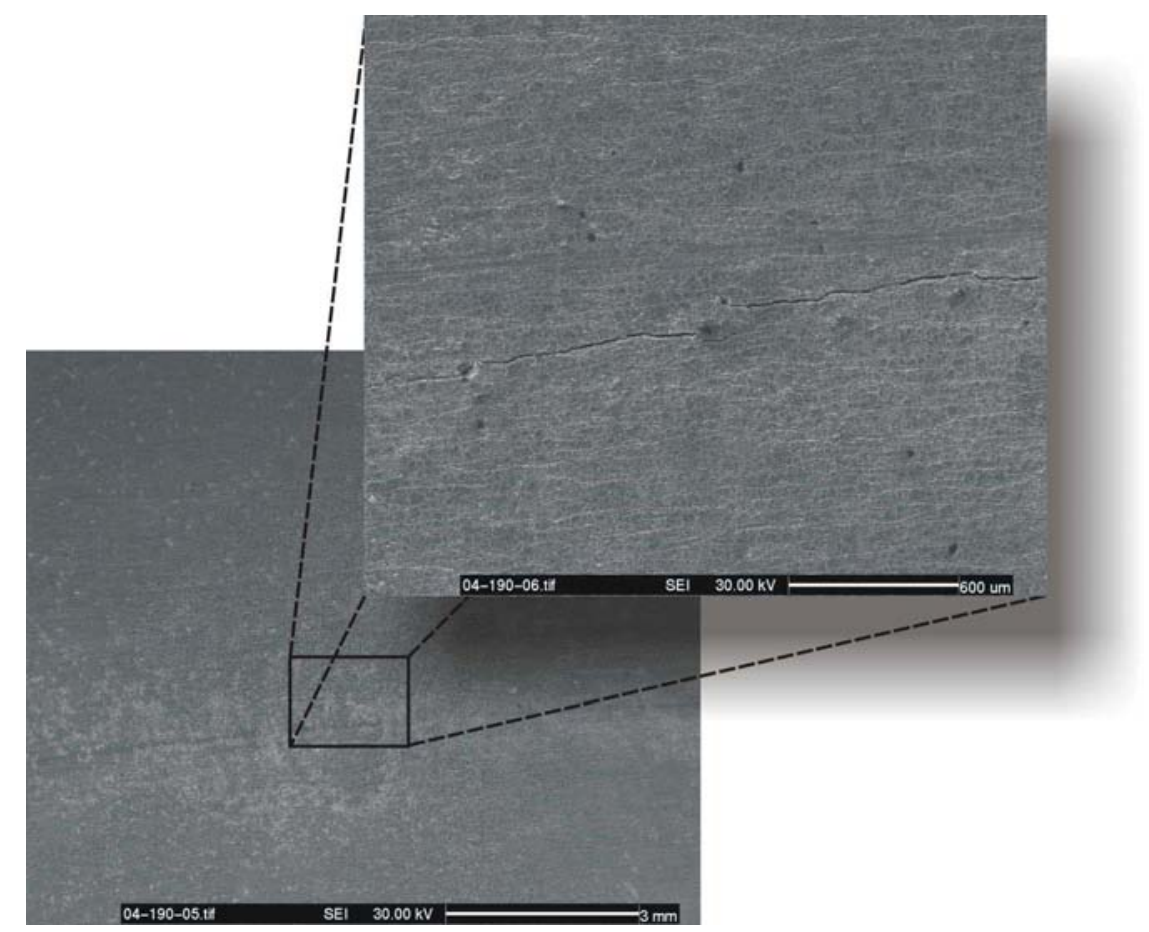

Figure 9-17

Internal surface examination of $90^{\circ}$ position showing axial cracking that followed attacked grain boundaries from pickling treatment. 


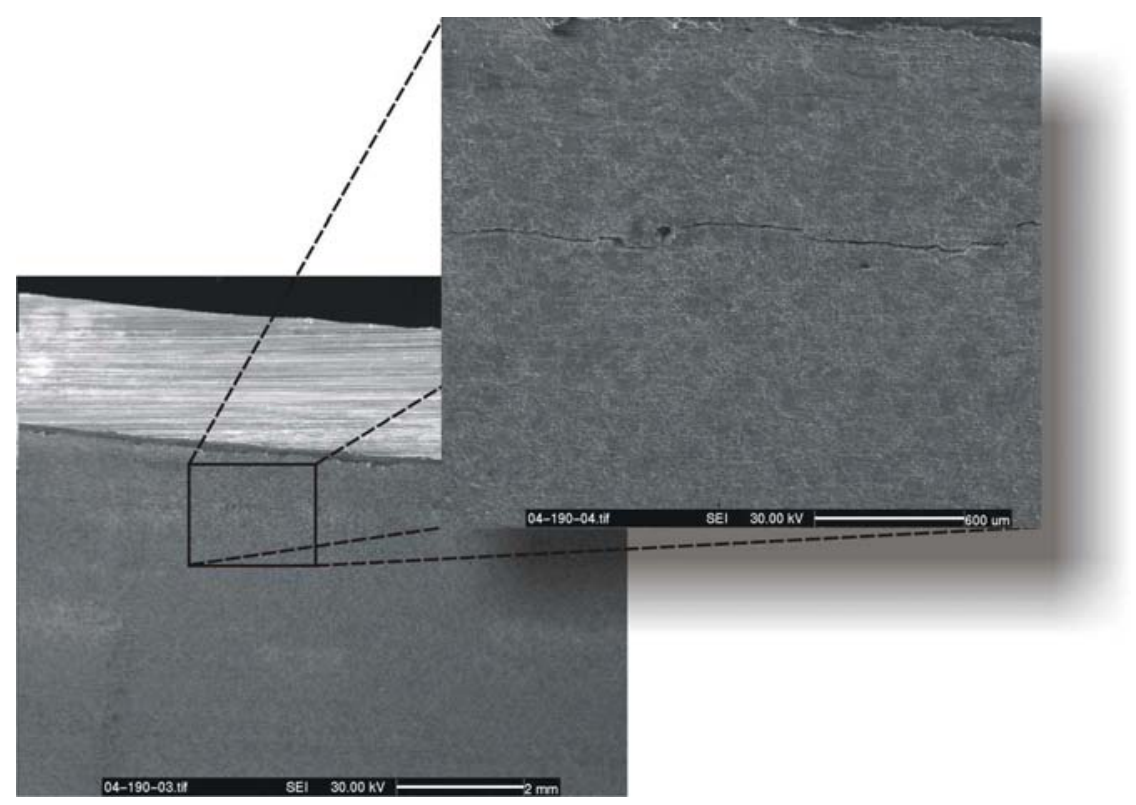

Figure 9-18

Internal surface examination of $180^{\circ}$ position showing axial cracking.

One representative crack of the primary defect causing leakage was broken open to allow fractography at higher magnifications. Figure 9-19 displays the specimen used for SEM examination. This location revealed a fracture appearance with striations indicating a step-wise crack progression under cyclic loading. The fact that the fracture progressed from the internal towards the external surface, the general morphology and the multiple crack presence at this location indicated corrosion fatigue. The striation spacing was then determined by evaluating corresponding images of the fracture surface. The spacing in the area associated with crack initiation was determined as approximately $1.5 \mu \mathrm{m}$. The mid fracture area showed a spacing of approximately $1.2 \mu \mathrm{m}$. The final stages of the crack disclosed a striation spacing of approximately $3.5 \mu \mathrm{m}$. Typical views of the different zones of the opened fracture are shown in Figure 9-20.

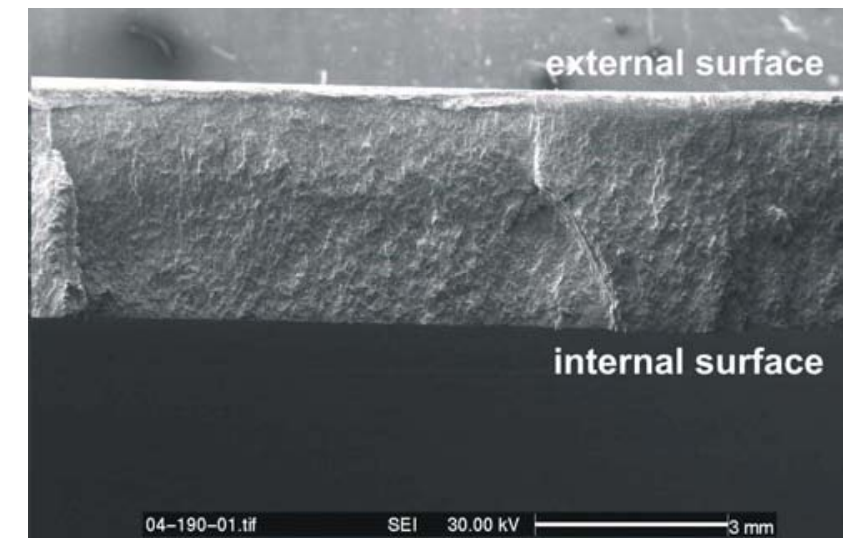

Figure 9-19

Opened axial fracture of $270^{\circ}$ position. 


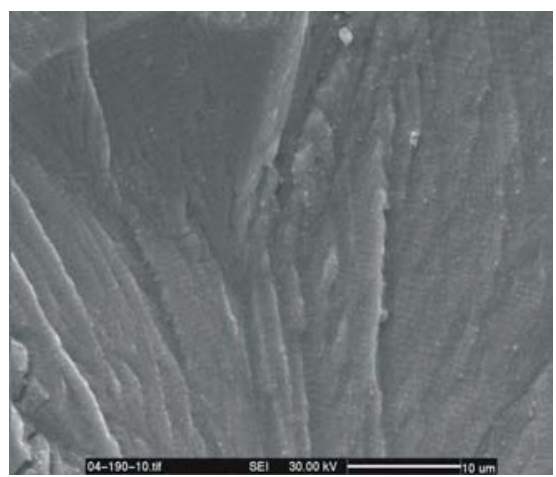

crack initiation

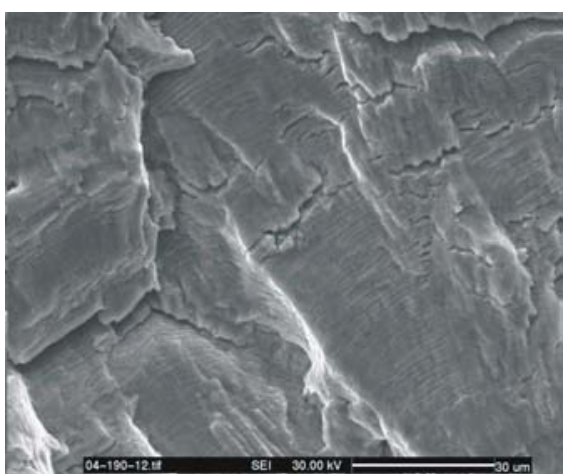

mid fracture

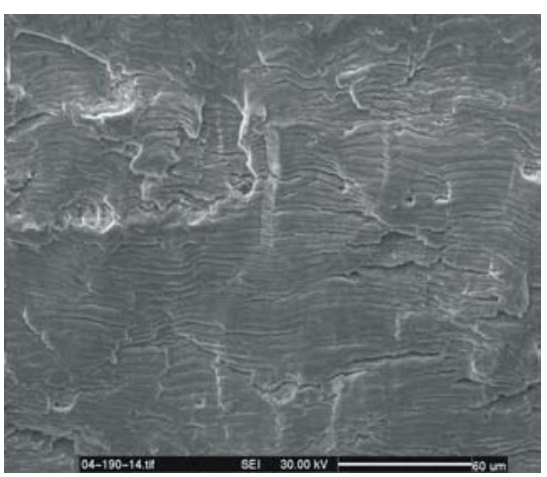

final stages

Figure 9-20

Typical views of fracture surface found at the $270^{\circ}$ position; the morphology indicates step-wise crack progression under the combined influence of mechanical loading and environment.

\section{Metallography}

The selected locations S1 and S2 (see Figure 9-21) were extracted from the U-bend half shells for metallurgical analysis. The specimens were mounted into bakelite and polished to a $1 \mu \mathrm{m}$ surface finish and etched with appropriate agents. The examination was performed with a metallurgical microscope.
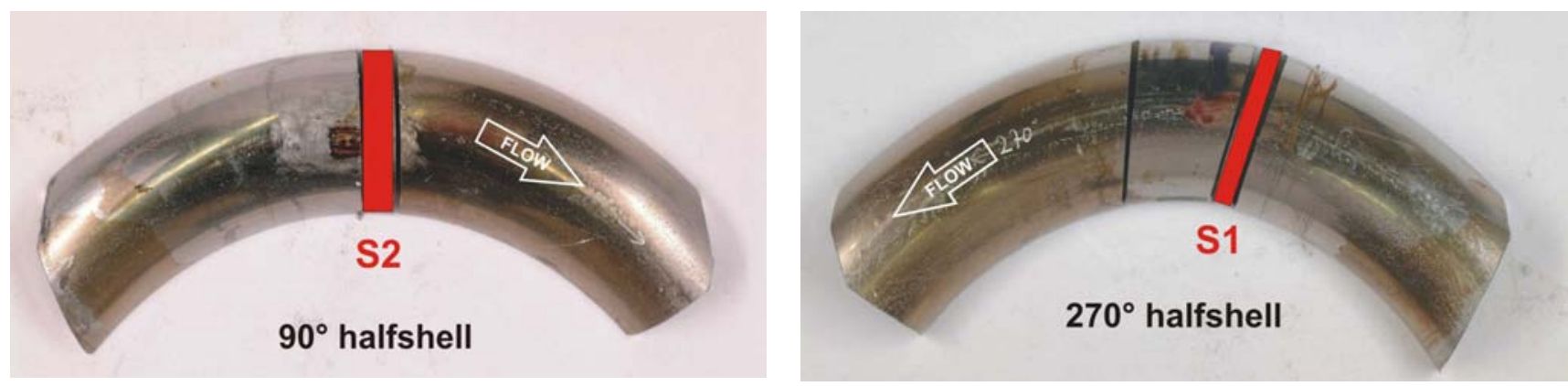

Figure 9-21

Specimen removal plan for metallographic examination.

The microstructure of all examined specimens exhibited features typical for austenitic stainless steels and was considered sound. No anomalies that could have contributed to the failure were found.

Metallurgical analysis of the $270^{\circ}$ position confirmed one primary axial through-wall defect that had initiated on the internal surface and had propagated towards the external surface in a transgranular manner. This primary defect was also accompanied by numerous smaller axial 
cracks, the maximum depth of which was determined as approximately $940 \mu \mathrm{m}$, representing about 28 \% of the tube’s wall thickness see Figure 9-22).

Also, the $180^{\circ}$ position exhibited transgranular axial cracking propagating from the internal towards the external surface. The approximate crack depth within this prepared cross-section was determined as $960 \mu \mathrm{m}$, representing about $28 \%$ of the tube's wall thickness. Figure 9-23 displays a typical example of cracking found in this position.

The $90^{\circ}$ position presented very similar findings with multiple axially oriented, transgranular cracking that had initiated on the internal surface and propagated towards the external surface. The maximum crack depth within this prepared cross-section was determined as $745 \mu \mathrm{m}$, representing about $22 \%$ of the tube's wall thickness. Figure 9-24 displays a typical example of cracking found in the $90^{\circ}$ position.

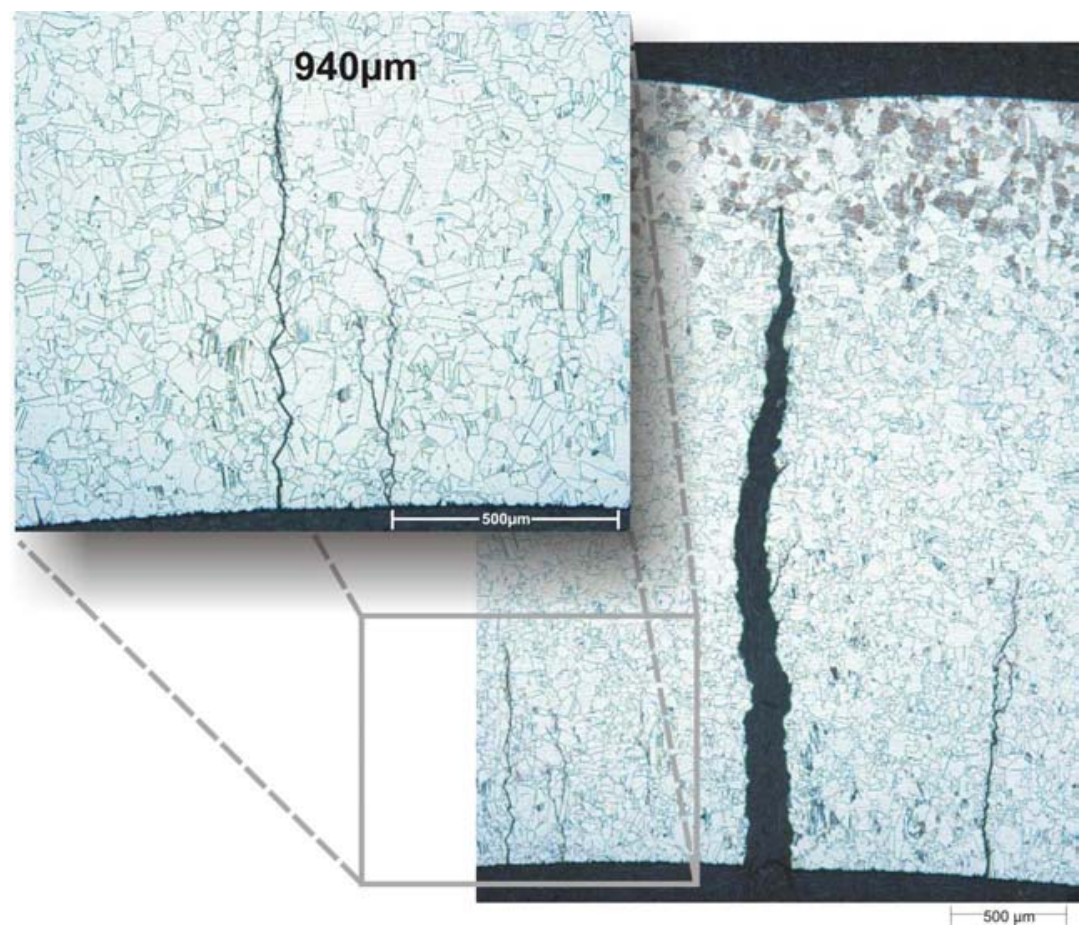

Figure 9-22

Cross sectional view of $270^{\circ}$ position showing multiple transgranular cracks propagating from the internal towards the external surface (Specimen S1). 


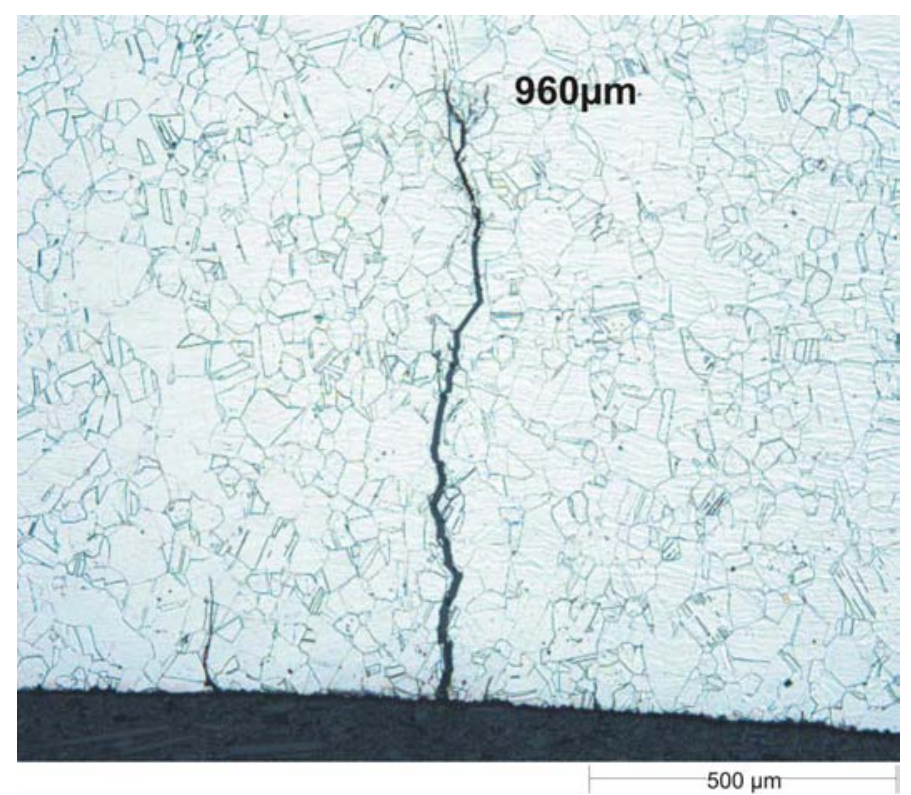

Figure 9-23

Cross-sectional view of $180^{\circ}$ position showing multiple transgranular cracks propagating from the internal towards the external surface (Specimen S1); the numbers represent approximate crack depths.

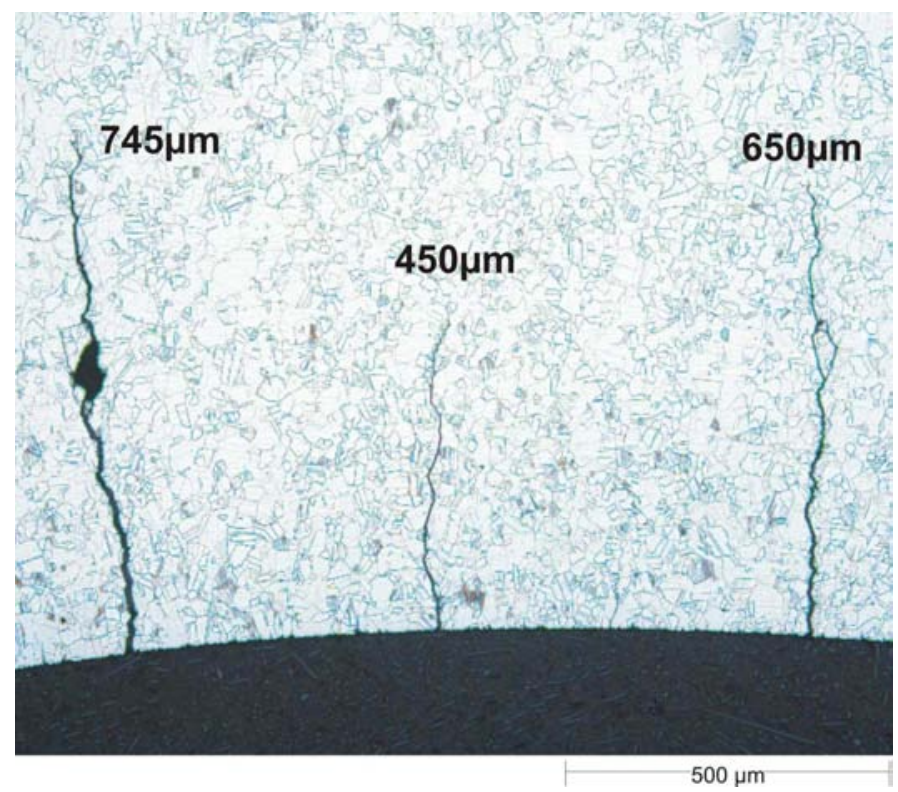

Figure 9-24

Cross-sectional view of $90^{\circ}$ position showing multiple transgranular cracks propagating from the internal towards the external surface (Specimen S2); the numbers represent approximate crack depths. 


\section{Summary of Results}

The following results can be summarized from environmental test 4b:

- Water chemistry within the range of specified values

- $\quad$ ECP $-550 \mathrm{mV}_{\mathrm{H}, \mathrm{T}}$, Redox Pot. $-450 \mathrm{mV}_{\mathrm{H}, \mathrm{T}}$ for high flow rate $(\approx 2.1 \mathrm{~m} / \mathrm{s})$

- Total number of cycles: 3616

- Leakage due to internally initiated axial through-wall defect in the $270^{\circ}$ position

- Polishing of external surface resulted in no external crack initiation in this test

- All internal defects at $90^{\circ}, 180^{\circ}$ and $270^{\circ}$ were axial, environmentally assisted cracks; Initiation appeared to have occurred predominantly along surface texture caused by pickling

- Location $0^{\circ}$ was free of cracking

- No internal circumferential cracking was observed

- No microstructural anomalies were observed

Figure 9-25 provides a graphic summary of the extent of cracking and crack locations.

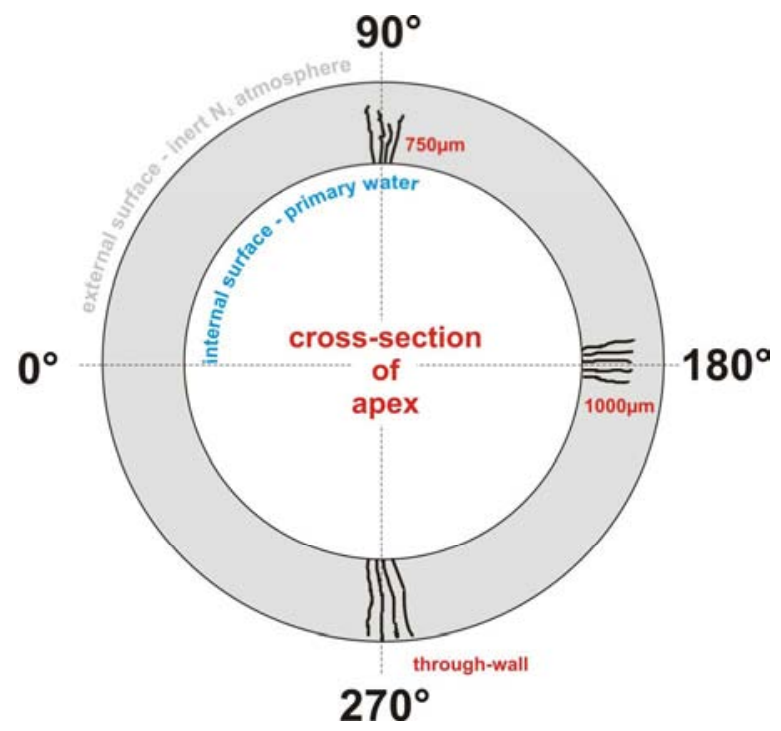


Figure 9-25

Schematic summary of crack locations, orientation and approximate crack depths (if available) of Test $4 \mathrm{~b}$; schematic provides a cross-sectional view of the apex looking downstream; please note that schematic is not to scale.

\section{Conclusions from Test $4 \mathrm{~b}$}

This test clearly showed an effect of primary water on the fatigue behavior of the U-bend under cyclic load, since multiple axial cracking at the internal surface of the apex was observed and characterized. Having implemented a less severe strain amplitude of $0.4 \%$ and, more importantly, a polished external surface at the apex, the environmental aspects of failure were dominant. No external, purely mechanical crack initiation occurred in this test. The bend of test 4b definitely failed from internally initiating cracks due to combined efforts of mechanical loading and environment, since all fracture surfaces exhibited evidence of corrosion fatigue.

A beneficial effect of the high flow rate (4100 l/h versus $10 \mathrm{l} / \mathrm{h})$ was not observed. Very similar to test $4 \mathrm{a}$, this test achieved a total number of approximately 3616 cycles. Again the crack initiation at all internal surfaces appeared to be favored by attacked grain boundaries as a result of the pickling treatment during the U-bend manufacturing. 


\section{0 \\ ENVIRONMENTAL TEST 4D}

\section{Test Set-Up and Approach}

In analyzing all previously conducted tests, the question arose whether counter-measures should be implemented to minimize the effects of surface discontinuities on crack initiation. Polishing of the external surface during test $4 \mathrm{~b}$ successfully prevented external crack initiation. However, Framatome suspected that attacked grain boundaries from pickling and most likely also traces from the bending mandrel had acted as crack initiation sites on the internal surface. Hence, it was decided to perform a test with both externally and internally polished surfaces. This test, not being part of the initial text matrix, was labeled test $4 \mathrm{~d}$ and performed with the following U-bend instrumentation and basic test parameters:

- internally electropolished surface to minimize surface effects on internal crack initiation

- $\quad$ pre-conditioning of the internal surface by lengthy exposure to simulated primary water

- $\quad$ instrumented U-bend with three bonded HT strain gauges at the $0^{\circ}, 90^{\circ}$ and $180^{\circ}$ position

- externally polished apex area to minimize surface effects on external crack initiation

- $\quad$ strain amplitude of $\pm 0.4 \%$ (total strain range of $0.8 \%$ )

- $\quad$ strain rate of $1 \times 10^{-4} \mathrm{~s}^{-1}$

- $\quad$ testing temperature $\mathrm{T}=240^{\circ} \mathrm{C}$, pressure $\mathrm{p}=50$ bar

- HT water chemistry comprised 1200 ppm B as $\mathrm{H}_{3} \mathrm{BO}_{3}+2 \mathrm{ppm} \mathrm{Li}$ as $\mathrm{LiOH}$

- oxygen content was adjusted to $<<10 \mathrm{ppb}$, no $\mathrm{H}_{2}$ injection

- the impurity level was adjusted to $\mathrm{Cl}^{-}+\mathrm{F}^{-}+\mathrm{SO}_{4}{ }^{2-}<100 \mathrm{ppb}$

- water sampling and chemical analysis of $\mathrm{B}, \mathrm{Li}, \mathrm{Cl}^{-}, \mathrm{F}^{-}, \mathrm{SO}_{4}{ }^{2-}, \mathrm{pH}$ during start-up and before shut down 
- high flow rate: $4100 \mathrm{l} / \mathrm{h} \approx 2.2 \mathrm{~m} / \mathrm{s}$ for $26.5 \mathrm{~mm} \mathrm{ID}$

\section{Electropolishing}

The electro-polishing of the internal surface was performed by the company Poligrat based in Munich. Prior to actual testing, a trial bend was used to confirm the effectiveness of the polishing process. Generally the electro-polishing removing approximately $30 \mu \mathrm{m}$ was able to smoothen most of the texture formed by the attacked grain boundaries as shown in Figure 10-1.

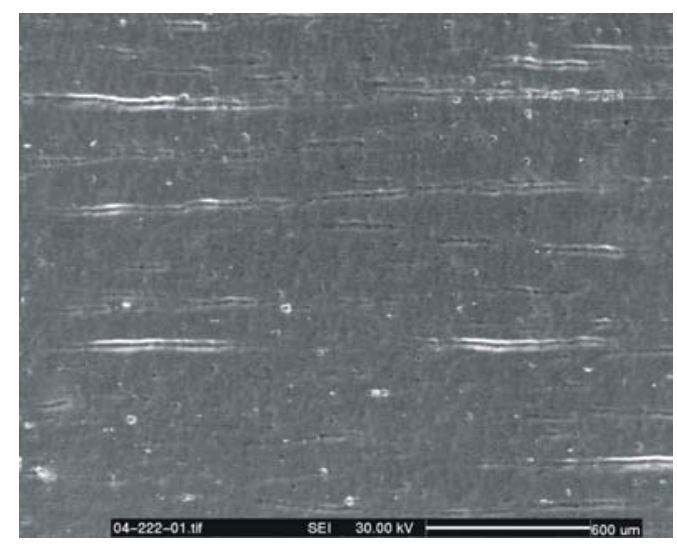

\section{Figure 10-1}

Typical view of electropolished surface obtained by SEM of trial bend.

However, a certain axial texture originating partly from inclusions and partly from traces left behind by the bending mandrel was still evident. Figure 10-2 displays an SEM photograph at higher magnifications showing the internal surface of the trial bend in the as-polished condition versus a non-polished surface taken from a typical bend that was subject to testing. Most of the "intergranular" attack was removed. After the results were found to be satisfactory in (mutual agreement with EPRI) the bend intended for test $4 \mathrm{~d}$ was electro-polished followed by the regular pre-oxidation performed prior to every test.

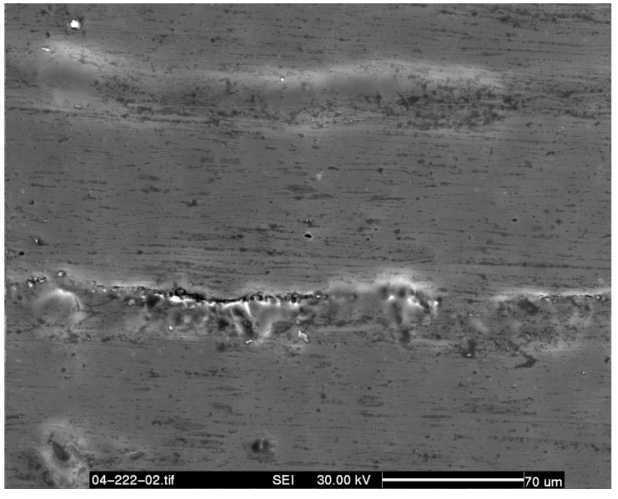

a) electropolished

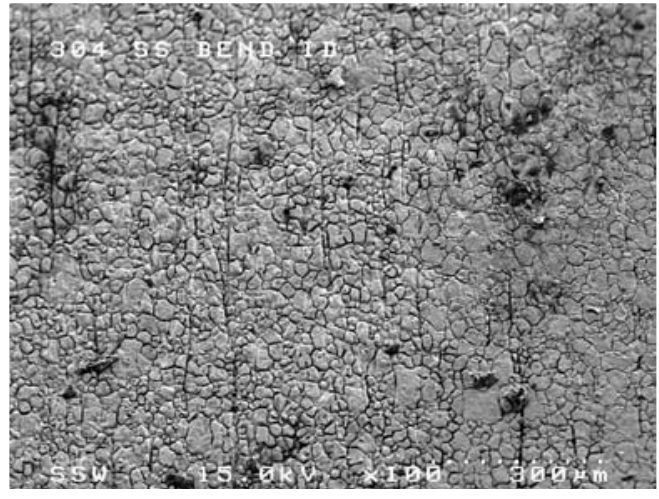

b) as-received from $B \& W$ 
Figure 10-2

Comparison of electropolished surface with typical as-received surface.

\section{Results}

\section{Water Chemistry}

The mechanical loading of the U-bend during testing was not commenced until the specified requirements with respect to test temperature, water chemistry/purity and electrochemical corrosion/redox potentials were met. Water sampling before start-up and loading assured this as displayed in Table 10-1.

\begin{tabular}{|c|c|c|c|c|c|c|c||}
\hline $\begin{array}{c}\text { water } \\
\text { sampling }\end{array}$ & $\begin{array}{c}\mathbf{B} \\
\mathbf{p p m}\end{array}$ & $\begin{array}{c}\mathbf{L i} \\
\mathbf{p p m}\end{array}$ & $\mathbf{p H}$ & $\begin{array}{c}\text { chloride } \\
\mathbf{p p b}\end{array}$ & $\begin{array}{c}\text { sulfate } \\
\mathbf{p p b}\end{array}$ & $\begin{array}{c}\text { fluoride } \\
\mathbf{p p b}\end{array}$ & remarks \\
\hline $\begin{array}{c}\text { before loading, test } \\
\text { temperature was } \\
\text { reached }\end{array}$ & 1192 & 2.15 & - & - & - & - & $\begin{array}{c}\text { conductivity } \\
\text { outlet: } 23 \mu \mathrm{S} / \mathrm{cm}\end{array}$ \\
\hline during testing & 1235 & 2.11 & 6.5 & $<10$ & $<10$ & 36 & $\begin{array}{c}\text { conductivity } \\
\text { outlet: } 21.8 \mu \mathrm{S} / \mathrm{cm} \\
\mathrm{O}_{2} \approx 2 \mathrm{ppb}\end{array}$ \\
\hline before shut down & 1227 & 2.29 & - & $<10$ & $<10$ & 36 & $\begin{array}{r}\text { conductivity } \\
\text { outlet: } 22 \mu \mathrm{S} / \mathrm{cm} \\
\left(\mathrm{T}=76^{\circ} \mathrm{C}\right)\end{array}$ \\
\hline
\end{tabular}

Table 10-1

Results from water sampling during environmental Test 4 d.

During testing, the water chemistry was monitored continuously with respect to test temperature, conductivity and electrochemical corrosion potential (ECP) and redox potential. Figure 10-3 and Figure 10-4 show the inlet and outlet conductivity, the test temperature as well as ECP and the redox potential for the entire duration of environmental test 4a. The ECP showed values of approximately $-550 \mathrm{mV} \mathrm{H}_{\mathrm{T}}$ and the redox potential was measured at approximately $-500 \mathrm{mV}_{\mathrm{H}, \mathrm{T}}$. The target test temperature of $240{ }^{\circ} \mathrm{C}$ was held very stable for the entire test.

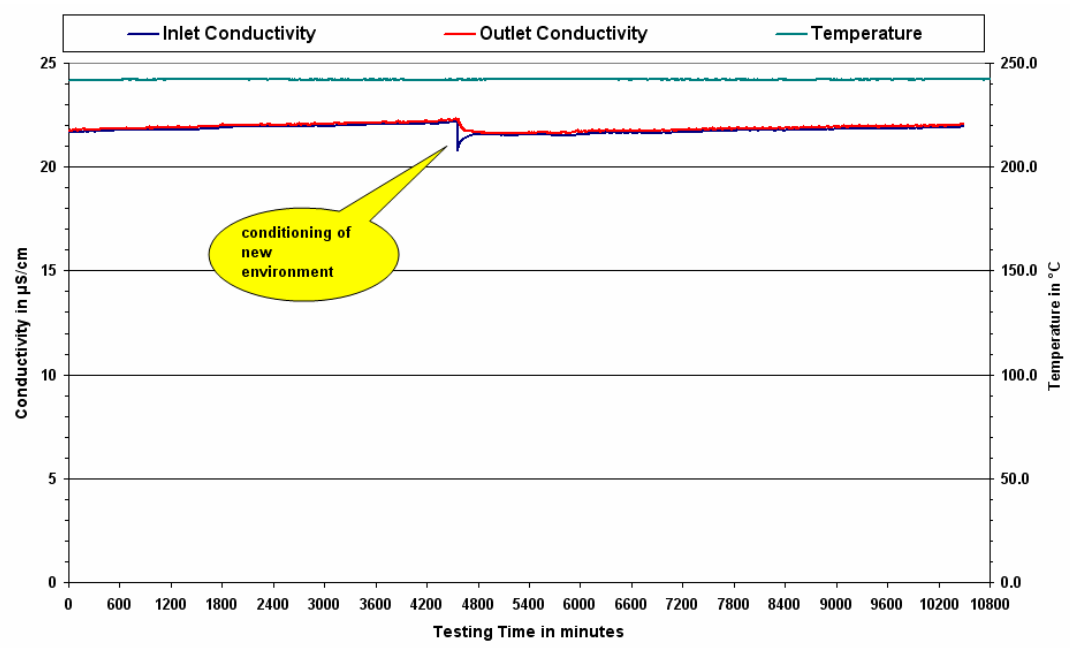


Figure 10-3

Conductivity and temperature vs. testing time.

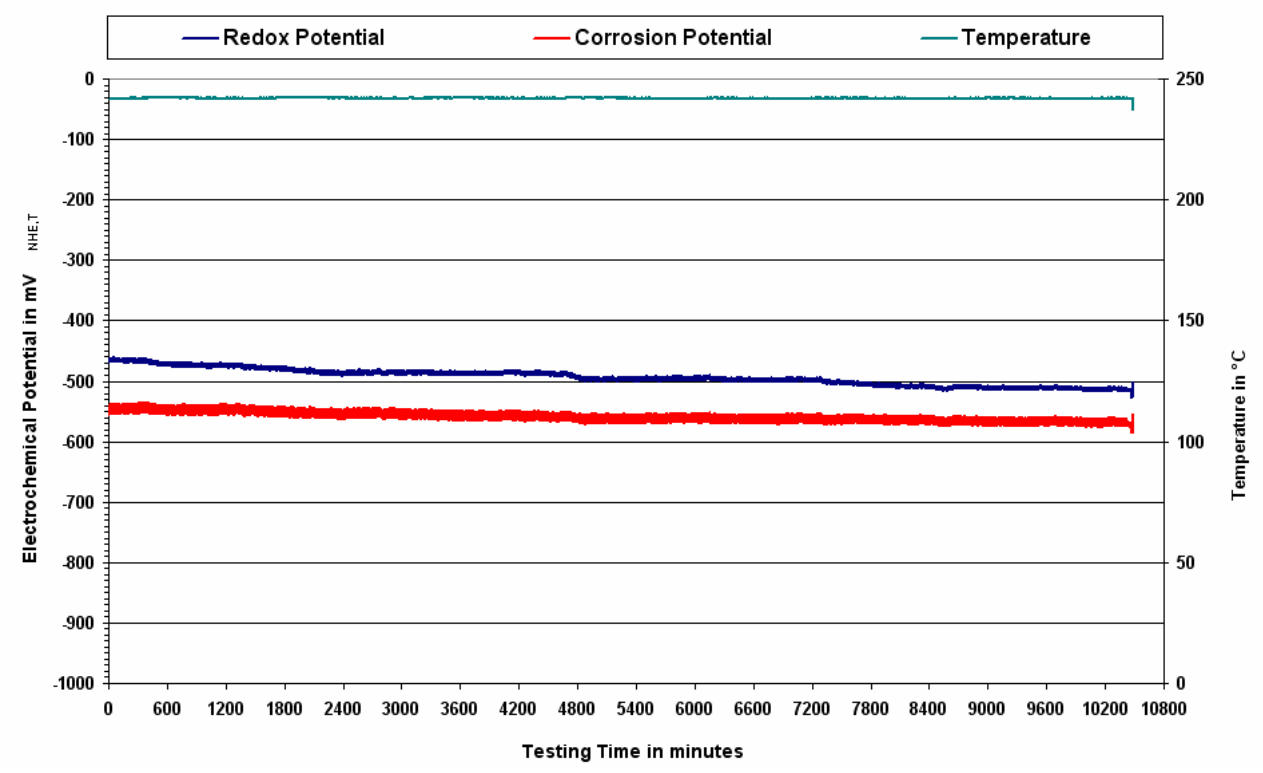

Figure 10-4

Temperature, electrochemical corrosion and redox potential vs. testing time.

\section{Mechanical Data}

Having reached the desired levels with regards to water chemistry and test temperature the loading sequence was started. The basic test parameters used for mechanical loading of the Ubend are given in Table 10-2. Initially the bend was loaded with a triangular wave shape for the first 5 cycles to evaluate the response. The strain rate used for the first 5 cycles was $1 \times 10^{-5} \mathrm{x} \mathrm{s}^{-1}$. Cycles 6 to 10 were performed with a strain rate of $1 \times 10^{-4} \mathrm{x} \mathrm{s}^{-1}$. To this point the test was performed displacement controlled with strain triggered switch points at $\pm 0.4 \%$ strain amplitude. Cycle 10 was used to determine the displacements necessary for the remaining test, which was performed under displacement control only. Figure 10-5and Figure 10-6 illustrate the mechanical data for cycles 1 to 5 and 6 to 10, respectively. The strain response for the cycles 1 to 10 is provided in Figure 10-7. The load vs. displacement hysteresis for the first 10 cycles is displayed in Figure 10-8 and Figure 10-9 and indicated fairly stable bend behavior.

The leading $180^{\circ}$ intrados strain gauge stopped working at approximately cycle 1000 as a result of the cyclic loading. The available strain data is shown in Figure 10-10. Generally, the bend showed relatively stable behavior throughout the entire test since the load response to the given displacements was uniform as displayed in Figure 10-11. The load vs. displacement hysteresis for the entire test is displayed in Figure 10-12. After suffering from a through-wall defect, the test was terminated at cycle 3835. 


\begin{tabular}{|c|c|c|c|c|c||}
\hline cycle & $\begin{array}{c}\text { wave } \\
\text { shape }\end{array}$ & $\begin{array}{c}\text { control } \\
\text { channel }\end{array}$ & strain rate & switch point & $\begin{array}{c}\text { switch off } \\
\text { criterion }\end{array}$ \\
\hline $\mathbf{0 - 5}$ & triangular & $\begin{array}{c}\text { displacement } \\
\text { strain triggered } \\
\text { switching point }\end{array}$ & $1 \times 10^{-5} \mathrm{~s}^{-1}$ & $\begin{array}{c}+0.4 \% \\
-0.4 \%\end{array}$ & \\
\hline \multirow{2}{*}{$\mathbf{1 0}$} & triangular & $\begin{array}{c}\text { displacement } \\
\text { strain triggered } \\
\text { switching point }\end{array}$ & $1 \times 10^{-4} \mathrm{~s}^{-1}$ & $\begin{array}{l}+0.4 \% \\
-0.4 \%\end{array}$ & \\
\hline $\mathbf{1 0} \mathbf{- 3 8 3 5}$ & triangular & displacement & $1 \times 10^{-4} \mathrm{~s}^{-1}$ & $\begin{array}{l}+4.83 \mathrm{~mm} \\
-5.03 \mathrm{~mm}\end{array}$ & failure \\
\hline
\end{tabular}

Table 10-2

Basic test parameters of mechanical loading during Test $4 d$.

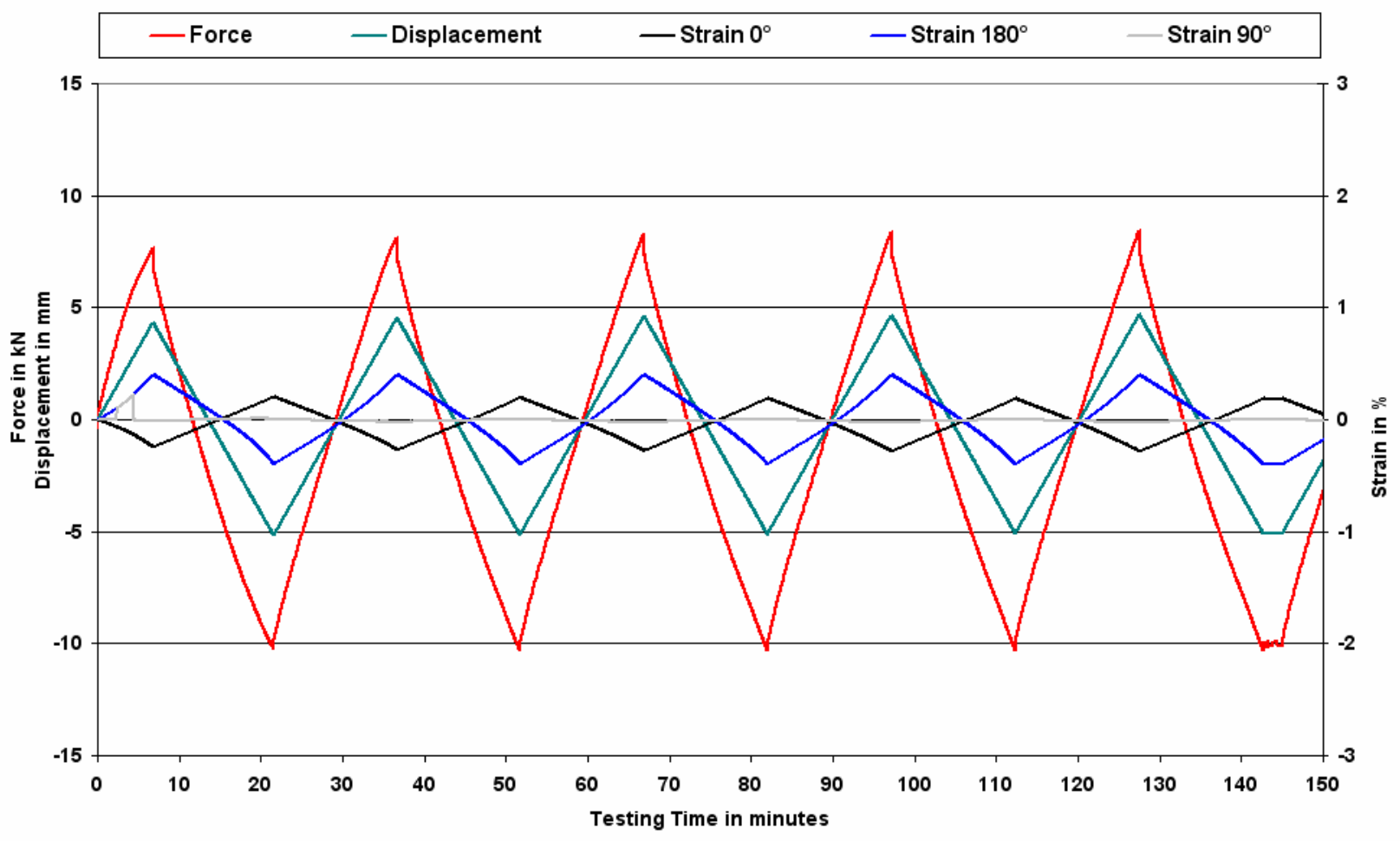

Figure 10-5

Mechanical data for Cycles 1 to 5 . 


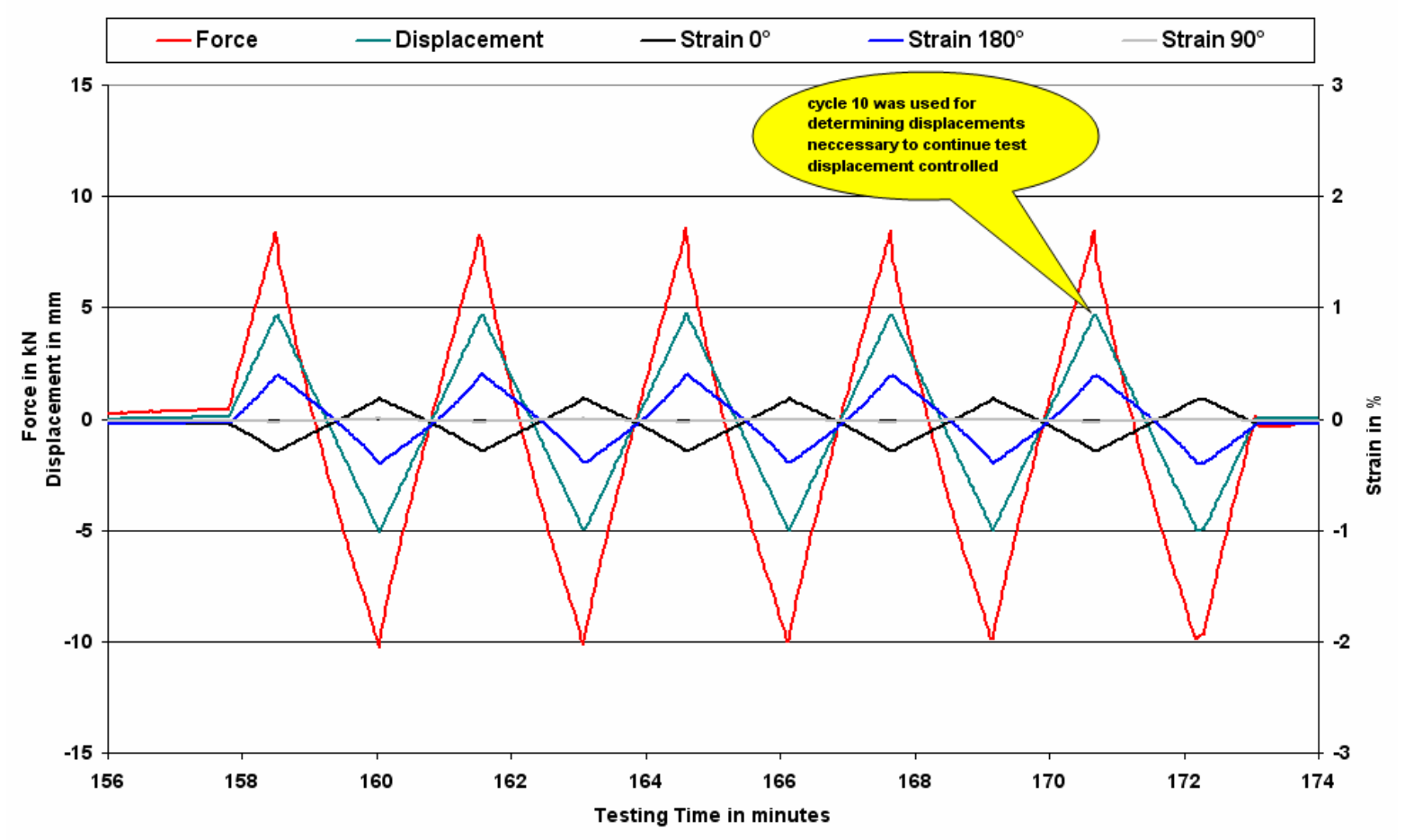

Figure 10-6

Mechanical data for Cycles 6 to 10.

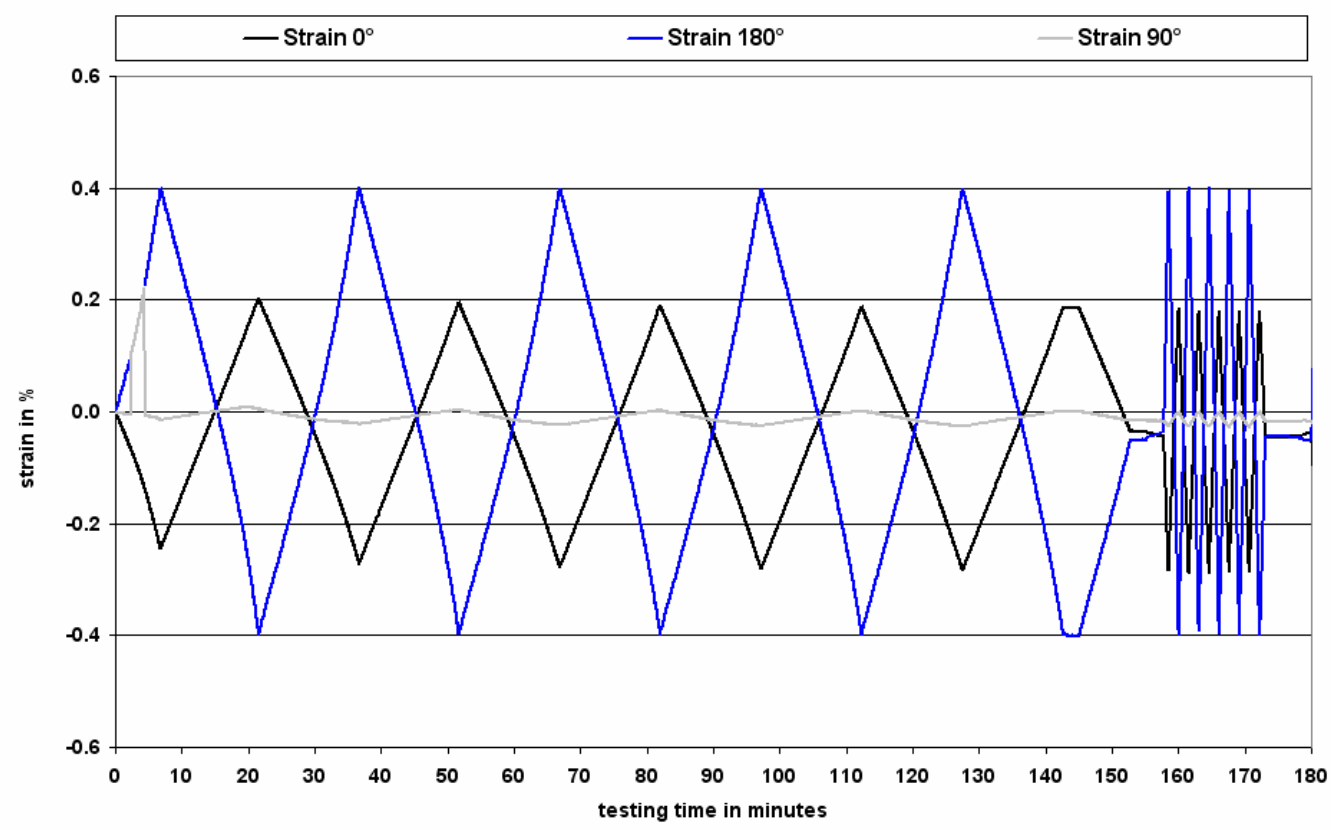


Figure 10-7

Strain data for Cycles 1 to 10.

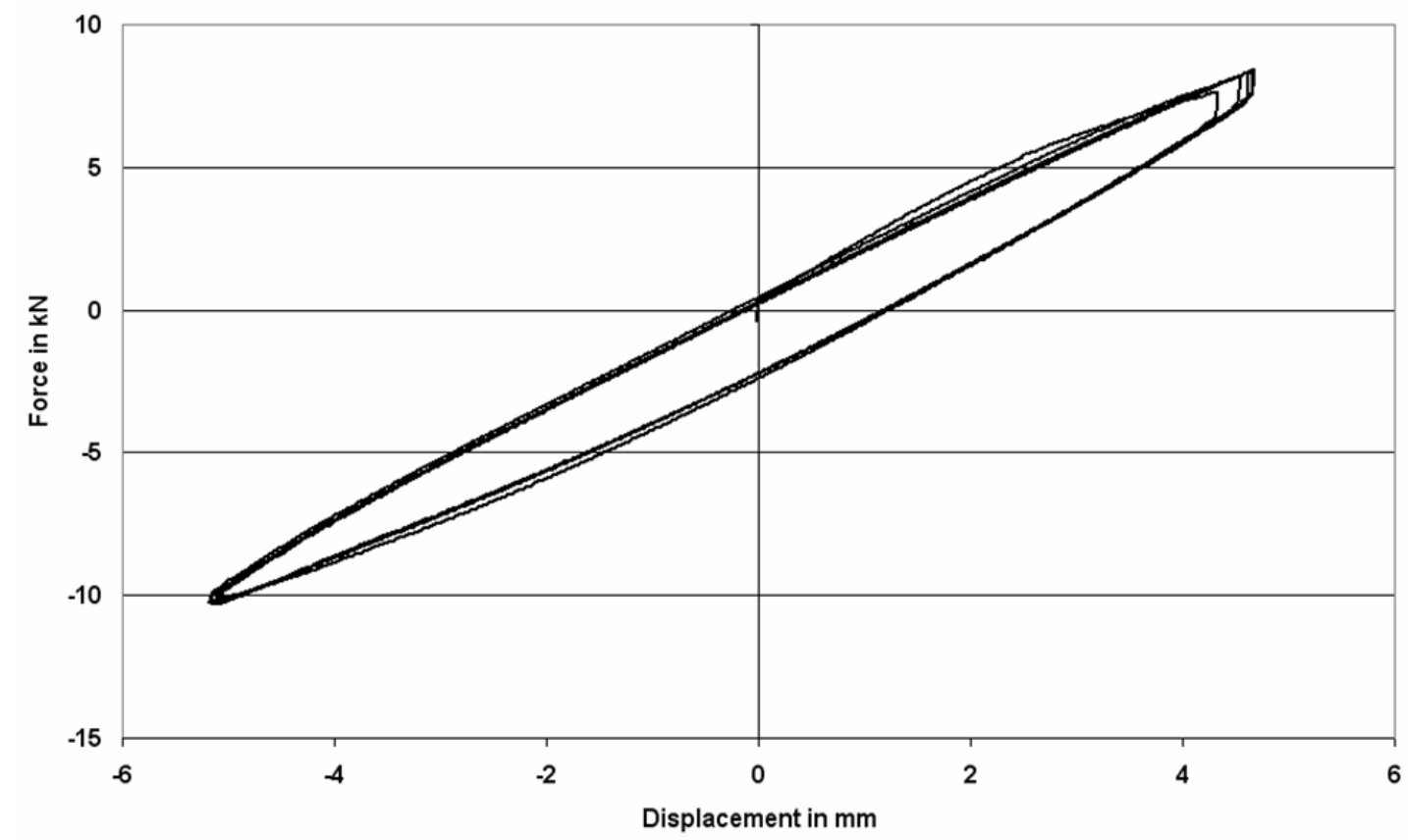

Figure 10-8

Load vs. displacement for Cycles 1 to 5.

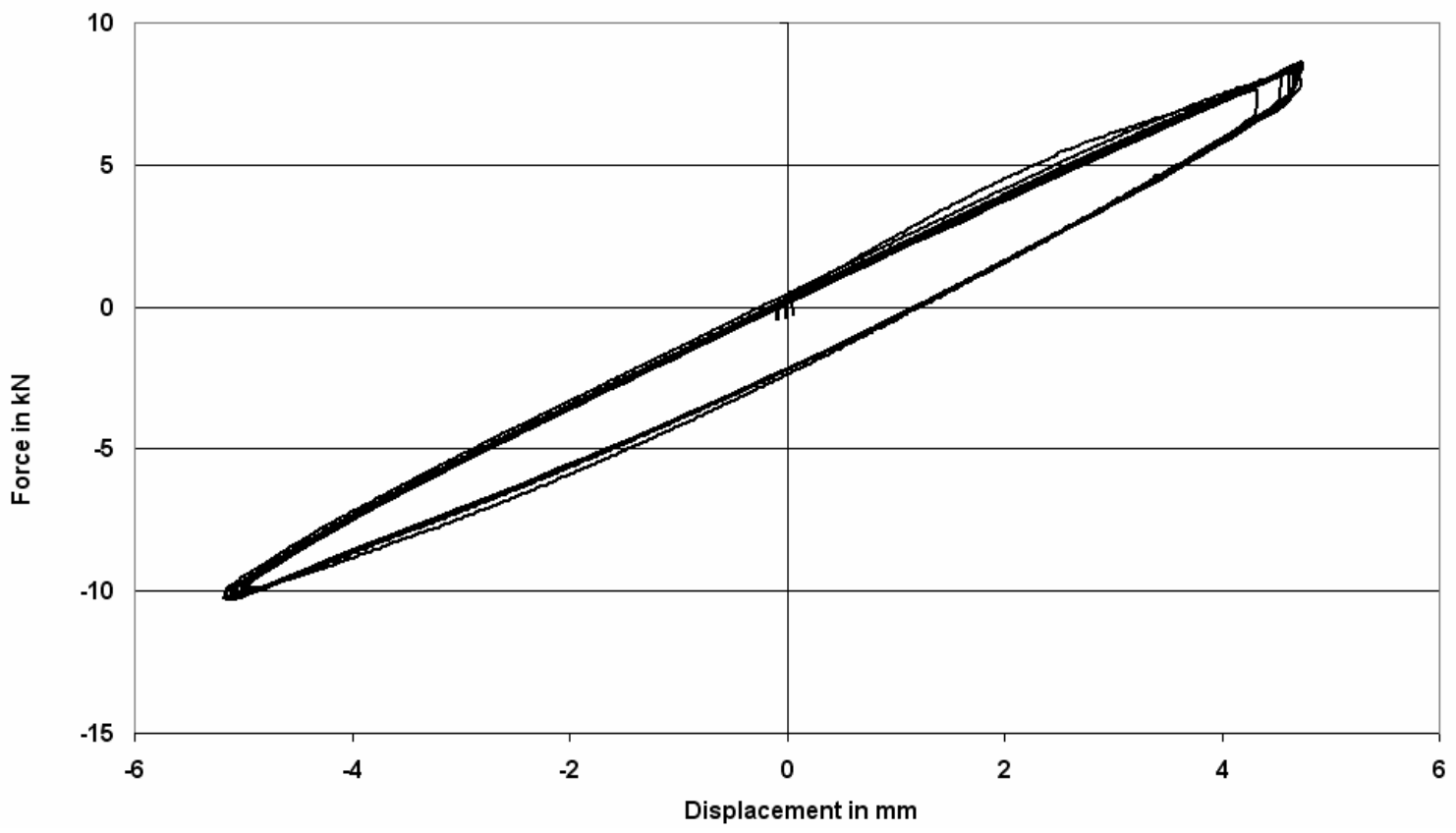


Figure 10-9

Load vs. displacement for Cycles 1 to 10.

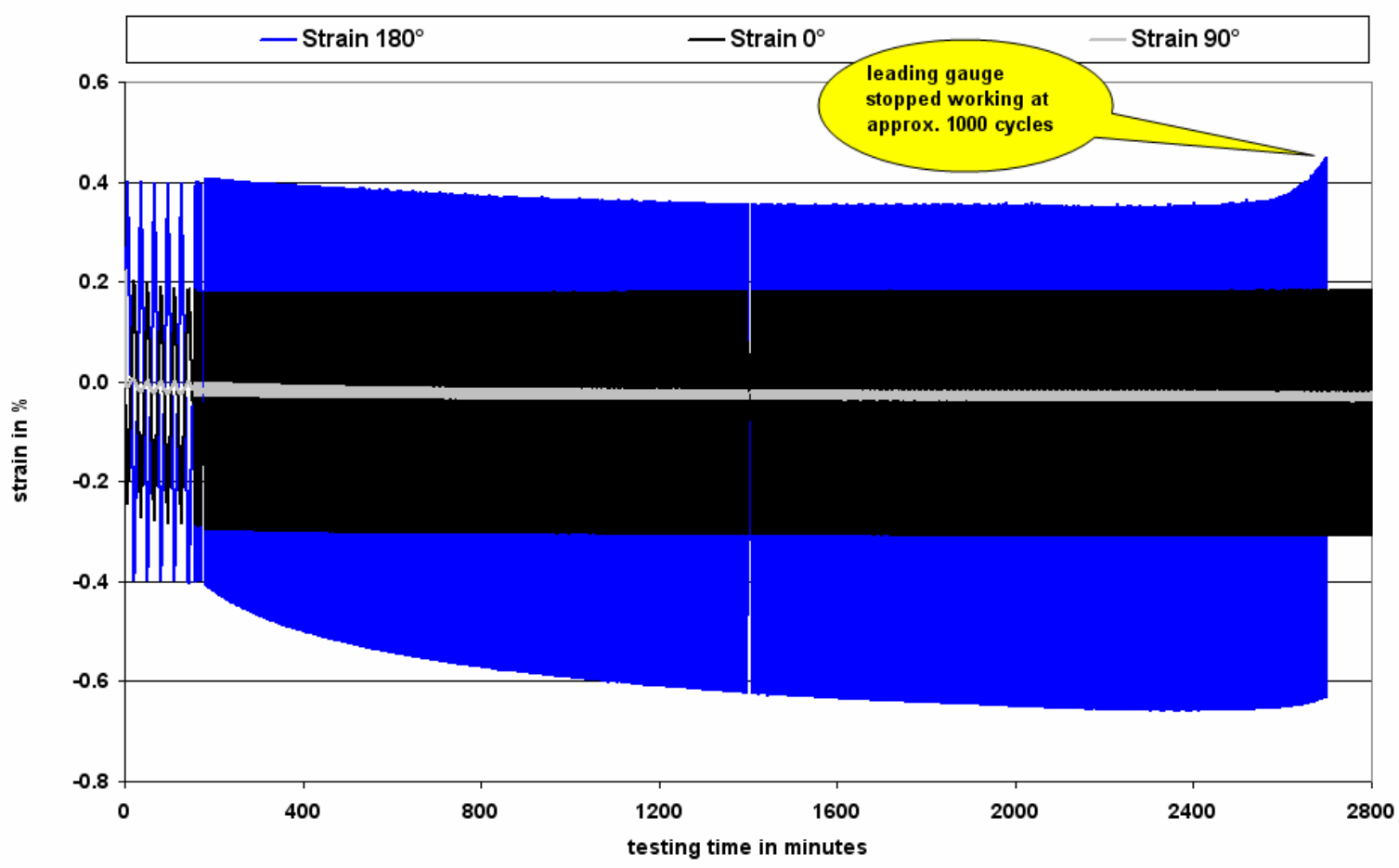


Figure 10-10

All available strain data.

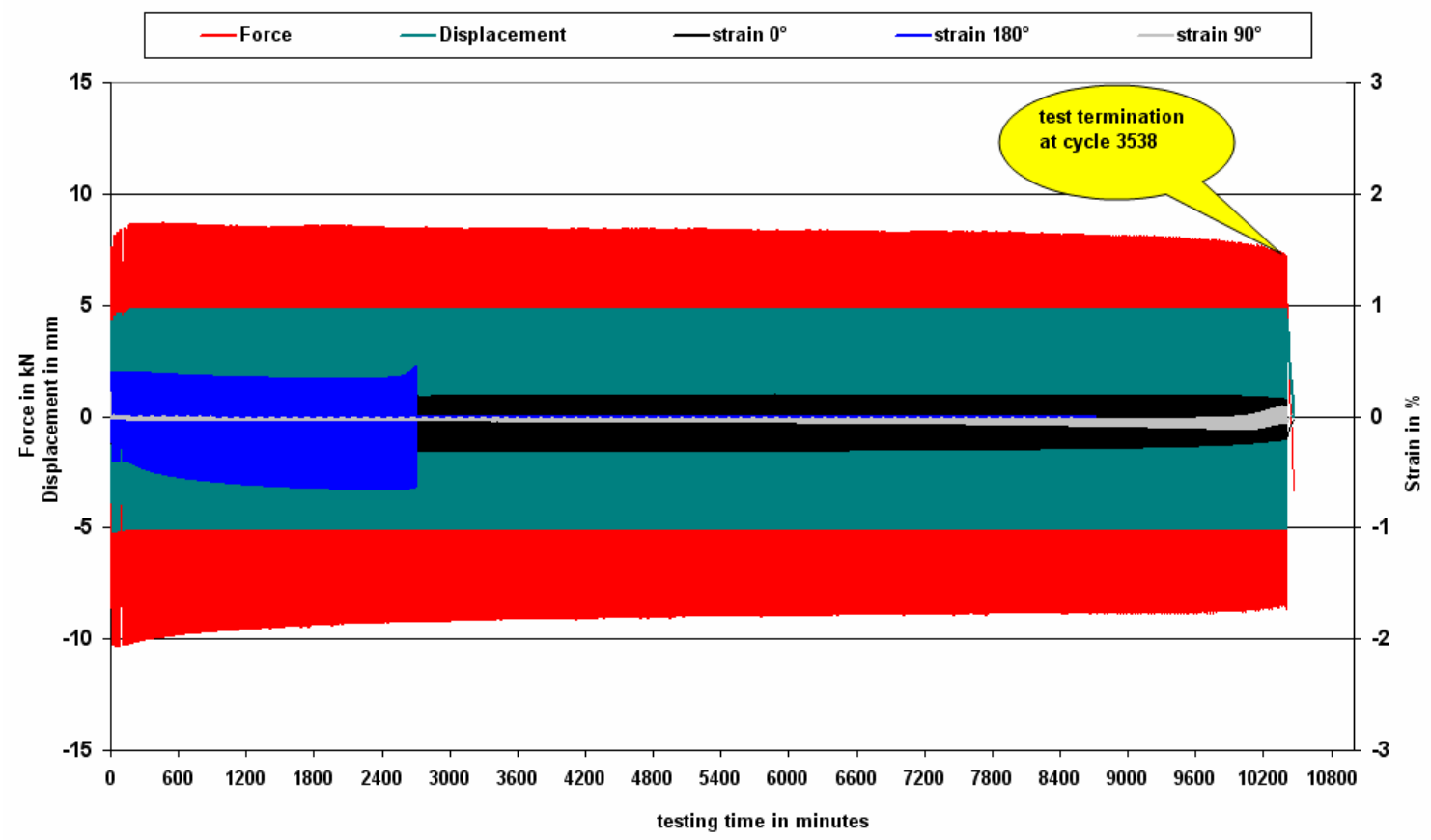

Figure 10-11

All mechanical data.

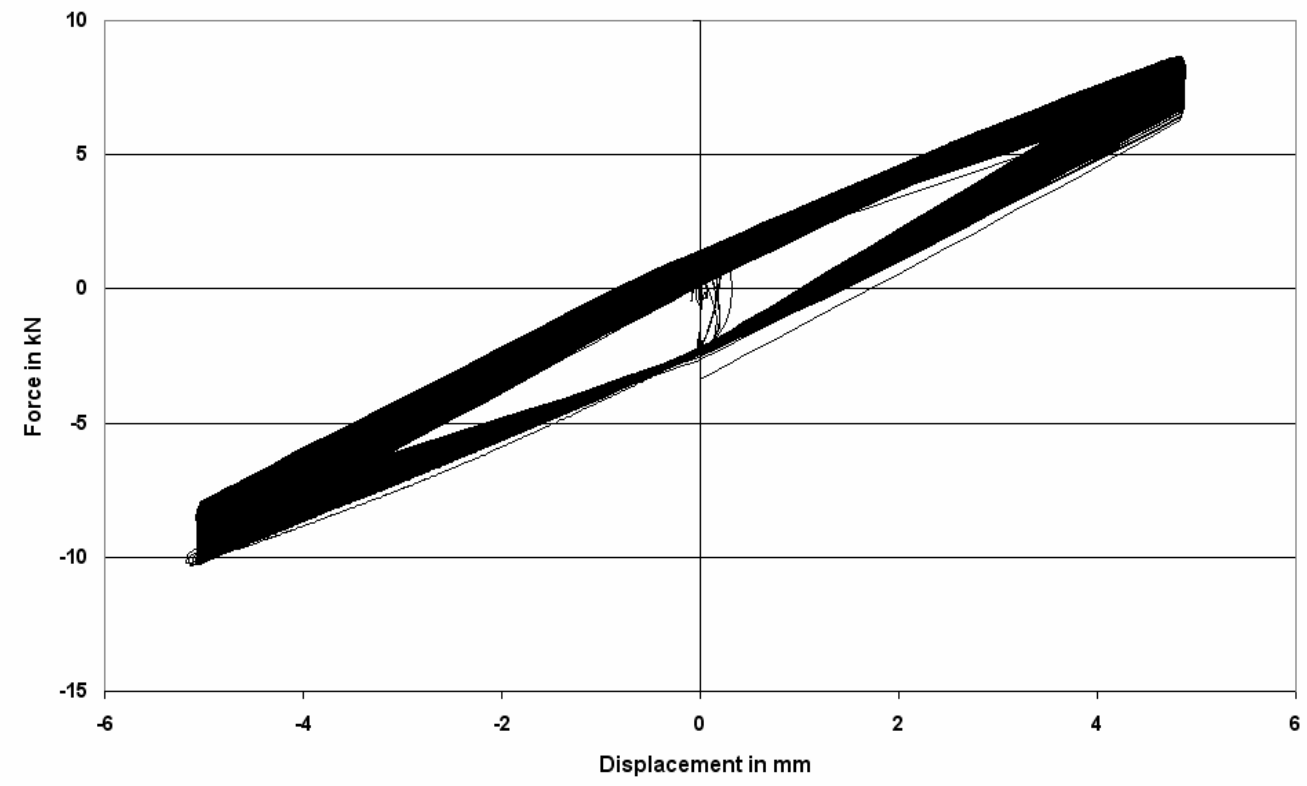


Figure 10-12

Load vs. displacement for entire test.

\section{Post-Test Characterization}

After the physical testing part of environmental test $4 \mathrm{~b}$ was accomplished the U-bend was removed from the testing rig, the additional tubing for optimized flow condition was cut off and the bend was prepared for post test characterization entailing the following tasks:

- Visual inspection of tested U-bend

- Dye penetrant inspection (DPI)

- Fractography of selected locations including examination at high magnifications using scanning electron microscopy (SEM)

- Metallography of selected locations

\section{Visual Inspection}

In an almost identical manner to previous tests of this series, the bend exhibited one primary axial fissure at the $270^{\circ}$ position. Small remnants of crystallized boric acid were found adjacent to the leakage indicating that this defect had developed into a through-wall fissure causing the loss of some environment. No other primary defects visible to the naked eye were found on the external surface during visual inspection. 


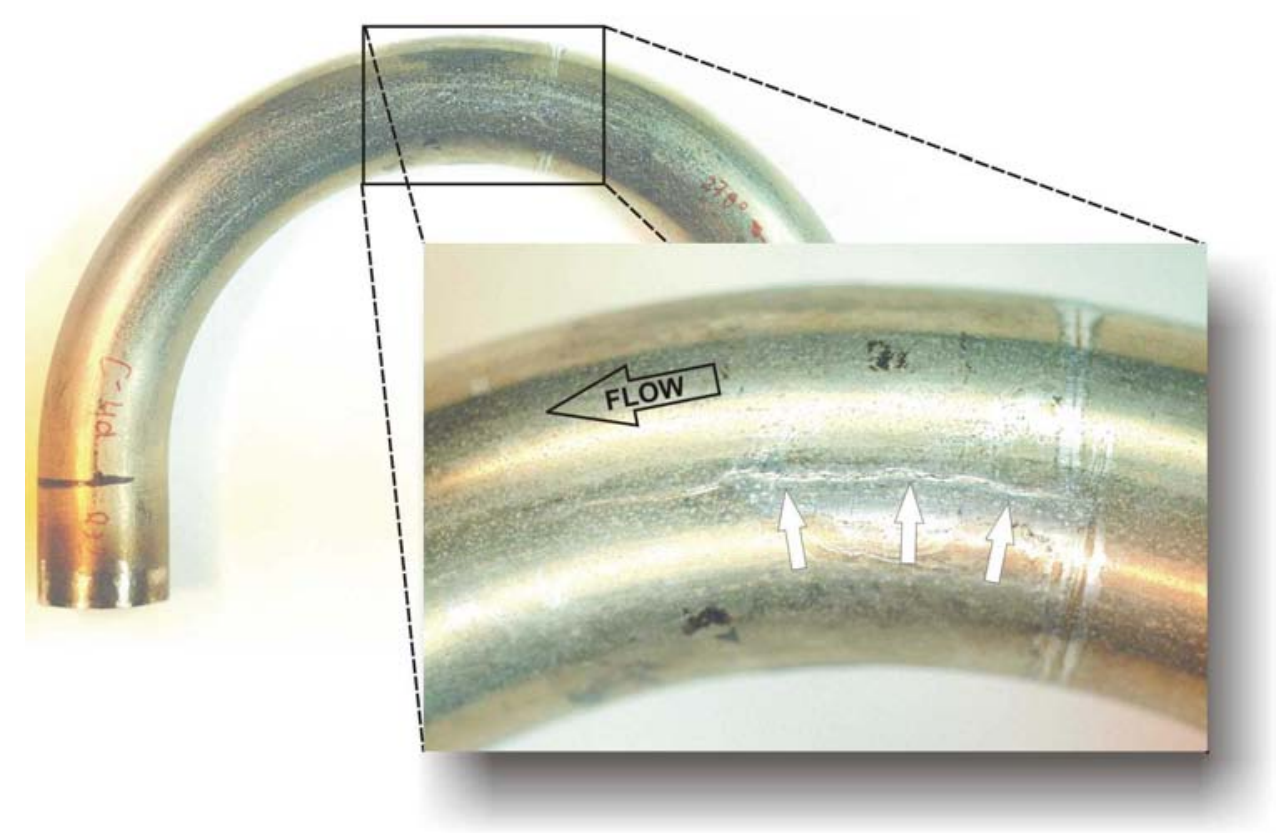

Figure 10-13

Axial through-wall defect in the $270^{\circ}$ position.

\section{Dye Penetrant Inspection}

A narrow piece containing the bend apex with an approximate length of $100 \mathrm{~mm}$ was sectioned from the bend and split in two half shells for further inspection with dye penetrant. Both the internal and external surfaces were examined.

The findings from visual inspection were confirmed since the $270^{\circ}$ position exhibited an axial fissure on the external surface as shown in Figure 10-14. The internal surface of the same location exhibited a narrow band of multiple axial cracking, which extended over a length of approximately $60 \mathrm{~mm}$ as displayed in Figure 10-15.

Also, the internal surface at the $90^{\circ}$ position revealed a narrow band of axial cracking showing similar extensions as displayed in Figure 10-16. The external surface at the $90^{\circ}$ position was free of indications. 


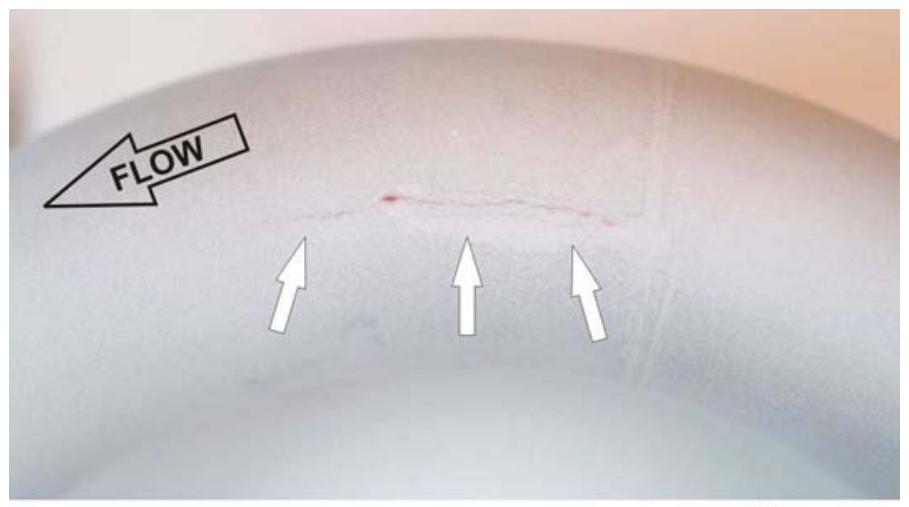

$\longmapsto 20 \mathrm{~mm} \longrightarrow$

Figure 10-14

External $270^{\circ}$ position confirming an axial fissure (approximate length $\mathbf{4 0} \mathrm{mm}$ ).

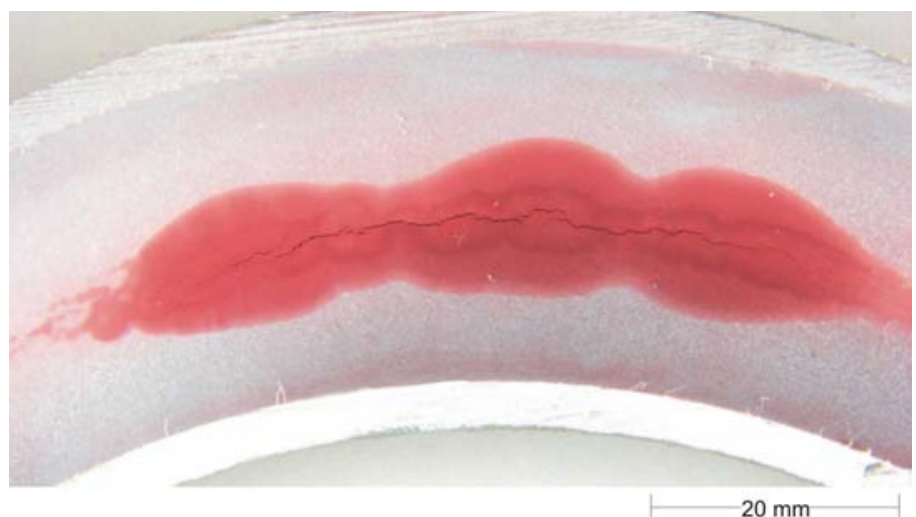

Figure 10-15

Internal $270^{\circ}$ position confirming multiple axial cracking (approximate length $60 \mathrm{~mm}$ ).

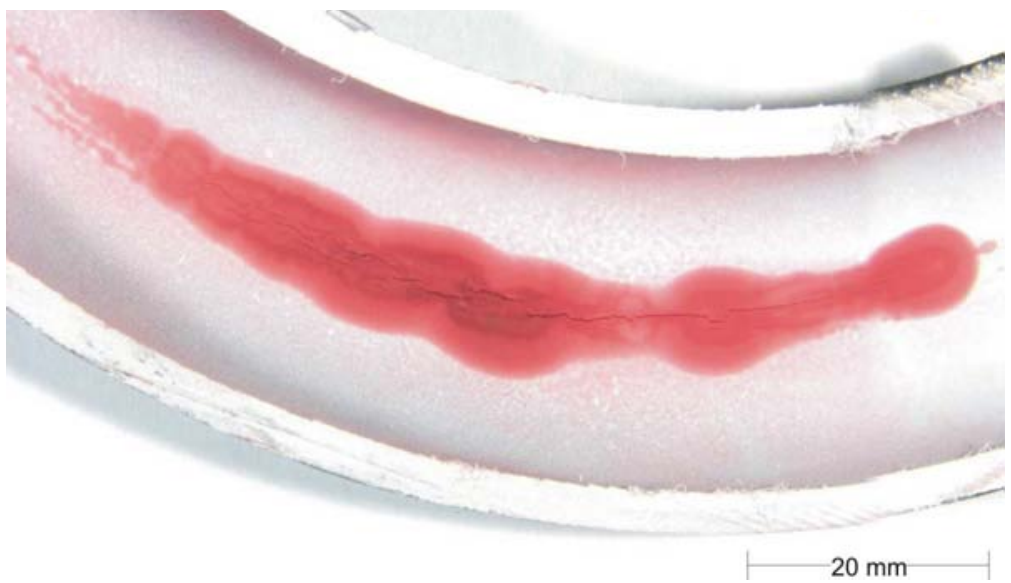

Figure 10-16

Internal $90^{\circ}$ position confirming multiple axial cracking (approximate length $60 \mathrm{~mm}$ ). 
Despite the external surface polishing, which successfully prevented cracking in the previous test (Test 4b), this test again suffered from a small amount of very fine circumferential cracking at the $180^{\circ}$ intrados position as displayed in Figure $10-17$. The internal surface at the $180^{\circ}$ intrados position revealed multiple axial indications. The internal defects at the $180^{\circ}$ position were much finer and less pronounced if compared to the $270^{\circ}$ and $90^{\circ}$ positions, respectively. The extrados position was free of cracking on both the internal and external surfaces.

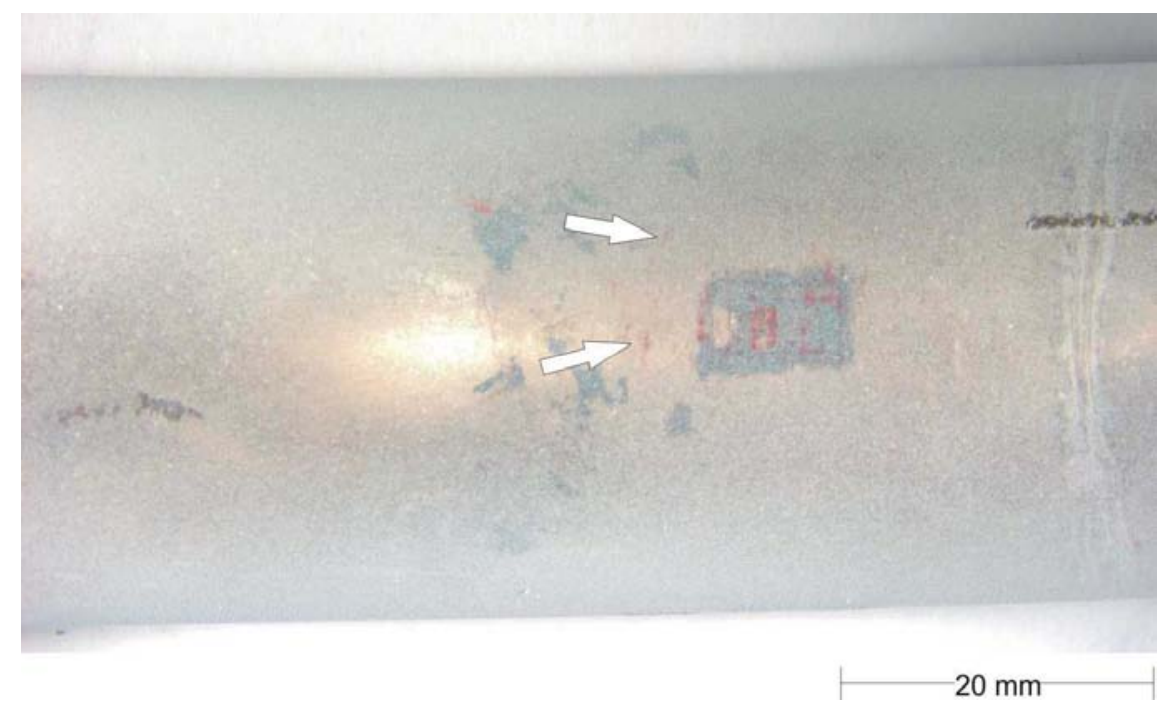

Figure 10-17

External surface of intrados showing fine circumferential cracking as indicated by white arrows.

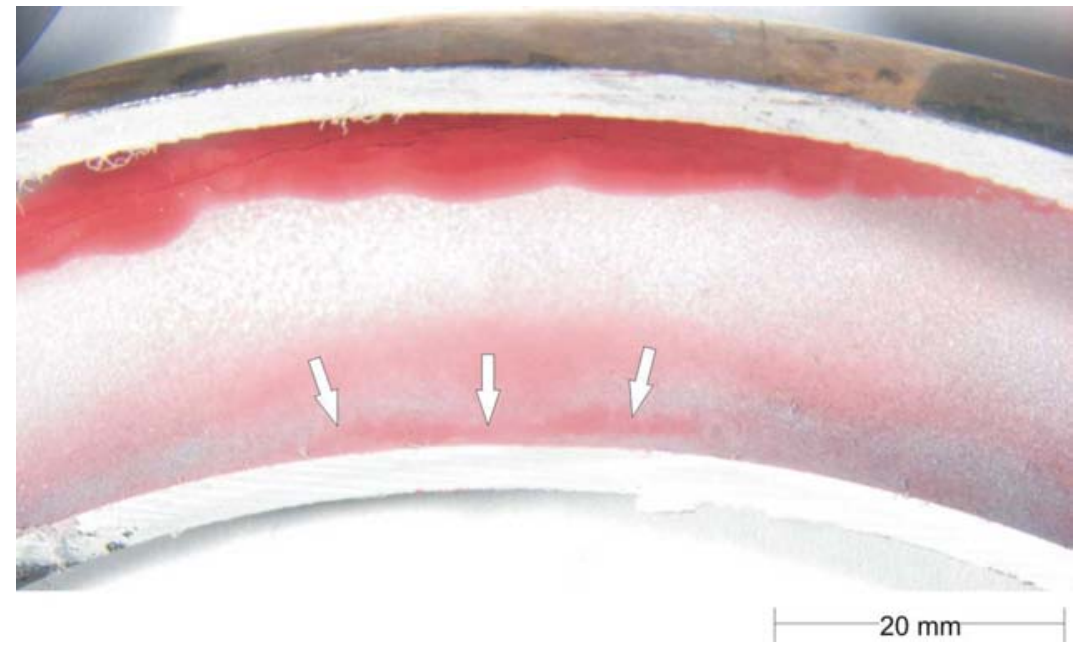

Figure 10-18

Internal $180^{\circ}$ intrados position showing axial indications as indicated by white arrows. 


\section{Scanning Electron Microscopy}

The internal surface at the $270^{\circ}$ position was examined at higher magnification using the SEM. Findings from DPI were confirmed since this position revealed multiple axial cracking that had initiated on the internal surface. The typical texture-bound crack initiation along attacked grain boundaries was not observed, due to the electro-polished surface. An example of cracking found at the internal $270^{\circ}$ position is shown in Figure $10-19$.

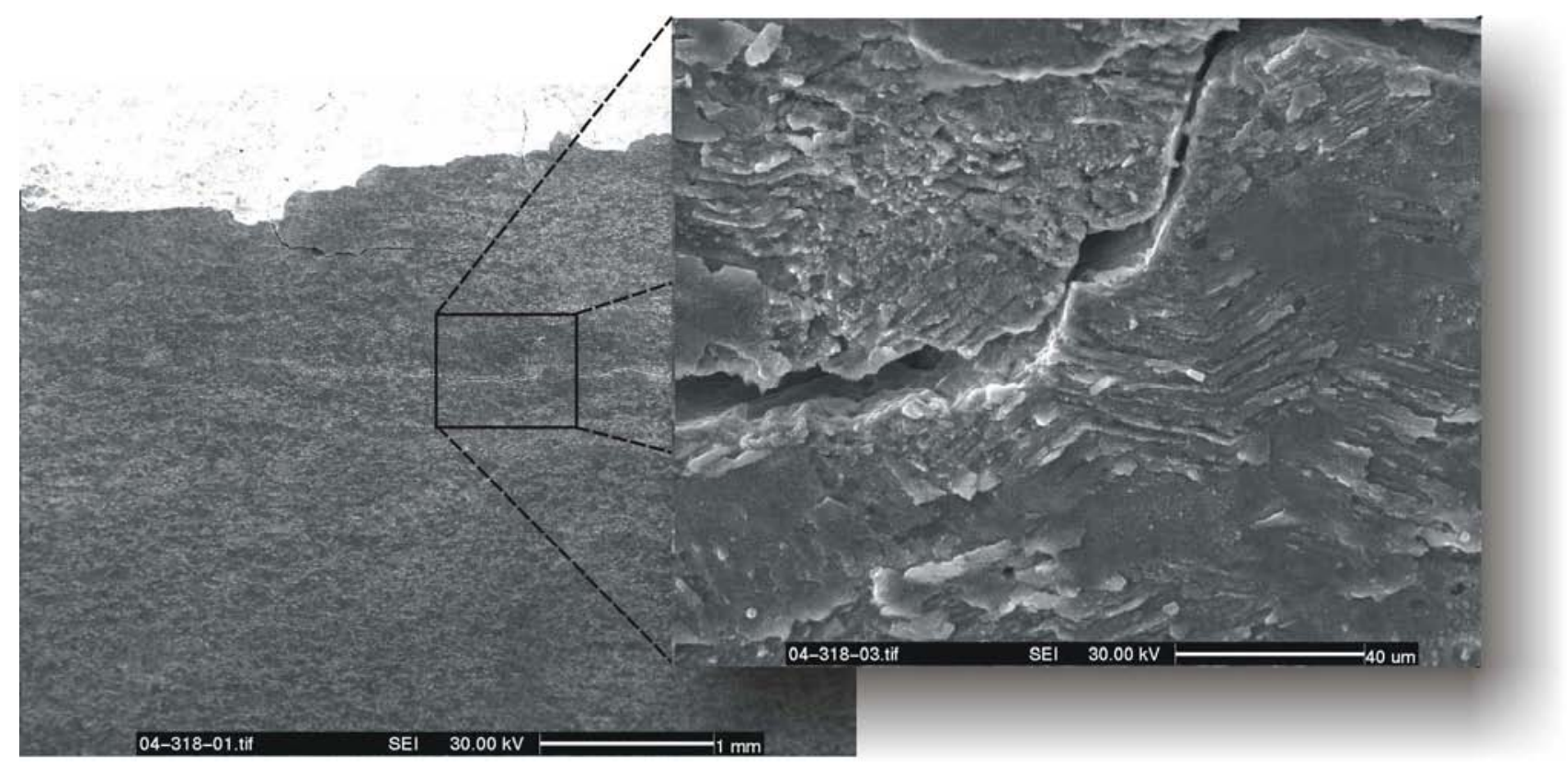

Figure 10-19

Internal surface of $270^{\circ}$ position showing axial cracking.

One representative crack from the primary defect causing leakage( $270^{\circ}$ position) was broken open to allow fractography at higher magnifications. Figure 10-20 displays the specimen used for SEM examination. Figure 10-21 shows close-ups of two areas that were under investigation. These locations revealed a fracture appearance with striations indicating a step-wise crack progression under cyclic loading. The fact that the fracture progressed from the internal towards the external surface, the general morphology and the multiple crack presence at this location indicated corrosion fatigue. The striation spacing was then determined by evaluating corresponding images of the fracture surface. The spacing in the area associated with crack initiation was determined as approximately $0.5 \mu \mathrm{m}$. The mid- fracture area showed a spacing of approximately $1 \mu \mathrm{m}$. The final stages of the crack disclosed a striation spacing of approximately $5 \mu \mathrm{m}$. Typical views of the different zones of the opened fracture are shown in Figure 10-22. 


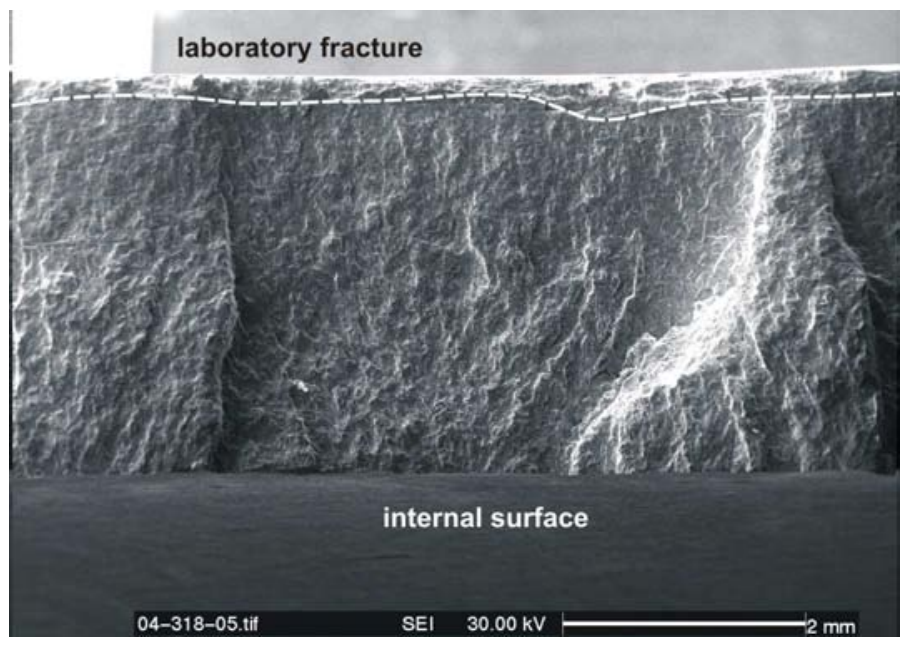

Figure 10-20

Broken open fracture at $270^{\circ}$ position used for SEM.

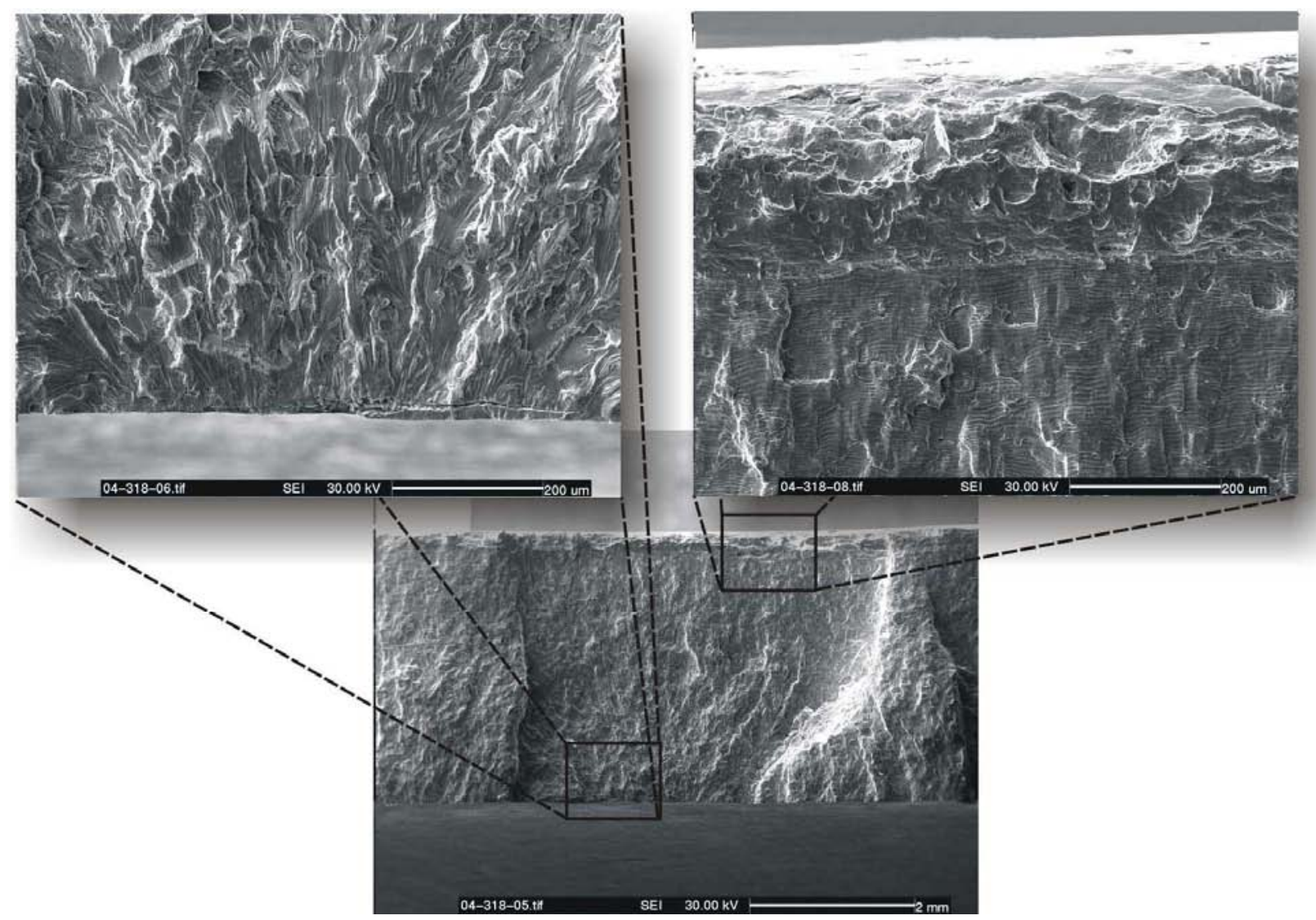

Figure 10-21

Areas examined at the $270^{\circ}$ position. 


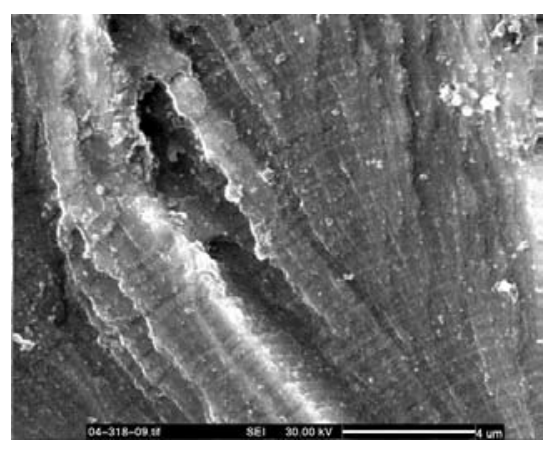

initiation area

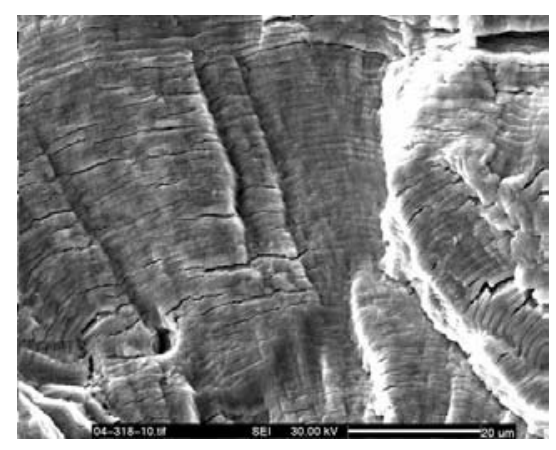

mid fracture

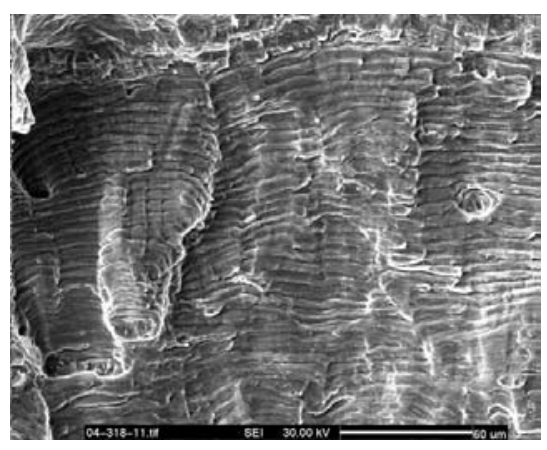

final stages

Figure 10-22

Stages of crack progression found at the $270^{\circ}$ position; the morphology indicates stepwise crack progression under the combined influence of mechanical loading and environment.

\section{Metallography}

The selected locations S1 and S3 (see Figure 10-23) were extracted from the U-bend half shells for metallurgical analysis. The specimens were mounted into bakelite and polished to a $1 \mu \mathrm{m}$ surface finish and etched with appropriate agents. The examination was performed with a metallurgical microscope. The microstructure of all examined specimens exhibited features typical for austenitic stainless steels and was considered sound. No anomalies that could have contributed to the failure were found.
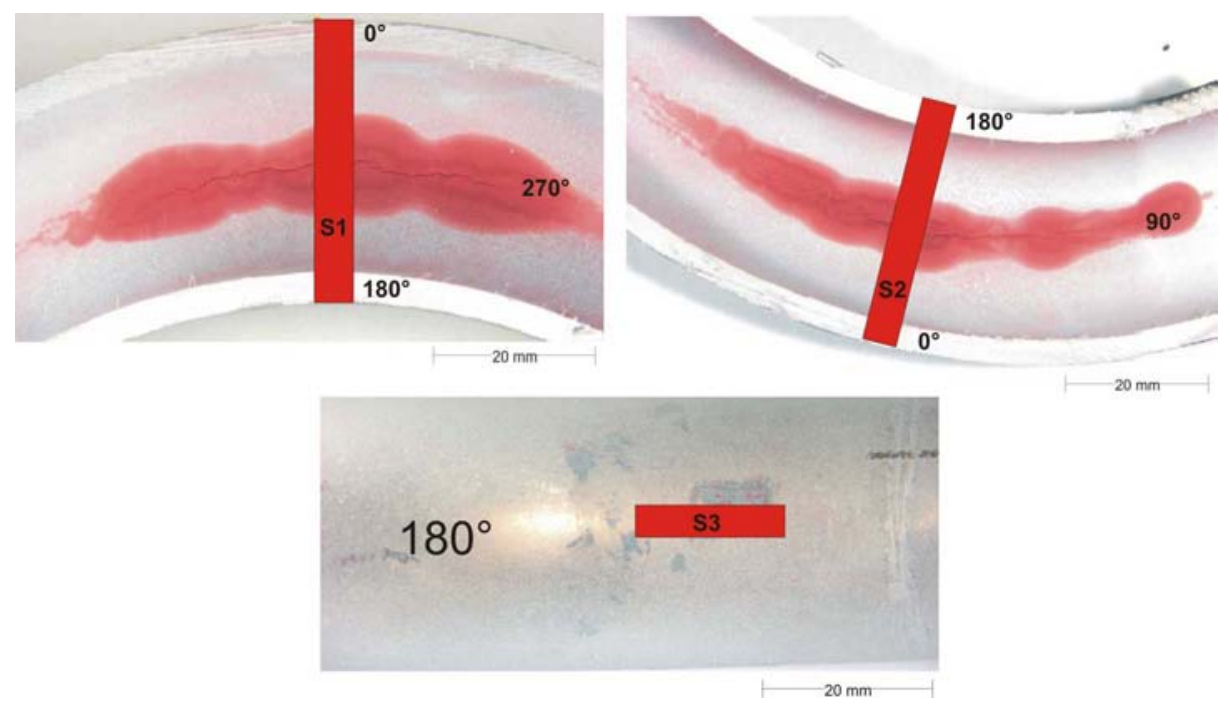

Figure 10-23

Removal plan of extracted specimens. 
Metallurgical analysis of the $270^{\circ}$ position confirmed one primary axial through-wall defect that had initiated on the internal surface and had propagated towards the external surface in a transgranular, branched manner. This primary defect was also accompanied by numerous smaller axial cracks the maximum depth of which was determined as approximately $1300 \mu \mathrm{m}$, representing about $38 \%$ of the tube's nominal wall thickness. The $90^{\circ}$ position presented very similar findings with multiple axially oriented, transgranular cracking that had initiated on the internal surface and propagated towards the external surface. The maximum crack depth within this prepared cross-section was determined as $2600 \mu \mathrm{m}$, representing about $76 \%$ of the tube's nominal wall thickness. Figure 10-24 displays a typical example of cracking found in the $270^{\circ}$ and $90^{\circ}$ positions, respectively.

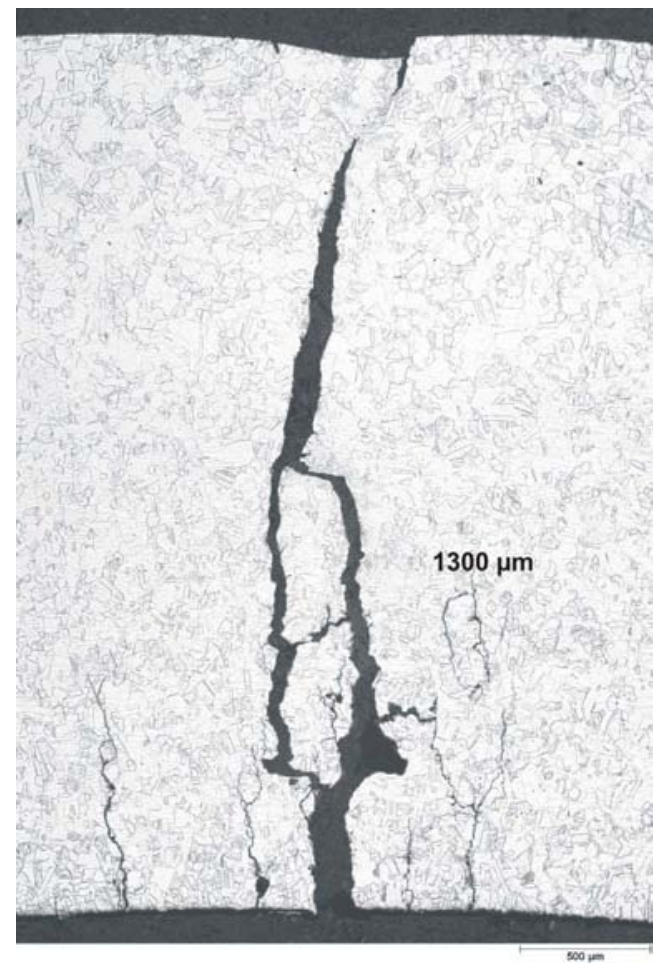

$270^{\circ}$ position (specimen S1)

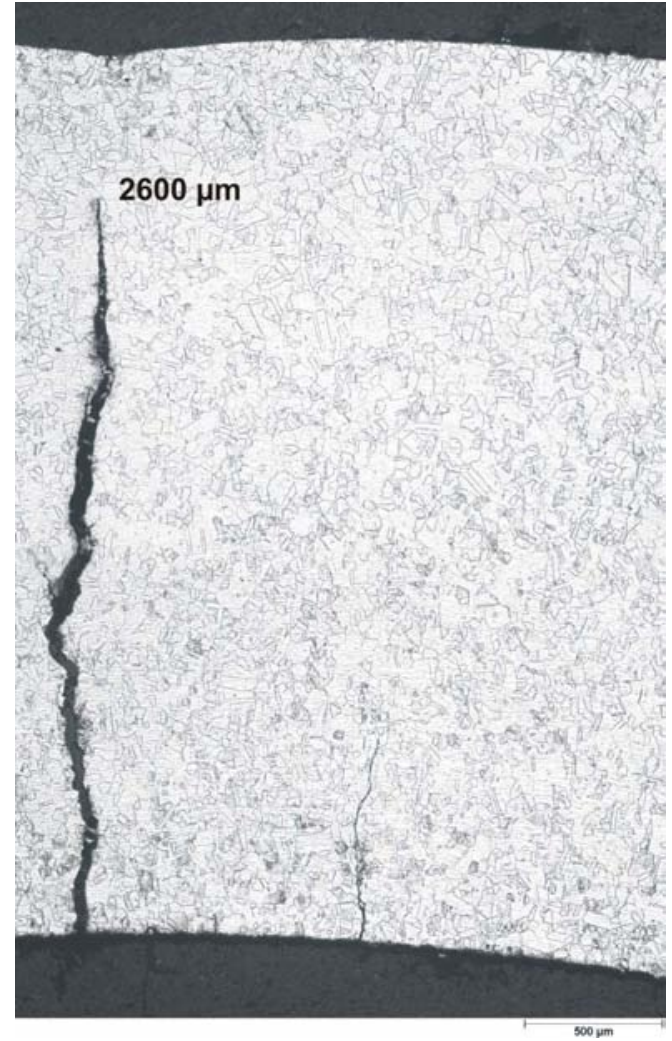

$90^{\circ}$ position (specimen S2)

Figure 10-24

Cross-sections of the $270^{\circ}$ and $90^{\circ}$ position over the entire wall thickness; the numbers represent approximate crack depths.

Also, the $180^{\circ}$ position exhibited transgranular axial cracking propagating from the internal towards the external surface. The approximate crack depth within this prepared cross-section was determined as $680 \mu \mathrm{m}$, representing about $20 \%$ of the tube's nominal wall thickness. Despite the externally polished surface, circumferential cracking was found with a maximum depth of approximately $200 \mu \mathrm{m}$, representing about $6 \%$ of the tube's nominal wall thickness. Figure 10-25 displays a typical example of cracking found in this position. 


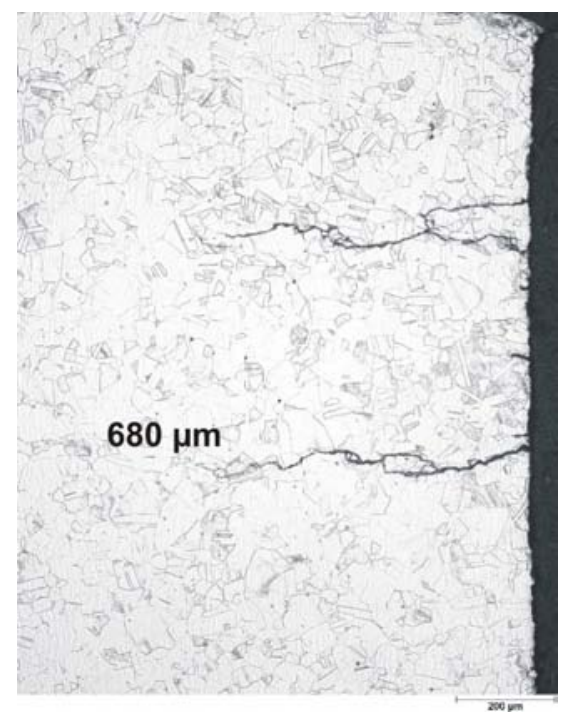

internal axial cracking (specimen S1)

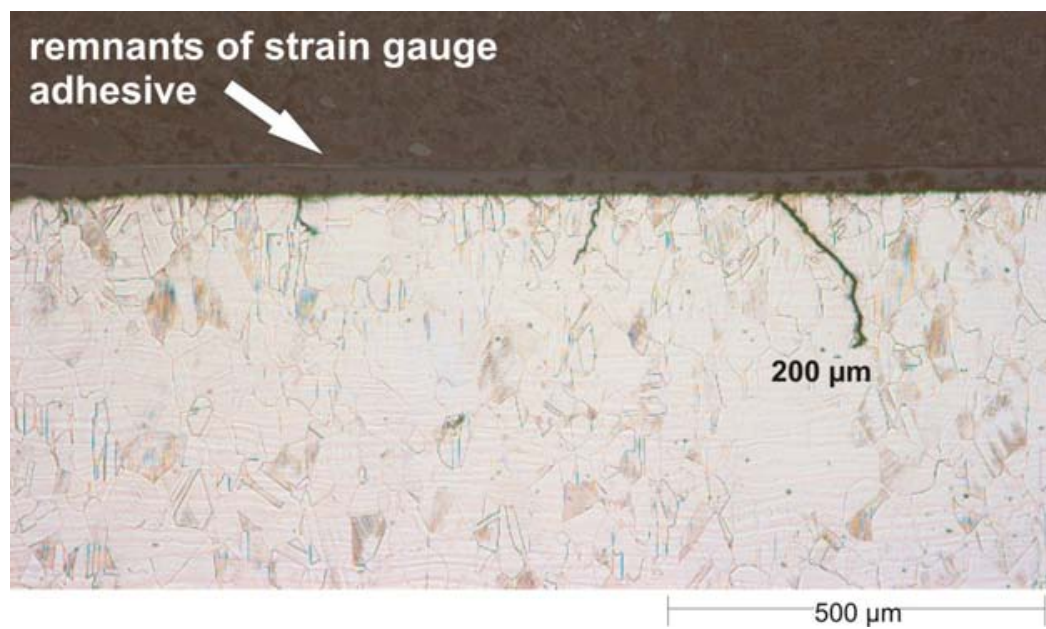

external circumferential cracking (specimen S3)

Figure 10-25

Metallography of the $180^{\circ}$ position confirmed both axial and circumferential cracking on the internal and external surface, respectively. The numbers represent approximate crack depths.

\section{Summary of Results}

The following results can be summarized from environmental test $4 \mathrm{~d}$ :

- Water chemistry within the range of specified values

- $\quad$ ECP: $-550 \mathrm{mV}_{\mathrm{H}, \mathrm{T}}$, Redox Potential: $-500 \mathrm{mV}_{\mathrm{H}, \mathrm{T}}$ for high flow rate $(\approx 2.1 \mathrm{~m} / \mathrm{s})$

- Total number of achieved cycles: 3835

- Leakage due to internally initiated through-wall, axial cracking in the $270^{\circ}$ position

- Polishing of external surface could not prevent external crack initiation entirely; observed circumferential cracking had an approximate depth of $200 \mu \mathrm{m}$

- All internal defects at $90^{\circ}, 180^{\circ}$ and $270^{\circ}$ were axial, environmentally assisted cracking

- Location $0^{\circ}$ was free of cracking

- No internal circumferential cracking was observed

- No microstructural anomalies were observed 
Figure 10-26 graphically summarizes the extent of cracking and corresponding locations.

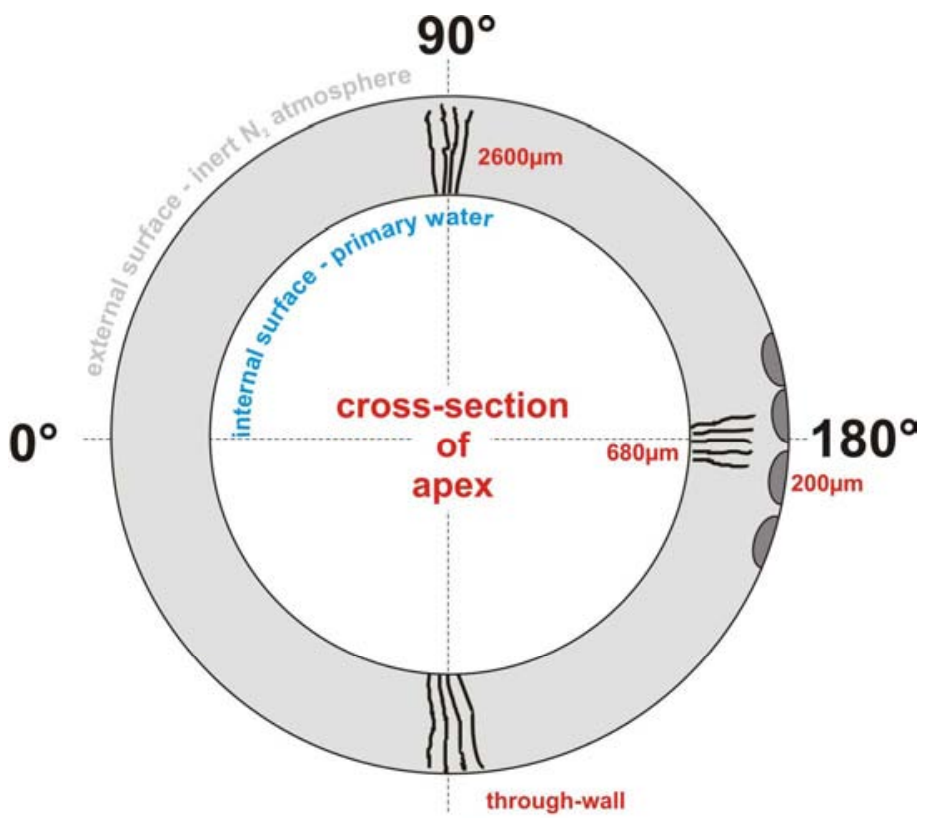

$270^{\circ}$

Figure 10-26

Schematic summary of crack locations, orientation and approximate crack depths (if available) of Test $4 \mathrm{~d}$; schematic provides a cross-sectional view of the apex looking downstream; please note that schematic is not to scale.

\section{Conclusions from Test $4 \mathrm{~d}$}

This test clearly showed an effect of primary water on the fatigue behavior of the U-bend under cyclic load, since multiple axial cracking at the internal surface of the apex was observed and characterized. The overall failure scenario observed showed very similar features if compared to other bends within the test 4 series. The primary failure causing leakage again was caused by axial, environmentally assisted cracking initiating on the internal surface atthe $270^{\circ}$ position. Having implemented a less severe strain amplitude of $0.4 \%$, and polished external and internal surfaces, the environmental aspects of failure were dominant.

However, in contrast to test $4 \mathrm{~b}$, the external polishing could not prevent some external crack initiation in the form of very shallow, circumferential cracks. Also, electropolishing of the internal surface did not have a noticeable impact on the bend behavior, if compared to the other previously tested bends.

A true beneficial effect of high flow rate $(4100 \mathrm{l} / \mathrm{h}$ versus $10 \mathrm{l} / \mathrm{h})$ was not observed. In comparison to test 4a this test achieved a slightly higher total number of approximately 3800 cycles, but the difference of roughly 200 cycles cannot be interpreted as statistically significant increase in fatigue life. 



\section{1 \\ ENVIRONMENTAL TEST 4A'}

\section{Test Set-Up and Approach}

In order to provide better comparability, one additional test within the test 4 series was performed. This test, labeled 4a', was performed under identical conditions to test 4a, with the exception that this time the apex was externally polished to minimize surface effects. Thus, direct comparison of results became possible between an externally polished, high- flow (test 4b) and low flow (test 4a').

The following U-bend instrumentation and test parameters were employed:

- pre-conditioning of the internal surface by lengthy exposure to simulated primary water

- instrumented U-bend with three bonded HT strain gauges at the $0^{\circ}, 90^{\circ}$ and $180^{\circ}$ position

- $\quad$ strain amplitude of $\pm 0.4 \%$ (total strain range of $0.8 \%$ )

- $\quad$ strain rate of $1 \times 10^{-4} \mathrm{~s}^{-1}$

- $\quad$ externally polished apex to minimized surface effects

- $\quad$ testing temperature $\mathrm{T}=240^{\circ} \mathrm{C}$, pressure $\mathrm{p}=50 \mathrm{bar}$

- HT water chemistry comprising 1200 ppm B as $\mathrm{H}_{3} \mathrm{BO}_{3}+2 \mathrm{ppm} \mathrm{Li}$ as $\mathrm{LiOH}$

- oxygen content adjusted to $<<10 \mathrm{ppb}$, no $\mathrm{H}_{2}$ injection

- the impurity level adjusted to $\mathrm{Cl}^{-}+\mathrm{F}^{-}+\mathrm{SO}_{4}{ }^{2-}<100 \mathrm{ppb}$

- Water sampling and chemical analysis of $\mathrm{B}, \mathrm{Li}, \mathrm{Cl}^{-}, \mathrm{F}^{-}, \mathrm{SO}_{4}{ }^{2-}, \mathrm{pH}$ during start-up and before shut down

- flow rate adjusted to $<10 \mathrm{l} / \mathrm{h}$ (corresponds to $\approx 0.005 \mathrm{~m} / \mathrm{s}$ for an ID of $26.5 \mathrm{~mm}$ ) 


\section{Results}

\section{Water Chemistry}

The mechanical loading of the U-bend during testing was not commenced until the specified requirements with respect to test temperature, water chemistry/purity and electrochemical corrosion/redox potentials were met. Water sampling before start-up and loading assured that the specified requirements were met, as displayed in Table 11-1.

\begin{tabular}{|c|c|c|c|c|c|c|c||}
\hline $\begin{array}{c}\text { water } \\
\text { sampling }\end{array}$ & $\begin{array}{c}\mathbf{B} \\
\mathbf{p p m}\end{array}$ & $\begin{array}{c}\mathbf{L i} \\
\mathbf{p p m}\end{array}$ & $\mathbf{p H}$ & $\begin{array}{c}\text { chloride } \\
\mathbf{p p b}\end{array}$ & $\begin{array}{c}\text { sulfate } \\
\mathbf{p p b}\end{array}$ & $\begin{array}{c}\text { fluoride } \\
\mathbf{p p b}\end{array}$ & remarks \\
\hline $\begin{array}{c}\text { before loading, } \\
\text { test temperature } \\
\text { was reached }\end{array}$ & 1232 & 2.31 & & - & - & - & cond. outlet: $22.3 \mu \mathrm{S} / \mathrm{cm}$ \\
\hline during testing & 1184 & 2.14 & 6.5 & $<10$ & $<10$ & 35 & $\begin{array}{c}\text { cond.(out) }=20.7 \mu \mathrm{S} / \mathrm{cm} \\
\mathrm{O}_{2} \text { (out) } \approx 2 \mathrm{ppb}\end{array}$ \\
\hline before shut down & 1216 & 2.2 & & 20 & $<10$ & 27 & $\begin{array}{c}\text { cond.(out) }=22.4 \mu \mathrm{S} / \mathrm{cm} \\
\mathrm{O}_{2} \text { (out) } \approx 2 \mathrm{ppb}\end{array}$ \\
\hline
\end{tabular}

Table 11-1

Water chemistry data of Test 4a'

During testing, the water chemistry was monitored continuously with respect to test temperature, conductivity and electrochemical corrosion potential (ECP) and redox potential. Figure 11-1 and Figure 11-2 show the inlet and outlet conductivity, the test temperature as well as ECP and the redox potential for the entire duration of environmental test 4a'. The inlet and outlet conductivity was held within specified values.

The ECP showed values of approximately $-550 \mathrm{mV}_{\mathrm{H}, \mathrm{T}}$ and the redox potential was measured at approximately $-500 \mathrm{mV}_{\mathrm{H}, \mathrm{T}}$. The target test temperature of $240{ }^{\circ} \mathrm{C}$ was held very stable for the entire test.

The data acquisition system suffered from an unforeseen shut down and stopped acquiring data from 4700 to 7500 testing minutes. However, the graphs shown in Figure 11-1 and Figure 11-2 contain data for this affected period, which was generated manually by adding the mean average of the last and first available data point. 


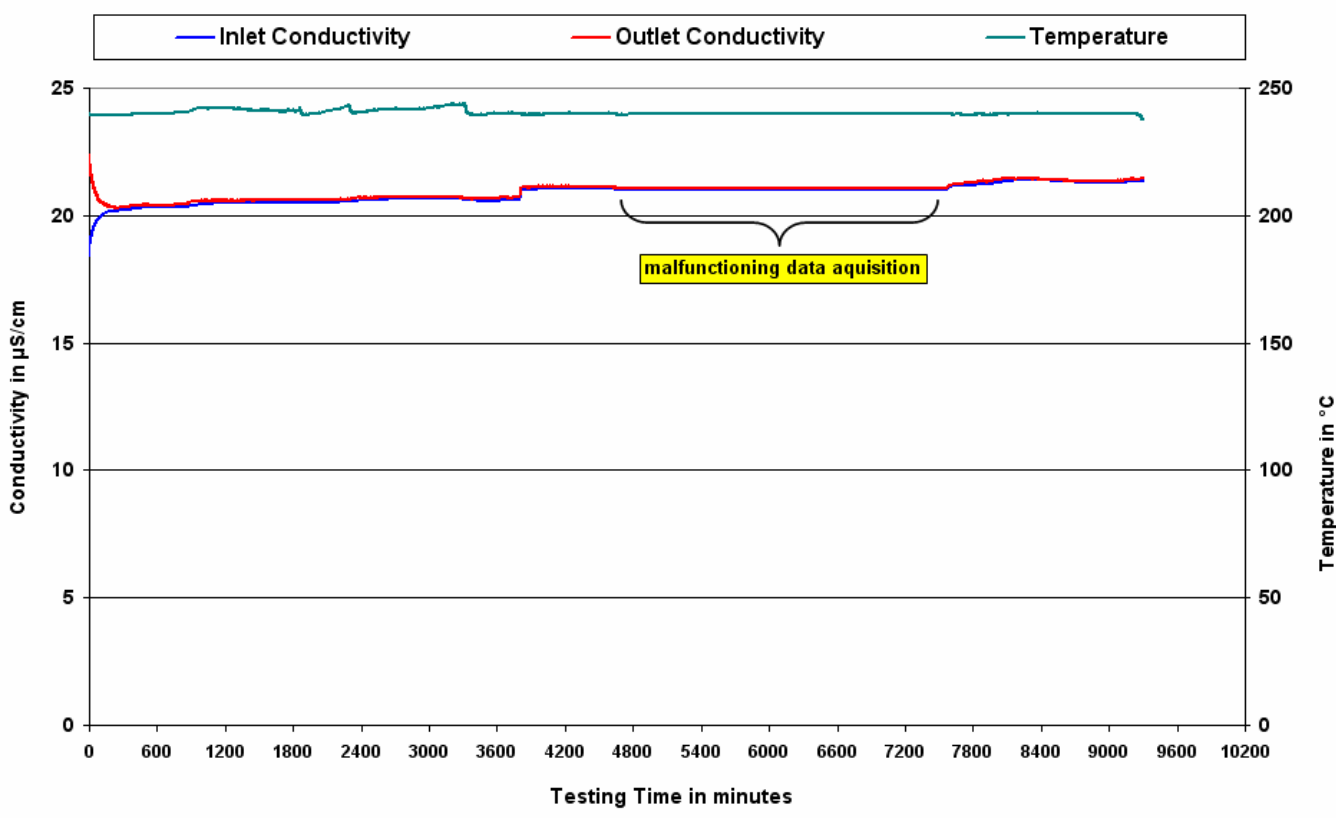

Figure 11-1

Conductivity and temperature vs. testing time for Test $4 a$.

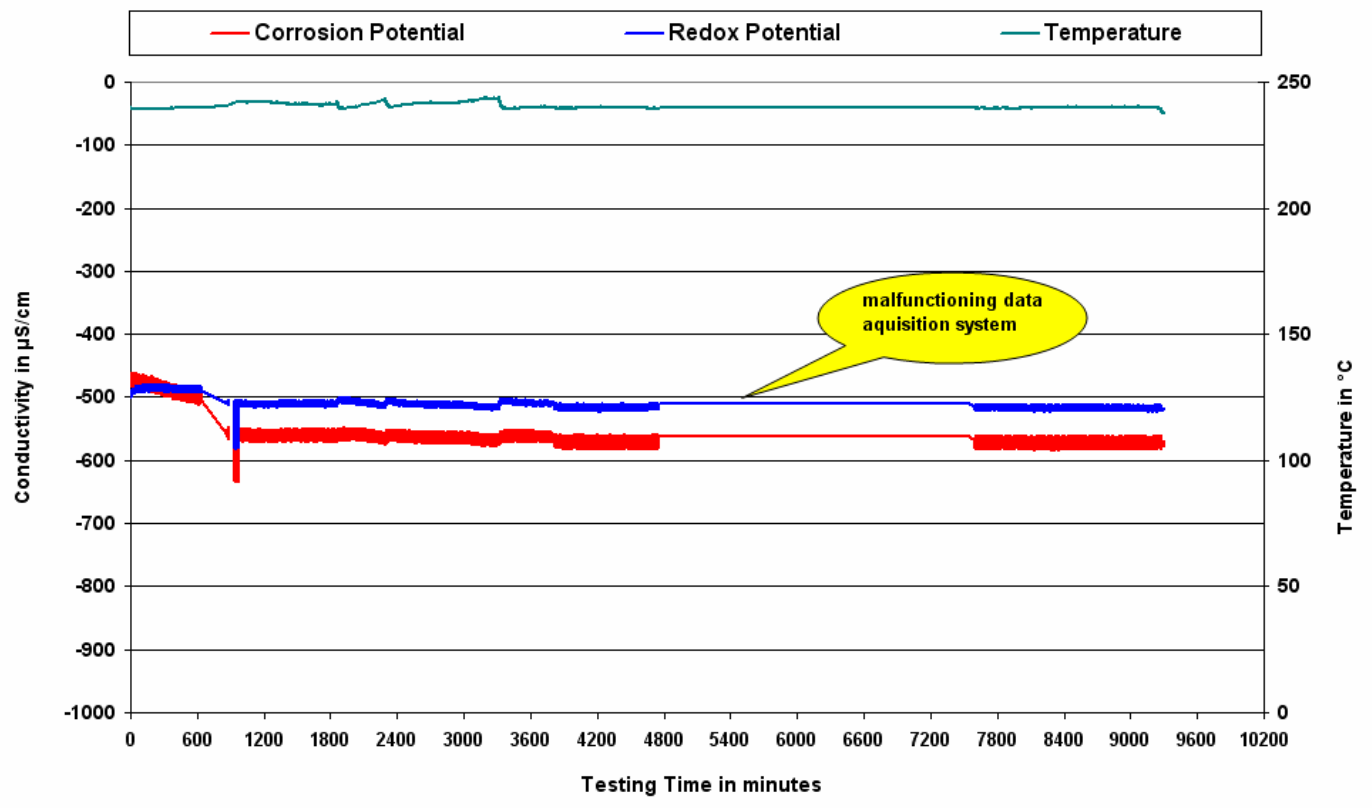

Figure 11-2

Temperature, corrosion and redox potential vs. testing time for Test 4a'. 


\section{Mechanical Data}

The basic test parameters used for mechanical loading of the U-bend are given in Table 11-2. Initially the bend was loaded with a triangular wave shape for the first 5 cycles to evaluate the Ubend response. The strain rate used for the first 5 cycles was $1 \times 10^{-5} \mathrm{x} \mathrm{s}^{-1}$. Cycle 6 to 10 were performed with a strain rate of $1 \times 10^{-4} \mathrm{x} \mathrm{s}^{-1}$. For unknown reasons, the system control of the tensile machine stopped working twice within this test sequence and had to be re-started again. To this point the test was performed displacement controlled with strain triggered switch points at $\pm 0.4 \%$ strain amplitude. The load vs. displacement hysteresis for the first 10 cycles is displayed in Figure 11-6 and Figure 11-7 and indicated fairly stable bend behavior. Cycle 10 was used to determine the displacements necessary for the remaining test, which was performed under displacement controlonly. Figure 11-3 and Figure 11-4 illustrate the mechanical data for cycles 1 to 5 and 6 to 10, respectively. The strain response for the cycles 1 to 10 is provided in Figure 11-5.

The leading $180^{\circ}$ intrados strain gauge stopped working at cycle 810 as a result of the cyclic loading. The available strain data is shown in Figure 11-8. Generally, the bend showed relatively stable behavior throughout the entire test since the load response to the given displacements was uniform as displayed in Figure 11-9. The load vs. displacement hysteresis for the entire test is displayed in Figure 11-10.

\begin{tabular}{|c|c|c|c|c|c|}
\hline cycle & $\begin{array}{c}\text { wave } \\
\text { shape }\end{array}$ & $\begin{array}{c}\text { control } \\
\text { channel }\end{array}$ & strain rate & switch point & $\begin{array}{c}\text { switch off } \\
\text { criteria }\end{array}$ \\
\hline \hline $\mathbf{1}-\mathbf{5}$ & triangular & $\begin{array}{c}\text { displacement } \\
\text { strain triggered } \\
\text { switching point }\end{array}$ & $1 \times 10^{-5} \mathrm{~s}^{-1}$ & $\begin{array}{c}+0.4 \% \\
-0.4 \%\end{array}$ & - \\
\hline \multirow{2}{*}{$\mathbf{- 1 0}$} & triangular & $\begin{array}{c}\text { displacement } \\
\text { strain triggered } \\
\text { switching point }\end{array}$ & $1 \times 10^{-4} \mathrm{~s}^{-1}$ & $\begin{array}{l}+0.4 \% \\
-0.4 \%\end{array}$ & - \\
\hline $\mathbf{1 1} \mathbf{- 3 4 3 7}$ & triangular & displacement & $1 \times 10^{-4} \mathrm{~s}^{-1}$ & $\begin{array}{l}+4.9 \mathrm{~mm} \\
-5.1 \mathrm{~mm}\end{array}$ & failure \\
\hline
\end{tabular}

Table 11-2

Basic mechanical data of Test 4a'. 


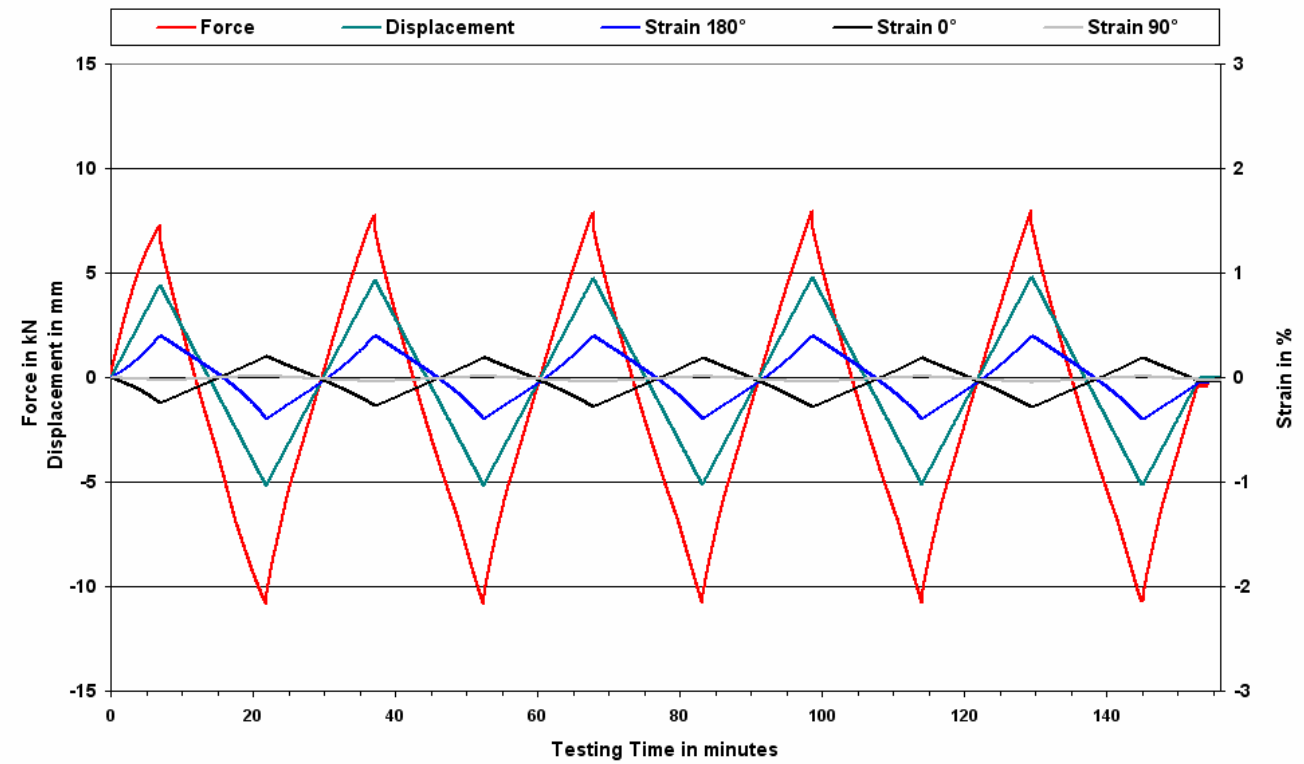

Figure 11-3

Mechanical data for Cycles 1 to 5 .

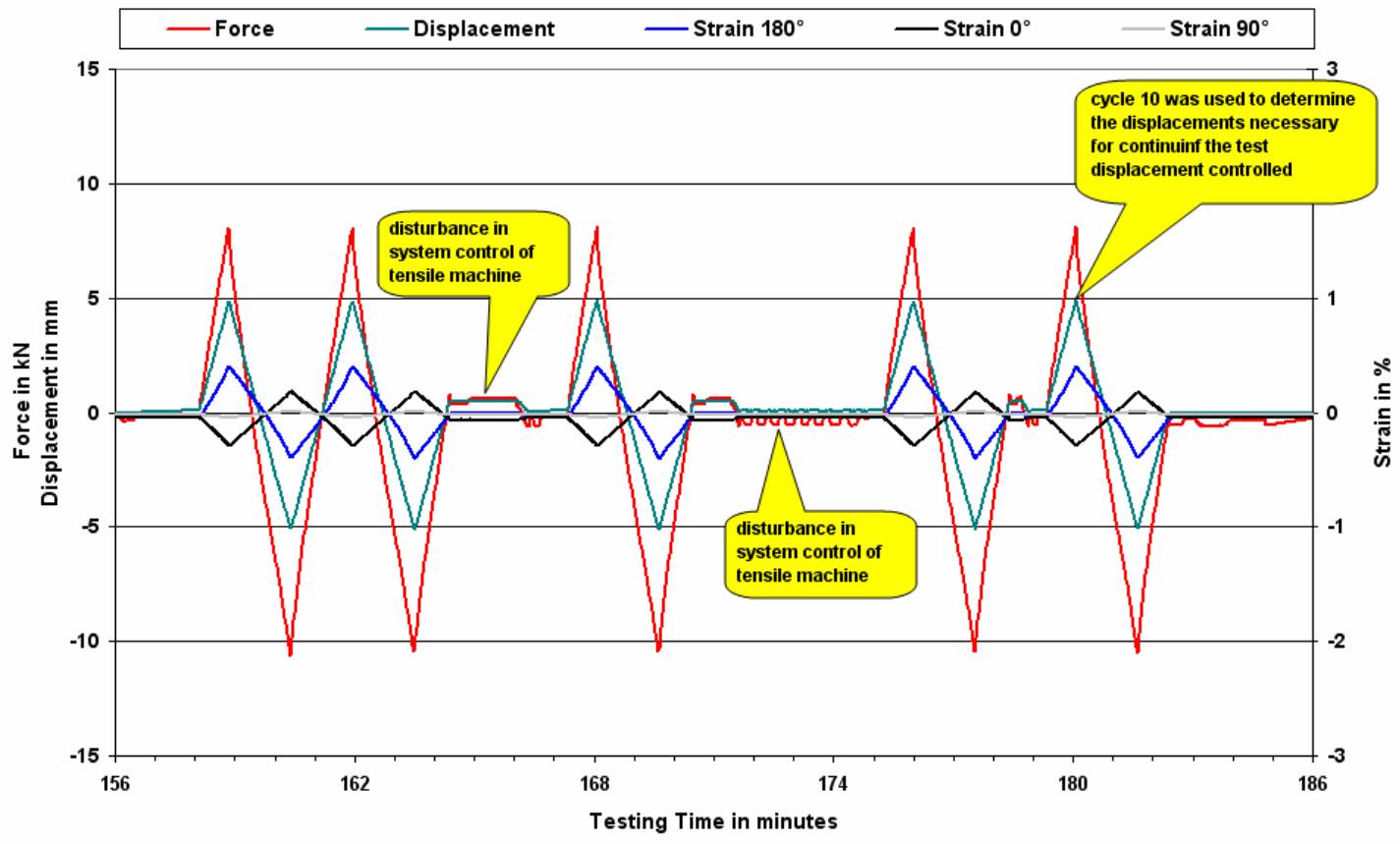

Figure 11-4

Mechanical data for Cycles 6 to 10. 


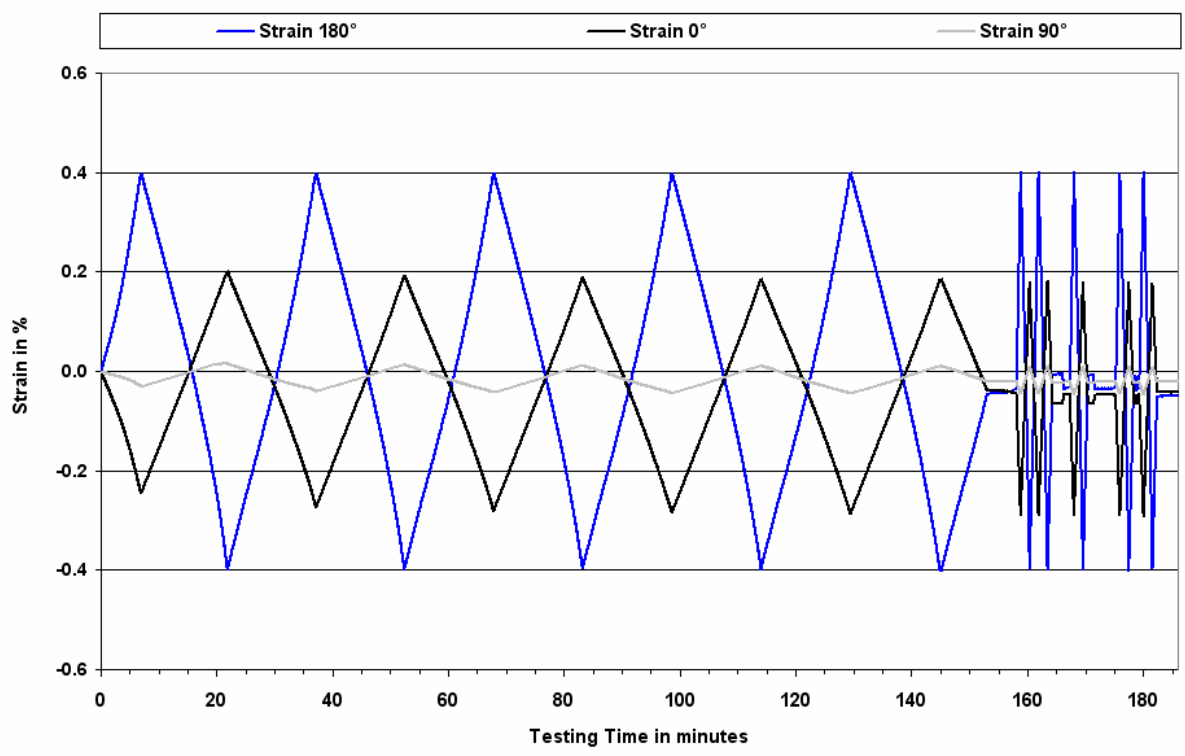

Figure 11-5

Strain response for Cycles 1 to 10.

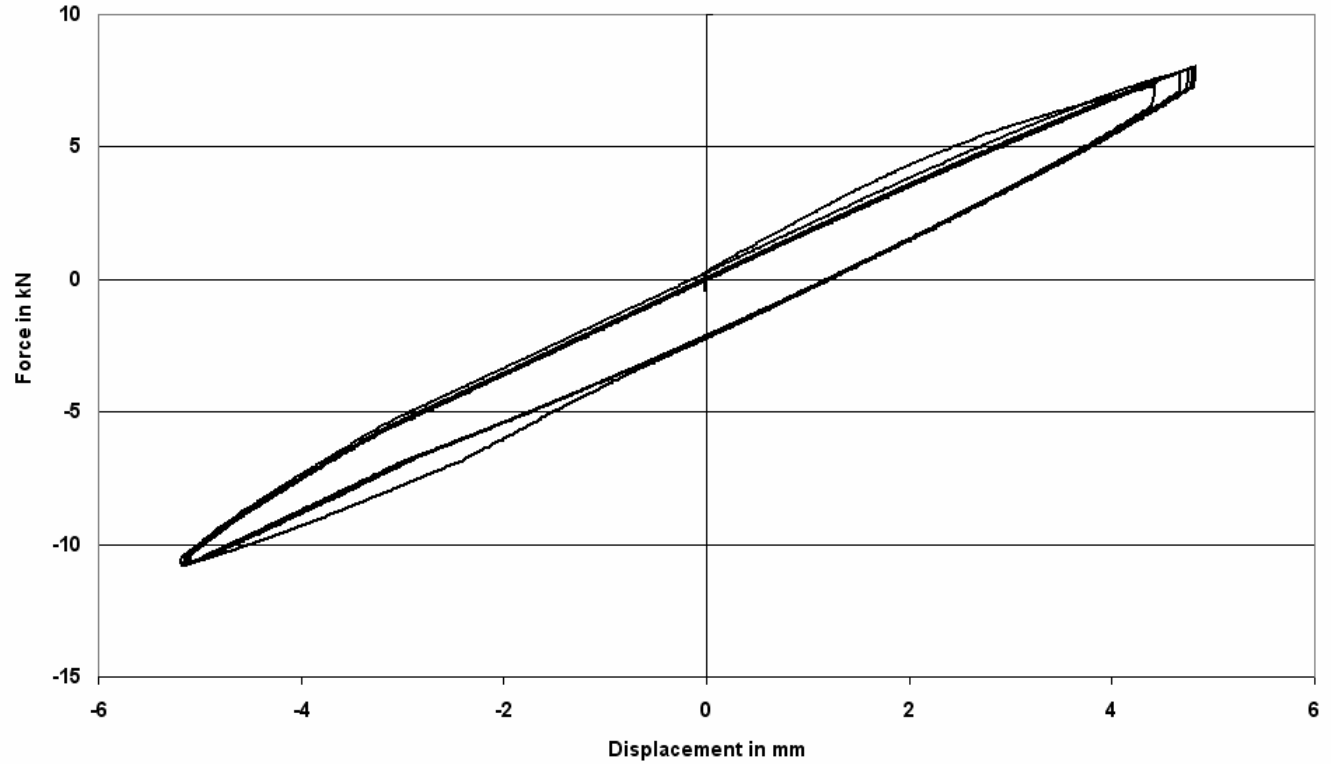

Figure 11-6

Load vs. displacement hysteresis for Cycles 1 to 5 . 


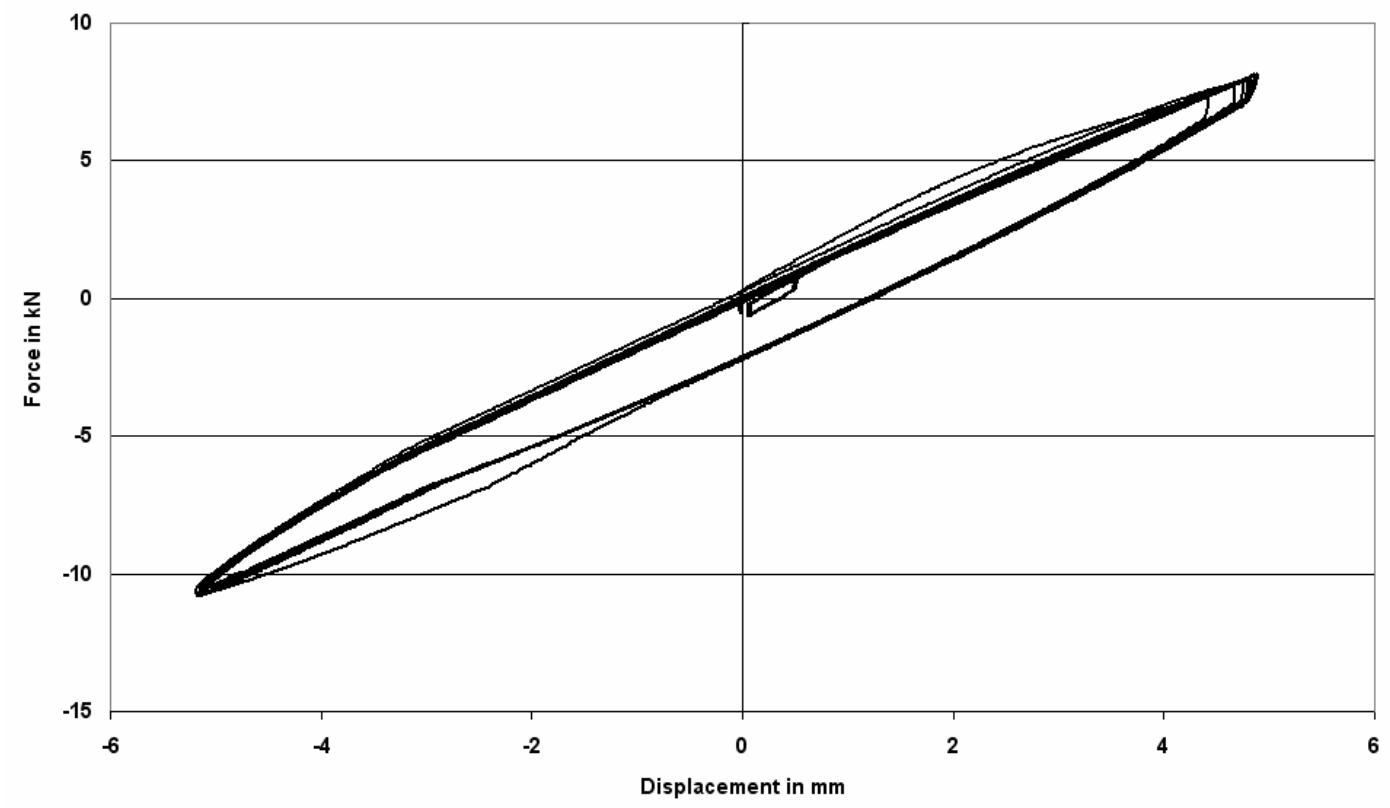

Figure 11-7

Load vs. displacement hysteresis for Cycles 1 to 10.

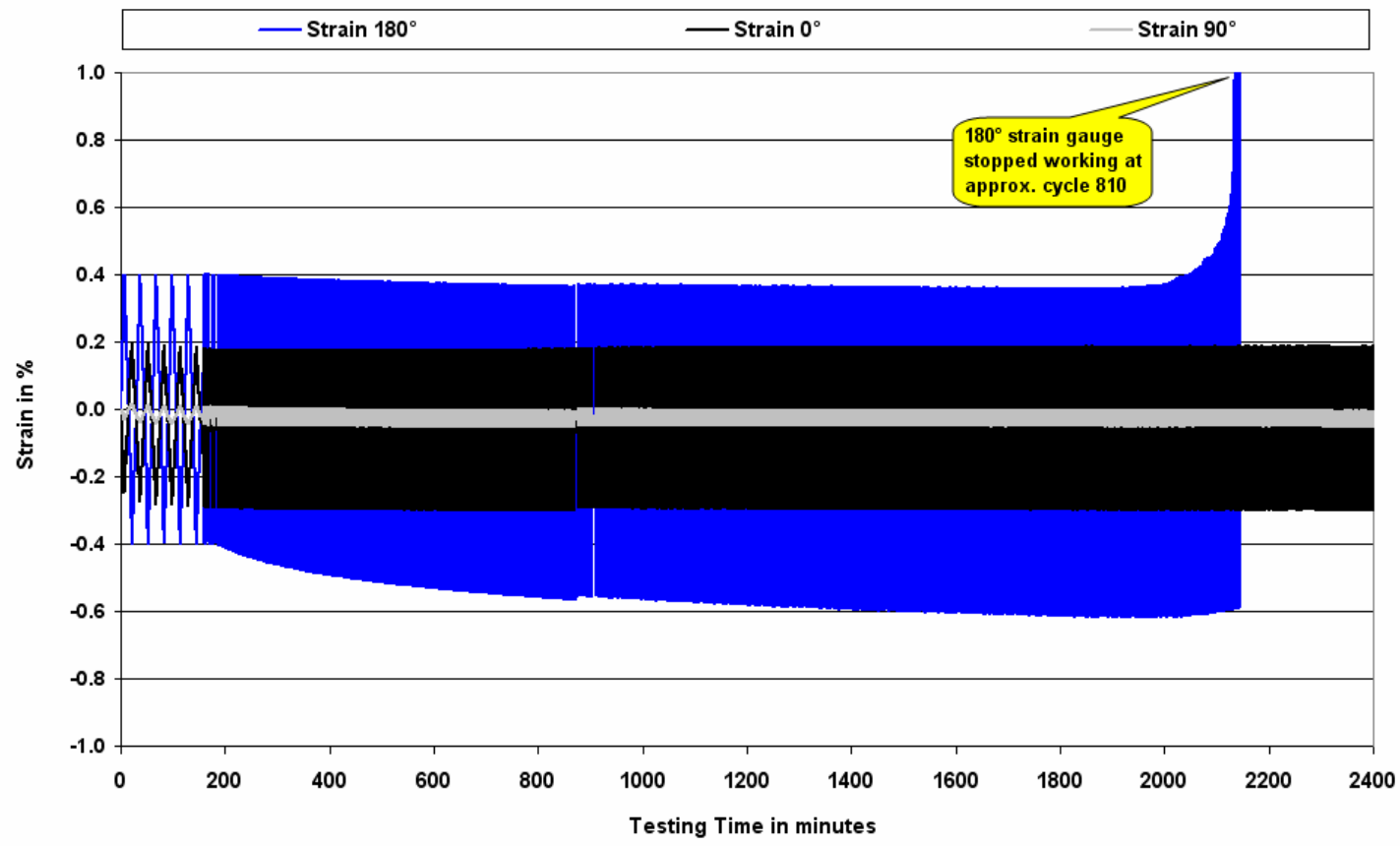

Figure 11-8

All available strain data. 


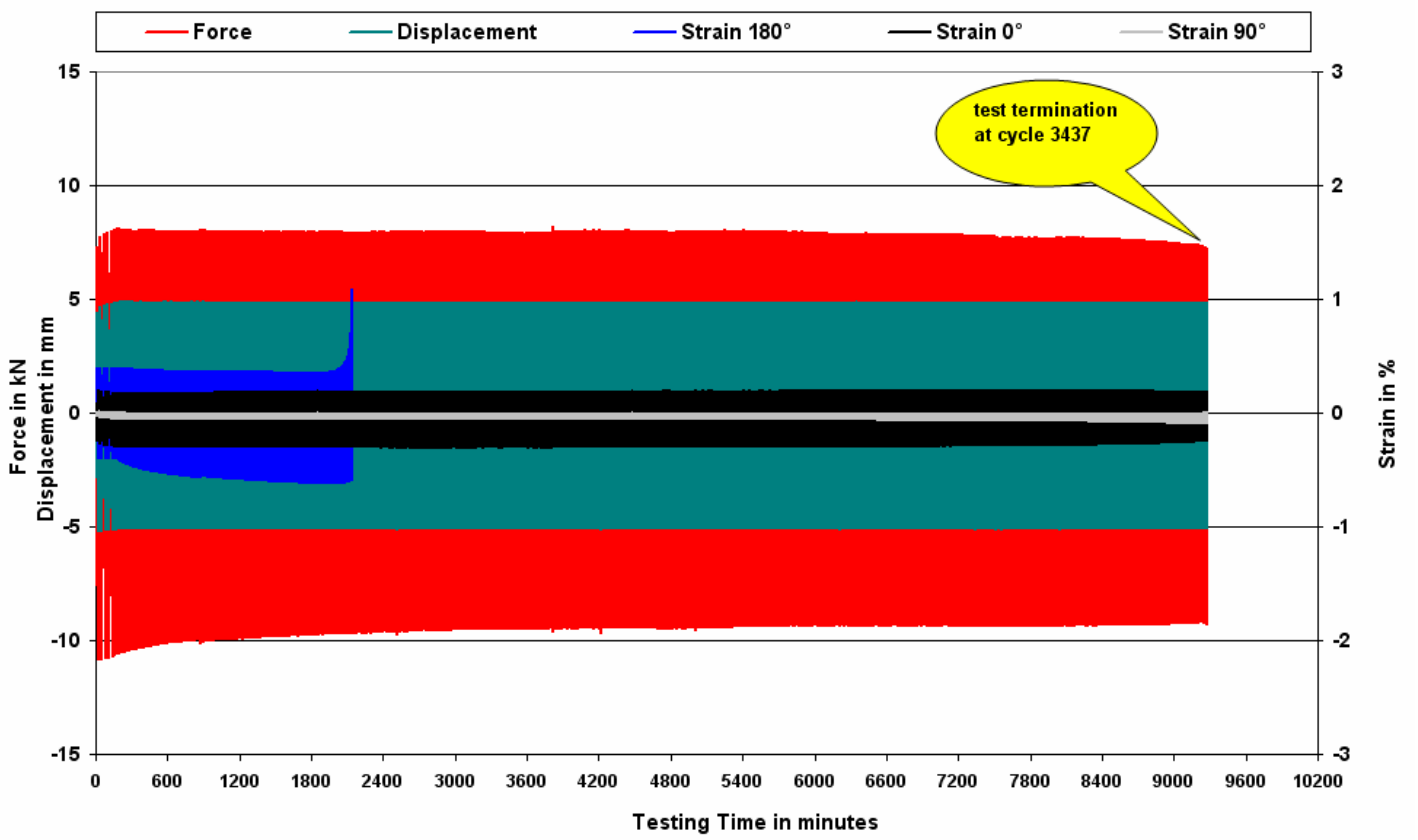

Figure 11-9

All mechanical data for Test $4 a$.

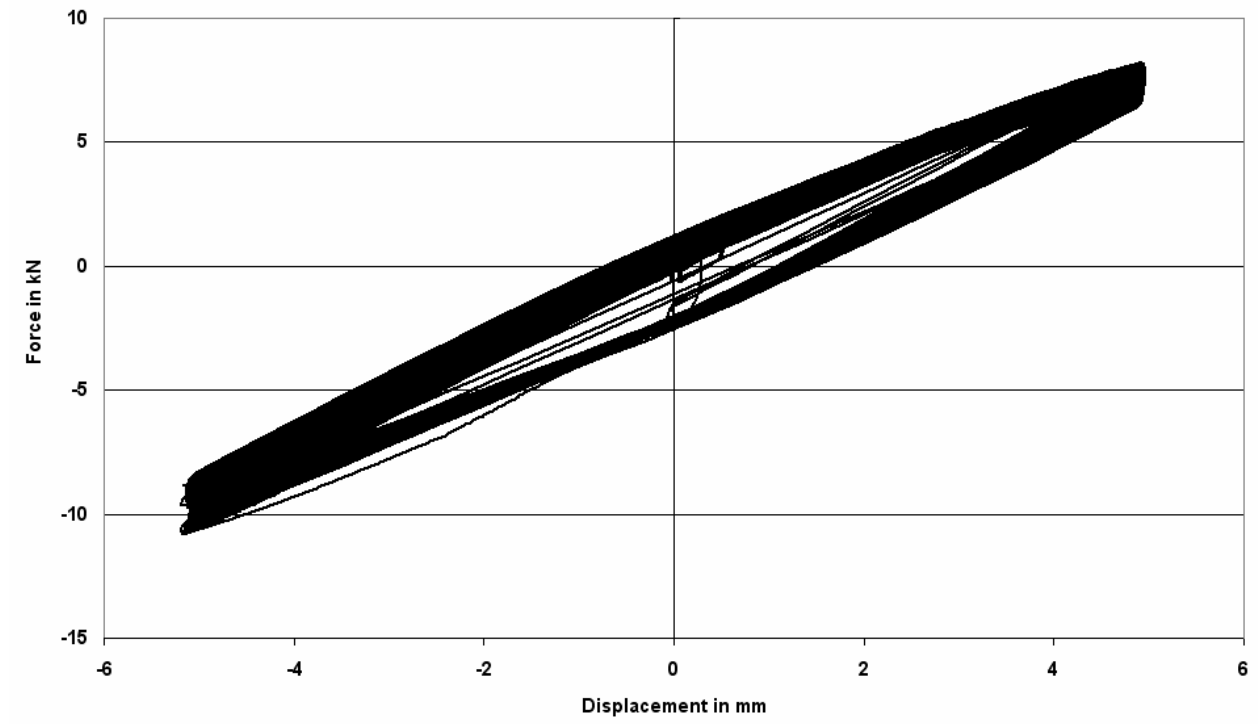

Figure 11-10

Load vs. displacement hysteresis for entire Test $4 a^{\prime}$. 


\section{Post Test Characterization}

After the physical testing part of environmental test 4a' was accomplished the U-bend was removed from the testing rig, the additional tubing for optimized flow condition was cut off and the bend was prepared for post test characterization entailing the following tasks:

- Visual inspection of tested U-bend

- Dye penetrant inspection (DPI)

- Fractography of selected locations at high magnifications using scanning electron microscopy (SEM)

- Metallography of selected locations

\section{Visual Inspection}

Visual inspection revealed one primary defect in the form of a narrow band of axial cracks. This band had an approximate length of $20 \mathrm{~mm}$ and was located in the $270^{\circ}$ position as shown in Figure 11-11. Remnants of crystallized boric acid were found adjacent to the leakage indicating that this defect had developed into a through-wall fissure causing the loss of environment. No other primary defects visible to the naked eye were found on the external surface during visual inspection.

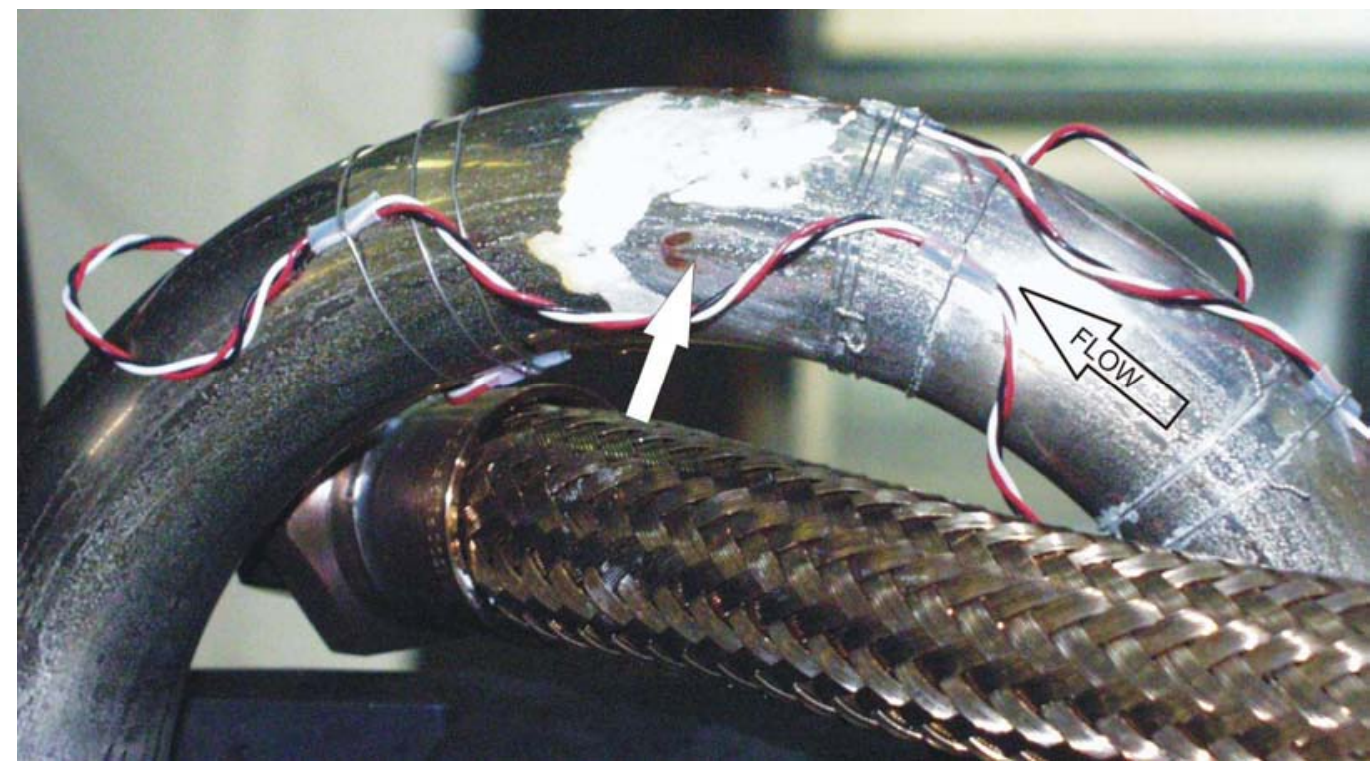

Figure 11-11

$270^{\circ}$ position (in-situ and rotated ca. 90 degrees) showing leakage indicated by white arrow. 


\section{Dye Penetrant Inspection}

A narrow piece containing the bend apex with an approximate length of $70 \mathrm{~mm}$ was sectioned from the bend and split in two half shells for further inspection with dye penetrant. Both the internal and external surfaces were examined. Typical views of the inspected surfaces are displayed in Figure 11-12.

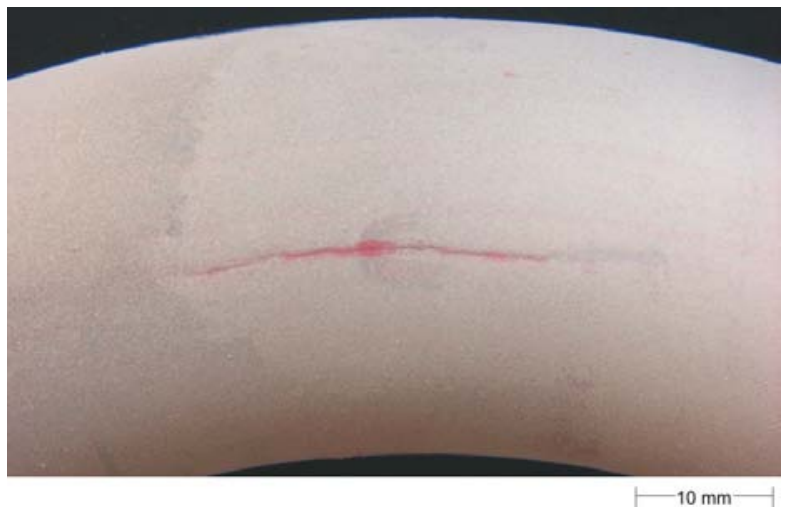

external surface

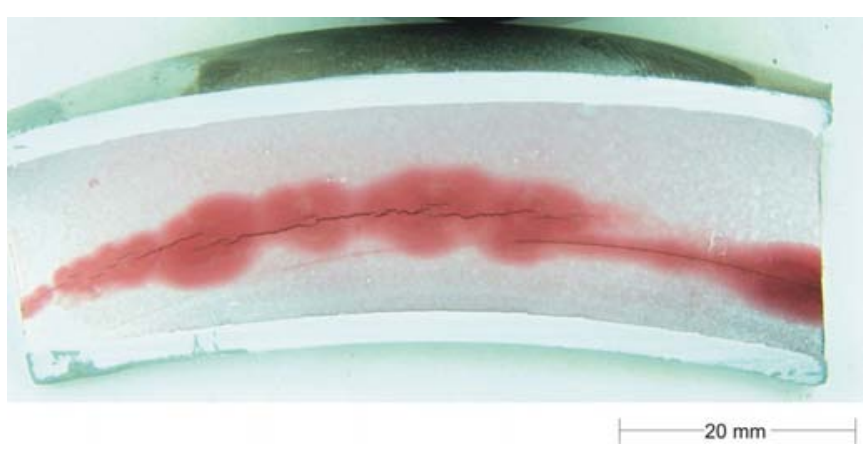

internal surface

Figure 11-12

DPI at $270^{\circ}$ position showing axial cracking on both the internal and external surfaces.

The findings from visual inspection were confirmed, since the $270^{\circ}$ position revealed multiple axial cracking on both the internal and external surfaces. With an approximate length of $70 \mathrm{~mm}$ the extent of axial cracking on the internal surface was greater than at the external surface, where the fissure had a length of approximately $30 \mathrm{~mm}$.

The $90^{\circ}$ position disclosed a similar failure appearance with a narrow band of multiple axial cracking on the internal surface, as shown in Figure 11-13. However, the cracking at this bend location had not developed into a through-wall defect, since the external surface was free of indications.

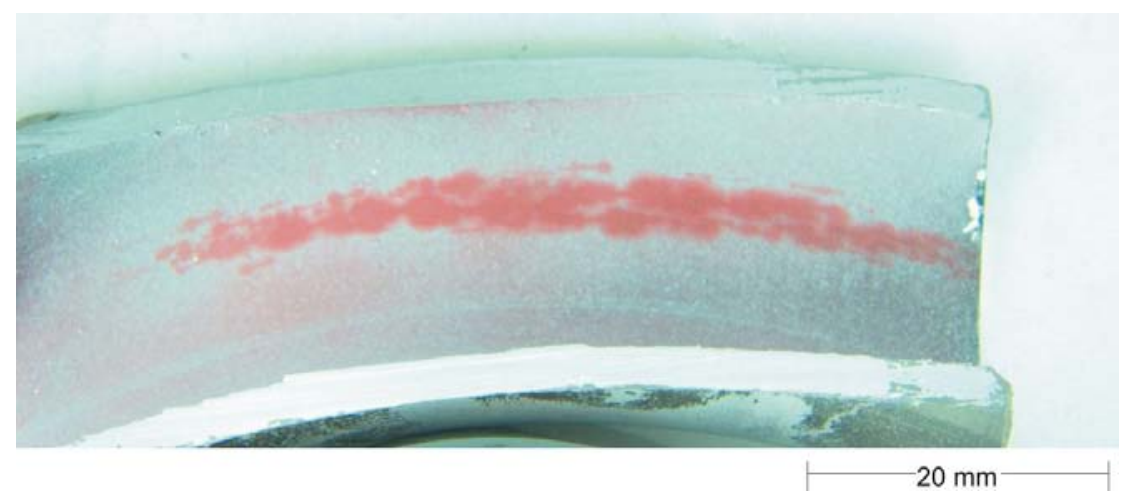

Figure 11-13

$\mathrm{DPI}$ at $90^{\circ}$ position showing multiple axial cracking. 
The $180^{\circ}$ intrados position revealed a small array of circumferential cracking on the external surface, whereas the internal surface suffered from very fine axial cracking. Views of the internal and external findings are displayed in Figure 11-14. The internal defects of the $180^{\circ}$ position were much finer and less pronounced if compared to the $270^{\circ}$ and $90^{\circ}$ positions, respectively.

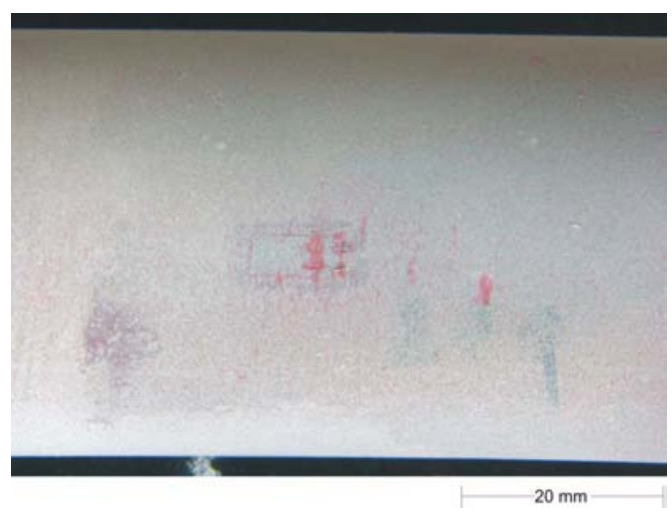

external surface

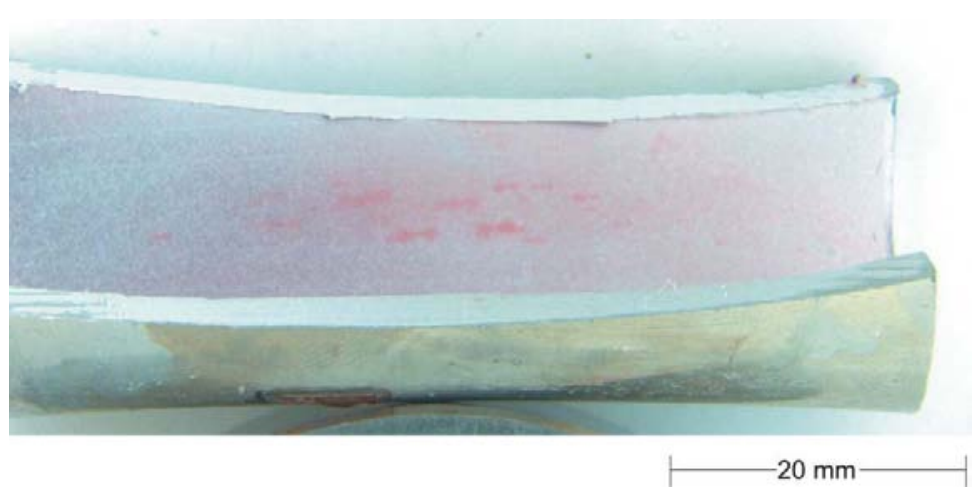

internal surface

Figure 11-14

DPI at $180^{\circ}$ intrados position confirming circumferential cracking on the external and axial cracking on the internal surfaces.

\section{Scanning Electron Microscopy}

Locations of interest of the external and internal surfaces were also examined at higher magnifications using the SEM. The internal surface at the $270^{\circ}$ position exhibited multiple axial cracking as shown in Figure 11-15. As reported in all previously tested bends the axial cracking predominantly followed attacked grain boundaries from the pickling treatment.

One representative axial crack found 0atthe $270^{\circ}$ position was broken open for detailed fractography at higher magnifications. Figure 11-16 illustrates the specimen with the laboratory fracture as well as the actual fracture surface to be investigated. The morphology revealed a striation pattern with varying spacing indicating a step wise crack progression under cyclic loading as displayed in Figure 11-17. The appearance indicated the combined efforts of mechanical loading and environment typical for corrosion fatigue. This is consolidated by the fact that the fracture progressed from the internal towards the external surface, by the flatter pronounced morphology and the multiple crack presence at this location. 


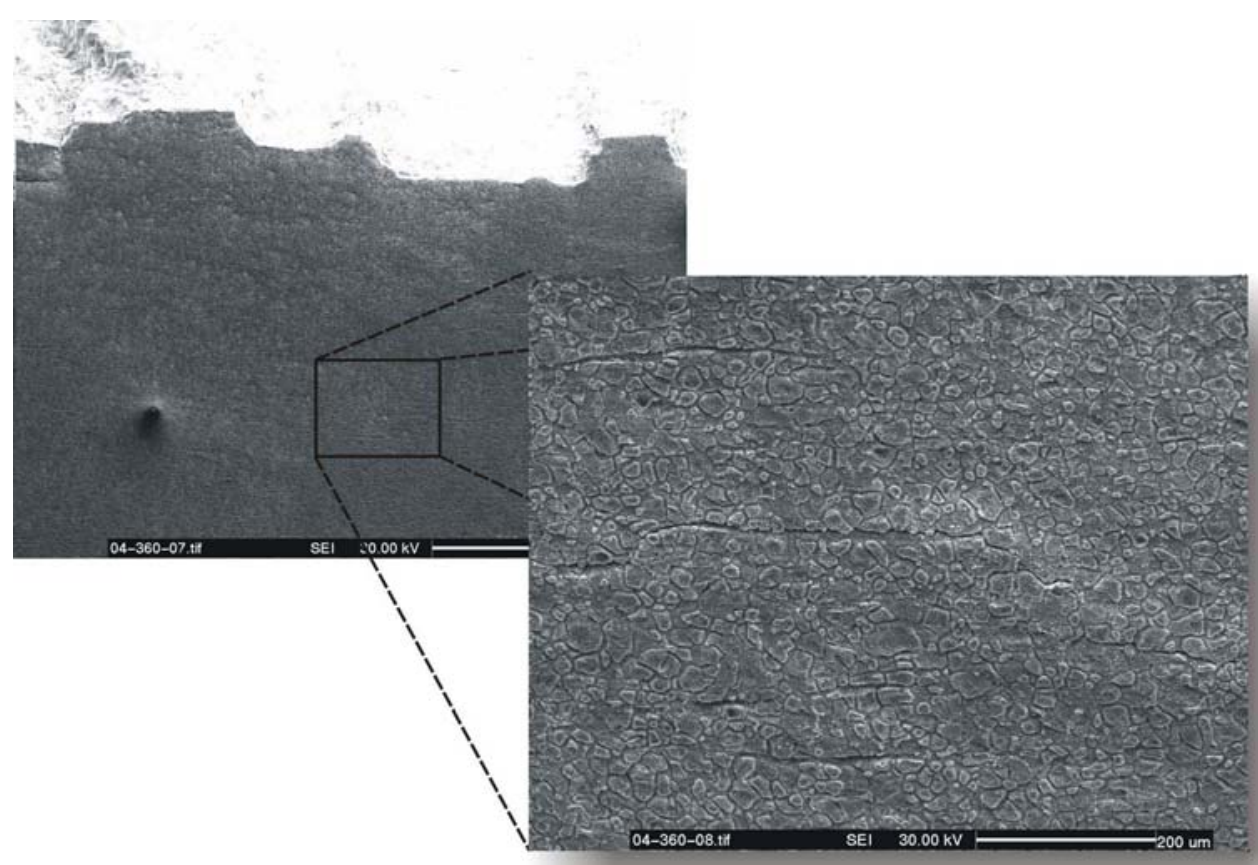

Figure 11-15 SEM surface examination confirming axial cracking that predominantly followed attacked grain boundaries.

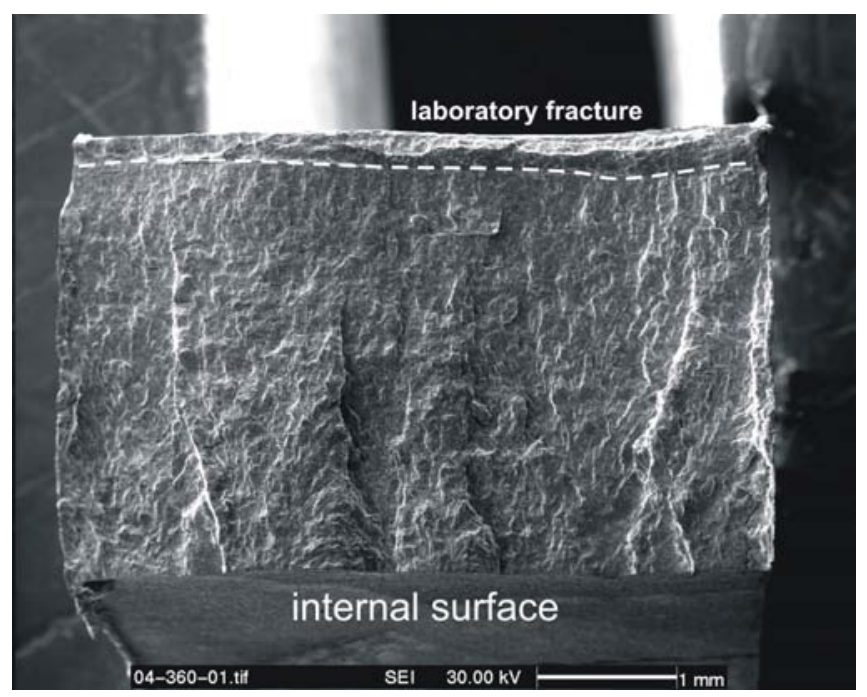

Figure 11-16

Broken open crack at $270^{\circ}$ position that was used for fractography.

Different stages of crack progression confirming corrosion fatigue at $270^{\circ}$ position. 


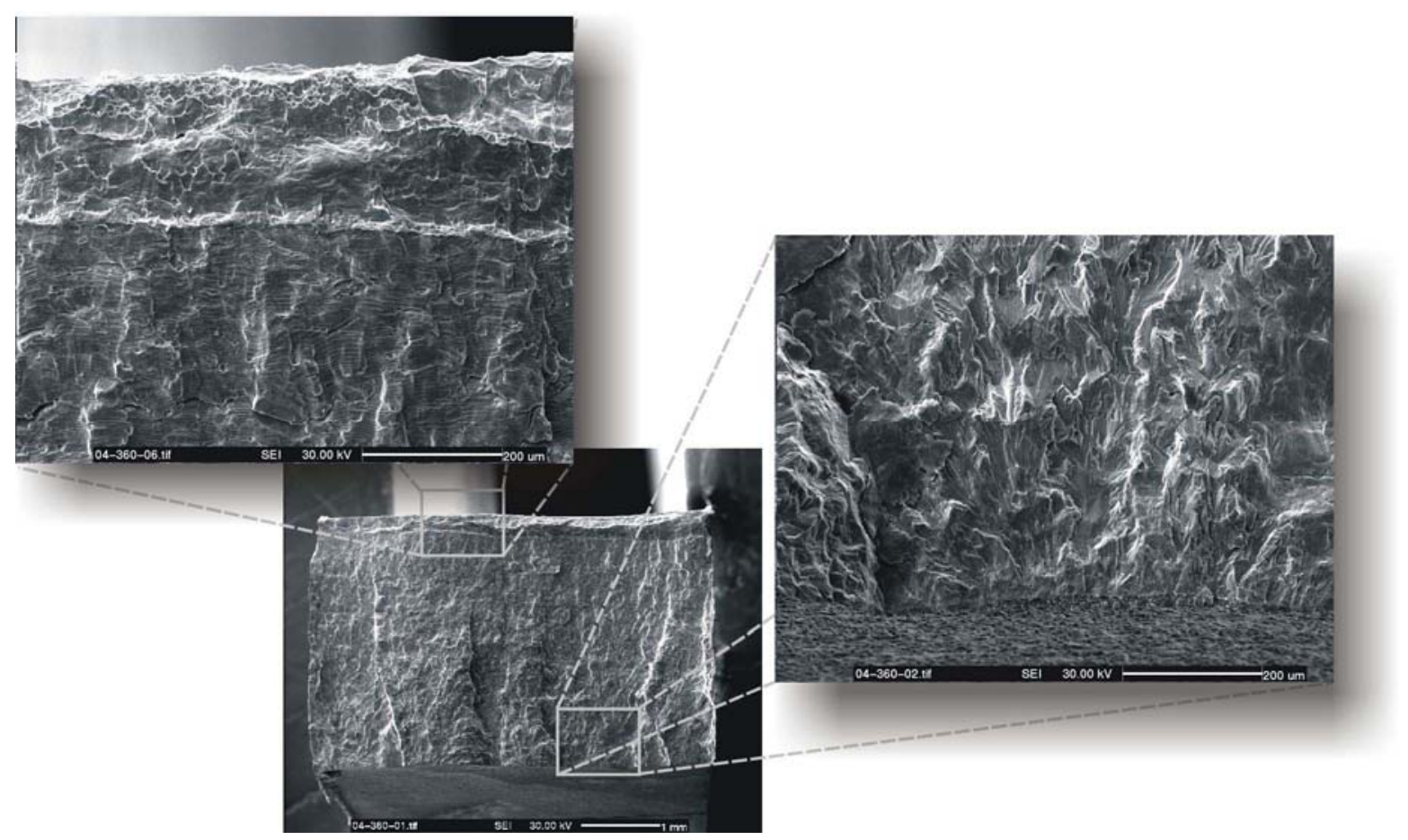

Figure 11-17

Different stages of crack progression confirming corrosion fatigue at $270^{\circ}$ position.

The striation spacing was then determined by evaluating corresponding images of the fracture surface. The spacing in the area associated with crack initiation was determined as approximately $0.5 \mu \mathrm{m}$. The mid fracture area showed a spacing of approximately $1 \mu \mathrm{m}$. The final stages of the crack disclosed a striation spacing of approximately $5 \mu \mathrm{m}$.

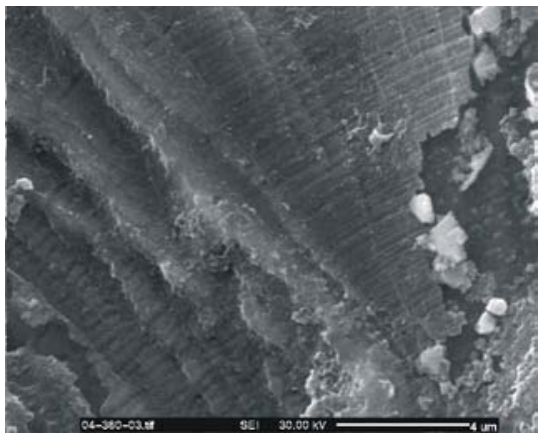

fracture initiation

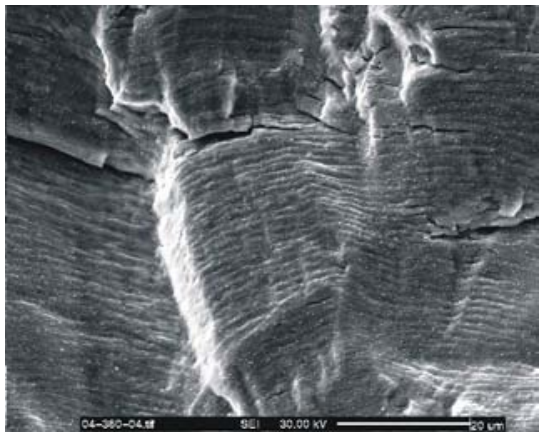

mid fracture

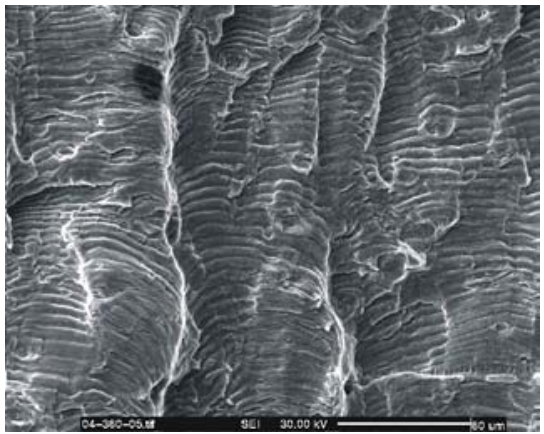

final stages

Figure 11-8

Stages of crack progression found at the $270^{\circ}$ position; the morphology indicates stepwise crack progression under the combined influence of mechanical loading and environment. 


\section{Metallography}

The Microstructure of selected locations labeled S1 to S3 as displayed in Figure 11- below were evaluated. The specimens were extracted from the bend, mounted and polished to a $1 \mu \mathrm{m}$ surface finish and etched with appropriate agents. The evaluation was conducted with a metallurgical microscope at varying magnifications.

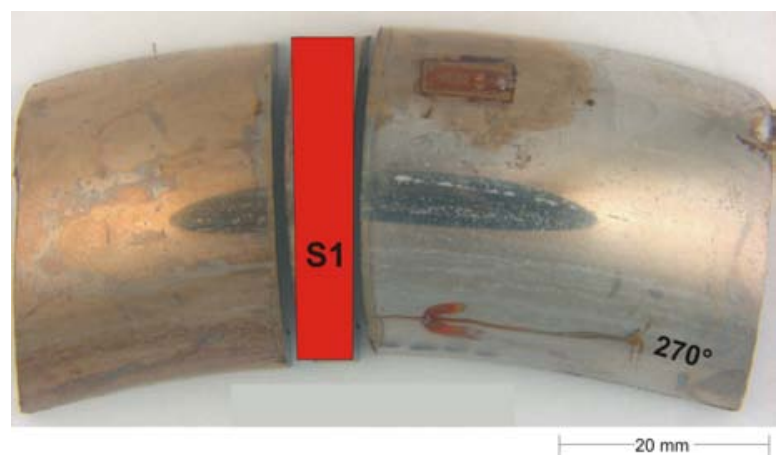

$270^{\circ}$ halfshell

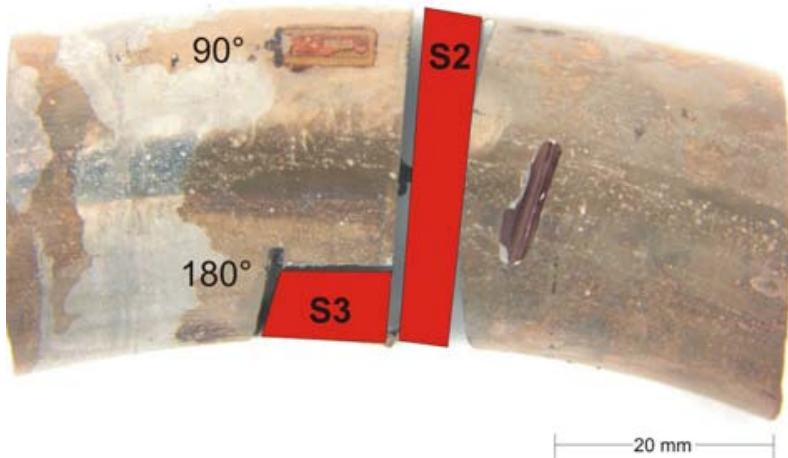

$90^{\circ}$ halfshell

Figure 11-9

Specimen removal plan for metallographic examination.

All examined microstructures appeared to be generally sound, since they exhibited features typical for austenitic stainless steels with no anomalies to be found. The indications from visual and dye penetrant inspection were confirmed since all corresponding locations exhibited cracking.

The $270^{\circ}$ position suffered from multiple axially oriented cracks, one of which had developed into a through-wall defect. The maximum crack depth of parallel located cracks was determined to be $810 \mu \mathrm{m}$, representing about $25 \%$ of the nominal wall thickness. All observed cracking had initiated at the internal surface and propagated under the combined efforts of mechanical loading and environmental effects towards the external surface (see Figure 11-). The propagation mode was found to be exclusively transgranular. 


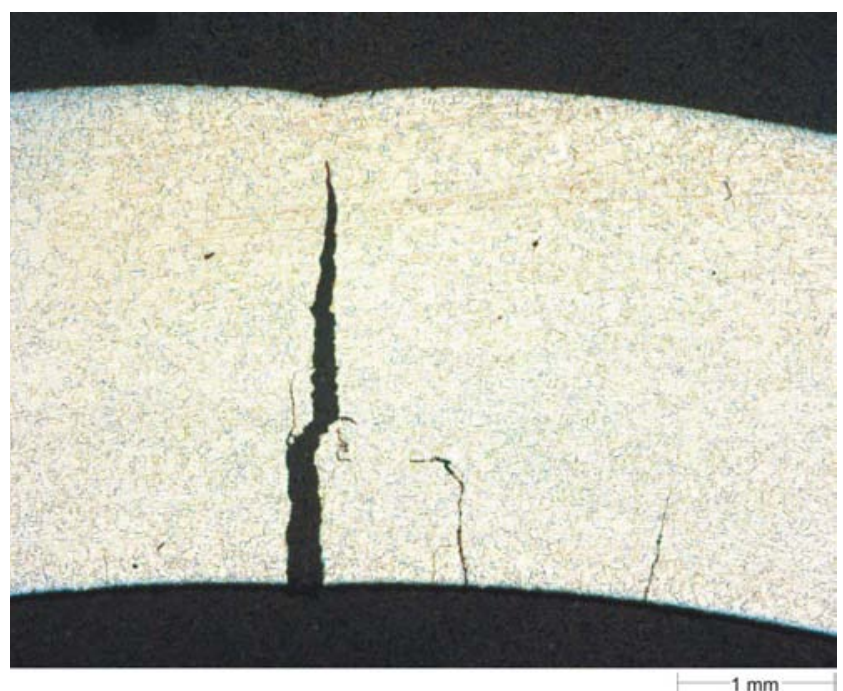

a)

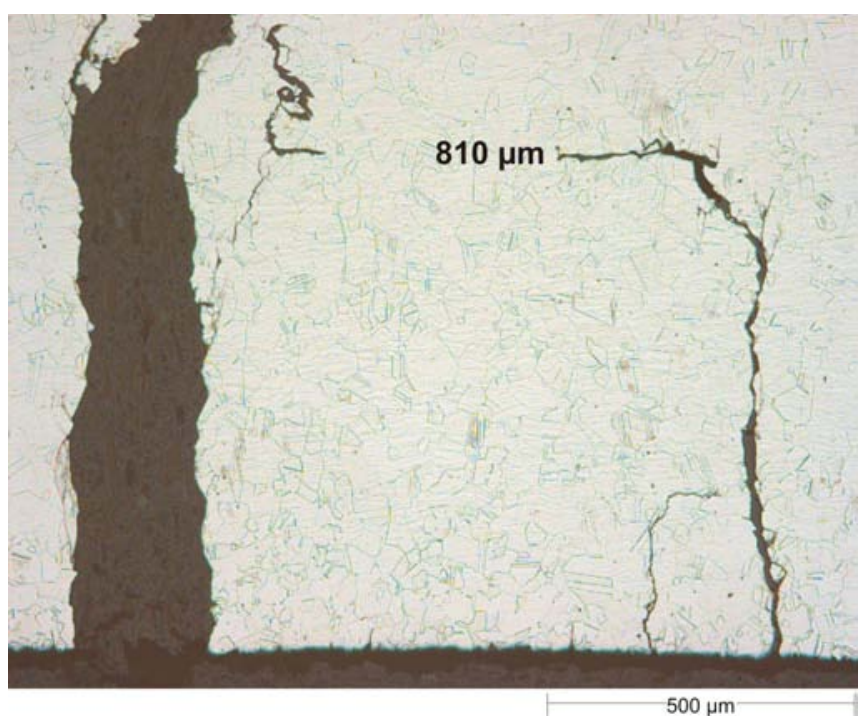

b)

Figure 11-20

Metallography of $270^{\circ}$ position (Specimen S1) confirming transgranular corrosion fatigue; a) overall view; b) close-up of parallel oriented crack.

The $90^{\circ}$ position exhibited a very similar appearance with multiple axially oriented cracks propagating from the internal towards the external surface in a transgranular manner. Identical to previous examined locations, crack initiation had occurred at attacked grain boundaries. The maximum crack depth within this prepared specimen was determined to be $1050 \mu \mathrm{m}$, representing approximately $30 \%$ of the tube's nominal wall thickness as shown in Figure 11-.

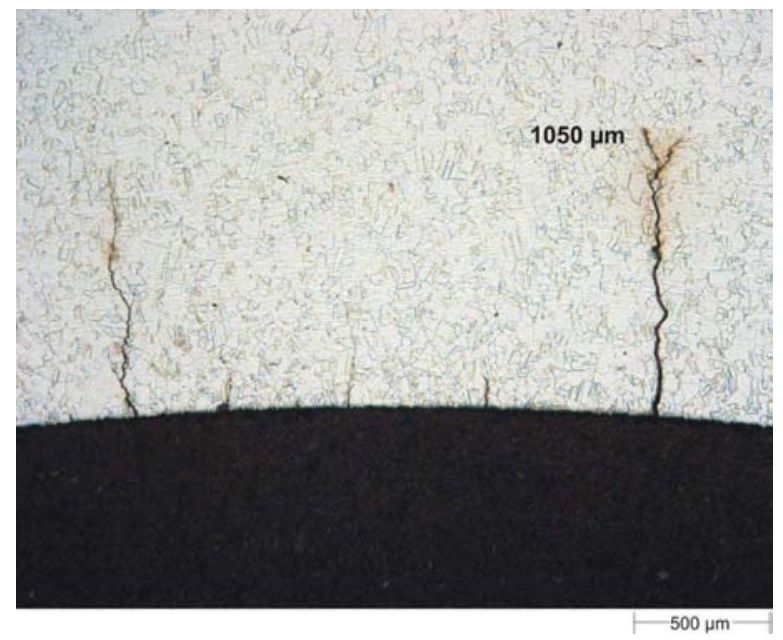

Figure 11-1

Metallography of $90^{\circ}$ position confirmed multiple axial cracking propagating in a transgranular manner from the internal towards the external surface. 
The $180^{\circ}$ position exhibited circumferentially oriented cracking originating on the external surface and axial cracking on the internal surface, as shown in Figure 11-. In both cases, the propagation mode was transgranular. The maximum depth of the circumferential, external cracking within this prepared cross-section was determined to be $300 \mu \mathrm{m}$, representing approximately $9 \%$ of the tube's nominal wall thickness. The maximum crack depth of the internal axial cracking was determined to be $500 \mu \mathrm{m}$, representing approximately $15 \%$ of the nominal wall thickness.

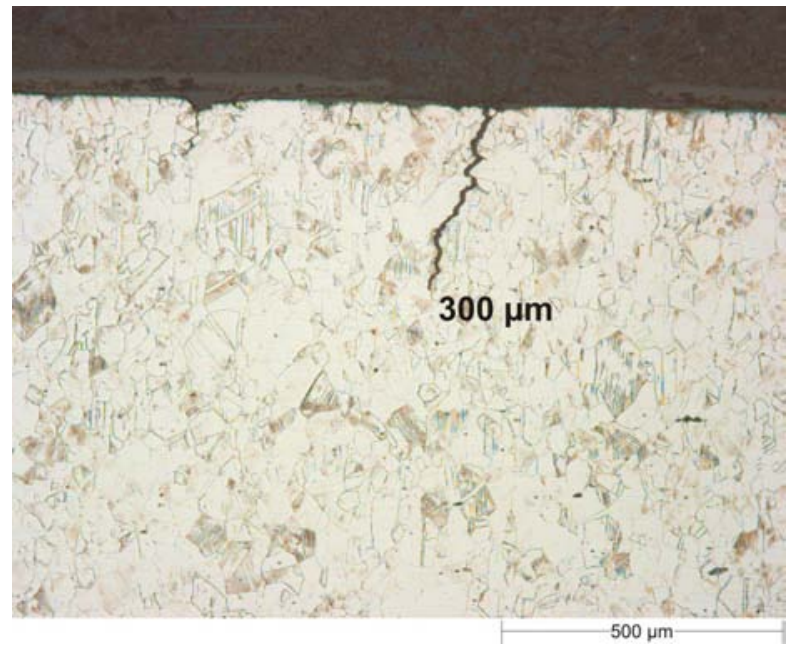

external surface circumferential

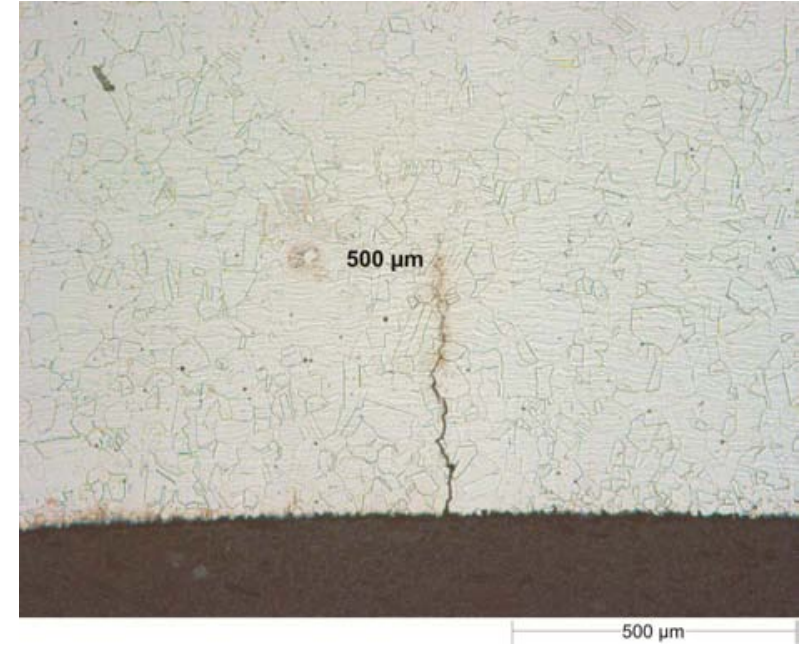

internal surface axial

Figure 11-2

Metallography of $180^{\circ}$ position confirming external circumferential and internal axial cracking.

\section{Summary of Results}

The following results can be summarized from environmental test 4a':

- Water chemistry within the range of specified values

- $\quad$ ECP $-550 \mathrm{mV}_{\mathrm{H}, \mathrm{T}}$, Redox Pot. $-500 \mathrm{mV}_{\mathrm{H}, \mathrm{T}}$ for low flow rate $(\approx 0.005 \mathrm{~m} / \mathrm{s})$

- Total number of cycles: 3437

- Leakage due to internally initiated axial through-wall cracking in the $270^{\circ}$ position;

- At $270^{\circ}, 90^{\circ}$ and $180^{\circ}$ and positions, axial cracking on internal surface

- The $0^{\circ}$ position was free of cracking

- No internal circumferential cracking was observed 
- External polishing did not entirely prevent external crack initiation; Small array of multiple circumferential cracks on the external surface of intrados ( $180^{\circ}$ position)

- All cracks were transgranular and showed features typical of fatigue; all internal axially initiated cracks showed evidence of environmental assisted progression (corrosion fatigue)

- No metallurgical anomalies were observed

Figure 11- graphically summarizes the extent and locations of cracking.

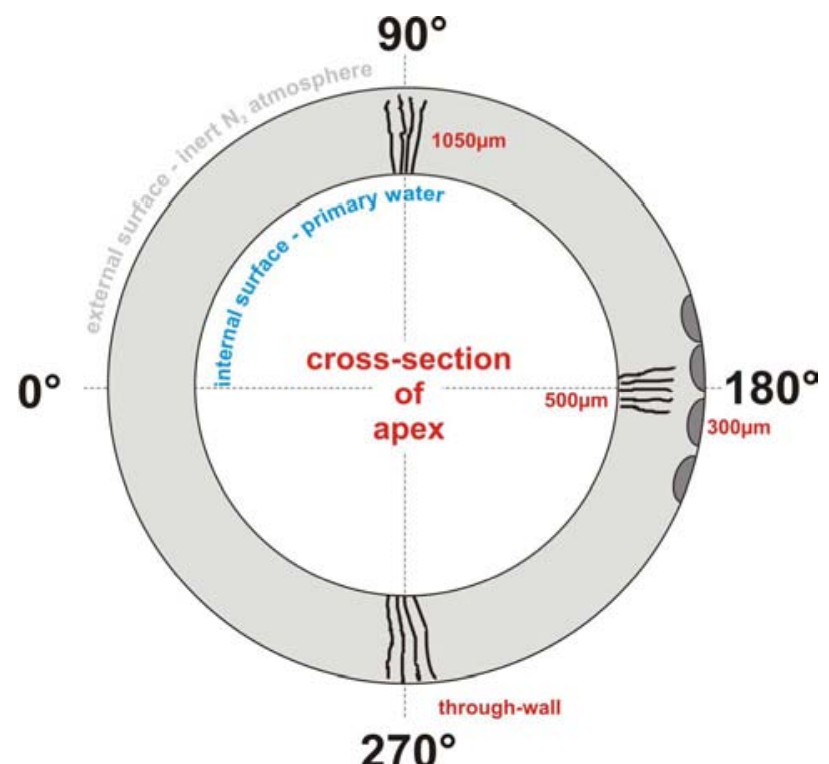

Figure 11-3

Schematic summary of crack locations, orientation and approximate crack depths (if available) of Test 4a'; schematic provides a cross-sectional view of the apex looking down-stream; please note that schematic is not to scale.

\section{Conclusions from Test 4a'}

Again, this test showed an effect of primary water on the fatigue behavior of the U-bend under cyclic load, since multiple axial cracking at the internal surface of the apex was observed and characterized. Having implemented a strain amplitude of $0.4 \%$, the combined efforts of environment and mechanical loading led to failure. This resulted in a total number of approximately 3437 cycles. The circumferential cracking in the external intrados area was attributed to pure mechanical loading, and external polishing did not prevent crack initiation entirely. The bend of test 4a' failed from internally initiating cracks due to corrosion fatigue. 
This additional test was performed to allow direct comparison between low flow and high flow conditions (test 4b versus 4a') of two similarly prepared bends. However, a clear effect of flow rate could not be observed. Test $4 \mathrm{~b}$ achieved 3616 cycles whereas test 4a' achieved 3437 cycles. This difference of approximately 180 cycles is not considered statistically significant. 


\section{2 \\ SUMMARY OF TEST RESULTS WITH $\pm 0.4 \%$ STRAIN AMPLITUDE}

For the test series 4 , all performed with a cyclic strain amplitude of $\pm 0.4 \%$ strain at a rate of $1 \times 10^{-4} \mathrm{~s}^{-1}$,the following statements can be made.

Environmental fatigue dominates failure of bend under cyclic loading:

- Failure due to multiple axial cracks in the $270^{\circ}$ position around the bend, all initiating from the water-wetted internal surface

- Additional, deep axial cracking from the ID at the intrados $\left(180^{\circ}\right)$ and $90^{\circ}$ positions, but the extrados $\left(0^{\circ}\right)$ was free of cracking

- $\quad$ Cycles to failure approximately $3600 \pm 200$

Mechanical fatigue also led to OD circumferential cracking at the intrados:

- Extent was greatly reduced or even eliminated by surface polishing

- OD cracks do not appear to have influenced the measured cycles to failure

Electropolishing the ID surface appeared to have little or no effect on the cycles to failure, or the number/depth of additional axial cracks. This suggests that the as-received component condition (pickled surface with shallow intergranular attack) is not detrimental for initiation of environmental fatigue, despite the observed tendency of the axial cracks to follow the pickled surface texture.

No clear effect of flow rate observed to date, although the cycles to failure were slightly higher at high flow. 


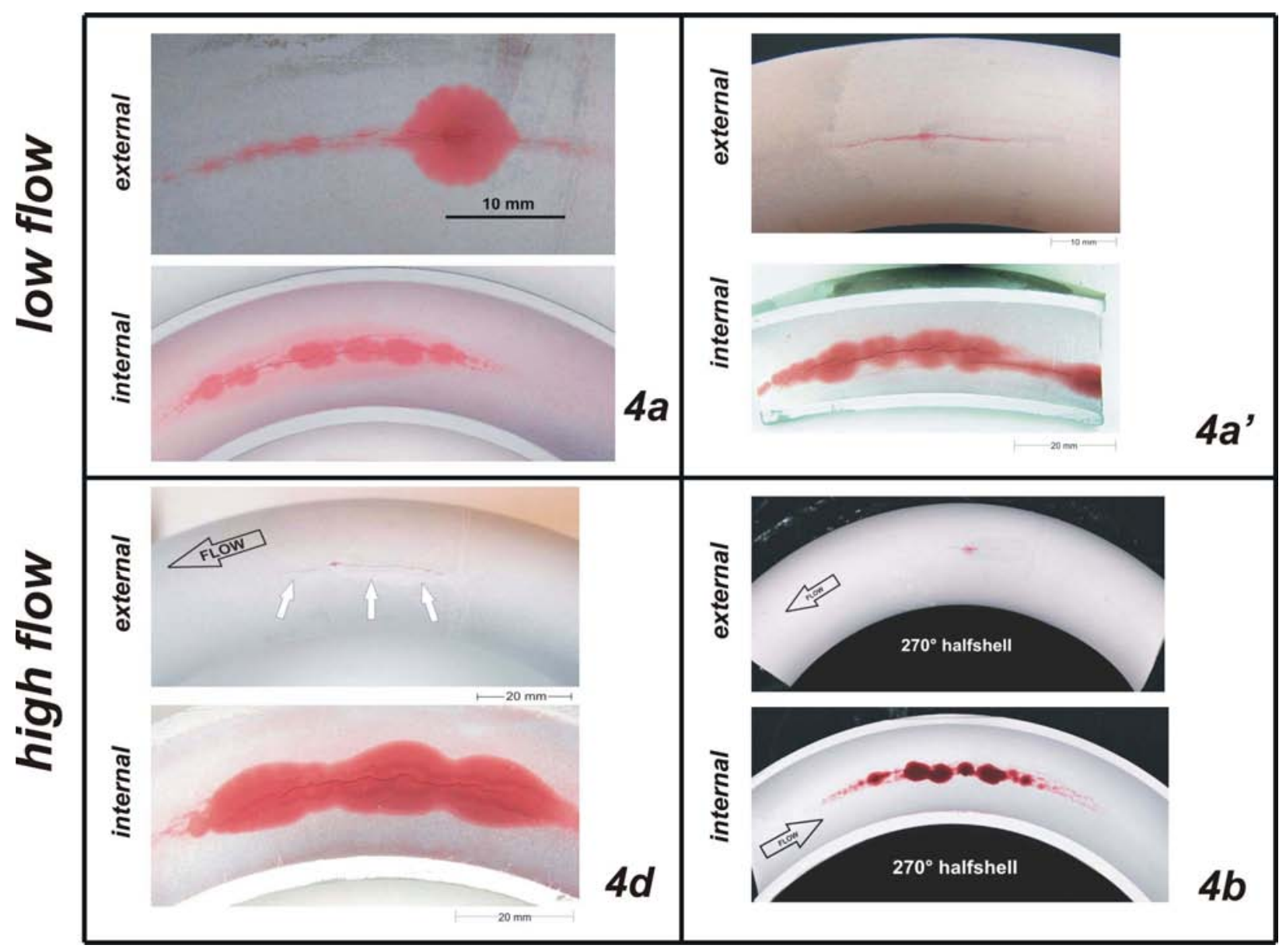

Figure 12-1

Summary of DPI findings during Test Series 4. 


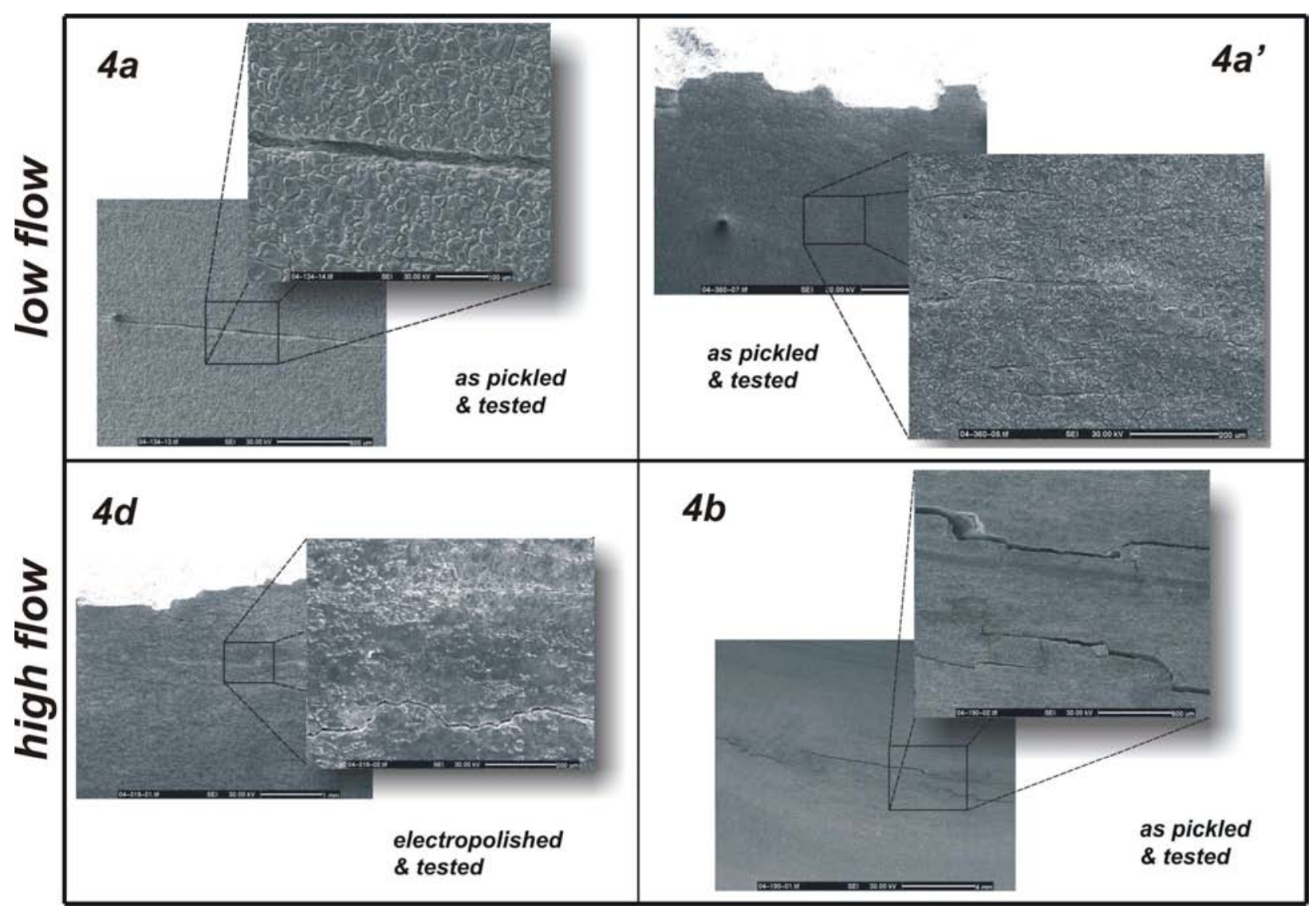

Figure 12-2

Summary of SEM surface examination during Test Series 4. 


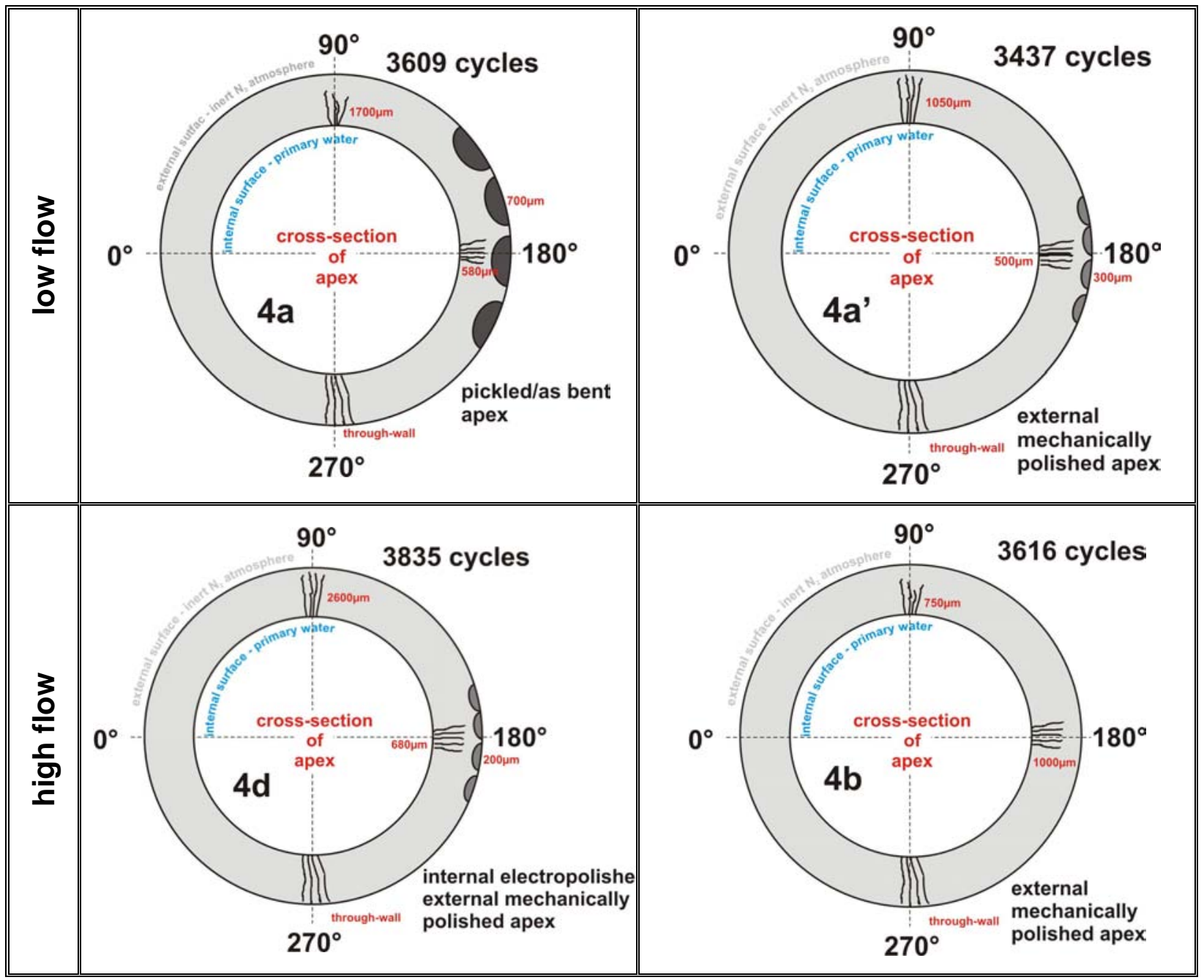

Figure 12-3

Summary of crack locations and depths observed during Test Series 4. 


\section{3 \\ SUMMARY, DISCUSSION AND CONCLUSIONS FROM TEST PROGRAM TO DATE}

\section{General}

Having completed BLT2 and environmental testing during Phase B (test 2a and 2b) and Phase C (test $4 \mathrm{a}$, test $4 \mathrm{a}$, test $4 \mathrm{~b}$ and test $4 \mathrm{~d}$ ), the following paragraphs will summarize basic test parameters and the results obtained. Finally, conclusions will be drawn from the program accomplished so far.

BLT2 was performed with a strain amplitude of $\pm 0.6 \%$ strain at a rate of $1 \times 10^{-4} \mathrm{~s}^{-1}$ under inert $\mathrm{N}_{2}$ atmosphere. Phase $\mathrm{B}$ and Phase $\mathrm{C}$ tests were also performed with a strain rate of $1 \mathrm{x}^{-4} \mathrm{~s}^{-1}$. The load application occurred at an R-ratio of -1 resulting in fully reversed load cycles. The difference between Phase $\mathrm{B}$ and Phase $\mathrm{C}$ was primarily that Phase $\mathrm{B}$ was performed with a strain amplitude of $\pm 0.6 \%$, whereas Phase $C$ was performed with a strain amplitude of $\pm 0.4 \%$. Particular differences between individual tests within one series will be addressed in the corresponding paragraphs.

The water chemistry in the environmental tests was controlled within specified limits and can be considered similar for all tested bends. The dissolved oxygen ranged between $2 \mathrm{ppb}$ to $3 \mathrm{ppb}$ and the testing temperature was held at $240^{\circ} \mathrm{C}$. The electrochemical corrosion potential was controlled at approximately $-550 \mathrm{mV}_{\mathrm{NHE}, \mathrm{T}}$ and the Redox potential at approximately $-500 \mathrm{mV}$ NHE,T for all conducted tests. The flow conditions were adjusted appropriately for each test. The low flow condition was controlled at $10 \mathrm{l} / \mathrm{h}$ and the high flow rate at $4100 \mathrm{l} / \mathrm{h}$. Considering the average bend geometry this corresponded to approximately $0.005 \mathrm{~m} / \mathrm{s}$ for the low flow and $2.2 \mathrm{~m} / \mathrm{s}$ for the high flow condition. Table 13-1 compares all the tests accomplished so far and provides the key testing data and results obtained.

\section{BLT2}

The U-bend tested during BLT 2 suffered from multiple, circumferential crack indications on the $\mathrm{OD}$, arranged in an array at the $180^{\circ}$ intrados position. The primary failure occurred due to propagation of a circumferential through-wall defect that originated on the external surface of the intrados. The relatively straight crack progression in a transgranular manner and the fracture appearance with striations clearly indicated a purely mechanical driven fatigue failure with a total number of 1750 achieved cycles. 


\begin{tabular}{|c|c|c|c|c|c|c|c|c|c|c|c|}
\hline \multirow[t]{2}{*}{ test } & \multirow{2}{*}{$\begin{array}{l}\text { strain } \\
\text { ampli } \\
\text { tude }\end{array}$} & \multirow[t]{2}{*}{$\begin{array}{l}\text { displace- } \\
\text { ments }\end{array}$} & \multicolumn{2}{|c|}{ surface condition } & \multirow[t]{2}{*}{$\begin{array}{l}\text { flow } \\
\text { rate }\end{array}$} & \multirow[t]{2}{*}{$\begin{array}{l}\text { cycles to } \\
\text { failure }\end{array}$} & \multirow{2}{*}{$\begin{array}{c}\text { dominant } \\
\text { failure } \\
\text { location \& } \\
\text { mechanism }\end{array}$} & \multicolumn{2}{|c|}{$\begin{array}{c}\text { striation } \\
\text { spacing mid } \\
\text { fracture area }\end{array}$} & \multirow{2}{*}{$\begin{array}{c}\text { env. axial } \\
\text { crack depth } \\
180^{\circ} \\
\text { position }\end{array}$} & \multirow{2}{*}{$\begin{array}{l}\text { env. axial } \\
\text { crack depth } \\
90^{\circ} \text { position }\end{array}$} \\
\hline & & & ext. & int. & & & & env. & mech. ${ }^{1)}$ & & \\
\hline BLT2 & $\pm 0.6 \%$ & $\begin{array}{l}+6.9 \mathrm{~mm} \\
-4.7 \mathrm{~mm}\end{array}$ & \multicolumn{2}{|c|}{ as pickled } & $\begin{array}{c}\text { stagnant } \\
\mathrm{N}_{2}\end{array}$ & 1705 & $\begin{array}{l}180^{\circ} \mathrm{OD} \\
\text { mechanical }\end{array}$ & - 2) & $2 \mu \mathrm{m}$ & $-2)$ & - 2) \\
\hline $2 a$ & $\pm 0.6 \%$ & $\begin{array}{l}+6.50 \mathrm{~mm} \\
-4.85 \mathrm{~mm}\end{array}$ & \multicolumn{2}{|c|}{ as pickled } & low & 1520 & $\begin{array}{c}180^{\circ} \\
\text { mechanical }\end{array}$ & $1 \mu \mathrm{m}$ & $5 \mu \mathrm{m}$ & $>1000 \mu \mathrm{m}$ & $N / A^{3)}$ \\
\hline $2 b$ & $\pm 0.6 \%$ & $\begin{array}{l}+7.15 \mathrm{~mm} \\
-5.4 \mathrm{~mm}\end{array}$ & \multicolumn{2}{|c|}{ as pickled } & high & $\begin{array}{c}1238 \\
\text { notch } \\
\text { initiation }\end{array}$ & $\begin{array}{l}180^{\circ} \mathrm{OD} \\
\text { mechanical }\end{array}$ & $1 \mu \mathrm{m}$ & $2.5 \mu \mathrm{m}$ & $400 \mu \mathrm{m}$ & $N / A^{3)}$ \\
\hline $4 a$ & $\pm 0.4 \%$ & $\begin{array}{l}+4.82 \mathrm{~mm} \\
-5.25 \mathrm{~mm}\end{array}$ & \multicolumn{2}{|c|}{ as pickled } & low & 3609 & $\begin{array}{c}270^{\circ} \mathrm{ID} \\
\text { environm. }\end{array}$ & $3 \mu \mathrm{m}$ & $\begin{array}{c}1 \mu \mathrm{m} \\
\left(180^{\circ}\right)\end{array}$ & $580 \mu \mathrm{m}$ & $1700 \mu \mathrm{m}$ \\
\hline $4 a^{\prime}$ & $\pm 0.4 \%$ & $\begin{array}{l}+4.91 \mathrm{~mm} \\
-5.07 \mathrm{~mm}\end{array}$ & $\begin{array}{c}\text { mech. } \\
\text { polished }\end{array}$ & $\begin{array}{c}\text { as } \\
\text { pickled }\end{array}$ & low & 3437 & $\begin{array}{l}270^{\circ} \mathrm{ID} \\
\text { environm. }\end{array}$ & $1 \mu \mathrm{m}$ & $\begin{array}{l}\mathrm{N} / \mathrm{A}^{3)} \\
\left(180^{\circ}\right)\end{array}$ & $500 \mu \mathrm{m}$ & $1050 \mu \mathrm{m}$ \\
\hline $4 b$ & $\pm 0.4 \%$ & $\begin{array}{l}+5.07 \mathrm{~mm} \\
-5.08 \mathrm{~mm}\end{array}$ & $\begin{array}{c}\text { mech. } \\
\text { polished }\end{array}$ & $\begin{array}{c}\text { as } \\
\text { pickled }\end{array}$ & high & 3616 & $\begin{array}{l}270^{\circ} \mathrm{ID} \\
\text { environm. }\end{array}$ & $1 \mu \mathrm{m}$ & $-{ }^{2)}$ & $1000 \mu \mathrm{m}$ & $750 \mu \mathrm{m}$ \\
\hline $4 d$ & $\pm 0.4 \%$ & $\begin{array}{l}+4.83 \mathrm{~mm} \\
-5.03 \mathrm{~mm}\end{array}$ & $\begin{array}{l}\text { mech. } \\
\text { polished }\end{array}$ & $\begin{array}{l}\text { electrop } \\
\text { olished }\end{array}$ & high & 3835 & $\begin{array}{l}270^{\circ} \mathrm{ID} \\
\text { environm. }\end{array}$ & $1 \mu \mathrm{m}$ & $\begin{array}{l}N / A^{3)} \\
\left(180^{\circ}\right)\end{array}$ & $680 \mu \mathrm{m}$ & $2600 \mu \mathrm{m}$ \\
\hline \multicolumn{12}{|c|}{ 1) OD crack initiation $\quad{ }^{2)}$ not existing } \\
\hline \multicolumn{12}{|c|}{ 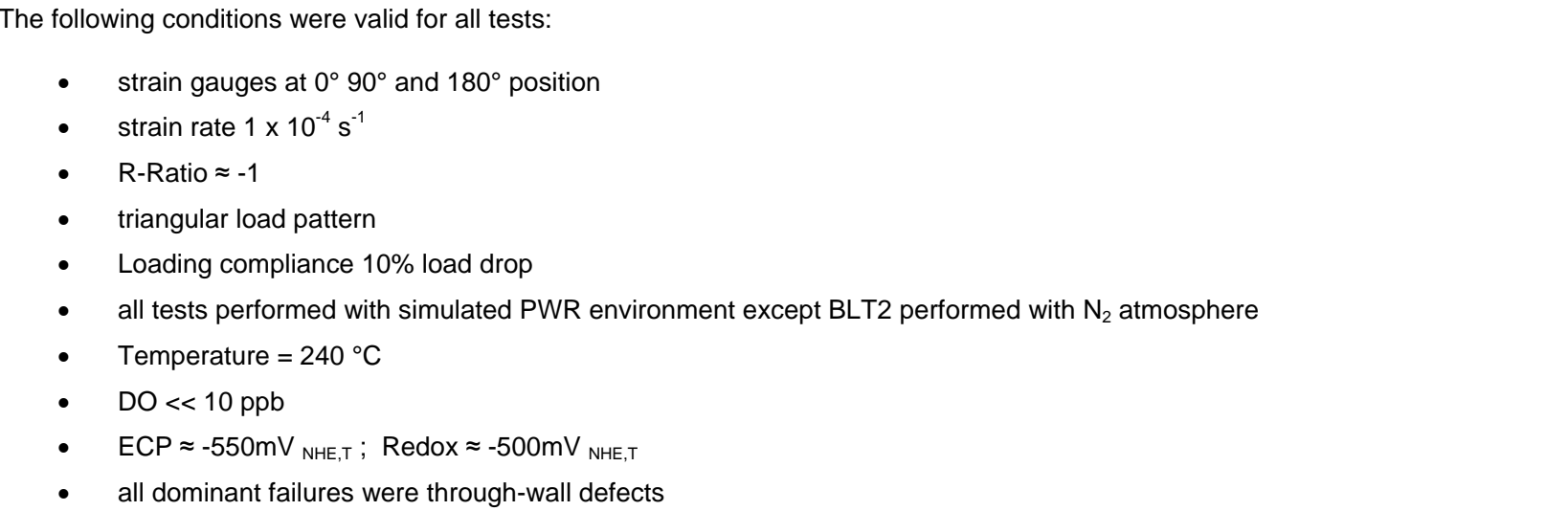 } \\
\hline
\end{tabular}

Table 13-1

Condensed summary of important results for all tested bends.

\section{Phase B}

The strain amplitude of $\pm 0.6 \%$ strain used in Phase B for test series 2 appears to be too severe for the intended corrosion fatigue testing. Similar to BLT2, the strain field at the apex induced mechanical fatigue, initiating on the external surface of the intrados, in both tests $2 \mathrm{a}$ and $2 \mathrm{~b}$. The propagation mode of this mechanical driven fracture was exclusively transgranular and proved to be the dominant life-time determining failure mechanism.

However, it should be clearly stated that environmental cracking did occur in the form of axial corrosion fatigue cracks at numerous internal positions. Once initiated, all environmental cracks 
propagated in a transgranular manner typical for corrosion fatigue. However, due to the severe loading, this failure mechanism did not develop into the life-time determining factor. The mechanical dominance would thus have prevented the observation of a beneficial flow rate effect, if present. The low flow rate test $2 a$ achieved 1520 cycles, whereas the high flow rate test $2 \mathrm{~b}$ only achieved 1238 cycles. However, the lower number in test $2 \mathrm{~b}$ is primarily attributed to a relatively "rough" external apex surface that included circumferential scratches acting as stress rising notches. This led to early crack initiation and premature failure.

Figure 13-1 graphically summarizes the results from test series 2 and BLT2, both tested within one strain amplitude domain. In contrast to BLT2, the effects of a simulated PWR environment are clearly revealed by the presence of axial, internally initiated cracking in tests 2a and $2 \mathrm{~b}$.

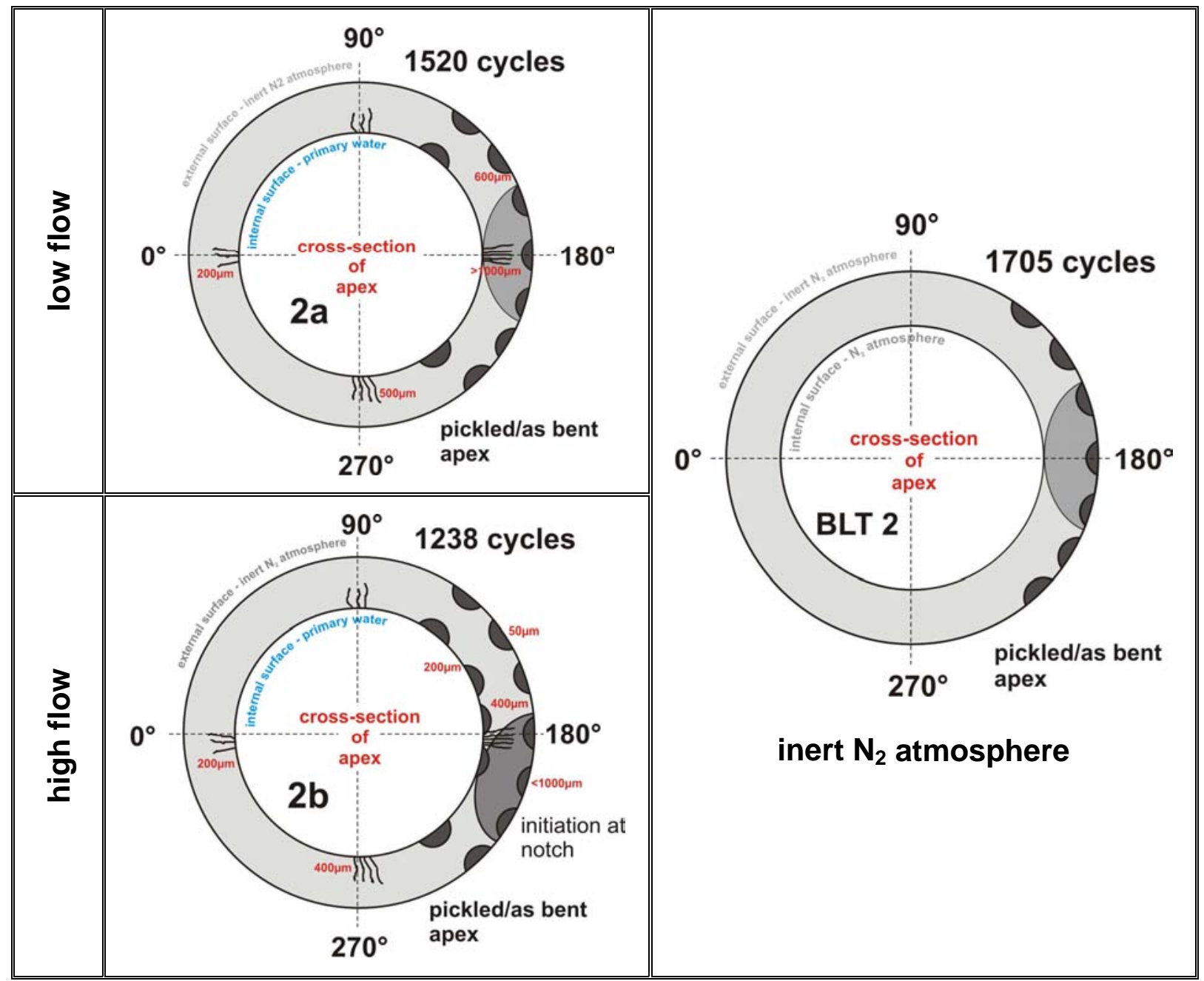

Figure 13-1

Summary of results obtained during Test Series 2 and BLT 2 (Strain amplitude: $\pm 0.6 \%$; strain rate: $\left.1 \times 10^{-4} \mathrm{~s}^{-1}\right)$. 


\section{Phase C}

Having implemented a less severe strain amplitude of $\pm 0.4 \%$ strain in Phase $C$ for the test series 4 , mechanical dominance of crack initiation and propagation no longer occurred. The strain field present at the apex region predominantly triggered internally initiating, axial corrosion fatigue cracks that determined the bends' fatigue life. Once initiated, the environmentally driven cracks propagated in a transgranular manner typical for corrosion fatigue. For internally initiating cracks, the failure position was to be expected in either the $90^{\circ}$ or $270^{\circ}$ position (as already outlined in Chapter 3 on load considerations). In fact, the bends of this series 4 had in common that all primary failures occurred in the form of through-wall defects in the $270^{\circ}$ position.. It is believed that slight asymmetry during loading, which cannot be excluded entirely, might have resulted in preferential crack initiation at the 270 rather than the 90 position.

The results of test 4a showed that external crack initiation at the intrados position could not be prevented entirely, even with a lower strain amplitude of $\pm 0.4 \%$ strain. As a consequence, the bends for test $4 \mathrm{~b}$, test $4 \mathrm{a}$ ' and test $4 \mathrm{~d}$ were mechanically polished in the apex region with the intention of suppressing external crack initiation as far as possible. However, with the exception of test $4 \mathrm{~b}$, where the bend was completely free of external cracking, all other remaining tests of series 4 did again exhibit shallow, external circumferential cracking, even though the apex region had undergone mechanical polishing. It should be noted, however, that the external polishing did have an beneficial effect, since the circumferential cracking observed in test 4d and test 4a' was shallower by at least a factor of 2 if compared to the non-polished external surface of test 4a. Figure 13-2 graphically summarizes the extent and location of external cracking for test series 4 . In comparison to the internal, environmentally triggered defects the extent of circumferential, mechanical cracking during test series 4 was generally considered negligible and it is not believed that this had a major effect on the cycles to failure.

Apart from mechanically polishing of the external apex region, the bend for test $4 \mathrm{~d}$ was also internally smoothened by electropolishing in an attempt to inhibit preferential crack initiation along attacked grain boundaries, which was up to that point believed to have had a detrimental effect on testing. However, a true beneficial effect of this treatment was not observed. Examination of the test data yielded very similar results in terms of failure location and appearance, as well as achieved cycles, if compared to all other tests of this series 4 . In the context of transferability of small scale component testing to actual plant conditions, it is believed that the use of as-pickled versus electropolished internal surfaces is more reasonable, since it better reflects the actual component condition.

Again, the beneficial effect of higher flow rates could not be observed within the test series 4. A direct comparison is provided by the low flow test 4a' and the high flow test $4 \mathrm{~b}$, both exhibiting identical test parameters. Test 4a' yielded a total number 3437 cycles and test $4 \mathrm{~b}$ yielded a total of 3616 cycles. This increase in achieved cycles of the high flow test $4 \mathrm{~b}$ corresponds to approximately $5 \%$ increase in lifetime. Considering the statistical variations during fatigue testing (easily containing scatter of $\pm 30 \%$ ) this increase cannot be considered a clear effect. 


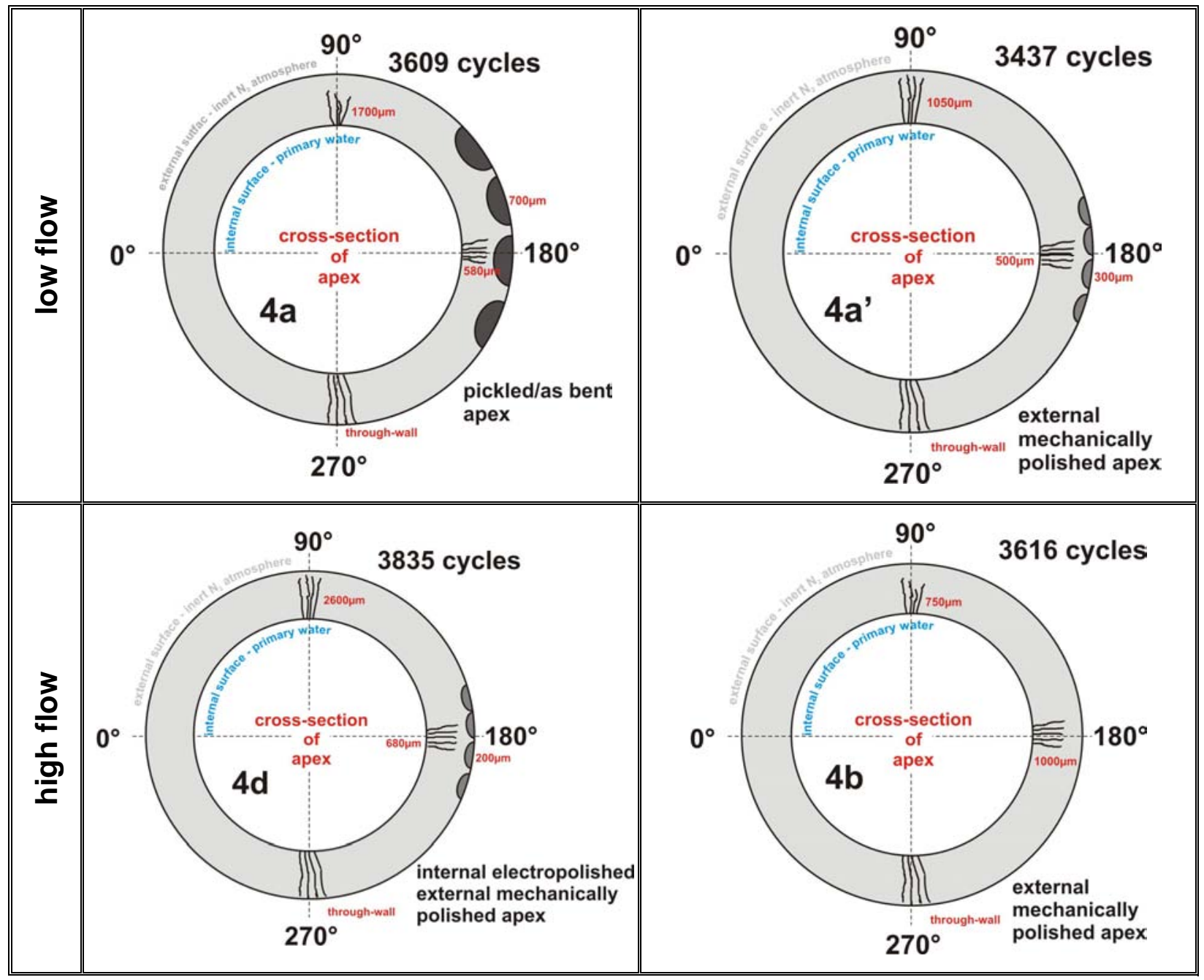

Figure 13-2

Summary of results obtained during Test Series 4 (strain amplitude: $\pm 0.4 \%$; strain rate: $\left.1 \times 10^{-4} \mathrm{~s}^{-1}\right)$.

\section{Discussion}

Testing for BLT 3 (i.e., baseline test in an inert atmosphere, but otherwise directly comparable to test series 4) continues in the present program and a final analysis of the results presented above must await these results. The interpretation provided here is thus preliminary in nature.

Mechanical fatigue, in the form of circumferential cracking from the OD surface of the intrados, appears to dominate failure of the U-bend specimens under cyclic loading at a strain amplitude of $\pm 0.6 \%$, even in the presence of simulated PWR primary water at the ID. The latter led, however, to the simultaneous formation of multiple, deep cracks at the $0,90,180$ and $270^{\circ}$ 
positions, as well as ID circumferential cracking of limited depth in the intrados region. All of the cracks from both external and internal surfaces were transgranular in nature, but differences in the extent of branching and in the appearance of the fatigue striations on the fracture surfaces provide evidence that the water environment had affected both crack initiation and growth.

This $180^{\circ}$ OD failure location is known both from strain gauge measurements and theoretical considerations to experience the highest stresses. The cycles to failure were relatively low (1200 to 1700) in all cases and this result appears to have been influenced more by notch effects at the external surface than by interaction of the main mechanical fatigue crack with the environmentally assisted cracks growing outward from the internal surface. No real effect of flow rate was discernible, but comparison possibilities were limited in this phase of testing.

At the lower strain amplitude of $\pm 0.4 \%$, however, environmentally assisted fatigue clearly dominates failure of the bends, which then occurs as result of multiple axial cracking from the ID surface in the $270^{\circ}$ position.

Additional, deep, axial cracking was observed at the internal surface in the $90^{\circ}$ position and at the intrados $\left(180^{\circ}\right)$, but not at the extrados. Circumferential cracking was minor in nature (particularly on bends subjected to external mechanical polishing) and restricted entirely to the OD surface at the intrados. The location and orientation of the main cracking is consistent with the areas of highest circumferential strain at the water-wetted ID surface (particularly from bend ovalization during cyclic loading), although the axial OD strain is still expected to be numerically higher. An additional baseline test in inert atmosphere at the same strain amplitude will be performed to confirm this assessment and provide a direct experimental value for the bend fatigue life without environmental effects.

The cycles to failure fell in the range of $3600 \pm 200$ for all 4 tests and preliminary analysis suggests that these values correspond to an environmental effect of around 3 times reduction in the expected air fatigue life, which appears to be consistent with published data [1, 2]. Neither the presence/absence of secondary OD cracking, nor the improvement in internal surface finish obtained in one case by electropolishing a specimen, seem to have affected the measured bend lifetime. The latter finding is of some practical importance, since it suggests that the typical, asreceived component condition (pickled surface with shallow intergranular attack plus some minor damage from bending) is not detrimental with regard to the overall effects of environmental fatigue, despite some apparent tendency for cracking to initiate preferentially at such locations.

The cycles to failure were slightly higher at high flow rate in this phase of testing, but the difference is not considered significant. It is likely that a greater influence of flow would have been observed for experiments showing a more pronounced environmental reduction in fatigue life and further tests at slower cyclic strain rates are planned to investigate this. 


\section{Conclusion and Future Work}

The environmental fatigue testing of mini-components (cold drawn, 304L stainless steel Ubends) carried out to date in the present EPRI-MRP program allows the following conclusions to be drawn:

- In accordance with literature data, PWR primary water can have a significant effect on the high-temperature fatigue behavior of austenitic stainless steel components, as demonstrated by the observed change in failure mode and location between specimens tested with nitrogen and simulated reactor coolant in contact with the internal surface of the bend.

- Metallography and fractography suggest that the environment is acting by affecting both crack initiation and crack growth.

- No obvious, life-time increasing effect of higher flow rate has been observed in tests to date (cycles to failure differ only by about 6\%), but this may still appear if the environmental influence is increased, e.g., by decreasing cyclic strain rates.

- The typical, as-received component condition (pickled surface with shallow intergranular attack plus some minor damage from bending) does not appear to be detrimental with regard to the effects of environmental fatigue.

In addition to a baseline test in nitrogen at a strain amplitude of $\pm 0.4 \%$ (to allow more direct comparison with tests in simulated primary water), further environmental testing at a lower strain rate $\left(5 \times 10^{-6} \mathrm{~s}^{-1}\right)$ is planned in order to permit final conclusions to be drawn with regard to the influence of flow rate. Upon completion of the program, additional analysis of the bend loading in all tests will also allow a more detailed comparison of the results obtained with design curves, published data for small tensile specimens, and with component field experience.

\section{References:}

[1] R.E. Nickell et al., "Materials Reliability Program (MRP) Evaluation of Fatigue Data Including Reactor Water Environmental Effects" (MRP-49), EPRI, Palo Alto, CA and the U.S. Department of Energy, Washington, D.C.: 2001. 1003079.

[2] K. Tsutsumi, et al., "Fatigue Life Reduction in PWR Water Environment for Stainless Steels", PVP-Volume 410-2, pp. 23-24, ASME PVP 2000, Seattle, WA. 




\author{
About EPRI \\ EPRI creates science and technology solutions for the \\ global energy and energy services industry. U.S. \\ electric utilities established the Electric Power \\ Research Institute in 1973 as a nonprofit research \\ consortium for the benefit of utility members, their \\ customers, and society. Now known simply as EPRI, \\ the company provides a wide range of innovative \\ products and services to more than 1000 energy- \\ related organizations in 40 countries. EPRI's \\ multidisciplinary team of scientists and engineers \\ draws on a worldwide network of technical and \\ business expertise to help solve today's toughest \\ energy and environmental problems.
}

EPRI. Electrify the World

\section{Export Control Restrictions}

Access to and use of EPRI Intellectual Property is granted with the specific understanding and requirement that responsibility for ensuring full compliance with all applicable U.S. and foreign export laws and regulations is being undertaken by you and your company. This includes an obligation to ensure that any individual receiving access hereunder who is not a U.S. citizen or permanent U.S. resident is permitted access under applicable U.S. and foreign export laws and regulations. In the event you are uncertain whether you or your company may lawfully obtain access to this EPRI Intellectual Property, you acknowledge that it is your obligation to consult with your company's legal counsel to determine whether this access is lawful. Although EPRI may make available on a case by case basis an informal assessment of the applicable U.S. export classification for specific EPRI Intellectual Property, you and your company acknowledge that this assessment is solely for informational purposes and not for reliance purposes. You and your company acknowledge that it is still the obligation of you and your company to make your own assessment of the applicable U.S. export classification and ensure compliance accordingly. You and your company understand and acknowledge your obligations to make a prompt report to EPRI and the appropriate authorities regarding any access to or use of EPRI Intellectual Property hereunder that may be in violation of applicable U.S. or foreign export laws or regulations.

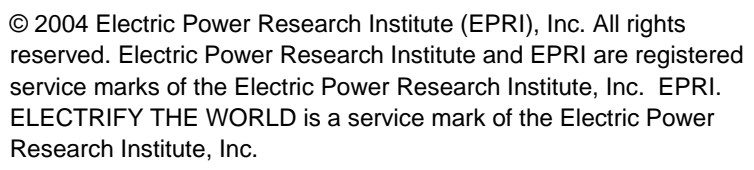

